\title{
ENGINEERING DISEASE RESISTANCE IN PLANTS
}

Jerôme Custers 


\begin{tabular}{|c|c|}
\hline \multirow[t]{3}{*}{ Promotor: } & Prof. dr. ir. P.J.G.M. de Wit \\
\hline & Hoogleraar in de Fytopathologie \\
\hline & Wageningen Universiteit \\
\hline \multirow[t]{3}{*}{ Co-promotor: } & Dr. M.H. Stuiver \\
\hline & Head of genomics, BASF Plant Science GmbH, Limburgerhof, \\
\hline & Duitsland \\
\hline \multirow[t]{4}{*}{ Promotie commissie: } & Prof. dr. B.J.C. Cornelissen, Universiteit van Amsterdam \\
\hline & Prof. dr. A.H.J. Bisseling, Wageningen Universiteit \\
\hline & Dr. ir. A. Schots, Wageningen Universiteit \\
\hline & Dr. ir. A.R. van der Krol, Wageningen Universiteit \\
\hline
\end{tabular}


Jerôme H.H.V. Custers

\title{
Engineering disease resistance in plants
}

\author{
Proefschrift \\ Ter verkrijging van de graad van doctor \\ op gezag van de rector magnificus \\ van Wageningen Universiteit, \\ Prof. Dr. M.J. Kropff, \\ in het openbaar te verdedigen \\ op maandag 8 januari 2007 \\ des namiddags te vier uur in de Aula.
}


ISBN 90-8504-567-3 


\section{CONTENTS}

\section{Chapter 1}

General introduction: Plant defence mechanisms and the use of the hypersensitive response to engineer broad-spectrum disease resistance

\section{Chapter 2}

Aim and outline of thesis

\section{Chapter 3}

T-DNA tagging of a pathogen inducible promoter in Arabidopsis thaliana

\section{Chapter 4}

Isolation of two novel pathogen-inducible promoters: Evaluation of promoter-UidA fusions in transgenic potato plants using a combination of histochemical staining and quantitative RT-PCR

\section{Chapter 5}

Transcriptional reprogramming in potato leaves following infiltration of the Cladosporium fulvum avirulence protein Avr9

\section{Chapter 6}

Isolation and characterisation of a class of carbohydrate oxidases from higher plants, with a role in active defence

Chapter 7

Engineering disease resistance in plants

\section{Chapter 8}

Summarizing Discussion

Summary

Samenvatting

Publications

Nawoord 



\section{CHAPTER 1}

GENERAL INTRODUCTION:

PLANT DEFENCE MECHANISMS AND THE USE OF THE HYPERSENSITIVE RESPONSE TO ENGINEER BROADSPECTRUM DISEASE RESISTANCE

Jerôme H.H.V. Custers 


\section{SUMMARY}

Plants and pathogens have evolved very sophisticated systems to survive in nature. Plants need to escape or resist infection and pathogens need to colonize their hosts in order to acquire nutrients to reproduce. Plants have evolved mechanisms to resist pathogen invasion that consists of different defence layers. Firstly, pathogens are resisted by a waxy layer covering the epidermal cells. Secondly, plants contain large amounts of preformed secondary metabolites that display antimicrobial activities. They are effective in many cases but some pathogens produce enzymes that can detoxify these antimicrobial compounds or in some cases even developed mechanisms where breakdown products of these antimicrobial compounds interfere with host defence systems. Induced defences are generally the last layers of defence in plants and are in most cases sufficient to (partly) ward off pathogens. Presently, at least three different non-specific induced defence pathways have been described. Firstly the SA-dependent pathway is induced by necrosis-inducing pathogens and triggers systemic acquired resistance (SAR). A second pathway, similar to SAR, can be induced by non-pathogenic rhizobacteria, is dependent on JA and ETH and is designated Induced Systemic Resistance (ISR). A third pathway is also regulated by the plant hormones JA and ETH and is effective against a set of different pathogens not affected by ISR.

A very effective defence system in plants is gene-for-gene resistance. This induced resistance mechanism is based on the interaction between a plant-derived resistance $(R)$ gene product and an Avr-gene product (elicitor) produced by the pathogen. This interaction is generally very specific and results in the triggering of a strong resistance response including the HR. Elicitor molecules often contribute to virulence of the pathogen. Pathogens are potentially able to circumvent recognition by the host by either shedding the elicitor- or Avr-gene or altering its specificity. Shedding of the gene might have a severe impact on virulence and occurs therefore rarely. Conversely, plants have the ability to evolve new resistance specificities as the majority of $R$-genes consist of large clusters of homologous genes facilitating the generation of novel $R$-genes by intragenic recombination, duplication and mutation.

One of the most promising strategies to engineer disease resistance in plants is the deployment of this gene-for-gene resistance in transgenic plants. In order to achieve this, a pathogen derived Avrgene that is placed under the transcriptional control of a pathogen-inducible promoter, is transferred to a plant containing the matching $R$-gene. Crucial for this approach is the pathogen-inducible promoter since activation of this system in the absence of pathogens can be very detrimental to plant growth and yield. Additional research is required to obtain promoters that meet these criteria. Increasing the knowledge on transcription factors that control promoter activity and their cis-acting elements will facilitate the engineering of "synthetic" promoters that possess the required characteristics.

\section{INTRODUCTION}

Plants are challenged continuously by many different potential pathogens but they are very successful in resisting the vast majority of them. Thus, plants have evolved sophisticated defence systems to combat these potential pathogens, which make use of very diverse infection strategies. The few pathogens that are able to cause disease have developed very sophisticated mechanisms to suppress or overcome the host defence system. Viruses, bacteria and fungi require, at least in certain stages of their life cycle, living host cells to reproduce (obligate biotrophs, biotrophs and 
hemibiotrophs), whereas some bacteria and fungi (necrotrophs) use toxins or enzymes to kill and live on dead host cells.

Plants employ different lines of defence. A first line of passive defence includes the waxy cuticle and the plant cell wall. Already at this stage, many potential pathogens are prevented from entering the plant. When specific pathogens are able to evade or break this barrier, either through wounds or stomata, by producing cuticle- or cell wall dissolving enzymes or by mechanical disruption, plants contain as a second line of defence large amounts of so-called preformed antimicrobial compounds aimed at directly inhibiting pathogen growth.

As a third line of defence, plants have developed the ability to activate defence. Some inducible defence mechanisms are mediated by or activated through the plant signaling molecules, salicylic acid, jasmonic acid and ethylene. One of the most effective inducible defence mechanisms is based on the gene-for-gene interaction resulting in a rapid localized cell death (the hypersensitive response, HR) and activation of local and systemic defences. This gene-for-gene interaction is mediated by the recognition of a pathogen-derived avirulence factor (encoded by an Avr gene) by the complementary plant resistance protein (encoded by an $R$ gene) and is very specific for particular pathogen-plant genotype combinations. One of the hallmarks of this defence response is the HR, which displays many similarities with programmed cell death (apoptosis) observed in other higher organisms. Exploitation of gene-for-gene resistance for engineering broad-spectrum disease resistance can be achieved by placing a pathogen-derived Avr-gene under transcriptional control of a plant-derived pathogen-inducible promoter in a plant containing the matching $R$-gene, thereby creating a non-specific HR-inducing system.

In this chapter, an overview is presented of the different plant defence mechanisms, different aspects of gene-for-gene resistance, and its potential to be used in engineering disease resistant plants.

\section{CONSTITUTIVE DEFENCES}

The initial defence layer that potential pathogens encounter is permanently present and consists of mechanical and chemical barriers. The outer layer of most plant organs, the cuticle, is composed of layers of fatty acid-like compounds also known as wax. The main purpose of this waxy layer is to protect the plant from desiccation and pathogen entry. Most viral, bacterial and fungal pathogens are unable to disrupt this layer and can only enter the plant through wounds or natural openings like stomata and hydathodes. Some pathogens, like Magnaporthe grisea and Colletotrichum spp., have developed mechanisms to enter the plant through the cuticle. After surface attachment, these fungi develop appressoria and penetration pegs that can build an enormous turgor pressure to mechanically disrupt the plant cuticle (Bechinger et al., 1999; Tucker and Talbot, 2001). Other fungal pathogens like Fusarium ssp. produce cutinase to dissolve the waxy layer. Disruption of this cutinase gene in Fusarium solani f.sp. pisi resulted in decreased virulence, supporting the important role of cuticle degradation for this fungus (Rogers et al., 1994). Similarly, site directed mutagenesis of cutinase of the Brassica napus pathogen Pyrenopeziza brassicae resulted in failure of infecting host cotyledons (Li et al., 2003). In contrast with these observations, disruption of cutinase genes in other fungal pathogens did not affect virulence (Stahl and Schäfer, 1992; Sweigard et al., 1992; Van Kan et al., 1997). These fungal pathogens might contain multiple cutinase genes of which only some are essential for pathogenicity. The importance of the waxy layer in preventing pathogen 
entrance was also shown in mutant plants of Sorghum bicolor. These mutant plants displayed reduced cuticle deposition and as a result increased susceptibility to the fungal pathogen Exserohilum turcicum (Northern corn leaf blight) (Jenks et al., 1994).

The underlying cell wall is a barrier that can also stop pathogens from entering the cell. The cell wall mainly consists of (hemi-) cellulose, a polymer of ß-1,4-glucans and pectin. Many different bacterial, fungal and oomycete pathogens produce cell wall-dissolving enzymes like cellulases, polygalacturonases and xylanases (Lisker et al., 1975; Guo et al., 1995; Sexton et al., 2000; Shi et al., 2000; Torto et al., 2002; Wei et al., 2002). These enzymes are predominantly expressed during infection and are often required for full virulence (Isshiki et al., 2001; Lev and Horwitz, 2003). In plants, cellulose synthases are involved in production of cellulose for cell wall assembly. Mutations in specific cellulose synthase genes can reduce the levels of cellulose and simultaneously activate lignin formation and other induced defence responses (Cano-Delgado et al., 2003).

When pathogens succeed in breaching these mechanical barriers, most plants still contain significant amounts of antimicrobial compounds, phenols, phenolic glycosides, unsaturated lactones, sulphur compounds, saponins, cyanogenic glycosides and glucosinolates. These compounds are released from the plant by lysis of vacuoles. In some cases precursors are activated by de novo synthesized plant enzymes, the so-called phytoanticipins (Osbourne, 1996). In contrast, phytoalexins are synthesized in response to pathogen attack from more remote precursors. Saponins from oat (avenacin) and tomato ( $\alpha$-tomatine) have been studied in great detail. Avenacin is the major resistance determinant in oat against take-all disease caused by Gaeumannomyces graminis var. tritici, which is able to cause disease in wheat and barley (lacking avenacin A1) but not in oats. One oat species has been identified that is defective in avenacin A1 and as a consequence is susceptible to this pathogen (Osbourne, 1996).

In tomato the saponin a-tomatine, a steroidal glycoalkaloid, is present in healthy plants, predominantly in leaves, flowers and green fruits (Roddick, 1974). Pathogens able to infect tomato plants contain the enzyme tomatinase to convert the toxic saponin to relatively inactive compounds (a-tomatidine, Osbourne, 1996). Bouarab et al. (2002) have shown, that during infection of the model plant Nicotiana benthamiana by the fungal pathogen Septoria lycopersici, the fungus is able to detoxify the saponin $\alpha$-tomatine using the enzyme tomatinase and that one of the degradation products, $\beta_{2}$-tomatine, suppresses induced defence responses in the host.

\section{INDUCED RESISTANCE}

Specific pathogens are able to circumvent various constitutive defence layers, whereas plants can respond by switching on induced defence mechanisms that can provide resistance to viruses, bacteria, fungi, oomycetes, nematodes and insects. Until now, three pathways have been identified that are dependent on salicylic acid (SA), jasmonic acid (JA) and ethylene (ETH), respectively.

The SA-dependent pathway can be induced by necrotizing pathogens inducing systemic acquired resistance (SAR) that provides protection against a broad range of pathogens. The JA- and ETHdependent pathway provides resistance against a number of necrotrophic fungal pathogens and insects. A third pathway (Induced Systemic Resistance (ISR)) is also dependent on JA and ETH and can be induced by some non-pathogenic rhizobacteria.

In Figure 1, these three pathways are schematically represented together with Arabidopsis gene products functioning in these pathways. The availability of a vast (and still increasing) number of 
mutants impaired in pathogen responses in Arabidopsis, the availability of genetically well-studied Arabidopsis-pathogen systems and the availability of its genome sequence makes this model plant a well suited object for these kinds of studies.

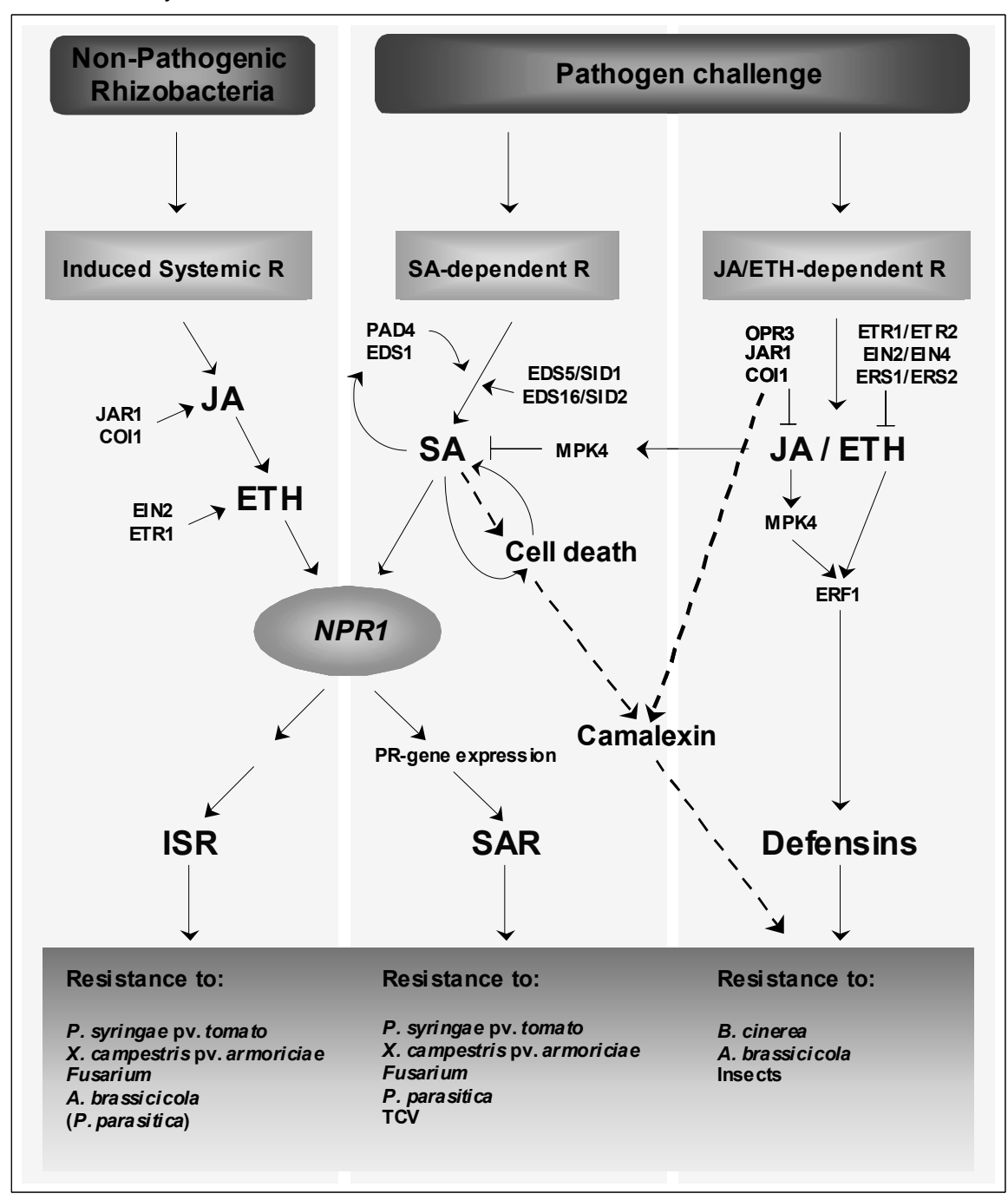

Figure 1. Three induced resistance pathways in Arabidopsis thaliana (adapted from Feys and Parker, 2000; Glazebrook, 2001). Mutants interfering with signaling and resistance are indicated together with the pathogens that are controlled by the respective pathways (Thomma et al., 1998; Pieterse et al., 2001). Pathogen listed between brackets is partially affected by resistance pathway indicated. Both SA and ISR signaling require the key regulatory gene Npr1. There is also evidence for considerable cross talk between the different pathways indicated by connecting lines ( $\rightarrow$ positive regulation, $\perp$ inhibition/negative regulation). See text for further details. 


\section{Salicylic acid-dependent resistance pathway}

Salicylic acid (SA) signaling is essential for SAR and is important for the initiation of local defence responses and for some gene-for-gene interactions. SAR is initiated when plants are challenged with pathogens that induce local necrosis (Ryals et al., 1996). SAR is completely dependent on SA since plants unable to accumulate $S A$ caused by the expression of a bacterial salicylate hydroxylase (NahG) are no longer able to develop SAR (Delaney et al., 1994). The role of SA is probably restricted to local signaling since Vernooij et al. (1994) have shown that SA is not the mobile signal for SAR development. SAR can also be induced by the SA analogs INA $(2,6-$ dichloroisonicotinic acid; Métraux et al., 1991) and BTH (benzo(1,2,3)thiadiazole-7-carbothioic acid S-methyl ester; Görlach et al., 1996). Characteristics of SAR include the induction of the expression of a distinct set of pathogenesis related (PR) proteins (Ryals et al., 1996).

$\mathrm{SA}$ can be synthesized in plants through the conversion of phenylalanine to trans-cinnamic acid mediated by the enzyme phenylalanine ammonia lyase (PAL) and subsequent chain shortening to benzoic acid, which can be hydroxylated to SA. Through the cloning of the Arabidopsis sid2/eds16 gene, a second pathway for SA biosynthesis has been revealed. The enzyme isochorismate synthase (Ics1), absent in sid2/eds16 plants, is responsible for the induced defence-related SA synthesis in Arabidopsis and is essential for resistance (Wildermuth et al., 2001). Another SAdeficient Arabidopsis mutant eds5/sid1 has a mutation in a gene coding for a protein with 9 to 11 transmembrane domains, a coil domain at the amino terminus, and similarity to MATE (multi drug and toxin extrusion) transporters (Nawrath et al., 2002) and might be involved in SA or precursor transport from the chloroplast to the cytosol or vice versa.

SA can be found in two forms in the plant: (i) free SA that probably has a signaling function and (ii) the main storage form, B-O-D-glucosalicylic acid (SAG), which is probably inactive in signaling (Ryals et al., 1996). Thus, the conversion of SAG to free and active SA can strongly influence SA signaling, whereas different plant species can also contain different amounts of endogenous SA. Potato has high levels of SA and is insensitive to SA analogs, whereas rice has a very high SA content compared to other plants species and can still develop a SAR-like response to exogenous SA application (Raskin et al., 1990; Coquoz et al., 1998; Ganesan and Thomas, 2001). The importance of these differences in endogenous SA levels for SA signaling, SAR and induced resistance remains to be elucidated.

Many studies on the role of SA in plant resistance have relied on the use of expression of the bacterial salicylate hydroxylase NahG, although plants expressing NahG might display several side effects. For example, the sid2/eds16 mutant accumulates wildtype levels of the phytoalexin camalexin after infection by avirulent $P$. syringae bacteria. This in contrast to Arabidopsis plants expressing NahG, which are no longer able to accumulate these amounts of camalexin (Nawrath and Metraux, 1999). Furthermore, expression of NahG in Arabidopsis affects $\mathrm{H}_{2} \mathrm{O}_{2}$ levels through accumulation of catechol and can result in altered JA and ETH levels (Van Wees and Glazebrook, 2003; Heck et al., 2003), indicating that expression of NahG is not the preferred method for depleting plants from SA.

A key regulator in the development of SAR is the Npr1-gene (Non-expressor of Pr also identified as Nim1, Non-inducible immunity and Sai1, Salicylic acid insensitive 1). Disruption of this gene, that functions downstream of SA, blocks the subsequent expression of several PR proteins like, PR1, BGL2 and PR5 and resistance to specific pathogens. The Npr1 protein contains ankyrin repeats 
and accumulates in the plant cell nucleus in response to SA (Cao et al., 1998). It has been shown that Npr1 can interact with transcription factors of the Tga-type and is able to stimulate binding of Tga2 to its target sequence (Zhang et al., 1999; Zhou et al., 2000; Despres et al., 2000). Npr1 is required for cross talk between SA and JA-mediated defence pathways through a function in the cytosol, whereas nuclear localization is required for SA-mediated defence signaling but not for suppression of JA levels (Spoel et al., 2003). Mou et al. (2003) have shown that Npr1 is present as oligomers in the cytosol of un-induced plants. Upon SAR induction, Npr1 is reduced to its monomeric form through changes in the cellular redox state and moves to the nucleus where it activates defence gene expression. Taken together, these data suggest that Npr1 in its oligomeric form in the cytoplasm is responsible for suppression of JA levels.

\section{Jasmonic acid- and ethylene-dependent resistance pathway}

Jasmonic acid (JA) and ethylene $(\mathrm{ETH})$ are often simultaneously required for resistance responses against specific pathogens. This is demonstrated by the fact that expression of some defence genes requires both plant hormones. For example, the pathogen-dependent induction of the plant defensin gene Pdf1.2 requires both signaling pathways (Penninckx et al., 1998). JA and JA-related compounds are also involved in developmental processes like pollen development and wound responses. ETH is, next to a role in pathogen defence, also involved in several physiological processes like fruit ripening and senescence (Bleeker and Kende, 1998). Both hormones are required for the development of Induced Systemic Resistance (ISR) and play a role in resistance to insects and necrotrophic fungal pathogens.

JA is produced through the octadecanoid pathway from the fatty acid metabolite $\alpha$-linolenic acid, which is oxygenated to hydroperoxy-linolenic acid by lipoxygenases. Further processing by allene oxide synthase and allene oxide cyclase results in 12-oxophytodienoic acid and further reduction to 12-oxophytoenoic acid. Subsequent carboxyl chain shortening by $\beta$-oxidation results in the formation of JA (Berger, 2002).

ETH is synthesized from the amino acid methionine via S-adenosyl methionine and 1aminocyclopropane- $\alpha$-carboxylic acid (ACC) mediated by ACC synthase and ACC oxidase respectively (Bleecker and Kende, 2000).

In Arabidopsis several mutants with defects in either JA- or ETH-dependent pathogen resistance have been identified (Berger, 2002). Mutants jar1 (jasmonate response 1) and coi1 (coronatine insensitive 1) display an attenuated JA responsiveness and increased sensitivity to necrotrophic pathogens. In addition the coi1 mutant is male sterile and displays increased sensitivity to insects. The opr3 mutant, is hampered in JA synthesis by a defect in the enzyme OPDA reductase. In contrast to coi1 mutant plants, the opr3 mutant is resistant to $A$. brassicicola and the dipteran insect Bradysia impatiens. Studies using this opr3 mutant in comparison to coi1 suggest that not only JA but also cyclopentenones play a role in pathogen defence signaling (Stinzi et al., 2001). The mpk4 mutant, which carries a mutation in a MAP kinase gene, displays next to insensitivity to JA and a dwarf phenotype, increased susceptibility to virulent bacterial pathogens, increased susceptibility to biotrophic fungal pathogens and reduced fertility (Petersen et al., 2000).

ETH signaling mutants were initially characterized by failing to display the socalled "triple response" phenotype recognized by thick and short roots and hypocotyls and a strong curve of the apical hook 
when exposed to ETH. In turn, mutants exhibiting the triple response phenotype in absence of exogenous ETH are either ETH overproducers or display constitutive ETH signaling. Mutants disturbed in the triple response also revealed altered responses to attack by specific pathogens. The volatile ETH signal is recognized by an ETH receptor complex in the plasma membrane formed by five homodimeric receptors Etr1, Etr2, Ein4, Ers1 and Ers2 (Stepanova and Ecker, 2000). Binding of ETH to these receptors requires copper as a cofactor. Single ETH receptor mutants of Arabidopsis fail to display ETH phenotypes indicating functional redundancy of ETH receptors. This is supported by the observation that plants mutant for multiple ETH receptors still display the triple response phenotype. Downstream of these ETH receptors the Constitutive Triple Response (Ctr1) protein, a Raf-like serine/threonine kinase, functions as a negative regulator of this signaling pathway and might be involved in a MAPK pathway (Stepanova and Ecker, 2000). Upon binding of $\mathrm{ETH}$, the receptors are deactivated and thereby unable to transduce a signal, resulting in inactive Ctr 1 and presumably suppression of the positive regulators Ein2, Ein3 and Ein5 is diminished. Positive regulator Ein2, contains several trans-membrane loops and displays similarity to NRAMP metal-ion transporters (Alonso et al., 1999). The ein2 mutant displays increased susceptibility to the necrotrophic fungus Botrytis cinerea indicating ETH is important for Botrytis resistance in Arabidopsis (Thomma et al., 1999).

$\mathrm{JA}$ and ETH signaling pathways are thought to converge at the activation of the Ethylene response factor 1 (Erf1) (Lorenzo et al., 2003). Erf1 encodes a transcription factor that regulates the expression of JA/ETH responsive genes providing resistance to necrotrophic fungi (Berrocal-Lobo et al., 2002). In addition, these very same plants displayed increased susceptibility to Pseudomonas syringae pv. tomato DC3000 infection (Berrocal-Lobo et al., 2002). This indicates that activation of the JA/ETH pathways can result in increased susceptibility to pathogens normally resisted by SAR. Erf1 expression can be activated by ETH or JA independently, but application of both hormones results in a synergistic effect. Further evidence for convergence upstream or at Erf1 was shown by the fact that Erf1 overexpression rescues coi1 and ein2 mutants (Lorenzo et al., 2003). A MYC transcription factor, recently cloned as the locus jai1/jin1, completely antagonizes Erf1. Both transcription factors activate a subset of JA-responsive genes that is repressed in the same situation by the other transcription factor giving rise to two diverging JA pathways (Lorenzo et al., 2004).

\section{Induced Systemic Resistance (ISR)}

Induced systemic resistance (ISR) in plants resembles the SAR phenomenon as in both cases activation results in protection of distal parts of the plant. ISR can be triggered by non-pathogenic rhizobacteria that are commonly found on plant roots. Many plant species are able to develop rhizobacteria-mediated ISR resulting in increased pathogen resistance. Most research on ISR has been performed on Arabidopsis with the ISR-inducing bacterium Pseudomonas fluorescens WCS417r. In Arabidopsis, resistance can be induced against the bacteria $P$. syringae pv tomato DC3000 and Xanthomonas campestris pv. amoracia, the fungal pathogens Fusarium oxysporum and Alternaria brassisicola and partially against the oomycete Hyaloperonospora parasitica.

ISR can be distinguished from SAR by the fact that ISR is independent of SA but requires functional JA/ETH signaling pathways (reviewed by Pieterse et al., 2001). A remarkable similarity between ISR and SAR in Arabidopsis is their requirement for a functional Npr1 gene. 
Since the induction of ISR is dependent on JA and ETH, it comes as no suprise that the Arabidopsis mutants jar1 and coi1 and the Arabidopsis ETH mutants ein2 and etr1 fail to develop ISR, respectively. Expression of NahG has no effect on the development of ISR, indicating that ISR is independent of SA (reviewed by Pieterse et al., 2001). The establishment of SAR is recognized by accumulation of specific sets of PR transcripts and proteins (Ryals et al., 1996). Likewise, when resistance is induced in Arabidopsis by treatment with JA and/or ETH, a specific, other, set of PR proteins is induced. Interestingly, none of the genes that are either SA- or ETH/JA- responsive are upregulated during ISR (Van Wees et al., 1999). One JA-inducible gene, Atvsp1, was upregulated when ISR-induced plants were challenged with pathogens (Van Wees et al., 1999). Results published by Ton et al. (2002) showed that ISR seems to be a reinforcement or enhancement of the JA/ETH-dependent basal resistance. The differential effectiveness of SAR and ISR in resistance is displayed in Figure 1.

\section{SPECIFIC (GENE-FOR-GENE) RESISTANCE}

Gene-for-gene resistance has originally been described in the 1940s by Flor (Flor, 1946) who studied the genetics of the interaction between flax and the rust fungus Melampsora lini. He observed that for each dominant resistance gene in the plant, one dominant avirulence gene in the rust fungus was present. The initial definition of pathogen avirulence genes implies that they have the ability to induce resistance in hosts carrying the complementary resistance genes. At first, the proposed working model for these gene-for-gene interactions implied a receptor-ligand model were the $R$-gene product (receptor) directly binds the avr gene product (elicitor or ligand) to trigger resistance. To date only in a few cases a direct interaction between the elicitor and the $\mathrm{R}$ protein has been shown (Jia et al., 2000; Deslandes et al., 2003). Now evidence accumulates that avirulence proteins possess virulence functions. Presumably, avirulence proteins bind to a plant target different from the R-protein. Resistance gene products might have evolved as guards of the virulence target, sensing its modification followed by initiation of plant defences. This hypothesis, known as the guard-model, has first been described by Van der Biezen and Jones (1998). A list of cloned avirulence genes, matching $R$-genes and possible virulence targets are shown in Table 1.

\section{$R$-genes and their functions}

Resistance genes are essential components for recognition of specific pathogens and the activation of plant defence pathways including HR. To date many resistance genes have been cloned providing resistance to pathogenic viruses, bacteria, fungi, nematodes and insects. An overview of the different structural classes of R-proteins is presented in Figure 2.

With the availability of the genome sequences of Arabidopsis thaliana and rice we gained more insight into the different classes of $\mathrm{R}$ proteins that exist in these plants. The largest class of $\mathrm{R}$ proteins in Arabidopsis and rice contain the NBS-LRR motifs (Goff et al., 2002). The LRRs (leucinerich repeats) are known in other proteins to be involved in protein-protein interactions, receptorligand binding and protein-carbohydrate interactions. The conserved NBS (nucleotide binding site) domain is involved in ATP or GTP binding. Part of this domain also shares identity with domains found in eukaryotic cell death-effector proteins Apaf1 and Ced4. This domain also designated as NB-ARC or Ap-ATPase domain might be involved in regulating cell death after avirulence determinant recognition 


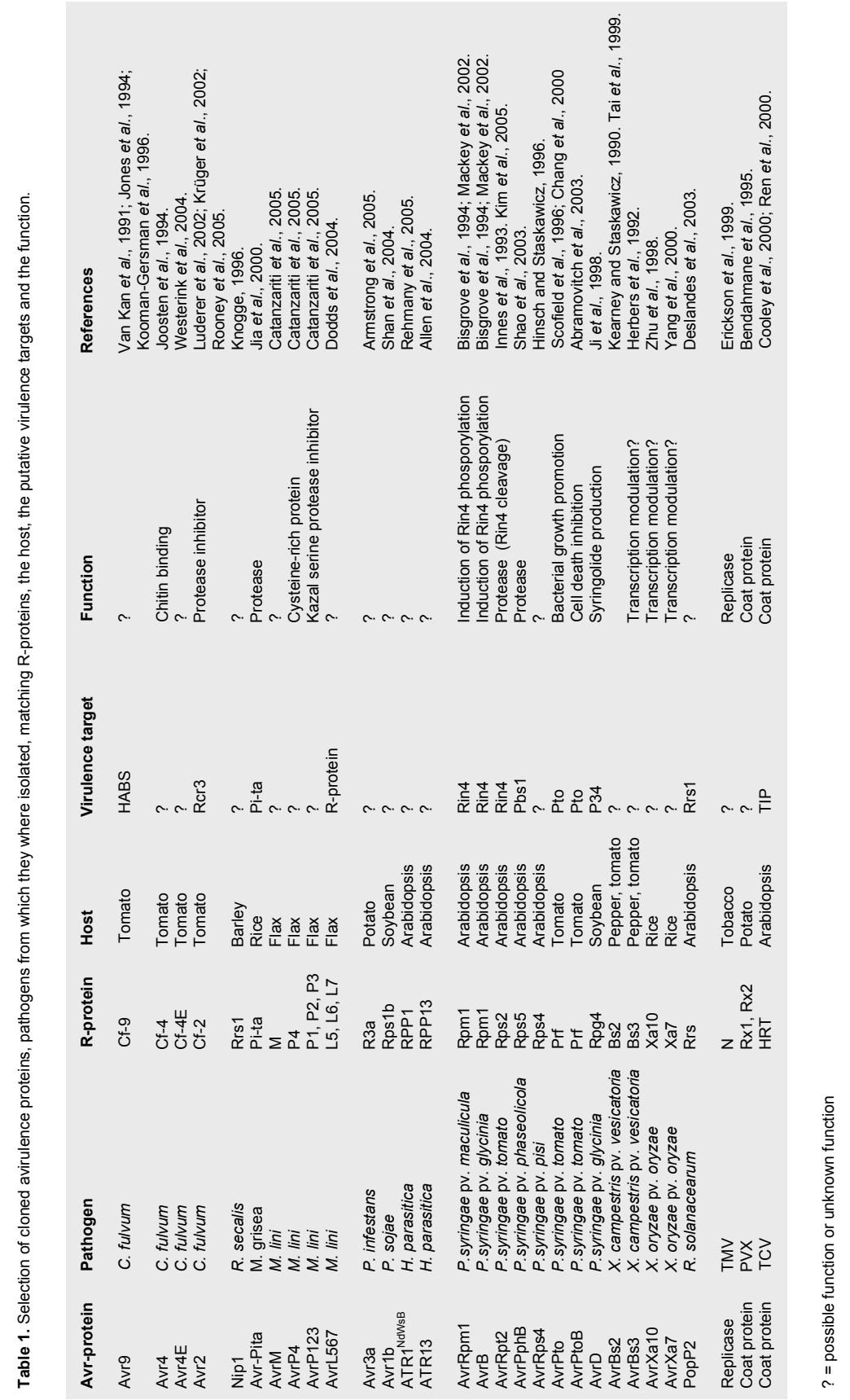


The NBS-LRR proteins can be subdivided into two subclasses. One containing an amino terminal region with homology to drosophila Toll and mammalian Interleukin (IL)-1 receptors (TIR-NBS-LRR proteins). The other subclass containing putative amino terminal leucine zipper/coiled-coil domains (LZ/CC-NBS-LRR proteins), (Dangl and Jones, 2001). Rice contains ca. 600 LZ/CC-NBS-LRR genes but no obvious TIR-NBS-LRR domains were found, whereas in Arabidopsis the TIR-NBSLRR subclass is prevailing (Goff et al., 2002). NBS-LRR proteins are supposed to be localized in the cytosol. One of the best studied NBS-LRR proteins, Rpm1, is localized to the plasma membrane, which is required for its function (Boyes et al., 1998).

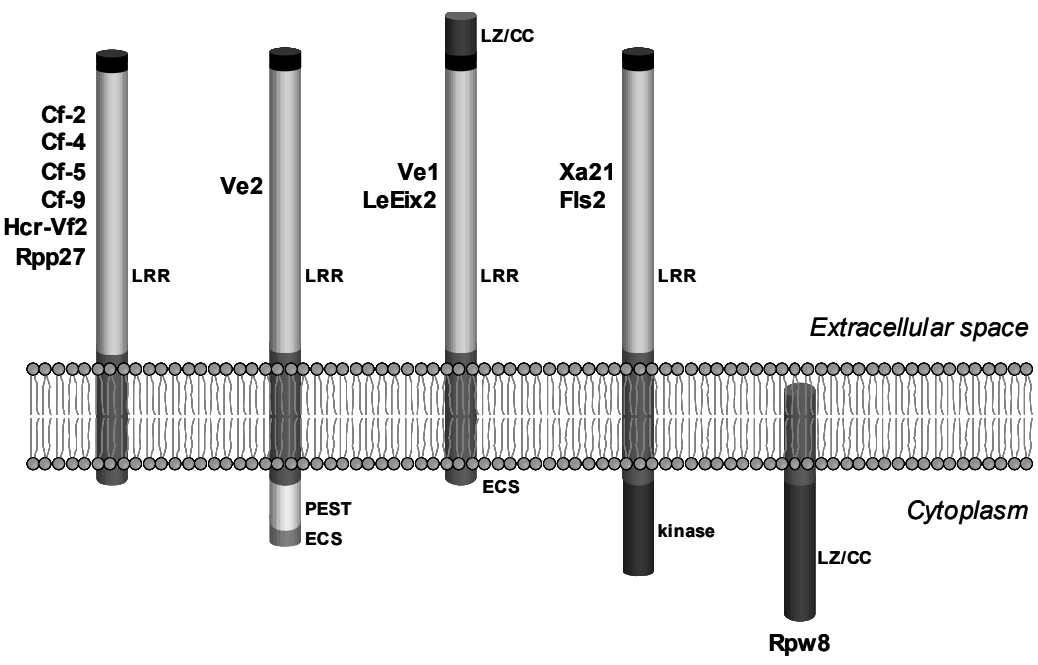

TIR NBS

N, L6, Rpp5, Rps4

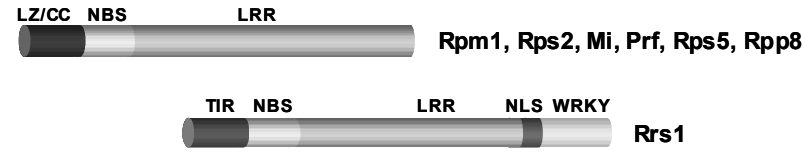

Figure 2. Schematic overview of the different R-protein classes currently identified. Almost all R-proteins contain a large domain that consists of leucine-rich repeats (LRRs). Different classes of intracellular R-proteins contain a nucleotide-binding site (NBS) that displays similarity to eukaryotic cell death effector proteins. They have different $\mathrm{N}$-terminal domains; one subclass contains leucine zippers (LZ) or coiled coil (CC) structures (LZ/CC-NBS-LRR) and one subclass has homology to Drosophila Toll and mammalian Interleukin (IL)-1 receptors (TIR-NBS-LRR). One member, Rrs1, contains in addition to the TIR-NBS-LRR domains a nuclear localization signal (NLS) and a WRKY domain. Another class of R-proteins contains an extracellular LRR domain, a transmembrane region and a short cytoplasmic tail and is represented by the tomato Cf proteins. Receptor-like kinase proteins contain an extracellular LRR domain, a membrane spanning domain and a cytoplasmic kinase domain. A very distinct class contains one member, Rpw8, and consists of a LZ/CC domain and is anchored in the plasma membrane. Adapted from Dangl and Jones (2001) and Hammond-Kosack and Parker (2003). See text for description and references of individual R-proteins. 
A third class of $R$-genes, the so-called Receptor-Like Proteins (RLPs), which includes the Cf-genes and Ve-genes from tomato mediating Cladosporium and Verticillium resistance, respectively, contain extracellular LRRs, a transmembrane domain and a short cytoplasmic tail. The tomato $C f$ genes confer gene-for-gene resistance to certain races of the fungal pathogen Cladosporium fulvum. The cytoplasmic domain of the Cf-9 protein interacts with a thioredoxin homolog in the cytoplasm, which appears a negative regulator of Cf-9-mediated cell death and defence in tomato and $N$. benthamiana (Rivas et al., 2004). The tomato Verticillium resistance proteins Ve1 and Ve2 contain, in addition to the extracellular LRR region and transmembrane domain, a cytoplasmic domain with similarity to endocytosis (ECS) domains. Furthermore, Ve1 contains an N-terminal coiled-coil domain and Ve2 a cytoplasmic PEST domain, found in proteins with a short half-life (Kawchuk et al., 2001). Recently, more Cf-like R-proteins have been identified, including Hcr-Vf2 conferring resistance to the fungal pathogen Venturia inaequalis in apple, LeEix2, recognizing the Trichoderma viride elicitor Eix in tomato (ethylene-inducing xylanase) and the RLP-like protein Rpp27 from Arabidopsis conferring resistance to multiple Peronospora isolates in accession Landsberg erecta (Ler) (Belfanti et al., 2004; Ron and Avni, 2004; Tör et al., 2004).

Another class of $R$-genes found in a wide variety of plant species and other eukaryotes, contains extracellular LRRs, a transmembrane motif and a cytoplasmic serine/threonine kinase domain (LRR-RLKs). These putative receptor kinases might transduce an extracellular signal directly through phosphorylation of other host cellular targets, but only a small portion of these genes is involved in disease resistance. For example, Clavata1 and Bri1 are receptor-like kinases and are involved in meristem development and brassinosteroid signal transduction, respectively (Clark et al., 1997; Li and Chory, 1997). Whereas Xa21 and Fls2 are LRR-RLKs determining resistance to Xanthomonas oryzae bacteria, expressing AvrXa21 in rice and a conserved domain in bacterial flagella in Arabidopsis, respectively (Song et al., 1995; Gómez-Gómez and Boller, 2000). The rice genome contains ca. 450 genes with extracellular LRRs of which approximately half contains a cytoplasmic RLK domain (Goff et al., 2002).

A very distinct R-protein, Rpw8, confers resistance to multiple powdery mildews in Arabidopsis. This R-protein consists of a cytoplasmic LZ/CC domain and a transmembrane domain without a LRR region (Xiao et al., 2001). The rice genome contains one Rpw8-like R-gene (Goff et al., 2002). TIRNBS-LRR protein Rrs1 confers resistance to Ralstonia solanacearum in Arabidopsis and contains a WRKY domain and a potential nuclear localization signal (NLS) at the C-terminus suggesting a direct involvement in modulating gene expression in response to pathogen infection (Deslandes et al., 2002). WRKY domains are involved in DNA binding and are found in a large family of zinc-finger transcription factors (WRKY transcription factors) of which some are involved in plant defence responses (Eulgem et al., 2000). Rrs1 interacts directly with the Ralstonia solanacearum type III effector PopP2 and both proteins co-localize to the plant cell nucleus probably directed by the PopP2 protein (Deslandes et al., 2003). Nuclear localization of this R-protein after recognition of PopP2 in concert with the structural features of transcription factors suggests a direct role in modulating (defence) gene expression.

LRRs are thought to determine avirulence determinant specificity. Domain swaps between several regions of the flax $R$-proteins of the $L$ class have revealed that specificity is indeed determined by the LRRs, but additional specificity resides in the TIR domains (Ellis et al., 1999; Luck et al., 2000).

Domain swaps between the very homologous tomato Cf-4 and Cf-9 proteins have revealed 
particular amino acid residues in the LRR region that are required for Avr4 recognition by a Cf-9 mutant (Van der Hoorn et al., 2001). Also in Rps2, functionality (ability to confer resistance) seems to reside in the LRR region. Differential functionality of Rps2 alleles in the different accessions of Arabidopsis suggests that the ability of Rps2 to interact with host factors might be determined by a few amino acids in the LRR domain (Banerjee et al., 2001).

Some R-proteins are able to recognize more than one avirulence factor. The Pseudomonas syringae $R$-gene Rpm1 is able to recognize AvrRpm1 and AvrB, which are structurally unrelated (Bisgrove et al., 1994; Grant et al., 1995). Like Rpm1, the tomato R-protein Mi also shows dual specificity since it confers resistance to both a nematode and an aphid (Rossi et al., 1998). The potato $R x$ and Gpa2 genes are close homologues and confer virus and nematode resistance, respectively (Van der Vossen et al., 2000) Another example of close homologues that confer resistance to two completely different pathogens are the Arabidopsis Hrt/Rpp8 alleles that provide virus (TCV) and oomycete (H. parasitica) resistance (Cooley et al., 2000). In the case of Rpm1, both avirulence factors bind to the same plant target (Rin4, Mackey et al., 2002). The guard hypothesis allows dual recognition specificity of Rpm1 (AvrRpm1 and AvrB) and the same might be true for the Mi gene (nematode and aphid) and other $R$-genes with dual/multiple specificity. Moreover, a third avirulence factor, AvrRpt2, interacts with Rin4. But now a second R-protein, Rps2, as well interacting with Rin4 is required for HR induction (Axtell and Staskawicz, 2003; Mackey et al., 2003). A limited number of plant virulence targets might be targeted by a wide array of pathogen virulence factors and modification of the virulence targets might be sensed by R-proteins that trigger defence signaling. Interestingly, the soybean $R$-gene Rpg1-b also recognizes Pseudomonas type III effector AvrB. When comparing Rpm1 and Rpg1-b, sequence similarity is very limited and only found in the conserved domains of the CC/LZ-NBS-LRR subclass (Ashfield et al., 2004).

Plants need to establish novel resistance specificities since pathogens have the potential to overcome existing resistances. Homologous $R$-genes are often present as large gene clusters in the genome, probably facilitating the development and evolution of novel specificities through gene conversion and crossing-over events (Michelmore and Meyers, 1998; Richly et al., 2002; Kruijt et al., 2004). Besides homogeneous clusters, also very heterogeneous clusters can be found and these probably originate from earlier evolution events (Richly et al., 2002). These heterogeneous $R$ gene clusters might represent the ultimate source for variation and valuable starting material for the generation of novel resistance specificities during evolution. The frequency of an $R$-gene in natural populations might be dependent of two phenomena: (i) the cost of virulence for the pathogen, since Avr-genes provide virulence and a selective advantage to the pathogen and (ii) the cost of resistance (or better, disease) to the host determining frequency of an $R$-gene in a population (Van der Hoorn et al., 2002).

\section{Avirulence genes}

In order to survive, plant pathogens need to colonize their host, evade the host defence machinery and extract the required nutrients for growth and reproduction. To accomplish this, pathogens contain a set of genes that contribute to virulence and pathogen fitness. Initially, they were identified and classified as avirulence proteins but as discussed above many appear to have a role in virulence as well. Fungal pathogens that colonize the plant extracellular space secrete avirulence proteins in the plant apoplast, where recognition presumably occurs at the host cell membrane. 
Several bacteria pathogenic on plants and mammals employ type III pili to inject avirulence proteins (type III effectors) in the host cytoplasm, where they probably find their host target. The proteins currently identified show large diversity and have very little in common. Some bacterial type III effectors and fungal avirulence proteins have proteolytic activity (Axtell et al., 2003; Shao et al., 2003). The current hypothesis is that they use this activity to cleave and modify their host target. Furthermore, some $P$. syringae type-III effectors suppress host programmed cell death (Abramovitch et al., 2003; Jamir et al., 2004). Table 1 displays a large selection of cloned avirulence genes from plant pathogenic viruses, bacteria and fungi, with the matching $R$-genes and possible virulence targets.

\section{Fungal avirulence genes}

Many fungal avirulence proteins have been identified and purified from fungi that colonize the intercellular space of the host. For example, the interaction between tomato and the biotrophic fungus $C$. fulvum, causing leaf mould disease of tomato, follows the gene-for-gene concept. To date four race-specific elicitors from $C$. fulvum have been cloned. The Avr9, Avr4 and Avr4E proteins were identified in apoplastic fluid of $C$. fulvum-infected susceptible tomato plants and their respective genes were cloned (Van Kan et al., 1991; Joosten et al., 1994; Westerink et al., 2004). The Avr2 gene was cloned through a PVX-based functional screen were a $C$. fulvum cDNA library was cloned behind the coat protein of PVX in Agrobacterium and screened on tobacco plants expressing the Cf-2 gene (Takken et al., 2000; Luderer et al., 2002).

Over the years, extensive research has been performed to elucidate the molecular mechanisms underlying Avr9 recognition in plants. Avr9 is a small cysteine-rich protein that is produced as a 63 amino acid precursor and is further processed by fungal and plant proteases to its 28 amino acid mature form (Van Kan et al., 1991; Van de Ackerveken et al., 1993). It contains three disulphide bridges in its mature form and forms a cysteine-knot structure (Vervoort et al., 1997). Attempts to demonstrate direct binding of the Avr9 elicitor to the Cf-9 protein have been unsuccessful (Luderer et al., 2001). Kooman-Gersman et al. (1996) have shown that tomato plasma membrane fractions and even membrane fractions from other solanaceous plants, can bind labeled Avr9 irrespective of the presence of the $\mathrm{Cf}-9$ gene product. The protein responsible for the binding of Avr9 was designated HABS (high affinity binding site) and has yet to be characterized. The current model for Avr9 perception in tomato involves binding of Avr9 to the HABS, which probably represents the virulence target and the Cf-9 protein probably guards the HABS.

The Avr2 gene has been cloned and encodes a 78 amino acid cysteine-rich protein with a predicted signal peptide of 20 amino acids. To date, no clear virulence function could be assigned to Avr2 since complementation of Avr2 deficient strains with Avr2 did not significantly enhance virulence (Luderer et al., 2002). Next to the Cf-2 gene, the tomato locus Rcr3 is also required for Avr2mediated C. fulvum resistance (Dixon et al., 2000). The Rcr3 gene encodes an extracellular cysteine protease (Krüger et al., 2002). Recently it was shown that Avr2 is able to bind and inhibit the Rcr3 protease enabling Cf-2 protein and HR activation (Rooney et al., 2005).

Like Avr2 and Avr9, the C. fulvum Avr4 protein is a secreted protein that is produced as a 135 amino acid preproprotein and is C- and N-terminally cleaved to an 86 amino acid mature protein (Joosten et al., 1994). The expression of Avr4 is strongly induced during infection and natural virulent strains contain single amino acid changes in Avr4 (Joosten et al., 1994). Until now no 
virulence function for Avr4 has been reported but recent results showed that Avr4 is able to bind chitin in vitro. Furthermore, $T$. viride and $F$. solani strains normally sensitive to basic plant chitinases are protected against these chitinases when Avr4 is added to the assay medium. Avr4 might form a protective layer around the chitin layer of the fungal cell wall and thereby protecting it against chitinase degradation (Van den Burg et al., 2003).

In addition to Avr proteins, C. fulvum secretes a class of proteins, known as Ecps (Extracellular Proteins), which are found in the apoplastic fluid isolated from $C$. fulvum-infected tomato plants (Wubben et al., 1994; Laugé et al., 1997; Laugé et al., 2000). They can also behave as Avr factors as some wild accessions of tomato respond with HR to treatment with Ecps (Laugé et al., 2000). Ecp1, 2, 4 and 5 are found in all isolates analyzed to date and contribute to $C$. fulvum virulence in tomato (Laugé et al., 1997).

The Rhynchosporium secalis race-specific elicitor Nip1 (necrosis inducing peptide 1) is able to trigger defence reactions in barley cultivars containing the R-gene Rrs1. The Nip1 gene encodes an elicitor protein of 82 amino acids that is processed to a 60 amino acid mature protein (Rohe et al., 1995). The Nip1 peptide is able to induce necrosis on almost all barley cultivars irrespective of the presence of the Rrs1 gene, wich is, however, at concentrations well above the Nip1 concentration necessary to induce necrosis in Rrs1 barley plants (Knogge, 1996).

The interaction between the rice $R$-gene product $\mathrm{Pi}$-ta and the Magnaporthe grisea avirulence gene product Avr-Pi-ta (formely known as Avr2-Yamo) is the first example of direct binding of an Avr factor to the cognate R-protein. The R-protein Pi-ta resembles cytoplasmic NBS-LRR proteins and Avr-Pi-ta shows homology to zinc metalloproteases. The full Avr-Pi-ta protein (223 amino acids) is not an active elicitor but an $\mathrm{N}$-terminal processed form (176 amino acids) consisting of the putative mature protease is the functional HR-inducing avirulence protein. Mutations in the presumed protease motif of Avr-Pi-ta render an inactive avirulence protein. The recognition event seems to occur in the cytoplasm of the host cell since Pi-ta is probably localized in the cytoplasm and only cytoplasmic expression of the active form of Avr-Pi-ta induces an HR (Jia et al., 2000). How M. grisea delivers Avr-Pi-ta to the host cell cytoplasm remains to be elucidated. A close interaction between fungal and plant cell membranes might occur during certain stages of infection and particularly fungal structures like haustoria might play a role in facilitating Avr protein delivery to plant cells.

Recent work has provided evidence that some fungi and oomycete plant pathogens are able to transport avirulence proteins into the cytoplasm of host cells (Armstrong et al., 2005; Chisholm et al., 2006; Dodds et al., 2006; Ellis et al., 2006). Melampsora lini is an obligate biotrophic fungus causing rust disease in flax. M. lini and other rust fungi are fully dependent on living plant cells and obtain their nutrients via a close interaction with the plant through haustorial structures. Recently, several $M$. lini avirulence proteins have been identified. Most of them act inside the plant cell suggesting direct avirulence protein transfer from the fungal haustorium to the plant cell cytoplasm. A large screen for haustorially expressed and secreted proteins from the flax rust fungus has identifed four secreted proteins cosegregating with known Avr loci. Functional analysis has shown that 3 out of 21 secreted proteins are recognized by $R$-gene loci in flax and for two of them, AvrM and AvrP4, expression inside plant cells triggers an $R$-gene dependent necrotic response (Catanzariti et al., 2006). A different set of flax rust fungus Avr proteins, AvrL567, is recognized by the complementary flax R proteins L5, L6 and L7. In this case, a direct interaction has been shown 
between the Avr- and R-protein in vitro. No known virulence function could be assigned to the AvrL567 proteins but the presence of intact encoding genes in all virulent rust strains suggest they have a benefit in fitness or virulence of the pathogen (Dodds et al., 2006).

$H$. parasitica, an obligate biotrophic oomycete pathogenic on the model plant Arabidopsis, also uses haustorial structures to colonize its host. Particular strains of $H$. parasitica contain Atr13, an avirulence gene of high polymorphic nature. Plants containing the complementary R-gene locus Rpp13, a highly polymorphic gene of the CC-NBS-LRR class, recognize ATR13 (Allen et al., 2004). The extreme polymorphic nature of both genes suggests both loci have evolved through diversifying selection.

Another well-known oomycete plant pathogen, $P$. infestans, employs a biotrophic life style during early phases of the infection process and shifts to a necrotrophic phase at later stages of the infection cycle. During the biotrophic phase, $P$. infestans uses haustoria to colonize the host. The Avr protein Avr3b was identified in a set of predicted secreted proteins and is recognized by $R$-gene $R 3 a$. In addition, the Avr3b gene appeared to be syntenic with the $H$. parasitica Avr gene ATR $1^{N a W s B}$ (Armstrong et al., 2005). The $H$. parasitica $A T R 1^{N d W s B}$ gene is detected by the Arabidopsis $R$-gene $R P P 1$. The ATR $1^{\mathrm{NaWsB}}$ protein contains a signal sequence for secretion and a particular motif, $\mathrm{RxRL}$, highly conserved among oomycete secreted proteins and elicitors (Rehmany et al., 2005). Remarkably, this motif is also found in proteins secreted and translocated to the host by the malaria causing parasite, Plasmodium falciparum. Since ATR $1^{\mathrm{NdWsB}}$ is found inside plant cells, it is hypothesized that this particular motif is involved in translocating oomycete effector proteins to the plant host cell (Ellis et al., 2006).

The gene $P w / 2$ determines host species specificity in the rice pathogen $M$. grisea. Strains harbouring a mutant allele of this gene have become pathogenic on the rice-related plant weeping lovegrass (Sweigard et al., 1995). Apparently, the Pw/2 gene renders M. grisea avirulent on weeping lovegrass. The $P w / 2$ allele appears to be genetically very unstable. Frequently mutants appear which have become pathogenic on weeping lovegrass (Sweigard et al., 1995). The Phytophthora infestans Inf1 elicitor is produced during infection of potato. Mutants deficient in Inf1 production via sense and antisense suppression are capable to infect the non-host plant Nicotiana benthamiana (Kamoun et al., 1998). Inf1 and Pwl2 represent non-host avirulence determinants for $P$. infestans and $M$. grisea isolates on $N$. benthamiana and weeping lovegrass, respectively, and these (non-host) resistances are probably based on gene-for-gene interactions as well.

\section{Bacterial avirulence genes}

To date more than 40 bacterial avr genes have been cloned and mostly from bacteria of the genera Pseudomonas and Xanthomonas (Bonas and Lahaye, 2002). Most of these bacterial avirulence genes are very distinct in structure and are secreted through the bacterial type III (hrp; hypersensitive response and pathogenicity) secretion system. This secretion system is conserved among several gram-negative pathogenic bacteria, including the human pathogens of the genera Yersinia, Salmonella, Shigella and E. coli, and the plant pathogens of the genera Erwinia, Pseudomonas, Xanthomonas and Ralstonia and is essential for their pathogenicity (Rossier et al., 1999; Cheng and Schneewind, 2000; Collmer et al., 2000). The type III secretion machinery facilitates the "injection" of pathogen proteins (effectors) into the host cell. Secretion of animal and plant pathogen Type III effectors is reciprocal suggesting universal signal recognition, which is 
generally embedded in the $\mathrm{N}$-terminal part of the protein (Collmer et al., 2000). Cloned avirulence genes from $P$. syringae include the well studied AvrRpm1 and AvrB (both recognized by plants carrying Rpm1), AvrRpt2 (recognized by Rps2), AvrPphB (recognized by Rps5/Pbs1), AvrPto (recognized by PrflPto) and AvrRps4 (recognized by Rps4).

Resistance in tomato to $P$. syringae pv. tomato strains carrying AvrPto is mediated by the cytoplasmic serine/threonine kinase Pto and the cytoplasmic LZ-NBS-LRR protein Prf (Salmeron et al., 1994; Salmeron et al., 1996; Scofield et al., 1996). AvrPto contributes to virulence of $P$. syringae pv. tomato in tomato lacking Pto or Prf (Chang et al., 2000). In the presence of Prf, binding of AvrPto to Pto induces a strong resistance response through the phosphorylation of the Pto interacting proteins Pti4, Pti5 and Pti6, proteins similar to the EREBP1 class of transcription factors and Pti1, a serine/threonine kinase. In the absence of Prf, AvrPto might exert its virulence function by suppression of Pto-mediated basal defence. A second Pseudomonas type III effector protein, AvrPtoB binds to Pto as well, despite its limited sequence similarity to AvrPto. However, amino acid residues that are required for AvrPto to bind to Pto are conserved between AvrPto and AvrPtoB (Kim et al., 2002). Interestingly, AvrPtoB is able to completely abolish programmed cell death (PCD) as a result of the resistance responses mediated by Pto and Cf-9. Moreover, AvrPtoB is capable to inhibit PCD mediated by the mammalian pro-apoptotic Bax protein and inhibits PCD in yeast (Abramovitch et al., 2003).

Rps5 is an LRR-containing R-protein and Pbs 1 is a serine/threonine kinase and both are required for HR-mediated resistance of Arabidopsis against Pseudomonas bacteria carrying the AvrPphB avirulence gene (Swidersky and Innes, 2001; Shao et al., 2003). AvrPphB is a type III effector protein that is able to proteolytically cleave the Pbs1 kinase. Pbs1 kinase activity and cleavage by AvrPphB are required for Rps5-mediated resistance to $P$. syringae bacteria carrying AvrPphB (Shao et al., 2003). Probably Pbs1 is the virulence target of AvrPphB and one of the Pbs1 cleavage products interacts with or activates Rps5 ultimately resulting in resistance.

$P$. syringae pv. maculicola bacteria expressing the AvrRpm1 protein are avirulent on Arabidopsis plants carrying the Rpm1 resistance gene. Rpm1 recognizes also the AvrB protein, produced by $P$. syringae pv. glycinia, a soybean pathogen. The AvrB protein is structurally unrelated to AvrRpm1. Amino terminal myristoylation of AvrB and AvrRpm1 is required for plasmamembrane association and full avirulence function (Nimchuk et al., 2000). Significant advances were made in Arabidopsis to elucidate the mechanism of recognition and the first experimental evidence has been generated that supports the proposed guard-hypothesis. The host cellular target of AvrB and AvrRpm1 in Arabidopsis, Rin4, has been cloned and is required for Rpm1-mediated resistance. Rin4 interacts with avrRpm1 and AvrB in yeast-2-hybrid experiments ( $\mathrm{Y} 2 \mathrm{H})$, but also interacts with Rpm1 in vivo. In uninfected tissue Rin4 and Rpm1 are in a complex and decreasing Rin4 protein levels by antisense RNA, inhibits Rpm1-induced HR, reduces Rpm1 protein levels and increases resistance to normally virulent isolates of $P$. syringae and $H$. parasitica. When Rpm1 is absent, AvrRpm1 as well as AvrB move into a complex with Rin4 and induce phosphorylation of Rin4 (Mackey et al., 2002).

A third bacterial type III effector protein that interacts with Rin4 is AvrRpt2. But in contrast to AvrB and AvrRpm1, AvrRpt2 mediates resistance of another R-protein, Rps2. As is the case for Rin4 and Rpm1, Rin4 and Rps2 associate in planta but as a result, Rin4 is cleaved and eliminated by AvrRpt2 (Axtell and Staskawicz, 2003; Mackey et al., 2003). Axtell et al. (2003) have shown that 
AvrRpt2 is a cysteine proteases and directed mutations in predicted catalytic domains abolished in planta processing and elimination of Rin4 and the ability to induce an Rps2-dependent resistance response. Concurrent with Rin4 elimination, Rpm1 (if present) is also eliminated which results in loss of Rpm1-mediated resistance.

Rin4 is required for Arabidopsis development and disruption of Rin4 is lethal. This effect can be suppressed by the construction of rin 4 rps2 double mutants, indicating that rin 4 lethality is due to inappropriate Rps2 activation. Rin4 rps2 mutant plants display basal resistance to virulent $P$. syringae pv tomato DC3000 bacteria. This basal resistance is however diminished in rin 4 rps 2 rpm1 triple mutant plants, indicating that the basal resistance is due to residual Rpm1 present in rin4 rps2 plants (Belkhadir et al., 2004).

Belkhadir et al. (2004) showed that weak virulent bacteria ( $P$. syringae pv maculicola $\mathrm{M} 6 \mathrm{C} \Delta \mathrm{E}$ ) displayed increased virulence when they expressed AvrRpt2 or AvrRpm1 in rps2 and rpm1 null mutants which was further enhanced in rps2 rin4 and rps2 rpm1 rin4 mutants, respectively. Moreover, AvrRpt2 function was strongly enhanced in rin4 rps2 plants. These data suggest that Rin4 is not required for AvrRpt2 and AvrRpm1 virulence and thus Rin4 is not the only virulence target for AvrRpt2 and AvrRpm1. In contrast to AvrRpm1, AvrB is not able to promote virulence on rpm1 plants. However, in soybean AvrB is able to contribute to virulence on susceptible plants, irrespective of Rin4 levels (Ashfield et al., 2004). Rin4 appears to be conserved in dicot plants as well as in many monocot plants. Analogous to Arabidopsis, in soybean interference of AvrRpt2 with AvrB-dependent activation of Rpg1-b-dependent resistance could be observed (Mackey et al., 2002; Ashfield et al., 2004).

A very distinct class of bacterial avirulence proteins is the AvrBs3 family of proteins found in Xanthomonas plant pathogenic bacteria. They all have a very similar structure $(90-97 \%$ homology) that consists of an $\mathrm{N}$-terminal domain that is required for type III secretion, a large central variable region that contains nearly identical repeats of 34 aa, and a C-terminus that contains NLS domains and an acidic activation domain (AAD). The central variable region determines the specificity of AvrBs3 since exchange of the repeat region of AvrXa10 with the repeat region of AvrXa7 or AvrBs3 results in, Xa7 and Bs3 R-gene specificity, respectively (Zhu et al., 1998). Furthermore, deletions in the central repeat region of AvrBs3 resulted in altered specificities (Herbers et al., 1992). The Cterminal NLS domains were found to be indispensable for avirulence function and target the proteins to the host cell nucleus. The C-terminal AAD domain is also necessary for avirulence function (HR induction). The AAD domains of both AvrXa10 and AvrBs3 can also stimulate transcription in yeast or can be replaced by the VP16 transcription activator from the Herpes simplex virus (Zhu et al., 1998; Szurek et al., 2001). For several of these proteins a putative virulence function has been described (Yang et al., 2000; Swarup et al., 1992). The current model is that the AvrBs3-type avirulence proteins are delivered to the host cell cytoplasm by the type III secretion system where the NLS signals facilitate nuclear transport (Szurek et al., 2001) where it might affect host cell metabolism by inducing transcriptional changes through the AAD domain. When the complementary $R$-gene is present an HR-like resistance response is initiated through a still unknown recognition mechanism. 


\section{Non-specific elicitors}

Plants have the ability to recognize conserved microbial structures as non-self and respond to them by switching on induced defence pathways. These microbial structures, also known as pathogenassociated molecular patterns (PAMPs), are general and non-specific elicitors that are broadly recognized, unlike race-specific avirulence proteins. Although these elicitor molecules are recognized by many different plant species, recognition mechanisms have very likely a gene-forgene basis.

Elicitins are small, ca. $10 \mathrm{kDa}$ proteins secreted by several Phytophthora species. They are able to induce an HR and resistance in tobacco against $H$. parasitica (Ricci et al., 1989). The Phytophthora elicitins have been divided in two groups based on structure and biological activity. They include the $\alpha$-elicitins, which are acidic proteins produced by $H$. parasitica, $P$. cactorum, $P$. capsici and $P$. citrophthora and the $\beta$-elicitins which are produced by $P$. cryptogea, $P$. cinnamomi and $P$. megasperma. The necrotic response induced by these elicitins involves all characteristics of the HR including local cell death, local induction of defence related proteins, SA accumulation and induction of systemic defence gene expression (Dorey et al., 1997). Pathogen-induced expression controlled by the Hsr203j promoter of the P. cryptogea cryptogein gene triggers an HR in tobacco upon pathogen infection and confers broad-spectrum fungal resistance (Keller et al., 1999). Cryptogein induces rapid plasma membrane depolarization in tobacco suspension cells followed by inhibition of glucose transport within minutes after elicitation (Bourque et al., 2002). Inhibition of glucose transport may account for competition for nutrients in the plant apoplast between the plant and the fungus.

Components of bacterial type III ( $h r p)$ secretion systems are also able to evoke defence responses in plants in a non-specific manner. For example, the pear fireblight-causing pathogen $E$. amylovora produces a protein, Harpin $(h r p N)$ that is able to induce a HR in tobacco. The protein is secreted through the type III system but is not translocated to the host cell cytoplasm (Wei et al., 1992). Harpin is able to trigger SAR and resistance to $H$. parasitica and $P$. syringae in Arabidopsis. This effect was abolished in Arabidopsis plants expressing the NahG gene or in npr1 mutants indicating that SA is required for Harpin-mediated SAR and resistance. In contrast, Arabidopsis meJA and ETH response mutants displayed wildtype resistance (Dong et al., 1999). The potato pathogen $R$. solanacearum produces an extracellular protein, PopA that is able to provoke an HR-like response in tobacco and some petunia cultivars. Pathogen induced expression of PopA can result in an artificial HR in tobacco and increased disease resistance (Belbahri et al., 2001).

Bacterial components that are able to elicit defence responses in plants and plant cells include fragments of the flagellae (flagellin) of $P$. syringae that induce defence responses in Arabidopsis (Felix et al., 1999) and $P$. avenae which can induce the HR and defence responses in cultured rice cells (Che et al., 2000). Bacterial flagellin perception in Arabidopsis is mediated by an LRR-RLK, Fls2, through a MAP kinase signal transduction pathway ultimately resulting in activation of a specific WRKY gene (Gómez-Gómez and Boller, 2000; Asai et al., 2002). Fls2 loss of function mutants displayed increased susceptibility to $P$. syringae DC3000 bacteria. This resistance defect could be complemented by Fls2 confirming the role of Fls2 in plant bacterial resistance at the level of flagellin perception (Zipfel et al., 2004).

The soybean oomycete pathogen $P$. sojae produces a $42 \mathrm{kDa}$ cell wall-associated glycoprotein that is able to elicit a defence response in parsley (a non-host) cell suspensions and in cell suspension 
of potato. An internal peptide of this protein, Pep13, is the minimal active moiety that retains full activity. The Phytophthora glycoprotein is a transglutaminase and the Pep13 moiety is exposed to the surface of the protein. This protein occurs in all Phytophthora species, with strongest conservation in the Pep13 region (Brunner et al., 2002). No homologues could be detected in plants or oomycete plant pathogens other than Phytophthora species. A high-affinity binding site, in the plasma membrane, binds Pep13. Mutational analysis showed that the Pep13 region could not easily be mutated as mutations that abolished eliciting activity also affected transglutaminase activity. It is not yet known whether this transglutaminase is crucial for growth or pathogenicity of Phytophthora (Parker, 2003). Similarly, a $24 \mathrm{kDa}$ protein was identified in $\mathrm{H}$. parasitica, that induces comparable responses in parsley. This so-called Npp1 protein is also able to evoke defence responses in Arabidopsis. Unlike Pep13, homologous sequences of Npp1 have been found in other oomycetes, fungi and bacteria but not in plants (Fellbrich et al., 2002).

The cell walls of fungi predominantly consist of chitin, a polymer of $B-1,4$-linked $N$-acetyl glucosamine presumably tightly interlinked with glucan polymers, both $\beta-1,3$ and $B-1,6$-linked (Wessels, 1990). A very distinct group of fungus-derived molecules that is able to elicitate several aspects of a plant defence response are glucan- and chitin-oligomers produced after chitinase- or glucanase-mediated degradation of fungal cell walls. Plants contain pathogen-responsive genes encoding chitinases and B-1,3-glucanases. When fungal pathogens enter plants, these enzymes mediate the release of oligomers from these fungal cell wall constituents (Keen and Yoshikawa, 1983). Subsequent sensing of these oligomers activates plant defence responses such as the release of reactive oxygen species, the triggering of systemic resistance responses, induced expression of defence genes (pathogenesis-related proteins) and accumulation of phytoalexins (Klarzynski et al., 2000; Ramonell et al., 2002; Akimoto-Tomiyama et al., 2003). Furthermore, active glucan elicitors have been shown to invoke protection against pathogen infection in tobacco (Kopp et al., 1989; Klarzynski et al., 2000). In addition, high-affinity cellular receptors have been identified for both chitin and glucan oligosaccharides (Cosio et al., 1996; Côté et al., 2000; Okada et al., 2002).

These results indicate that perception of fungal cell wall or bacterial components by plants can contribute substantially to the defence response and resistance of plants to pathogens. Pathogens are likely to respond to these mechanisms by counteracting either the effect of plant glucanases and chitinases or by protecting themselves against these enzymes. C. fulvum produces a protein Avr4 that is recognized by the tomato R-gene Cf-4, resulting in an HR and resistance (Joosten et al., 1994). The Avr4 protein structurally resembles chitin-binding proteins and is able to bind chitin and protect $T$. viride and F. solani against chitinase-mediated antifungal activity (Van den Burg et al., 2003). In addition, Phytophthora species secrete glucanase inhibitor proteins (GIPs) that provide protection against glucanase-mediated cell-wall degradation and release of glucan oligomers (Rose et al., 2002).

\section{Signaling in gene-for-gene resistance}

After Avr/R recognition the plant activates a complex network of responses. The signaling events underlying this network of integrated defence responses generally require the plant hormones SA, JA and ETH. Signaling through these pathways is required for the majority of the defence responses leading to gene-for-gene-dependent plant immunity (Parker et al., 2000). Most of the 
defence responses, including HR, usually require a functional SA pathway. This pathway has been discussed in previous sections. However, particular mutations have been identified, especially in Arabidopsis, known to affect or block gene-for gene resistance.

For example, eds1 blocks resistance mediated by specific TIR-NBS-LRR proteins and ndr1 impairs resistance mediated by LZ/CC-NBS-LRR proteins (Parker et al., 1996; Aarts et al., 1998). Nonetheless, there are also $R$-genes of these classes that function independently of eds 1 and $n d r 1$ suggesting that there exist several (at least three) $R$-gene mediated signaling pathways (Aarts et al., 1998; McDowell et al., 2000). Both ndr1 and eds1 have been cloned. Eds1 resembles eukaryotic lipases and $\mathrm{Ndr} 1$ is probably membrane associated with similarity to Hin1 and $\mathrm{Ng} 1$, which are tobacco proteins, induced during the HR (Century et al., 1997; Falk et al., 1999). Eds1 interacts in vitro and in vivo with Pad4, another lipase, and pad4 plants are deficient in camalexin accumulation, SA signaling and show reduced resistance to $P$. syringae (Jirage et al., 1999; Feys et al., 2001). Furthermore, Eds1 and Pad4 are essential regulators in the cell death initiated in Isd1 mutants (Rustérucci et al., 2001).

In barley plants powdery mildew resistance mediated by some Mla genes is dependent on Rar1. Rar1, a protein containing zinc-binding CHORD domains, interacts with plant orthologs of yeast Sgt1. Yeast Sgt1 is involved in the delivery of target proteins to the ubiquitinylation protein degradation machinery (Azevedo et al., 2002). Furthermore, Rpp5-mediated cell death and ROS production upon $H$. parasitica Noco2 infection in Arabidopsis requires the cooperation between Arabidopsis Rar1 and one of the Arabidopsis Sgt1 homologues (Austin et al., 2002). Arabidopsis Rar1 and Ndr1 both contribute to disease resistance but this contribution is dependent on the $R$ gene involved. This is exemplified by the fact that in the case of Rpm1-mediated resistance, the AtRar1 mutation has a significant stronger negative effect on resistance than the Ndr1 mutation and for Rps2-mediated resistance there is an opposite effect (Tornero et al., 2002).

Both Rar1 and Sgt1 are required for specific $R$-gene mediated resistance pathways. Some $R$-genes require both components whereas some only one. Rar1 and Sgt1 requirement is completely independent of Eds1/Pad4 and Ndr1-dependent signalling. Furthermore, both Rar1 and Sgt1 interact with the molecular chaperone protein, cytosolic heat-shock protein 90 (Hsp90). Arabidopsis contains four isoforms of Hsp90 and one is required for full Rps2-mediated resistance and is rapidly induced after pathogen infection (Takahashi et al., 2003). In N. benthamiana, both Hsp90 and Hsp70 are essential for Inf1-mediated HR and non-host resistance to $P$. cichorii bacteria (Kanzaki et al., 2003). It is suggested that after specific Avr-R gene recognition events suppressors of certain elements of the HR are targeted to the ubiquitinylation machinery for degradation resulting in the development of the HR and disease resistance.

The rice bacterial blight resistance gene Xa21 contains a cytoplasmic kinase domain that shares homology with Pto (Song et al., 1995). Point mutations in the kinase domain created an inactive Xa21 protein implying the requirement for Xa21 phosphorylation activity to relay the signal after AvrXa21 recognition (He et al., 2000). A chimeric Xa21 protein consisting of the LRR region derived from the Arabidopsis brassinosteroid receptor kinase Bri1 was able to initiate defence responses in rice cells when challenged with brassinolides (He et al., 2000). This confirms that the LRR region determines the recognition specificity whereas signaling specificity is determined by the cytoplasmic kinase. 
One well-known pathway for the transduction of signals from external stress stimuli is the mitogenactivated protein (MAP) kinase pathway. This pathway is found in many eukaryotes and consists of three interlinked kinases which transduce an external signal to the cell nucleus. A MAPKKK phosphorylates a MAPKK, which in turn activates a MAPK through dual threonine/tyrosine phosphorylation (He et al., 1999). MAPKs are translocated to the nucleus were they phosphorylate and thereby regulate transcription factors. Other targets of MAPKs are cytoskeletal proteins, other kinases, phospholipases or phosphatases. MAPKKKs are also capable of activating unrelated protein kinases (Hirt, 2000). Several plant MAPKs have been identified and a number is induced by pathogens or defence signaling compounds (Ligterink et al., 1997; He et al., 1999; Kumar and Klessig, 2000). Romeis et al. (1999) have identified two MAPKs that are activated after the recognition of Avr9 by Cf-9 in tobacco. They appeared to be similar to previously identified tobacco WIPK (wound induced protein kinase) and tobacco SIPK (SA-induced protein kinase), which indicates that gene-for-gene, wound and SA responses converge at a particular point in these signaling pathways. It has been demonstrated that downstream of flagellin recognition by Fls2, activation of a MAPK pathway is responsible for activation of a zinc-finger WRKY transcription factor resulting in disease resistance in Arabidopsis. In this signaling pathway a specific MAPKKK, MEKK1, activates multiple MAPKKs resulting in activation of at least two specific MAPKs (MPK3 and MPK6, orthologs of tobacco WIPK and SIPK respectively) that results in WRKY protein activation, defence gene expression and resistance (Asai et al., 2002). A different approach was followed using virus induced gene silencing (VIGS) of the tobacco Mapkkk, Npk1. Downregulation of expression results in impaired functioning of the R-genes $N, B s 2$ and $R x$ without affecting the functioning of Pto/Prf and Cf-4-mediated resistance (Jin et al., 2002). The Npk1-silenced plants also displayed reduced cell size and dwarfing suggesting a role for NPK1 both in development- and disease-signaling pathways. Furthermore, a MAPKKK has been identified that functions in cell death associated with HR and with susceptibility. This MAPKKKa was able to induce cell death when overexpressed in plants. Analysis of the involvement of downstream Mapkk and Mapk genes showed distinct MAPK pathways involved in resistance and disease-dependent cell death (Pozo Od et al., 2004).

\section{Hypersensitive response-related cell death}

The hypersensitive response $(H R)$ is characterised by the rapid death of host cells and the subsequent induction of local and systemic defences ultimately leading to pathogen resistance. The host cell death that develops, mostly at the site of attempted pathogen penetration, displays striking parallels with mammalian programmed cell death (PCD). Plant mutants that develop spontaneous HR-like lesions or develop spreading lesions after pathogen inoculation are very important tools to study cell death. These so-called lesion-mimic mutants are probably compromised in regulation of cell death associated with the plant response to pathogen attack.

\section{Role of the oxidative burst and nitric oxide in the development of the HR}

Reactive oxygen species (ROS) can be produced as a result of pathogen attack in plants. Often, this so-called oxidative burst is one of the earliest responses to (attempted) pathogen infection. Generally, in incompatible interactions the oxidative burst consists of two peaks. A very early (within one hour) transient one that generally precedes the development of HR, and a second one that 
appears after several hours. In compatible interactions the oxidative burst is limited to the first, early transient peak (Draper, 1997; Van Camp et al., 1999). The production of ROS, mainly consisting of $\mathrm{H}_{2} \mathrm{O}_{2}$ and $\mathrm{O}_{2}{ }^{-}$, has multiple roles in the plant defence response. $\mathrm{H}_{2} \mathrm{O}_{2}$ has a direct antimicrobial effect and has a role in the oxidative cross-linking of cell walls at the site of infection (Bradley et al., 1992). ROS can induce defence genes and an $\mathrm{HR}$. That $\mathrm{H}_{2} \mathrm{O}_{2}$ itself can induce expression of defence genes and as a result enhances resistance of plants to pathogens, has been shown by the overexpression of $\mathrm{H}_{2} \mathrm{O}_{2}$-generating enzymes in plants (Wu et al., 1995; Wu et al., 1997; Kazan et al., 1998; Murray et al., 1999; Kachroo et al., 2003; Custers et al., 2004). Similar results were obtained when plants, deficient for the $\mathrm{H}_{2} \mathrm{O}_{2}$-removing enzyme catalase, were exposed to high light to provoke $\mathrm{H}_{2} \mathrm{O}_{2}$ accumulation (Chamnongpol et al., 1998). Alvarez et al., (1998) have elegantly shown that the generation of an HR in Arabidopsis after treatment with an avirulent $P$. syringae strain induced necrotic "micro-lesions" in distal tissue. These so-called microbursts also involve local $\mathrm{H}_{2} \mathrm{O}_{2}$ accumulation, and are completely dependent on the primary oxidative burst. Microbursts appear to be required for the subsequent development of systemic immunity in this system.

The major source for ROS production in response to pathogen attack has not been identified yet. Inhibitor studies in several systems with diphenylene iodinium (DPI), an inhibitor of the mammalian neutrophil NADPH oxidase, revealed that plants contain functional homologues of this enzyme complex and that they are involved in the plant oxidative burst (Levine et al., 1994; Alvarez et al., 1998). Several homologues of this human respiratory burst oxidase have been sequenced in plants and Arabidopsis contains six homologues of the major subunit gp91 ${ }^{\text {phox }}$ (Groom et al., 1996; Torres et al., 1998). Knockouts of two of these homologues (AtrbohD and AtrbohF), that are normally highly expressed, indicated that they are required for full ROS production in incompatible interactions between Arabidopsis and the bacterial pathogen $P$. syringae and the oomycete $H$. parasitica (Torres et al., 2002). Other possible sources of extracellular hydrogen peroxide in specific plant-pathogen interactions include pH-dependent cell wall peroxidases (Bolwell et al., 1995), oxalate oxidases (Lane et al., 1993; Zhou et al., 1998), amine oxidases (Bolwell and Wojtaszek, 1997) and carbohydrate oxidases (Custers et al., 2004). The relative contribution of the ROSgenerating systems in pathogen defence remains to be elucidated in detail.

Nitric oxide (NO) also plays an important role in pathogen-triggered HR in plants (Delledonne et al., 1998; Durner et al., 1998). In mammals NO is involved in signaling in the immune response and in programmed cell death (PCD), and is produced through the enzyme nitric oxide synthase (NOS). There are several lines of evidence supporting a role for $\mathrm{NO}$ in plant defence. One has been able to measure increased NOS activity during the incompatible interaction between tobacco and TMV (Durner et al., 1998) Through the use of specific NOS inhibitors it is possible to abolish NO accumulation during the resistance response in plants (Delledonne et al., 1998; Durner et al., 1998). Until now, it has proven to be extremely difficult to identify plant proteins with NOS activity. Guo et al. (2003) have been able to clone a plant gene, AtNOS1 in Arabidopsis, by using a sequence of a protein implicated in NO synthesis in snails. A mutant line, homozygous for this gene displayed $25 \%$ reduction of NOS activity compared to wildtype and displayed several growth defects. In this Arabidopsis line NOS is constitutively expressed and expression could be enhanced by treatment with the plant hormone abscisic acid (ABA) (Guo et al., 2003). 
$\mathrm{NO}$ accumulation alone is not sufficient to induce cell death and it is only effective in conjunction with ROS. This synergistic effect between NO and ROS is detected at sub-cell death concentrations of $\mathrm{H}_{2} \mathrm{O}_{2}$. The cell death triggering activity of $\mathrm{NO}$ and ROS is dependent on a critical balance between $\mathrm{NO}$ on the one hand and $\mathrm{H}_{2} \mathrm{O}_{2} / \mathrm{O}_{2}{ }^{-}$on the other (Delledonne et al., 1998; Delledonne et al., 2001). The fact that in plants $\mathrm{NO}$ can form peroxynitrite in conjunction with $\mathrm{O}_{2}{ }^{-}$and that this reactive compound would be responsible for induction of cell death and defence signaling (as in mammalian cells) is rather unlikely since exogenous application of peroxynitrite to soybean cells did not trigger cell death (Delledonne et al., 2001). In Arabidopsis, cell death mediated by avirulent $P$. syringae bacteria was strongly reduced (without affecting disease resistance) when the natural peroxynitrite scavenger urate was applied (Alamillo and Garcia-Olmedo, 2001).

\section{USE OF GENE-FOR-GENE RESISTANCE TO ENGINEER DISEASE RESISTANCE}

One of the most promising strategies to engineer broad-spectrum disease resistance in plants is the exploitation of the HR. By placing a pathogen-derived elicitor gene under control of a pathogeninducible promoter, an "artificial" HR can be activated after pathogen infection (Figure 3). The HR comprises of the local collapse and death of the invaded tissue, the triggering of local defences and the activation of a systemic defence response. This very powerful strategy requires two main components: firstly an elicitor gene that encodes a product that can induce local cell death and the associated local and systemic defence responses and secondly a tightly regulated plant derived pathogen-inducible promoter that responds exclusively to pathogen infection. This feature of the pathogen-inducible promoter is essential for the success of this technology, since induction of this system by other stimuli will result in undesired damage to the plant or may be accompanied by yield losses.

Keller et al. (1999) have produced transgenic tobacco plants expressing the fungal elicitin, cryptogein, under control of the promoter of the pathogen and HR responsive gene Hsr203j. These transgenic tobacco plants displayed broad-spectrum resistance to fungal pathogens, even to the necrotrophic pathogen Botrytis cinerea. Transgenic tobacco plants expressing the $R$. solanacearum HR-inducing protein PopA regulated by the same promoter also showed increased resistance. However, an expanding cell death phenotype was observed, in lines were the PopA gene is driven by the Hsr203j promoter (Belbahri et al., 2001), the PopA elicitor is produced locally and an HR is initiated which in turn triggers the Hsr203j promoter again, leading to the expanding cell death phenotype. It is remarkable that the HR induced by one elicitor (PopA) does trigger the Hsr203j promoter whereas another elicitor, cryptogein, is not capable of inducing Hsr203j. This suggests that there are qualitative differences in HR development, downstream signaling and defence gene expression triggered by these two elicitors. In collaboration between Pierre de Wit's lab and our lab transgenic tomato plants (containing Cf-9) were generated expressing the C. fulvum Avr9 elicitor under control of the pathogen-inducible potato Gst1 (Prp1) promoter. Several transformation events displayed immunity to virulent isolates of $C$. fulvum and showed enhanced tolerance to powdery mildew (Oidium neolycopersici), P. infestans and TSWV (M. Stuiver, unpublished results). Here we could observe a clear correlation between the time needed for the pathogen to complete its lifecycle and the level of resistance. The relatively slow invading biotrophic fungal pathogens $C$. fulvum and O. neolycopersici clearly triggered small HR lesions and growth of the fungi was successfully arrested. In contrast, the very fast and aggressive $P$. infestans infection could only be arrested 
under environmental conditions less favourable to $P$. infestans growth and that supported HR development. Transfer of the Avr9 gene to other solanaceous crops is possible but simultaneous transfer of the Cf-9 resistance gene is necessary to provoke an HR (Hammond-Kosack et al., 1998; Van der Hoorn et al., 2000). This might extend the use of the system to potato to engineer resistance to late blight disease. Also other AvrlR gene combinations might be used to engineer disease resistance, and the elicitor can be targeted either to the apoplast or to the cytoplasm. For example, when expressing the Avr9 protein in plants, it is targeted to the apoplastic space (as done by $C$. fulvum) were it is recognized at the outside of the plant cell carrying the Cf-9 protein. Activation of Avr9 expression in a single cell might result in recognition of extracellular Avr9 in adjacent cells as well resulting in the onset of the HR in multiple cells. In contrast, in planta expression of type III effectors that are recognized in a gene-for-gene manner in the cytoplasm (i.e. AvrRpm1, AvrB, AvrRpt2, AvrPto) will result in a single cell activation/recognition system, since no diffusion to adjacent cells will occur.

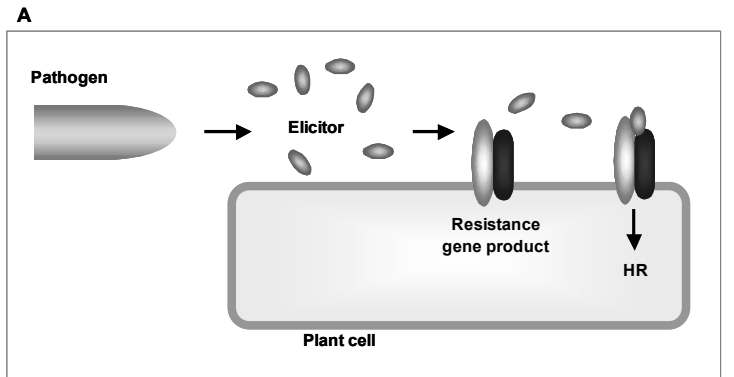

B

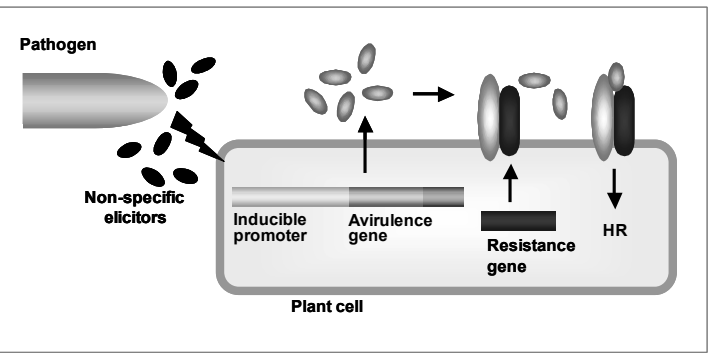

Figure 3. Exploitation of gene-for-gene resistance to generate broad-spectrum disease resistance. A. Natural situation where recognition of a pathogen-produced avirulence gene product is mediated by a plant resistance gene product. The recognition initiates the hypersensitive response which is effective in arresting pathogen growth. B. Transfer of a pathogen-derived avirulence gene to the plant under transcriptional control of a plant-derived pathogen-inducible promoter that creates a more broadly activated defence system. Upon pathogen infection, the pathogen-inducible promoter is activated to transcribe the Avr gene to produce the elicitor protein that is subsequently recognized by the cognate R-protein. Likely in most cases a third plant component (virulence target) is involved in indirect recognition of the elicitor protein.

A variant of the artificial HR strategy utilizes specific signal transduction components, that normally act downstream of AvrlR-gene recognition and are able to trigger an Avr-independent HR. This can be accomplished by pathogen-induced expression of a constitutively activated signal transduction 
component or a component that is able to alleviate the effect of an inhibitor of the HR (Stuiver et al., 1999). The latter type of resistance strategy also requires tightly regulated pathogen-inducible promoters. Furthermore, it is important to use a signal transduction component that is far upstream in the signal transduction pathway to ensure triggering of all the responses required to confer disease resistance. Signal transduction molecules that function far downstream in pathways might only induce a limited set of defence responses. Transient expression of constitutively activated Arabidopsis Ndr1 proteins in tobacco resulted in enhanced development of cell death compared to the unmodified Ndr1 protein (Stuiver et al., 1999). The same authors were able to activate the rice receptor kinase resistance protein Xa21 by removing the extracellular LRR domain or the extracellular LRR domain including the transmembrane region. Likewise expression of a constitutively active form of the rice Rac protein resulted in increased protection of rice plants against a virulent race of $X$. oryzae and in reduced lesion size induced by a virulent race of $M$. grisea (Kawasaki et al., 1999; Ono et al., 2001). Similarly, expression of a constitutively active form of the tomato kinase Pto, conferring resistance to $P$. syringae pv. tomato, resulted in activation of resistance responses and cell death in the presence of Prf, independent of the presence of AvrPto (Rathjen et al., 1999).

From results obtained so far, it is clear that the use of an HR triggering system can be very effective in providing pathogen resistance. It has many advantages over other biotechnological strategies for pathogen resistance but some questions concerning its efficacy remain to be answered. One of the main requirements is that the system is not active in the absence of pathogens preventing growth defects or yield losses. These negative effects can occur when systems are used that provide constitutively activated or very loosely regulated resistance pathways. It is yet unknown whether such an HR-inducing system is effective in inhibiting necrotrophic pathogens. It has been reported that non-HR cell death can enhance disease caused by Botrytis in Arabidopsis plants (Govrin and Levine, 2000), but HR might induce expression of relevant defence genes required to confer Botrytis resistance as it has been reported that necrotrophic fungi like Botrytis can be efficiently inhibited by an HR (Bonnet et al., 1996; Keller et al., 1999).

\section{Pathogen-inducible promoters}

Pathogen-inducible promoters are crucial for successful development of many transgenic disease resistance strategies including the pathogen-induced expression of elicitors of the HR. Constitutive expression of anti-microbial compounds or proteins and constitutive activation of disease resistance pathways very likely will result in deleterious side effects. In order to realize effective broadspectrum disease resistance, pathogen-inducible promoters should meet strict criteria. Firstly, pathogen-inducible promoters should be activated by a broad range of plant pathogens. Secondly, these promoters should not respond to abiotic stress or other commonly encountered environmental conditions. Thirdly, activation should be restricted to the site of attempted infection and sufficiently fast to initiate the HR to timely stop the pathogen.

Over the years, many pathogen-responsive plant genes and their promoters have been cloned and studied in great detail (Table 2). Their characteristics vary substantially and only a subset fits the requirements that would make them suitable for driving expression of elicitors of the HR. There are genes that show a rapid and localised activation upon pathogen infection whereas other genes respond more slowly or might even be activated in systemic tissue. Many pathogen-responsive 
genes are also responsive to the plant hormones SA, JA and ETH, involved in signaling upon pathogen infection. Many genes that can provide suitable promoters may be activated as a result of one of these non-specific induced resistance responses.

Cis-elements involved in the specific expression characteristics of the promoters of several pathogen-induced genes have been delineated (Martini et al., 1993; Schubert et al., 1997; Lebel et al., 1998; Pontier et al., 2001). Moreover, several plant transcription factors that play an important role in the activation of plant defence genes and bind to these cis-elements have been identified and have proven to be important in plant resistance (Yang and Klessig, 1996; Eulgem et al., 1999; Berrocal-Lobo et al., 2002).

\section{Pathogen-responsive genes}

Many pathogen-responsive genes have been identified but only a limited number of promoters has been cloned and tested extensively in transgenic plants (see Table 3 for selection of cloned and tested pathogen-inducible promoters). In planta testing of these promoters showed that the majority is activated by stimuli other than plant pathogens. Activation by wounding or plant hormones is very common and might be intrinsic to promoters that are responsive to multiple pathogens. Many are activated in a local fashion, just around the site of pathogen penetration, they are often induced during both compatible and incompatible interactions, albeit with different kinetics (incompatible = fast; compatible $=$ slow) .

Genes encoding the so-called "pathogenesis-related" (PR) proteins are generally induced by different pathogens and plant hormones. The Pr-1 group of genes is probably the most extensively characterized set as it is considered as a marker for systemic acquired resistance (SAR). In tobacco and Arabidopsis Pr-1 genes are responsive to treatment with SA and its analogues and are induced systemically as well (Uknes et al., 1993; Lebel et al., 1998). In contrast to tobacco and Arabidopsis, Pr-1 in wheat is not inducible by activators of SAR (Molina et al., 1998). The Arabidopsis Pr-1 promoter has been subject of extensive analysis to uncover the elements required for the regulation of its expression; both sequences necessary for positive and negative regulation were identified (Lebel et al., 1998). Members of the PR-10 family of genes have been identified in many plant species including potato and Asparagus (Matton and Brisson, 1989; Warner et al., 1993). The promoter of the potato Pr-10a gene (Sth-2) is induced by wounding, elicitor treatment and $P$. infestans infection and several cis-elements required for pathogen-responsiveness have been identified. A $14 \mathrm{bp}$ imperfect palindromic sequence, similar to the W-box palindrome, seems essential for pathogen-responsiveness of Sth-2 (Matton et al., 1993). The AoPR1 promoter isolated from Asparagus is strongly induced after wounding and fungal infection in transgenic tobacco plants and is also expressed in mature pollen. Dissection of the promoter sequence revealed sequences similar to several cis-acting elements with a presumed role in pathogen-responsive gene expression (Warner et al., 1993). 


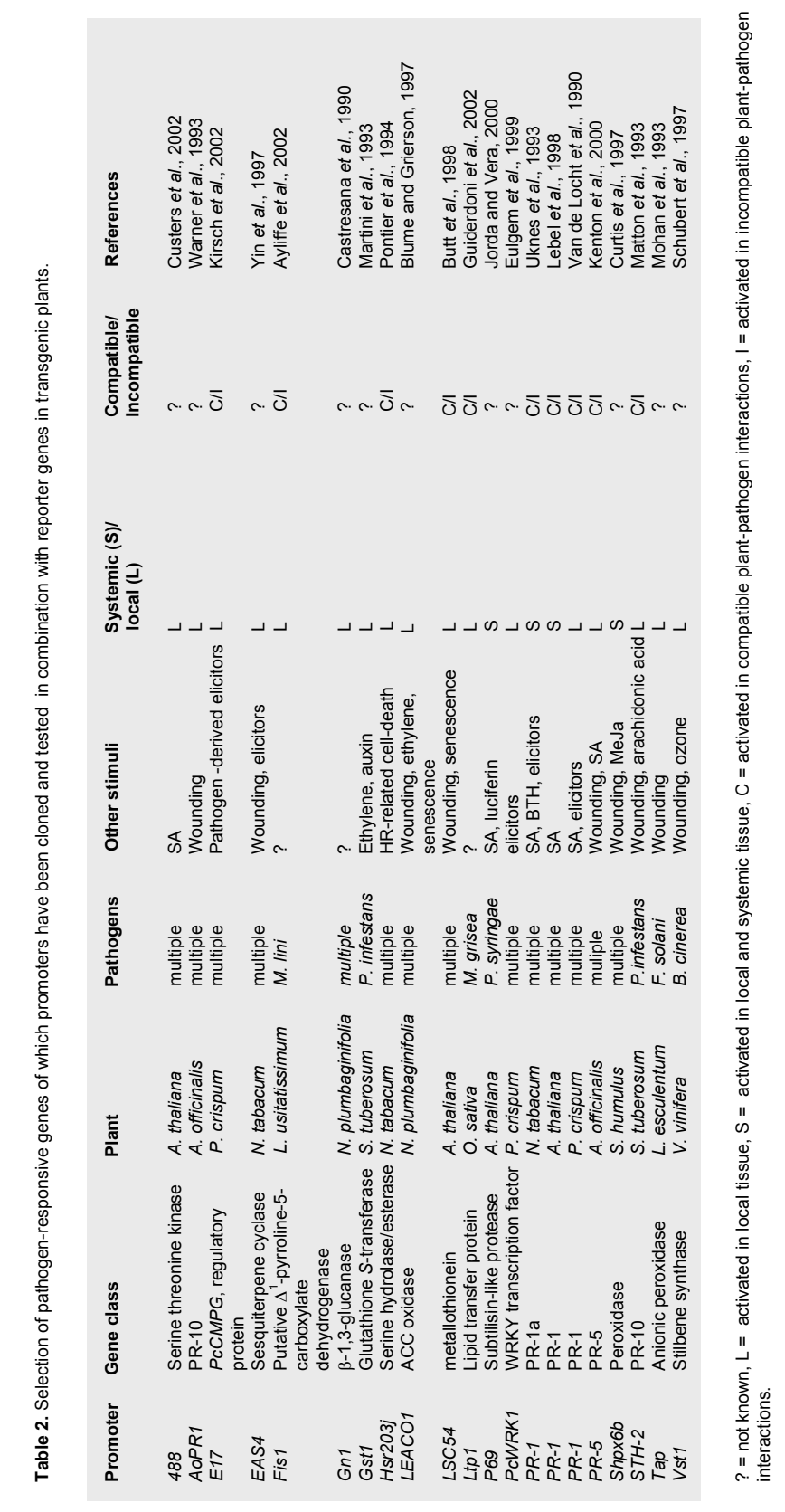


Glutathione S-transferases are widely present in the plant kingdom and are involved in the detoxification of many compounds. In Arabidopsis the Glutathione S-transferase (Gst) gene family consists of 47 members, with distinct expression patterns in response to different stress treatments (Wagner et al., 2002). Members of the Gst gene family respond very quickly to these different stress conditions, including oxidative stress (Edwards et al., 2000; Mauch and Dudler, 1994). The potato Gst1 or Prp1 gene is induced very early after P. infestans infection. An activator element of $239 \mathrm{bp}$, necessary and sufficient to confer $P$. infestans responsiveness in combination with a minimal promoter has been characterized and confers also responsiveness to nematodes (Martini et al., 1993; Strittmatter, 1995; Strittmatter et al., 1996). We have generated transgenic Cf-9 tomato plants, with the Avr9 gene under control of the 273 bp Gst1 element in combination with the CaMV 35 S minimal (-46) promoter, that display increased resistance to fungi and a viral pathogen (M. Stuiver, unpublished results). These results confirm the suitability of this engineered promoter for pathogen-induced expression of the Avr9 elicitor.

The grapevine Vst1 promoter is derived from the stilbene synthase gene that is involved in the biosynthesis of resveratrol in grapevine. Stilbenes have antimicrobial activity and play an important role in the defence system of some plants, and of grapevine in particular (Hain et al., 1993). The Vst1 promoter is responsive to pathogen infection, wounding and high ozone concentrations and promoter regions important for these characteristics have been delineated (Fischer, 1994; Schubert et al., 1997).

One of the key enzymes for phytoalexin synthesis in solanaceous plants is sesquiterpene cyclase. The promoter of the tobacco sesquiterpene cyclase gene, Eas4, is strongly upregulated by plant pathogens but some responsiveness to wounding is observed as well (Yin et al., 1997).

The promoter of the HR-specific gene Hsr203j has been successfully used, in combination with the genes encoding the HR elicitors cryptogein and PopA, to engineer disease resistance (Keller et al., 1999; Belbahri et al., 2001). Construction of deletion mutants of the Hsr203j promoter revealed a novel element required for HR-responsiveness (Pontier et al., 2001).

Fis1, upregulated by the rust fungus Melampsora lini in flax, was shown to be exclusively responsive in compatible interactions as shown by RNA blot analysis (Roberts and Pryor, 1995). However, extensive testing of the flax Fis1 promoter fused to the UidA gene showed also activation, although much less in incompatible rust-flax interactions (Ayliffe et al., 2002). This finding stresses the importance of carefully testing promoter-reporter gene fusions under various conditions. Homologues of this Fis1 gene have been detected in barley, maize, wheat and Arabidopsis, and rust responsiveness has been confirmed in barley and maize (Ayliffe et al., 2002).

The genes described above are just a few examples of pathogen-responsive genes that can provide useful promoters in combination with elicitors of the HR to engineer pathogen resistance. However almost all promoters described so far still possess less desirable characteristics (Table 3). Extensive studies on the structure and function of these promoters are required before they can be successfully employed in the resistance strategy.

\section{Regulatory elements of pathogen responsive genes and transcription factors}

To elucidate the principal mechanisms of gene activation in response to various pathogens many pathogen-responsive promoters have been dissected and analysed in functional studies. In this way many cis-elements involved or responsible for pathogen responsiveness and suppression of 
pathogen-induced expression, have been identified. In turn, this facilitated the identification of proteins that bind these cognate cis-elements to modulate gene transcription.

The W-box consensus sequence, $(\mathrm{C} / \mathrm{T}) \mathrm{TGAC}(\mathrm{C} / \mathrm{T})$, is found in many pathogen responsive genes. These include the parsley Pr-1 genes (Rushton et al., 1996), the potato Gst1 (a glutathione Stransferase; Hahn and Strittmatter, 1994) and Sth-2 genes (Pr-10-like; Matton et al., 1993), the grapevine Vst1 gene involved in phytoalexin biosynthesis (Schubert et al., 1997), the asparagus AoPR1 gene (Pr-10-like; Warner et al., 1993), the Arabidopsis and Catharanthus roseus isochorismate synthase genes (Wildermuth et al., 2001; Chapter 4) and others. Microarray analysis of more than 8000 Arabidopsis genes revealed a complete cluster of genes, including Pr-1, that are co-ordinately expressed during SAR and the upstream sequences of this cluster of genes are enriched in W-box consensus sequences (Maleck et al., 2000). In the Arabidopsis Pr-1 promoter a W-box like sequence was identified that seemed to be involved in negative regulation of inducible expression (Lebel et al., 1998). It has been shown that W-boxes are binding targets for members of the plant specific WRKY family of zinc-finger transcription factors. The members of this family of proteins contain a highly conserved region of 60 amino acids known as the WRKY domain (Eulgem et al., 2000). The WRKY gene family in Arabidopsis consists of ca. 75 members that can be separated into different classes. The parsley WRKY1 gene contains several W-box elements in its own upstream region, which suggests that there might be an auto regulatory, loop in WRKY1 expression (Eulgem et al., 1999). From Arabidopsis the Rrs1 (AtWRKY52) R-gene has been cloned, conferring resistance to $R$. solanacearum, that contains a WRKY domain, next to the LZ/CC, NBS and LRR domains (Deslandes et al., 2002). In this case R-protein activation after perception of the avirulence gene product might directly result in the induction of target gene and/or defence gene expression.

In Arabidopsis suspension cells, specific WRKY genes are induced through the bacterial flagellin elicitor/FIs2 receptor kinase-mediated activation of specific MAP kinase pathways. Overexpression of one of the WRKY targets of this MAP kinase pathway, AtWRKY29, in Arabidopsis plants results in increased pathogen resistance (Asai et al., 2002). Thus, it is clear that at least some members of the WRKY family of transcription factors are involved in activating defence gene expression and other stress responsive gene expression. The presence of such a large gene family demands extreme specificity of WRKY proteins binding to W-box elements to be able to direct the required response. The fact that not only TGAC core motifs were sufficient for elicitor induced expression but that a W-box palindrome (TGAC- $\mathrm{N}_{\mathrm{x}}-\mathrm{GTCA}$ ) is more effective in providing elicitor inducibility might indicate that two WRKY proteins could bind to a W-box palindrome and act as dimers (Eulgem et al., 1999).

The GCC-box (AGCCGCC) is present in many pathogen responsive genes and is thought to be involved in directing ETH-, drought- and cold-responsive expression. GCC-boxes are able to bind proteins of the EREBPIAP2 family of DNA binding proteins. Among proteins of this family are the Dreb1 and Dreb2 EREBPs that stimulate cold- and drought-responsive gene expression, respectively, and the ERFs (ETH response factors) in tobacco that confer ETH and pathogeninducible gene expression (Ohme-Takagi and Shinshi, 1995; Buttner and Singh, 1997; Liu et al., 1998). Pti4, Pti5 and Pti6 are EREBPs and overexpression of some of these EREBPs directly results in defence gene expression and increased pathogen resistance (Park et al., 2001). Different members of the ERF gene family in Arabidopsis can either activate or repress GCC box-mediated 
gene expression. The ERFs repressing GCC box-mediated gene expression also displayed a negative effect on transactivation activity of other transcription factors (Fujimoto et al., 2000). Constitutive expression of the Arabidopsis Erf1 transcriptional activator in Arabidopsis enhances resistance to the necrotrophic pathogens $B$. cinerea and Plectosphaerella cucumerina and increases susceptibility to $P$. syringae bacteria. In the response to $P$. cucumerina, SA and ETH appear to cooperate in contrast to the response to Pseudomonas where activation of the ETH pathway by Erf1 overexpression probably suppresses SA mediated resistance (Berrocal-Lobo et al., 2002).

Myb transcription factors have the ability to bind so-called Myb Recognition Elements (MREs). The Arabidopsis genome contains $121 \mathrm{Myb}$-like genes and several have been associated with the plant stress response (Chen et al., 2002). The tobacco MYB1 gene is induced by the TMV-triggered HR and during SAR. SA treatment also induces this gene and the tobacco $P R-1$ a promoter contains a MYB1 binding site (MBS) (Yang and Klessig, 1996). The Arabidopsis and C. roseus Ics genes, involved in induced SA biosynthesis, also contain a putative MBS, MBSII, in the upstream sequence (Wildermuth et al., 2001; Chapter 4). MBSII resembles the H-box consensus sequence (CCTACC; Fischer et al., 1994) that is present in many genes involved in phenylpropanoid metabolism connected to stress responsiveness (Yang and Klessig, 1996). This H-box consensus is involved in the wound and elicitor response and when 13 basepair multimers of this motif were fused to a minimal promoter, elicitor, JA and wound responsiveness was maintained (Takeda et al., 1999).

Here we have described only a small subset of transcription factor genes and cis-acting elements that play a role in plant defence gene expression and plant resistance. A distinct set of transcription factors appears to control gene expression in response to pathogen attack, cold, drought and osmotic stress but there seems to be substantial overlap in transcription factor gene expression in response to different biotic and abiotic stress factors (Chen et al., 2002).

\section{References} Aarts N., Metz M., Holub E., Staskawicz B.J., Daniels M.J. and Parker J.E., 1998. Different requirements for EDS1 and NDR1 by
disease resistance genes define at least two $R$ gene-mediated signaling pathways in Arabidopsis. Proc. Natl. Acad. Sci. USA 95: 10306-10311.

Abramovitch R.B., Kim Y.J., Chen S., Dickman M.B. and Martin G.B., 2003. Pseudomonas type III effector AvrPtoB induces plant disease susceptibility by inhibition of host programmed cell death. EMBO J. 22(1): 60-69.

Alamillo J.M. and Garcia-Olmedo F., 2001. Effects of urate, a natural inhibitor of peroxynitrite-mediated toxicity, in the response of Arabidopsis thaliana to the bacterial pathogen Pseudomonas syringae. Plant J. 25(5): 529-540.

Allen R.L., Bittner-Eddy P.D., Grenville-Btiggs L.J., Meitz J.C., Rehmany A.P., Rose L.E. and Beynon J.L., 2004. Host-paracite coevolutionary conflict between Arabidopsis and downey mildew. Science 306: 1957-1960.

Alonso J.M., Hirayama T., Roman G., Nourizadeh S. and Ecker J R., 1999. EIN2, a bifunctional transducer of ethylene and stress responses in Arabidopsis. Science 284: 2148-2152.

Armstrong M.R., Whisson S.C., Pritchard L., Bos J.I., Venter E., Avrova A.O., Rehmany A.P., Bohme U., Brooks K., Cherevach I., Hamlin N., White B., Fraser A., Lord A., Quail M.A., Churcher C., Hall N., Berriman M., Huang S., Kamoun S., Beynon J.L. and Birch P.R., 2004. An ancestral oomycete locus contains late blight avirulence gene Avr3a, encoding a protein that is recognized in the host cytoplasm. Proc. Natl. Acad. Sci. USA 102(21): 7766-7771.

Alvarez M.E., Pennel R.I., Meijer P., Ishikawa A., Dixon R.A. and Lamb C., (1998) Reactive Oxygen Intermediates Mediate a Systemic Signal network in the establishment of Plant Immunity. Cell 92; 773-784.

Asai T., Tena G., Plotnikova J., Willmann M.R., Chiu W., Gomez-Gomez L., Boller T., Ausubel F.M. and Sheen J., 2002. MAP Kinase signaling cascade in Arabidopsis innate immunity. Nature 415: 977-983

Ashfield T., Ong L.E., Nobuta K., Schneider C.M. and Innes R.W., 2004. Convergent evolution of disease resistance gene specificity in two flowering plant families. Plant Cell 16(2): 309-318. 
Austin M.J., Muskett P., Kahn K., Feys B.J., Jones J.D.G. and Parker J.E., 2002. Regulatory role of SGT1 in early R gene-mediated plant defences. Science 295: 2077-2080.

Axtell M.J. and Staskawicz B.J., 2003. Initiation of RPS2-specified disease resistance in Arabidopsis is coupled to the AvrRpt2directed elimination of RIN4. Cell 112: 369-377.

Axtell M.J., Chisholm S.T., Dahlbeck D. and Staskawicz B.J., 2003. Genetic and molecular evidence that the Pseudomonas syringae type III effector protein AvrRpt2 is a cysteine protease. Mol. Microbiol. 49(6): 1537-1546.

Ayliffe M.A., Roberts J.K., Mitchell H.J., Zhang R., Lawrence G.J., Ellis J.G. and Pryor T.J., 2002. A plant gene up-regulated at rust infection sites. Plant Physiol. 129: 169-180.

Azevedo C., Sadanandom A., Kitagawa K., Freialdenhoven A., Shirasu K. and Schulze-Lefert P., 2002. The RAR1 interactor SGT1, an essential component of $R$-gene-triggered disease resistance. Science 295: 2073-2076.

Banerjee D., Zhang X. And Bent A.F., 2001. The leucine-rich repeat domain can determine effective interaction between RPS2 and other host factors in Arabidopsis Rps2-mediated disease resistance. Genetics 158: 439-450.

Bechinger C., Giebel K..F, Schnell M., Leiderer P., Deising H.B. and Bastmeyer M., 1999. Optical measurements of invasive forces exerted by appressoria of a plant pathogenic fungus. Science 285(5435): 1896-1899.

Belbahri L., Boucher C., Candresse T., Nicole M., Ricci P. and Keller H., 2001. A local accumulation of the Ralstonia solanacearum PopA protein in transgenic tobacco renders a compatible plant-pathogen interaction incompatible. Plant J. 28(4): 419-430.

Belfanti E., Silferberg-Dilworth E., Tartarini S., Pattochi A., Barbieri M., Zhu J., Vinatzer B.A., Gianfranchesci L., Gessler C. and Sansavini S. 2004. The HcrVf2 genefrom a wild apple confers scab resistance to a transgenic cultivated variety. Proc. Natl. Acad. Sci. USA 101 (3): 886-890

Belkhadir Y., Nimchuck Z., Hubert D.A., Mackey D. and Dangl J.L., 2004. Arabidopsis RIN4 negatively regulates disease resistance mediated by RPS2 and RPM1 downstream or independent of the NDR1 signal modulator and is not required for the virulence functions of bacterial type III effectors AvrRpt2 or AvrRpm1. Plant Cell 16: 2822-2835.

Bendahmane A., Kohn B.A., Dedi C. and Baulcombe D.C., 1995. The coat protein of potato virus X is a strain specific elicitor of Rx-1 mediated virus resistance in potato. Plant J. 8:933-941.

Berger S., 2002. Jasmonate-related mutants of Arabidopsis as tools for studying stress signaling. Planta 214: 497-504.

Berrocal-Lobo M., Molina A. and Solano R., 2002. Constitutive expression of ETHYLENE-RESPONSE-FACTOR1 in Arabidopsis confers resistance to several necrotrophic fungi. Plant J. 29(1): 23-32.

Bisgrove S.R., Simonich M.T., Smith N.M., Sattler A. and Innes R.W., 1994. A disease resistance gene in Arabidopsis with specificity for two different pathogen avirulence genes. Plant Cell 6(7): 927-933.

Bleeker, A.B. and Kende, H., 2000. Ethylene: A gaseous signal molecule in plants. Annu. Rev. Cell Dev. Biol. 16: 1-18.

Blume B. and Grierson D., 1997. Expression of ACC oxidase promoter-GUS fusions in tomato and Nicotiana plumbaginifolia regulated by developmental and environmental stimuli. Plant J. 12(4): 731-746.

Bolwell GP, Butt VS, Davies DR, Zimmerlin A., 1995. The origin of the oxidative burst in plants. Free Radic Res. 23(6): 517-532.

Bolwell G.P. and Wojtaszek P., 1997. Mechanisms for the generation of reactive oxygen species in plant defence - a broad perspective. Physiol. Mol. Plant Path. 51: 347-366.

Bonas U. and Lahaye T., 2002. Plant disease resistance triggered by pathogen-derived molecules: refined models of specific recognition. Curr. Opin. Microbiol. 5: 44-50.

Bonnet P., Bourdon E., Ponchet M., Blein J.P. and Ricci P., 1996. Acquired resistance triggered by elicitins in tobacco and other plants. Eur. J. Plant Pathol. 102: 181-192.

Bouarab K., Melton R., Peart J., Baulcombe D. and Osbourn A., 2002. A saponin-detoxifying enzyme mediates suppression of plant defences. Nature 418: 889-892.

Bourque S., Lemoine R., Sequeira-Legrand A., Fayolle L., Delrot S. and Pugin A., 2002. The elicitor cryptogein blocks glucose transport in tobacco cells. Plant Physiol. 130(4): 2177-2187.

Boyes D.C., Nam J. and Dangl J.L., 1998. The Arabidopsis thaliana RPM1 disease resistance gene product is a peripheral plasma membrane protein that is degraded coincident with the hypersensitive response. Proc. Natl. Acad. Sci. USA 95: 15849-15854.

Bradley D.J., Kjellbom P. and Lamb C.J., 1992. Elicitor and wound induced oxidative cross-linking of a proline-rich plant cell wall protein: A novel, rapid defence response, Cell 70: 21-30.

Brunner F., Rosahl S., Lee J., Rudd J.J., Geiler C., Kauppinen S., Rasmussen G., Scheel D. and Nurnberger T., 2002. Pep-13, a plant defence-inducing pathogen-associated pattern from Phytophthora transglutaminases. EMBO J. 21: 6681-6688. 
Butt A., Mousley C., Morris K., Beynon J., Can C., Holub E., Greenberg J.T. and Buchanan-Wollaston V., 1998. Differential expression of a senescence-enhanced metallothionein gene in Arabidopsis in response to isolates of Peronospora parasitica and Pseudomonas syringae. Plant J. 16(2): 209-221.

Buttner M. and Singh K.B., 1997. Arabidopsis thaliana ethylene-responsive element binding protein (AtEBP), an ethylene inducible, GCC-box DNA binding protein interacts with an OCS binding protein. Proc. Natl. Acad. Sci. USA 94: 5961-5966.

Cano-Delgado A., Penfield S., Smith C., Catley M. and Bevan M., 2003. Reduced cellulose synthesis invokes lignification and defence responses in Arabidopsis thaliana. Plant J. 34(3): 351-362.

Cao H., Glazebrook J., Clarke J.D., Volko S. and Dong X., 1998. The Arabidopsis NPR1 gene that controls systemic acquired resistance encodes a novel protein containing ankyrin repeats. Cell 88: 57-63.

Castresana C., de Carvalho F., Gheysen G., Habets M., Inze D. and Van Montagu M., 1990. Tissue-specific and pathogen-induced regulation of a Nicotiana plumbaginifolia beta-1,3-glucanase gene. Plant Cell 2(12): 1131-1143.

Catanzariti A-M., Dodds P.M., Lawrence G.J., Ayliffe M.A. and Ellis J.G., 2006. Haustorially expressed secreted proteins from flax rust are highly enriched for avirulence elicitors. Plant Cell 18(1): 243-256.

Century K.S., Shapiro A.D., Clarke J.D., Volko S., Holub E. and Staskawicz B.J., 1997. NDR1, a pathogen-induced component required for Arabidopsis disease resistance. Science 278: 1963-1965.

Chamnongpol S., Willekens H., Moeder W., Langebartels C., Sandermann H., Van Montagu M., Inze D. and Van Camp W., 1998. Defence activation and enhanced pathogen tolerance induced by $\mathrm{H}_{2} \mathrm{O}_{2}$ in transgenic tobacco. Proc. Natl. Acad. Sci. USA 95: 58185823.

Chang J.H., Rathjen J.P., Bernal A.J., Staskawicz B.J. and Michelmore R.W., 2000. AvrPto enhances growth and necrosis caused by Pseudomonas syringae pv.tomato in tomato lines lacking either Pto or Prf. Mol Plant Microbe Interact. 13(5):568-571.

Che F.S., Nakajima Y., Tanaka N., Iwano M., Yoshiba T., Takayama S., Kadota I. and Isogai A., 2000. Flagellin from an incompatible strain of Pseudomonas avenae induces a resistance response in cultured rice cells. J. Biol. Chem., 275(41): 32347-32356.

Chen W., Provart N.J., Glazebrook J., Katagiri F., Chang H-S., Eulgem T., Mauch F., Luan S., Zou G., Witham S.A., Budworth P.R., Tao Y., Xie Z., Chen X., Lam. S., Kreps J.A., Harper J.F., Si-Ammour A., Mauch-Mani B., Heinlein M., Kobayashi K., Hohn T., Dangl J.L., Wang X. and Tong Zhu., 2002. Expression profile matrix of Arabidopsis transcription factor genes suggests their putative functions in response to environmental stresses. Plant Cell 14:559-574.

Cheng L.W. and Schneewind O., 2000. Type III machines of Gram-negative bacteria: delivering the goods. Trends Microbiol. 8(5): 214-220.

Chisholm S.T., Coaker G., Day B. and Staskawicz B.J., 2006. Host-Microbe interactions: Shaping the evolution of the plant immune response. Cell 124: 803-814.

Clark S.E., Williams R.W. and Meyerowitz E.M., 1997. The CLAVAT1 gene encodes a putative receptor kinase that controls shoot and floral meristem size in Arabidopsis. Cell 89: $575-585$.

Collmer A., Badel J.L., Charkowski A.O., Deng W-L., Fouts D.E., Ramos A.R., Rehm A.H., Anderson D.M., Schneewind O., Van Dijk K. and Alfano J.R., 2000. Pseudomonas syringae Hrp type III secretion system and effector proteins. Proc. Natl. Acad. Sci. USA K. and Alfano J.R.
97(16): $8770-8777$.

Cooley M.B., Pathirana S., Wu H.J., Kachroo P. and Klessig D.F., 2000. Members of the Arabidopsis HRT/RPP8 family of resistance genes confer resistance to both viral and oomycete pathogens. Plant Cell 12: 663-676.

Coquoz J-L., Buchala A. and Metrauz J-P., 1998. The biosynthesis of salicylic acid in potato plants. Plant Physiol. 117: 1095-1101.

Cosio E.G., Feger M., Miller C.J., Anetlo L. and Ebel J., 1996. High-affinity binding of fungal $\beta$-glucan elicitors to cell membranes of species of the plant family Fabaceae. Planta 200: 92-99.

Côté F., Roberts K. and Hahn M., 2000. Identification of high-affinity binding sites for the hepta- $\beta$-glucoside elicitor in membranes of the model legumes Medicago truncatula and Lotus japonicus. Planta 211: 596-605.

Curtis M.D., Rae A.L., Rusu A.G., Harrison S.J. and Manners J.M., 1997. A peroxidase gene promoter induced by phytopathogens and methyl jasmonate in transgenic plants. Mol Plant Microbe Interact. 10(3): 326-338.

Custers J.H.H.V., Melchers L.S., Tigelaar H., Bade J.B., Spiegeler J.J.M., Van der Meijs P.J., Simons L.H. and Stuiver M.H., 2002. TDNA tagging of a pathogen-inducible promoter in Arabidopsis thaliana. Mol. Plant Pathol. 3(4): 239-249.

Custers J.H.H.V., Harrison S.J., Sela-Buurlage M.B., Van Deventer E., Lageweg W., Howe P.W., Van der Meijs P.J., Ponstein A.S., Simons L.H., Melchers L.S. and Stuiver M.H., 2004. Isolation and characterisation of a class of carbohydrate oxidases from higher plants, with a role in defence. Plant J. 39(2): 147-160.

Dangl J.L. and Jones J.D.G., 2001. Plant pathogens and integrated defence responses to infection. Nature 411: 826-833.

Delaney T.P., Uknes S., Vernooij B., Friedrich L.,Weymann K., Negrotto D., Gaffney T., Gut-Rella M., Kessmann H., Ward E. and Ryals J., 1994. A central role of Salicylic Acid in plant disease resistance. Science 266: 12471250. 
Delledonne M., Xia Y., Dixon R.A and Lamb C., 1998. Nitric oxide functions as a signal in plant disease resistance. Nature 394: 585588

Delledonne M., Zeier J., Marocco A and Lamb C., 2001. Signal interaction between nitric oxide and reactive oxygen intermediates in the plant hypersensitive disease resistance response. Proc. Natl. Acad. Sci. USA 98(23): 13454-13459.

Deslandes L., Olivier J., Theulieres F., Hirsch J., Feng D.X., Bittner-Eddy P., Beynon J. and Marco Y., 2002. Resistance to Ralstonia solanacearum in Arabidopsis thaliana is conferred by the recessive RRS1-R gene, a member of a novel family of resistance genes. Proc. Natl. Acad. Sci. USA 99(4): 2404-2409.

Deslandes L., Olivier J., Peeters N., Feng D.X., Khounlotham M., Boucher C., Somssich I., Genin S. and Marco Y., 2003. Physical interaction between RRS1-R, a protein conferring resistance to bacterial wilt, and PopP2, a type III effector targeted to the plant nucleus. Proc. Natl. Acad. Sci. USA 100(13): 8024-8029.

Despres C., DeLong C., Glaze S., Liu E. and Fobert P.R., 2000. The Arabidopsis NPR1/NIM1 protein enhances the DNA binding activity of a subgroup of the TGA family of bZIP transcription factors. Plant Cell 12(2): 279-290.

Dixon M.S., Golstein C., Thomas C.M., Vander Biezen E.A. and Jones J.D.G., 2000. Genetic complexity of pathogen perception by plants: The example of Rcr3, a tomato gene required specifically by Cf-2. Proc. Natl. Acad. Sci. USA 97: 8807-8814.

Dodds P.N., Lawrence G.J., Catanzariti A-M., The T., Wang C-I.A., Ayliffe M.A., Kobe B. and Ellis J.G., 2006. Direct protein interaction underlies gene-for-gene specificity and coevolution of the flax resistance genes and flax rust avirulence genes. Proc. Natl. Acad. Sci. USA 103(23): 8888-8893.

Dong H., Delaney T.P., Bauer D.W. and Beer S.V., 1999. Harpin induces disease resistance in Arabidopsis through the systemic acquired resistance pathway mediated by salicylic acid and the NIM1 gene. Plant J. 20(2): 207-215

Dorey S., Baillieul F., Pierrel M., Saindrenan P., Fritig B. and Kauffmann S., 1997 Spatial and Temporal Induction of Cell Death, Defence genes, and Accumulation of Salicylic Acid in Tobacco Leaves Reacting Hypersensitively to a Fungal Glycoprotein elicitor. Mol. Plant-Microbe Interact. 10(5), 646-655.

Draper J., 1997. Salicylate, superoxide synthesis and cell suicide in plant defence. Trends Plant Sci. 2(5): 162-165.

Durner J., Wendehenne D. and Klessig D.F., 1998. Defence gene induction in tobacco by nitric oxide, cyclic GMP and cyclic ADPribose. Proc. Natl. Acad Sci. USA 95: 10328-10333.

Edwards R., Dixon D.P. and Walbot V., 2000. Plant Glutathione S-transferases: enzymes with multiple functions in sickness and in health. Trends Plant Sci. 5(5): 193-198,

Ellis J.G., Lawrence G.J., Luck J.E. and Dodds P.N., 1999. Identification of regions in alleles of flax rust resistance gene $L$ that determine differences in gene-for-gene specificity. Plant Cell 11: 495-506.

Ellis J.G., Catanzariti A-M. and Dodds P.N., 2006. The problem of how fungal and oomycete avirulence proteins enter plant cells. Trends Plant Sci. 11(2): 61-63.

Erickson F.L., Holzberg S., Calderon Urrea A., Handley V., Axtell M., Corr C. and Baker B., 1999. The helicase domain of the TMV replicase protein induces the N-mediated resistance response in tobacco. Plant J. 18: 67-75.

Eulgem T., Rushton P.J., Schmelzer E., Hahlbrock K. and Somssich I., 1999. Early nuclear events in plant defence signaling: rapid gene activation by WRKY transcription factors. EMBO J. 18(17): 4689-4699.

Eulgem T., Rushton P.J., Robatzek S. and Somssich I.E., 2000. The WRKY superfamily of plant transcription factors. Trends Plant Sci. 5(5): 199-206.

Falk A., Feys B.J., Frost L.N., Jones J.D.G., Daniels M.J. and Parker J.E., 1999. EDS1, an essential component of R-gene mediated disease resistance in Arabidopsis has homology to eukaryotic lipases. Proc. Natl. Acad. Sci. USA 96: 3292-3297.

Fellbrich G., Romanski A., Varet A., Blume B., Brunner F., Engelhardt S., Felix G., Kemmerling B., Krzymowska M. and Nurnberger T., 2002. NPP1, a Phytophthora-associated trigger of plant defence in parsley and Arabidopsis. Plant J. 32(3): 375-390.

Feys B.J. and Parker J.E., 2000. Interplay of signaling pathways in plant disease resistance. Trends in Genet. 16(10): 449-455.

Feys B.J., Moisan L.J., Newman M-A. and Parker J.E., 2001. Direct interaction between the Arabidopsis disease resistance signaling proteins, EDS1 and PAD4. EMBO J 20: 5400-5411.

Felix G., Duran J.D., Volko S. and Boller T., 1999. Plants have a sensitive perception system for the most conserved domain of bacterial flagellin. Plant J. 18: 265-276.

Fischer R., 1994. Optimierung der heterologen expression von stilbensynthasegenen für den pflanzenschutz. Ph.D. thesis, University of Hohenheim, Germany.

Flor H.H., 1946. Genetics of pathogencity in Melampsora lini.. J. Agric. Res. 73: 335-357. 
Fujimoto S.Y., Ohta M., Usui A., Shinshi H. and Ohme-Takagi M., 2000. Arabidopsis ethylene-responsive element binding factors act as transcriptional activators or repressors of GCC box-mediated gene expression. Plant Cell 12: 393-404.

Ganesan V. and Thomas G., 2001. Salicylic acid response in rice: influence of salicylic acid on $\mathrm{H}_{2} \mathrm{O}_{2}$ accumulation and oxidative stress. Plant Sci. 160: 1095-1106.

Glazebrook J., 2001. Genes controlling expression of defence responses in Arabidopsis--2001 status. Curr Opin Plant Biol. 4(4): 301308

Goff S.A. et al., 2002. A draft sequence of the Rice genome (Oryza sativa L. ssp. japonica). Science 296: 92-100.

Gómez-Gómez L. and Boller T., 2000. FLS2: An LRR receptor-like kinase involved in the perception of the bacterial elicitor flagellin in Arabidopsis. Mol. Cell 5: 1003-1011.

Görlach J., Volrath S., Knauf-Beiter G., Hengy G., Beckhove U., Kogel K-H., Oostendorp M., Staub T., Ward E., Kessmann H. and Ryals J., 1996. Benzothiadiazole, a novel class of inducers of systemic acquired resistance, activates gene expression and disease resistance in wheat. Plant Cell 8: 629-643.

Govrin E.M. and Levine A., 2000. The hypersensitive response facilitates plant infection by the necrotrophic pathogen Botrytis cinerea. Curr Biol. 10(13): 751-757.

Grant M.R., Godiard L., Straube E., Ashfield T., Lewald J., Sattler A., Innes R.W. and Dangl J.L., 1995. Structure of the Arabidopsis RPM1 gene enabling dual specificity disease resistance. Science 169: 1095-1105.

Groom Q.J., Torres M.A., Fordham-Skelton A.P., Hammond-Kosack K.E., Robinson N.J. and Jones J.D., 1996. rbohA, a rice homologue of the mammalian gp91phox respiratory burst oxidase. Plant J. 10(3): 515-522.

Gu Y.Q., Yang C., Thara V.K., Zhou J. and Martin G.B., 2000. Pti4 is induced by ethylene and salicylic acid, and its product is phosphorylated by the Pto kinase. Plant Cell 12: 771-785.

Guiderdoni E., Cordero M.J., Vignols F., Garcia-Garrido J.M., Lescot M., Tharreau D., Meynard D., Ferriere N., Notteghem J.L. and Delseny M., 2002. Inducibility by pathogen attack and developmental regulation of the rice Ltp1 gene. Plant Mol Biol. 49(6): 683-699.

Guo F-Q., Okamoto M. and Crawford N.M., 2003. Identification of a plant nitric oxide synthase gene involved in hormone signaling. Science 302: 100-103.

Guo W., Gonzalez-Candelas L. And Kolattukudy P.E.,1995. Cloning of a novel constitutively expressed pectate lyase gene pelB from Fusarium solani f. sp. Pisi (Nectria haematococca, mating type VI) and characterization of the gene product expressed in Pichia pastoris. J. Bacteriol. 177(24): 7070-7077.

Hahn K. and Strittmatter G., 1994. Pathogen-defence gene prp1-1 from potato encodes an auxin-responsive glutathione Stransferase. Eur. J. Biochem. 226(2): 619-626.

Hain R., Reif H.J., Krause E., Langebartels R., Kindl H., Vornam B., Wiese W., Schmelzer E., Schreier P.H., Stocker R.H. and Stenzel K., 1993. Disease resistance results from foreign phytoalexin expression in a novel plant. Nature 361(6408): 153-156.

Hammond-Kosack, K.E., Tang S., Harrison, K. and Jones, J.D.G., 1998. The tomato Cf-9 disease resistance gene functions in tobacco and potato to confer responsiveness to the fungal avirulence gene product AVR9. Plant Cell 10: 1251-1266.

Hammond-Kosack K.E. and Parker J.E., 2003. Deciphering plant-pathogen communication: fresh perspectives for molecular resistance breeding. Curr. Opin. Biotechnol. 14(2): 177-193.

He Z.H., Wang Z.Y., Li J.M., Zhu Q., Lamb C., Ronald P. and Chory J., 2000. Perception of brassinosteroids by the extracellular domain of the receptor kinase BRI1. Science 288: 2360-2363.

Heck S., Grau T., Buchala A., Metraux J.P.,and Nawrath C., 2003. Genetic evidence that expression of NahG modifies defence pathways independent of salicylic acid biosynthesis in the Arabidopsis-Pseudomonas syringae pv. tomato interaction. Plant $J$. $36(3): 342-352$

Herbers K., Conrads-Strauch J. and Bonas U., 1992. Race-specificity of plant resistance to bacterial spot disease determined by repetitive motifs in a bacterial avirulence protein. Nature 356: 172-174.

Hinsch M. and Staskawicz B.J., 1996. Identification of a new Arabidopsis disease resistance locus, Rps4, and cloning of the corresponding avirulence gene, AvrRps4, from Pseudomonas syringae pv. Pisi. Mol. Plant Microbe Interact. 9: 55-61.

Innes R.W., Bent A.F., Kunkel B.N., Bisgrove S.R. and Staskawicz B.J., 1993. Molecular analysis of avirulence gene AvrRpt2 and identification of a putative regulatory sequence common to all known Pseudomonas syringae avirulence genes. J. Bacteriol. 175(15): identification

Isshiki A., Akimitsu K., Yamamoto M. and Yamamoto H., 2001. Endopolygalacturonase is essential for citrus black rot caused by Alternaria citri but not brown spot caused by Alternaria alternate. Molec. Plant-Microbe Interact. 14(6): 749-757.

Jamir Y., Guo M., Oh H.S., Petnicki-Ocwieja T., Chen S., Tang X., Dickman M.B., Collmer A. and Alfano J.R., 2004. Identification of Pseudomonas syringae type III effectors that can suppress programmed cell death in plants and yeast. Plant J. 37(4): $554-565$. 
Jenks M.A., Joly R.J., Peters P.J., Rich P.J., Axtell J.D. and Ashworth E.N., 1994. Chemically induced cuticle mutation affecting epidermal conductance to water vapour and disease susceptibility in Sorghum bicolour (L.) Moench. Plant Physiol. 105(4): 12391245.

Ji C., Slaymaker D., Okinaka Y., Takeuchi Y., Midland S.L., Sims J.J., Herman E. and Keen N., 1998. Characterization of a 34-kD soybean binding protein for the syringolide elicitors. Proc. Natl. Acad. Sci. USA 95: 3306-3311.

Jia Y., McAdams S.A., Bryan G.T., Hershey H.P. and Valent B., 2000. Direct interaction of resistance gene and avirulence gene products confers rice blast resistance. EMBO J. 19(15): 4004-4014.

Jin H., Axtell M.J., Dahlbeck D., Ekwenna O., Zhang S., Staskawicz B. and Baker B., 2002. NPK1, an MEKK1-like mitogen-activated protein kinase kinase kinase, regulates innate immunity and development in plants. Dev. Cell. 3(2): 291-297.

Jirage D., Tootle T.L., Reuber L., Feys B.J., Frost L.N., Parker J.E., Ausubel F.M. and Glazebrook J., 1999. Characterization of Arabidopsis thaliana PAD4 - Evidence for a positive feedback loop in salicylic acid signaling. Proc. Natl. Acad. Sci. USA 96: 1358313588.

Jones D.A., Thomas C.M., Hammond-Kosack K.E., Balint-Kurti P.J. and Jones J.D.G., 1994. Isolation of the tomato Cf-9 gene for resistance to Cladosporium fulvum by transposon tagging. Science 266: 789-793.

Joosten M.H.A.J., Cozijnsen A.J. and De Wit P.J.G.M., 1994. Host resistance to a fungal tomato pathogen lost by a single base-pair change in an avirulence gene. Nature $367: 384-386$.

Jordá, L. and Vera, P. 2000. Local and systemic induction of two defence-related subtilisin-like protease promoters in transgenic Arabidopsis plants. Luciferin induction of PR gene expression. Plant Physiol. 124: 1049-1057.

Kachroo A., He Z., Patkar R., Zhu Q., Zhong J., Li D., Ronald P., Lamb C. and Chattoo B.B., 2003. Induction of H2O2 in transgenic rice leads to cell death and enhanced resistance to both bacterial and fungal pathogens. Transgenic Res. 12(5): 577-586.

Kamoun S. Van West P., Vleeshouwers V.G.A.A., De Groot K.E. and Govers F., 1998. Resistance of Nicotiana benthamiana to Phytophthora infestans is mediated by the recognition of the elicitor protein INF1. Plant Cell 10: 1413-1425.

Kanzaki H., Saitoh H., Ito A., Fujisawa S., Kamoun S., Katou S., Yshioka H. and Terouchi R., 2003. Cytosolic HSP90 and HSP70 are essential components of INF1-mediated hypersensitive response and non-host resistance to Psuedomonas cichorii in Nicotiana benthamiana. Mol. Plant Pathol. 4(5): 383-391.

Kawasaki T., Hemni K., Ono E., Hatakeyama S., Iwano M., Satoh H. and Shimamoto K., 1999. The small GTP-binding protein Rac is a regulator of cell death in plants. Proc. Natl. Acad. Sci. USA 96: 10922-10926.

Kawchuk L.M., Hachey J., Lunch D.R., Kulcsar F., Van Rooyen G., Waterer D.R., Robertson A., Kokko E., Byers R., Howard R.J., Fischer R. and Prufer D., 2001. Tomato Ve disease resistance genes encode cell surface-like receptors. Proc. Natl. Acad. Sci. USA 98:6511-6515.

Kazan K., Murray F.R., Goulter K.C., Llewellyn D.J. and Manners J.M. (1998) Induction of Cell death in Transgenic Plants Expressing a Fungal Glucose Oxidase. Mol. Plant Microbe Interact 11(6): 555-562.

Kearney B. and Staskawicz B.J., 1990. Widespread distribution and fitness contribution of Xanthomonas campestruis avirulence gene AvrBs2. Nature 346: 385-386

Keen N.T. and Yoshikawa M., 1983. B-1,3 Endoglucanase from soybean releases elicitor active carbohydrates from fungal cell walls. Plant Physiol. 71: 460-465

Keller H., Pamboukdjian N., Ponchet M., Poupet A., Delon R., Verrier J-L., Roby D. and Ricci P., 1999. Pathogen-induced elicitin production in transgenic tobacco generates a hypersensitive response and non-specific disease resistance. Plant Cell 11: 223-235.

Kenton P., Darby R.M., Shelley G. and Draper J., 2000. A PR-5 gene promoter from Asparagus officinalis (AoPRT-L) is not induced by abiotic stress, but is activated around sites of pathogen challenge and by salicylate in transgenic tobacco. Mol. Plant Pathol. 1(6): 367-378

Kim Y.J., Lin N.C. and Martin G.B., 2002. Two distinct Pseudomonas effector proteins interact with the Pto kinase and activate plant immunity. Cell 109(5): 589-598.

Kim H.S., Desveaux D., Singer A.U., Patel P., Sondek J. and Dangl J.L., 2005. The Pseudomonas syringae effector AvrRpt2 cleaves its C-terminally acylated target, RIN4, from Arabidopsis membranes to block RPM1 activation. Proc Natl Acad Sci USA.102(18): 6496-6501.

Kirsch C., Logemann E., Lippok B., Schmelzer E. And Hahlbrock K., 2001. A highly specific pathogen-responsive promoter element from the immediate-early activated CMPG1 gene in Petroselinum crispum. Plant J. 26(2): 217-227.

Klarzynski O., Plesse B., Joubert J-M., Yvin J-C., Kopp M., Kloareg B. and Fritig B., 2000. Linear B-1,3-glucans are elicitors of defence responses in tobacco. Plant Physiol. 124: 1027-1037.

Knogge W., 1996. Fungal infection of plants. Plant Cell 8: 1711-1722. 
Kooman-Gersmann M., Honee G., Bonnema G. and De Wit P.J.G.M, 1996. A high-affinity binding site for the AVR9 peptide elicitor of Cladosporium fulvum is present on plasma membranes of tomato and other solanaceous plants. Plant Cell 8: 929-938.

Kopp M., Rouster J., Fritig B., Darvill A. and Albertsheim P., 1989. Host-pathogen interactions: XXXII. A fungal glucan preparation protects Nicotianae against infection by viruses. Plant Physiol. 90: 208-216.

Krüger J., Thomas C.M., Golstein C., Dixon M.S., Smoker M., Tang S., Mulder L. and Jones J.D., 2002. A tomato cysteine protease required for Cf-2-dependent disease resistance and suppression of autonecrosis. Science 296: 744-747.

Kruijt M., Brandwagt B.F and De Wit P.J.G.M., 2004. Rearrangements in the Cf-9 disease resistance cluster of wild tomato have resulted in three genes that mediate Avr9 responsiveness. Genetics 168(3): 1655-1663.

Kumar D. and Klessig D.F., 2000. Differential induction of tobacco MAP kinases by the defence signals Nitric Oxide, Salicylic Acid, Ethylene and Jasmonic Acid. Mol. Plant-Microbe-Interact. 13(3): 347-351.

Lane B.G., Dunwell J.M., Ray J.A., Schnitt M.R. and Cuming A.C., 1993. Germin, a protein marker of early plant development, is an oxalate oxidase. J. Biol. Chem. 268(17): 12239-12242.

Lauge R.., Joosten M.H.A.J., Van den Ackerveken G.F.J.M., Van den Broek H.W.J. and De Wit P.J.G.M., 1997. The In planta produced extracellular proteins ECP1 and ECP2 of Cladosporium fulvum are virulence factors. Mol. Plant-Microbe-Interact. 10: 725734.

Lauge R., Goodwin P.H., De Wit P.J.G.M. and Joosten M.H.A.J., 2000. Specific HR-associated recognition of secreted proteins of Cladosporium fulvum occurs in both host and non-host plants. Plant J. 23: 735-745.

Lebel E., Heifetz P., Thorne L., Uknes S., Ryals J. and Ward E., 1998. Functional analysis of regulatory sequences controlling $P R-1$ gene expression in Arabidopsis. Plant J. 16(2): 223-233.

Levine A., Tenhaken R., Dixon R. and Lamb C., 1994. H2O2 from the oxidative burst orchestrates the plant hypersensitive disease resistance response. Cell 79(4): 583-593.

Lev S. and Horwitz B.A., 2003. A mitogen-activated protein kinase pathway modulates the expression of two cellulose genes in Cochliobolus heterostrophus during plant infection. Plant Cell 15(4): 835-844.

Li J. and Chory J., 1997. A putative leucine-rich repeat receptor kinase involved in brassinosteroid signal transduction. Cell 90: 929-

Li D., Asby A.M. and Johnstone K., 2003. Molecular evidence that the extracellular cutinase Pbc1 is required for pathogenicity of Pyrenopeziza brassicae on oilseed rape. Mol. Plant-Microbe Interact.16(6):545-552.

Ligterink W., Kroj T., zur Nieden U., Hirt H. And Scheel D., 1997. Receptor-mediated activation of a MAP kinase in pathogen defence of plants. Science 276: 2054-2057.

Lisker N., Katan J. And Henis Y., 1975. Sequential production of polygalacturonase, cellulase and pectine lyase by Rhizoctonia solani. Can J. Microbiol. 21(9): 1298.

Liu Q., Kasuga M., Sakuma Y., Abe H., Miura S., Yamaguchi-Shinozaki K. and Shinozaki K., 1998. Two Transcription Factors, DREB1 and DREB2, with an EREBP/AP2 DNA Binding Domain Separate Two Cellular Signal Transduction Pathways in DroughtDREB1 and DREB2, with an EREBP/AP2 DNA Binding Domain Separate Two Cellular Signal Transduction
and Low-Temperature-Responsive Gene Expression, Respectively, in Arabidopsis. Plant Cell 10: 1391-1406.

Lorenzo O., Piqueras R., Sanchez-Serrano J.J. and Solano R., 2003. ETHYLENE RESPONSE FACTOR1 Integrates signals from Ethylene and Jasmonate pathways in Plant Defence. Plant Cell 15(1): 165-178.

Lorenzo O., Chico J.M., Sanchez-Serrano J.J. and Solano R., 2004. JASMONATE-INSENSITIVE1 encodes a MYC transcription factor essential to discriminate between different jasmonate regulated defence responses in Arabidopsis. Plant Cell 16: 1938-1950.

Luck J.E., Lawrence G.J., Dodds P.N., Shepherd K.W. and Ellis J.G., 2000. Regions outside of the leucine-rich repeats of Flax Rust resistance proteins play a role in specificity determination. Plant Cell 12: 1367-1377.

Luderer R., Rivas S., Nurnberger T., Mattei B., Van der Hooven H.W., Van der Hoorn R.A.L., Romeis T., Wehrfritz J-M.,Blume B., Nennstiel D., Zuidema D., Vervoort J., De Lorenzo G., Jones J.D.G., De Wit P.J.G.M. and Joosten M.H.A.J., 2001. No evidence for binding between resistance gene product Cf-9 of tomato and avirulence gene product AVR9 of Cladosporium fulvum. Mol. PlantMicrobe Interact 14: 867-876.

Luderer R., Takken F.L.W., De Wit P.J.G.M. and Joosten M.H.A.J., 2002. Cladosporium fulvum overcomes Cf-2 mediated resistance by producing truncated AVR2 elicitor proteins. Mol. Microbiol. 45: 875-884.

Mackey D., Holt B.F., III, Wiig A. and Dangl J.L., 2002. RIN4 interacts with Pseudomonas syringae type III effector molecules and is required for RPM1-mediated disease resistance in Arabidopsis. Cell 108: 743-754.

Mackey D., Belkhadir Y., Alonso J.M., Ecker J.R. and Dangl J.L., 2003. Arabidopsis RIN4 is a target of the type III virulence effector AvrRpt2 and modulates RPS2-mediated resistance. Cell 112: $379-389$.

Maleck K., Levine A., Eulgem T., Morgan A., Schmid J., Lawton K.A., Dangl J.L. and Dietrich R.A., 2000. The transcriptome of Arabidopsis thaliana during systemic acquired resistance. Nat. Gen. 26: 403-410. 
Martini N., Egen M., Runtz I. and Strittmatter G., 1993. Promoter sequences of a potato pathogenesis-related gene mediate transcriptional activation selectively upon fungal infection. Mol. Gen. Genet. 236:179-186.

Matton D.P and Brisson N., 1989. Cloning, expression, and sequence conservation of pathogenesis-related gene transcripts in potato. Mol. Plant-Microbe Interact. 2: 325-331.

Matton D.P., Prescott G., Bertrand C., Camirand A. and Brisson N., 1993. Identification of cis-acting elements involved in the regulation of the pathogenesis-related gene STH-2 in potato. Plant Mol. Biol. 22: 279-291.

Mauch F. and Dudler R., 1993. Differential induction of distinct glutathione-S-transferases of wheat by xenobiotics and by pathogen attack. Plant Physiol. 102(4): 1193-1201.

McDowell J.M., Cuzick A., Can C., beynon J., Dangl J.L. and Holub E.B., 2000. Downey mildew (Peronospora parasitica) resistance genes in Arabidopsis vary in functional requirements for NDR1, EDS1, NPR1 and salicylic acid accumulation. Plant J. 22(6): 523-529.

Métraux J-P., Ahl-Goy P., Staub T., Speich J., Steinemann A., Ryals J. and Ward E., 1991. Induced resistance in cucumber in response to 2,6-dichloroisonicotinic acid and pathogens. In Advances in Molecular Genetics of Plant-Microbe interactions, Vol. 1, H. Hennecke and D.P.S. Verma eds (Dordrecht, The Netherlands: Kluwer Academic Publishers), pp. 432-439.

Michelmore R.W. and Meyers B.C., 1998. Clusters of resistance genes in plants evolve by divergent selection and a birth-and-death process. Genome Res. 8(11): 1113-1130.

Mohan R., Bajar A.M. and Kolattukudy P.E., 1993. Induction of a tomato anionic peroxidase gene (tap1) by wounding in transgenic tobacco and activation of tap1/GUS and tap2/GUS chimeric gene fusions in transgenic tobacco by wounding and pathogen attack. Plant Mol Biol. 21(2): 341-354

Molina A., Gorlach J., Volrath S. and Ryals J., 1999. Wheat genes encoding two types of PR-1 proteins are pathogen inducible, but do not respond to activators of systemic acquired resistance. Mol Plant Microbe Interact. 12(1): 53-58.

Mou Z., Fan W. and Dong X., 2003. Inducers of plant systemic acquired resistance regulate NPR1 function through redox changes. Cell 113(7): 935-944.

Murray F., Llewellyn D., McFadden H., Last D., Dennis E.S. and Peacock W.J. (1999) Expression of the Talaromyces flavus glucose oxidase gene in cotton and tobacco reduces fungal infection, but is also phytotoxic. Mol. Breeding 5: 219-232.

Nawrath C. and Metraux J-P., 1999. Salicylic acid induction-deficient mutants of Arabidopsis express PR-2 and PR-5 and accumulate high levels of camalexin after pathogen inoculation. Plant Cell 11: 1393-1404.

Nawrath C., Heck S., Parinthawong N. and Metraux J-P., 2002. EDS5, and eesentail component of salicylic acid-dependent signaling for disease resistance in Arabidopsis, is a member of the MATE transporter family. Plant Cell 14: 275-286.

Nimchuk Z., Marois E., Kjemtrup S., Leister R.T., Katagiri F. And Dangl J.L., 2000. Eukaryotic fatty acylation drives plasma membrane targeting and enhances function of several type III effector proteins from Pseudomonas syringae. Cell 101: 353-363.

Ohme-Takagi M. and Shinshi H., 1995. Ethylene-inducible DNA binding proteins that interact with an ethylene-responsive element. Plant Cell. 7(2): 173-182.

Okada M., Matsumura M., Ito Y. and Shibuya N., 2002. High-affinity binding proteins for N-acetylchitooligosaccharide elicitor in the plasma membranes from wheat, barley and carrot cells: conserved presence and correlation with the responsiveness to the elicitor. Plant Cell Physiol. 43(5): 505-512.

Ono E., Wong H.L., Kawasaki T., Hasegawa M., Kodama O. and Shimamoto K., 2001. Essential role of the small GTPase Rac in disease resistance of rice. Proc Natl Acad Sci USA 98(2): 759-764

Osbourne A.E., 1996. Preformed antimicrobial compounds and plant defence against fungal attack. Plant Cell 8(10): 1821-1831.

Park J.M., Park C.J., Lee S.B., Ham B.K., Shin R. and Paek K.H., 2001. Overexpression of the tobacco Tsi1 gene encoding an EREBP/AP2-type transcription factor enhances resistance against pathogen attack and osmotic stress in tobacco. Plant Cell 13(5): $1035-1046$

Parker J.E., Holub E.B., Frost L.N., Falk A., Gunn N.D. and Daniels M.J., 1996. Characterization of eds1, a mutation in Arabidopsis suppressing resistance to Peronospora parasitica specified by several different RPP genes. Plant Cell 8: 2033-2046.

Parker J.E., Feys B.J., Van der Biezen E.A., Noel L., Aarts N., Austin M.J., Botella M.A., Frost L.N., Daniels M.J. and Jones J.D.G., 2000. Unravelling R gene-mediated disease resistance pathways in Arabidopsis. Mol. Plant Pathol. 1(1): 17-24.

Parker J.E., 2003. Plant recognition of microbial patterns. Trends Plant Sci. 8(6): 245-247.

Penninckx I.A., Thomma B.P., Buchala A., Metraux J.P. and Broekaert W.F., 1998. Concomitant activation of jasmonate and ethylene response pathways is required for induction of a plant defensin gene in Arabidopsis. Plant Cell 10(12): 2103-2113.

Petersen M., Brodersen P., Naested H., Andreasson E., Lindhart U., Johansen B., Nielsen H.B., Lacy M., Austin M.J., Parker J.E., Sharma S.B., Klessig D.F., Martienssen R., Mattson O., Jensen A.B. and Mundy J., 2000. Arabidopsis MAP Kinase 4 Negatively Regulates Systemic Acquired Resistance. Cell 103: 1111-1120. 
Pieterse C.M.J., Van Pelt J.A., Van Wees S.C.M., Ton J., Leon-Kloosterziel K.M., Keurentjes J.J.B., Verhagen B.W.M., Knoester M., Van der Sluis I., Bakker P.A.H.M. and Van Loon L.C., 2001. Rhizobacteria-mediated induced systemic resistance: triggering, signalling and expression. Eur. J. Plant Pathol. 107: 51-61.

Pontier D., Godiard L., Marco Y. and Roby D., 1994. Hsr203J, a tobacco gene whose activation is rapid, highly localized and specific for incompatible plant/pathogen interactions. Plant J. 5(4): 507-521.

Pontier D., Balague C., Bezombes-Marion I., Tronchet M., Deslandes L. and Roby D., 2001. Identification of a novel pathogenresponsive element in the promoter of the tobacco gene HSR203J, a molecular marker of the hypersensitive response. Plant J. 26(5): 495-507.

Pozo Od O., Pedley K.F. and Martin G.B., 2004. MAPKKKalpha is a positive regulator of cell death associated with both plant immunity and disease. EMBO J. 23(15): 3072-3082.

Ramonell K.M., Zhang B., Ewing R.M., Chen Y., Xu D., Stacey G. and Sommerville S., 2002. Microarray analysis of chitin elicitation in Arabidopsis thaliana. Mol. Plant Pathol. 3(5): 301-311.

Raskin I., Skubatz H., Tang W. and Meeuse B.J.D., 1990. Salicylic acid levels in thermogenic and non-thermogenic plants. Ann. Bot. 66: $369-373$

Rahtjen J.P., Chang J.H., Staskawicz B.J. and Michelmore R.W., 1999. Constitutively active Pto induces a Prf-dependent hypersensitive response in the absence of AvrPto. EMBO J. 18(12): 3232-3240.

Rehmany A.P., Gordon A., Rose L.E., Allen R.L., Armstrong M.R., Whissom S.C., Kamoun S., Tyler B.M., Birch P.R. and Beynon J.L., 2005. Differential recognition of highly divergent downey mildew avirulence gene alleles by RPP1 resistance genes from two Arabidopsis lines. Plant Cell 17: 1839-1850.

Ren T., Qu F. and Morris T.J., 2000. HRT gene function requires interaction between a NAC protein and viral capsid protein to confer resistance to turnip crinkle virus. Plant Cell 12: 1917-1926.

Ricci P., Bonnet P., Huet J-C., Sallantin M., Beauvais-Cante F., Bruneteau M., Billard V., Michel G. and Pernollet J-C., 1989. Structure and activity of proteins from pathogenic fungi Phytophthora eliciting necrosis and acquired resistance in tobacco. Eur. J. Biochem. 183: 555-563.

Richly E., Kurth J. and Leister D., 2002. Mode of amplification and reorganization of resistance genes during recent Arabidopsis thaliana evolution. Mol Biol Evol. 19(1): 76-84.

Rivas S., Rougon-Cardoso A., Smoker M., Schauser L., Yoshioka H. and Jones J.D., 2004. CITRX thioredoxin interacts with the tomato Cf-9 resistance protein and negatively regulates defence. EMBO J. 23(10): 2156-2165.

Roberts J.K. and Pryor A., 1995. Isolation of a flax (Linum usitatissimum) gene induced during susceptible infection by flax rust (Melampsora lini). Plant J. 8: 1-8.

Roddick J.G., 1974. The steroidal glycoalkaloid $\alpha$-tomatine. Phytochemistry 13: 9-25

Rogers L.M., Flaishman M.A. and Kolattukudy P.E., 1994. Cutinase gene disruption in Fusarium solain $f$ sp pisi decreases its virulence on pea. Plant Cell 6(7): 935-945.

Rohe M., Gierlich A., Hermann H., Hahn M., Schmidt B., Rosahl S. And Knogge W., 1995. The race-specific elicitor, NIP1, from the barley pathogen, Rynchosporium secalis, determines avirulence on host plants of the Rsr1 resistance genotype. EMBO J. 14: 41684177.

Romeis T., Piedras P., Zhang S.Q., Klessig D.F., Hirt H. and Jones J.D.G., 1999. Rapid Avr9- and Cf-9-dependent activation of MAP kinases in tobacco cell cultures and leaves: convergence of resistance gene, elicitor, wound, and salicylate responses. Plant Cell 11: 273-287.

Ron M. and Avni A., 2004. The receptor for the fungal ethylene-inducing Xylanase is a member of a resistance-like gene family in tomato. Plant Cell 16: 1604-1615.

Rooney H.C.E., Van 't Klooster J.W., Van der Hoorn R.A.L., Joosten M.H.A.J., Jones J.D.G. and De Wit P.J.G.M., 2005. Cladosporium Avr2 Inhibits tomato Rcr3 Protease required for Cf-2-dependent disease resistance. Science Online 21 April 2005 (www.scienceexpress.org).

Rose J.K.C., Ham K-S., Darvill A.G. and Albersheim P., 2002. Molecular cloning and characterization of glucanase inhibitor proteins (GIPs): Co-evolution of a counter-defence mechanism by plant pathogens. Plant Cell 14: 1329-1345.

Rossi M., Goggin F.L., Milligan S.B., Kaloshian I., Ullman D.E. and Williamson V.M., 1998. The nematode resistance gene Mi of tomato confers resistance against a potato aphid. Proc. Natl. Acad. Sci. USA 95: 9750-9754.

Rossier O., Wengelnik K., Hahn K. and Bonas U., 1999. The Xanthomonas Hrp type III system secretes proteins from plant and mammalian bacterial pathogens. Proc Natl Acad Sci USA 96(16): 9368-9373.

Rushton P.J., Torres J.T., Parniske M., Wernert P., Hahlbrock K. and Somssich I.E., 1996. Interaction of elicitor-induced DNA-binding proteins with elicitor response elements in the promoters of parsley PR1 genes. EMBO J. 15(20):5690-5700. 
Rushton P.J., Reinstädler A., Lipka V., Lippok B. and Somssich I.E., 2002. Synthetic plant promoters containing defined regulatory elements provide novel insights into pathogen- and wound-induced signaling. Plant Cell 14: 749-762.

Rustérucci C., Aviv D.H., Holt III B.F., Dangl J.L. and Parker J.E., 2001. The disease resistance signaling components EDS1 and PAD4 are essential regulators of the cell death pathway controlled by LSD1 in Arabidopsis. Plant Cell 13: 211-2224.

Ryals J.A., Neuenschwander U.H., Willits M.G., Molina A., Steiner H-Y. and Hunt M.D., 1996. Systemic Acquired Resistance. Plant Cell 8: 1809-1819.

Salmeron J.M., Barker S.J., Carland F.M., Mehta A.Y. and Staskawicz B.J., 1994. Tomato mutants altered in bacterial disease resistance provide evidence for a new locus controlling pathogen recognition. Plant Cell 6: 511-520.

Salmeron J.M., Oldroyd G.E.D., Rommens C.M.T., Scofield S.R., Kim H.S., Lavelle D.T., Dahlbeck D. and Staskawicz B.J., 1996. Tomato Prf is a member of of the leucine-rich-repeat class of plant disease resistance genes and lies embedded within the Pto kinase gene cluster. Cell 86: 123-133.

Schubert R., Fischer R., Hain R., Schreier P.H., Bahnweg G., Ernst D. and Sandermann H. Jr., 1997. An ozone-responsive region of the grapevine resveratrol synthase promoter differs from the basal pathogen-responsive sequence. Plant Mol Biol. 34(3): 417-426.

Scofield S.R., Tobias C.M., Rathjen J.P., Chang J.H., Lavell D.T., Michelmore R.W. and Staskawicz B.J., 1996. Molecular basis of gene-for-gene specificity in bacterial speck disease of tomato. Science 274: 2063-2065.

Sessa G., D'ascenzo M. and Martin GB., 2000. The major site of the pti1 kinase phosphorylated by the pto kinase is located in the activation domain and is required for pto-pti1 physical interaction. Eur. J. Biochem. 267(1):171-178.

Sexton A.C., Paulesen M. Woestemeyer J. and Howlett B.J., 2000. Cloning, characterization and chromosomal location of three genes encoding host-cell-wall-degrading enzymes in Leptosphaeria maculans, a fungal pathogen of Brassica spp. Gene 248(1-2): 89-97.

Shan W., Cao M., Leung D. and Tyler B.M., 2004. The Avr1b locus of Phytophthora sojae encodes an elicitor and a regulator required for avirulence on soybean plants carrying resistance gene Rps1b. Mol. Plant Microbe Interact. 17: 394-403.

Shao F., Golstein C., Ade J., Stoutemeyer M., Dixon J.E. and Innes R.W., 2003. Cleavage of Arabidopsis PBS1 by a bacterial type III effector. Science 301: 1230-1233.

Shi J., Wei Y. And Goodwin P.H., 2000. A comparison of the pectate lyase genes pel-1 and pel-2 of Colletotrichum gloeosporioides f.sp. malvae and the relationship between their expression in culture and during necrotrophic infection. Gene 243(1-2): 139-150.

Song W.Y., Wang G.L., Chen L.L., Kim H.S., Pi L.Y., Holsten T., Gardner J., Wang B., Zhai W.X., Zhu L.H., Fauquet F. and Ronald P.C., 1995. Receptor kinase-like protein encoded by the rice disease resistance gene, Xa21. Science 270(5243): 1804-1806.

Spoel S.H., Koorneef A., Claessens S.M., Korzelius J.P., Van Pelt J.A., Mueller M.J., Buchala A.J., Metraux J.P., Brown R., Kazan K., Van Loon L.C., Dong X. and Pieterse C.M., 2003. NPR1 modulates cross-talk between salicylate- and jasmonate-dependent defence pathways through a novel function in the cytosol. Plant Cell 15(3): 760-770.

Stahl D.J. and Schafer W., 1992. Cutinase is not required for fungal pathogenicity on pea. Plant Cell 4(6): 621-629.

Stepanova A.N. and Ecker J.R., 2000. Ethylene signaling: from mutants to molecules. Curr Opin Plant Biol. 3(5): 353-360.

Stinzi A., Weber H., Reymond P., Browse J. and Farmer E.E., 2001. Plant defence in the absence of jasmonic acid: The role of cyclopentenones. Proc. Natl. Acad. Sci. USA 98(22): 12837-12842.

Strittmatter G., 1995. Chimeric genes comprising a fungus-responsive element. International Patent Publication WO 96/28561.

Strittmatter G., Geysen G., Gianinazzi-Pearson V., Hahn K., Niebel A., Rohde W. and Tacke E., 1996. Infection with various types of organisms stimulate transcription from a short promoter fragment of the potato gst1 gene. Mol. Plant Microbe Interact. 9(1): 68-73.

Stuiver M.H., Simons L.H. and Custers J.H.H.V., 1999. Method for the induction of pathogen resistance in plants. Patent Publication WO99/45129.

Swarup S., Yang Y., Kingsley M.T. and Gabriel D.W., 1992. A Xanthomonas citri pathogenicity gene, pthA, pleiotropically encodes gratuitous avirulence on nonhosts. Mol. Plant Microbe Interact. 5(3): 204-213.

Sweigard J.A., Chumley F.G. and Valent B., 1992. Disruption of a Magnaporthe grisea cutinase gene. Mol. Gen. Genet. 232(2): 183190.

Sweigard J.A., Caroll A.M., Kang S., Farrall L., Chumley F.G. and Valent B., 1995. Identification, cloning, and characterization of $P W L 2$, a gene for host species specificity in the rice blast fungus. Plant Cell 7: 1221-1233.

Szurek B., Marois E., Bonas U. and Van den Ackerveken G., 2001. Eukaryotic features of the Xanthomonas type III effector AvrBs3: protein domains involved in transcriptional activation and the interaction with nuclear import receptors from pepper. Plant J. 26(5): 523-534. 
Tai T.H., Dahlbeck D., Clark E.T., Gajiwala P., Pasion R., Whalen M.C., Stall R.E. and Staskawicz B.J., 1999. Expression of the Bs2 pepper gene confers resistance to bacterial spot disease in tomato. Proc. Natl. Acad. Sci. USA 96: 14153-14158.

Takahashi A., Casais C., Ichimura K. and Shirasu K., 2003. HSP90 interacts with RAR1 and SGT1 and is essential for RPS2mediated disease resistance in Arabidopsis. Proc Natl Acad Sci USA 100(20): 11777-11782.

Takeda S., Sugimoto K., Otsuki H. and Hirochika H., (1999) A 13-bp cis-regulatory element in the LTR promoter of the tobacco retrotransposon Tto1 is involved in responsiveness to tissue culture, wounding, methyljasmonate and fungal elicitors. Plant J. 18(4): 383-393.

Takken F.L., Luderer R., Gabriels S.H., Westerink N., Lu R., de Wit P.J.G.M. and Joosten M.H.A.J., 2000. A functional cloning strategy, based on a binary PVX-expression vector, to isolate HR-inducing cDNAs of plant pathogens. Plant J. 24(2): 275-283.

Thomma B.P.H.J., Eggermont K., Penninckx I.A.M.A., Mauch-Mani B., Vogelsang R. Cammue B.P.A. and Broekaert W.F., 1998. Separate jasmonate-dependent and salicylate dependent defence-response pathways in Arabidopsis are essential for resistance to distinct microbial pathogens. Proc. Natl. Acad. Sci. USA 95: 15107-15111.

Thomma B.P.H.J., Eggermont K., Tierens K.F.M.J. and Broekaert W.F., 1999. Requirement of functional Ethylene-Insensitive 2 gene for efficient resistance of Arabidopsis to infection by Botrytis cinerea. Plant Physiol. 121: 1093-1101.

Ton J., Van Pelt J.A., Van Loon L.C. and Pieterse C.M.J., 2002. Differential effectiveness of salicylate-dependent and jasmonate/ethlene-dependent induced resistance in Arabidopsis. Mol. Plant Microbe Interact. 15(1): 27-34

Tornero P., Merrit P., Sadanandom A., Shirasu K., Innes R.W. and Dangl J.L., 2002. RAR1 and NDR1 contribute quantitatively to disease resistance in Arabidopsis, and their relative contributions are dependent on the $R$ gene assayed. Plant Cell 14: 1005-1015.

Torres M.A., Onouchi H., Hamada S., Machida C., Hammond-Kosack and Jones J.D.G., (1998) Six Arabidopsis homologues of the human respiratory burst oxidase (gp91 $\left.{ }^{\text {phox }}\right)$. Plant J. 14(3): 365-370.

Torres M.A., Dangl J.L. and Jones J.D.G., 2002. Arabidopsis gp9 $1^{\text {phox }}$ homologues AtrbohD and AtrbohF are required for accumulation of reactive oxygen intermediates in the plant defence response. Proc. Natl. Acad. Sci. USA 99(1): 517-522.

Torto T.A., Rauser L. and Kamoun S., 2002. The pipg1 gene of the oomycete Phytophthora infestans encodes a fungal-like endopolygalacturonase. Curr. Genet. 40(6): 385-390.

Tör M., Brown D., Cooper A., Woods-Tör A., Sjölander K., Jones J.D.G. and Holub E.B., 2004. Arabidopsis downey mildew resistance gene RPP27 encodes a receptor-like protein similar to CLAVATA2 and tomato Cf-9. Plant Physiol. 135: 1100-1112.

Tucker S.L. and Talbot N.J., 2001. Surface attachment and pre-penetration stage development by plant pathogenic fungi. Annu. Rev. Phytopathol. 39: 385-417.

Uknes S., Dincher S., Friedrich L., Negrotto D., Williams S., Thompson-Taylor H., Potter S., Ward E. and Ryals J., 1993. Regulation of Pathogenesis-related protein 1a expression in tobacco. Plant Cell 5: 159-169.

Van Camp W., Van Montagu M. and Inze D., 1998. $\mathrm{H}_{2} \mathrm{O}_{2}$ and NO: redox signals in disease resistance. Trends Plant Sci. 3(9): 330-

Van de Locht U., Meier I., Hahlbrock K. and Somssich I.E., 1990. A 125 bp promoter fragment is sufficient for strong elicitor-mediated gene activation in parsley. EMBO J. 9(9): 2945-2950.

Van der Biezen E.A. and Jones J.D.G., 1998. The NB-ARC domain: a novel signaling motif shared by plant resistance gene products and regulators of cell death in animals. Curr. Biol. 8: R226-R227.

Van den Ackerveken G.F., Vossen P. and De Wit P.J., 1993. The AVR9 race-specific elicitor of Cladosporium fulvum is processed by endogenous and plant proteases. Plant Physiol. 103(1): 91-96.

Van den Burg H.A., Westerink N., Francoijs K.J., Roth R., Woestenenk E., Boeren S., de Wit P.J., Joosten M.H., Vervoort J., 2003. Natural disulfide bond-disrupted mutants of AVR4 of the tomato pathogen Cladosporium fulvum are sensitive to proteolysis, circumvent Cf-4-mediated resistance, but retain their chitin binding ability. J Biol Chem. 278(30): 27340-27346.

Van der Hoorn R.A.L., Laurent F., Roth.R. and De Wit P.J.G.M., 2000. Agroinfiltration is a versatile tool that facilitates comparative analysis of Avr9/Cf-9-induced and Avr4/Cf-4-induced necrosis. Mol. Plant-Microbe Interact. 13: 439-446.

Van der Hoorn R.A.L., Roth R. And De Wit P.J.G.M., 2001. Identification of distinct specificity determinants in resistance protein Cf-4 allows construction of a Cf-9 mutant that confers recognition of avirulence protein AVR4. Plant Cell 13: 273-285.

Van der Hoorn R.A., De Wit P.J. and Joosten MH., 2002. Balancing selection favors guarding resistance proteins. Trends Plant Sci. 7(2): 67-71.

Van der Vossen E.A., Van der Voort J.N., Kanyuka K., Bendahmane A., Sandbrink H., Baulcombe D.C., Bakker J., Stiekema W.J. and Klein-Lankhorst R.M., 2000. Homologues of a single resistance-gene cluster in potato confer resistance to distinct pathogens: a virus and a nematode. Plant J. 23(5): 567-576.

Van Kan J.A., van den Ackerveken G.F. and de Wit P.J., 1991. Cloning and characterization of cDNA of avirulence gene avr9 of the fungal pathogen Cladosporium fulvum, causal agent of tomato leaf mold. Mol Plant Microbe Interact. 4(1): 52-59. 
Van Kan J.A., Van 't Klooster J.W., Wagemakers C.A., Dees D.C. and Van der Vlugt-Bergmans C.J., 1997. Cutinase A of Botryitis cinerea is expressed, but not essential, during penetration of gerbera and tomato. Molec. Plant-Microbe Interact. 10(1): 30-38.

Van Wees S.C., Luijendijk M., Smoorenburg I., Van Loon L.C. and Pieterse C.M., 1999. Rhizobacteria-mediated induced systemic resistance (ISR) in Arabidopsis is not associated with a direct effect on expression of known defence-related genes but stimulates the expression of the jasmonate-inducible gene Atvsp upon challenge. Plant Mol Biol. 41(4): 537-549.

Van Wees S.C. and Glazebrook J., 2003. Loss of non-host resistance of Arabidopsis NahG to Pseudomonas syringae pv. phaseolicola is due to degradation products of salicylic acid. Plant J. 33(4): 733-742.

Vernooij B., Friedrich L., Morse A., Reist R., Kolditz-Jawhar R., Ward E., Uknes S., Kessmann H. and Ryals J., 1994. Salicylic Acid Is Not the Translocated Signal Responsible for Inducing Systemic Acquired Resistance but Is Required in Signal Transduction. Plant Cell 6(7): 959-965.

Van den Hooven H.W., Van den Burg H.A., Vossen P., Boeren S., De Wit P.J.G.M., Vervoort J., 2001. Disulfide bond structure of the AVR9 elicitor of the fungal tomato pathogen Cladosporium fulvum: evidence for a cystine knot. Biochemistry 40(12): 3458-3466.

Vervoort J., Van den Hooven H.W., Berg A., Vossen P., Vogelsang R., Joosten M.H and De Wit P.J., 1997. The race-specific elicitor AVR9 of the tomato pathogen Cladosporium fulvum: a cysteine knot protein. Sequence-specific $1 \mathrm{H}$ NMR assignments, secondary structure and global fold of the protein. FEBS Lett 404(2-3): 153-158

Wagner U., Edwards R., Dixon D.P. and Mauch F., 2002. Probing the diversity of the Arabidopsis glutathione S-transferase gene family.Plant Mol Biol. 49(5): 515-532.

Warner S.A., Scott R. and Draper J., 1993. Isolation of an asparagus intracellular PR gene (AoPR1) wound-responsive promoter by the inverse polymerase chain reaction and its characterization in transgenic tobacco. Plant J. 3(2):191-201.

Wei Z.M., Laby R.J., Zumoff C.H., Bauer D.W., He S.Y., Collmer A. and Beer S.V., 1992. Harpin, elicitor of the hypersensitive response produced by the plant pathogen Erwinia amylovora. Science 257: 85-88

Wei Y., Shi J., Li J. And Goodwin P.H., 2002. Two pectin lyase genes, pnl-1 and pnl-2, from Colletotrichum gloeosporioides f.sp. malvae differ in a cellulose-binding domain and their expression during infection of Malva pusilla. Microbiology 148(7): 2149-2157.

Wessels J.G.H., 1990. Role of cell wall architecture in fungal tip growth generation. In Heath I.B. (Ed), Tip growth in plant and fungal cells, Academic Press, San Diego: 1-29.

Westerink N., Brandwagt B.F. De Wit P.J. and Joosten M.H., 2004. Cladosporium fulvum circumvents the second functional resistance gene homologue at the Cf-4 locus (Hcr9-4E ) by secretion of a stable avr4E isoform. Mol Microbiol. 54(2): 533-545.

Wildermuth M.C., Dewdney J., Wu G. and Ausubel F.M., 2001. Isochorismate synthase is required to synthesize salicylic acid for plant defence. Nature 414: 562-565.

Wu G., Shortt B.J., Lawrence E.B., Levine E.B., Fitzsimmons C. and Sha D., 1995. Disease Resistance Conferred by Expression of a Gene Encoding $\mathrm{H}_{2} \mathrm{O}_{2}$-Generating Glucose Oxidase in Trangenic Potato Plants. Plant Cell 7: 1357-1368.

Wu G., Shortt B.J., Lawrence E.B., Leon J., Fitzsimmons C., Levine E.B., Raskin I. and Sha D., 1997. Activation of Host Defence Mechanisms by Elevated Production of $\mathrm{H}_{2} \mathrm{O}_{2}$ in Transgenic Plants. Plant Physiol. 115: 427-435.

Wubben J.P., Joosten M.H. and De Wit P.J., 1994. Expression and localization of two in planta induced extracellular proteins of the fungal tomato pathogen Cladosporium fulvum. Mol Plant Microbe Interact. 7(4): 516-524.

Xiao S., Ellwood S., Calis O., Patrick E., Coleman M. and Turner J.G., 2001. Broad-spectrum mildew resistance in Arabidopsis thaliana mediated by RPW8. Science 291: 118-120.

Yang B., Zhu W., Johnson L.B. and White F.F., 2000. The virulence factor AvrXa7 of Xanthomonas oryzae pv. oryzae is a type III secretion pathway-dependent nuclear-localized doublestranded DNA-binding protein. Proc. Natl. Acad. Sci. USA 97(17): 9807-9812.

Yang Y. and Klessig D.F., 1996. Isolation and Characterization of a tobacco mosaic virus-inducible myb oncogene homolog from tobacco. Proc. Natl. Acad. Sci. USA 93: 14972-14977.

Yin S., Mei L., Newman J., Back K. and Chappell J., 1997. Regulation of sesquiterpene cyclase gene expression. Characterization of an elicitor- and pathogen-inducible promoter. Plant Physiol. 115(2): 437-451.

Zhang Y., Fan W., Kinkema M., Li X. and Dong X., 1999. Interaction of NPR1 with basic leucine zipper protein transcription factors that bind sequences required for salicylic acid induction of the PR-1 gene. Proc Natl Acad Sci USA. 96(11): 6523-6528.

Zhou J., Tang X. and Martin G.B., 1997. The Pto kinase conferring resistance to tomato bacterial speck disease interacts with proteins that bind a cis-element of pathogenesis-related genes. EMBO J. 16(11): 3207-3218.

Zhou F., Zhang Z., Gregersen P.L., Mikkelsen J.D., De Neergaard E., Collinge D.B. and Thordal-Christensen H., 1998. Molecular Characterization of the Oxalate Oxidase Involved in the Response of Barley to the Powdery Mildew Fungus. Plant Physiol. 117: 33- 
Zhou J.M., Trifa Y., Silva H., Pontier D., Lam E., Shah J. and Klessig D.F., 2000. NPR1 differentially interacts with members of the TGA/OBF family of transcription factors that bind an element of the PR-1 gene required for induction by salicylic acid. Mol Plant Microbe Interact. 13(2): 191-202.

Zhu W., Yang B., Chittoor J.M., Johnson L.B. and White F.F., 1998. AvrXa10 contains an acidic transcriptional activation domain in the functionally conserved $C$ terminus. Molec. Plant-Microbe Interact. 11(8): 824-832.

Zipfel C., Robatzek S., Navarro L., Oakeley E.J., Jones J.D.G., Felix G. and Boller T., 2004. Bacterial disease resistance in Arabidopsis through flagellin perception. Nature 428: 764-767. 


\section{CHAPTER 2}

AIM AND OUTLINE OF THESIS 
Chapter 2 


\section{AIM AND OUTLINE OF THIS THESIS}

In modern agriculture plant diseases caused by microbial pathogens can result in tremendous yield losses. Most crop protection strategies are based on conventional resistance breeding, crop rotation strategies and the application of antimicrobial compounds (e.g. fungicides). The exploitation of transgenic strategies could complement conventional crop protection approaches. Many attempts to improve plant resistance to microbial attack using GM (genetic modification) approaches have failed. This has often been due to poor agronomic properties and limited efficacy of the GM crops under field conditions. A very promising GM approach to engineer disease resistance makes use of the plant hypersensitive response (HR). Pathogen-induced expression of a pathogen-derived elicitor using a pathogen-responsive promoter induces the HR resulting in broad-spectrum disease resistance.

The research described in this thesis focuses on the use of the HR to engineer broad-spectrum disease resistance. In chapter 1 , an overview is presented of the current understanding of plant defence mechanisms and in particular the plant HR and its associated processes. Furthermore, the present knowledge regarding the components that are crucial to the use of the HR for engineering disease resistance ( $R$-genes, Avr-genes and pathogen-inducible promoters) is described.

Pathogen-inducible promoters are key components of this strategy. Chapter 3 and 4 focus on the identification and cloning of novel pathogen-inducible promoters and the characterization of these promoters in transgenic plants using different techniques. The Botrytis-responsive 488-promoter described in chapter 3 was identified in an Arabidopsis thaliana UidA promoter-tagging library. In a collection of 1500 transgenic $A$. thaliana plants, one line was identified that displayed Botrytisresponsive GUS expression. The sequence upstream of the UidA gene was isolated and its location in the Arabidopsis genome was determined. The open reading frame linked to this promoter sequence was identified and the expression characteristics in response to certain environmental stimuli were investigated. Chapter 4 describes the isolation of two novel promoters that respond locally to fungal infection. Both promoter sequences were fused to the UidA gene and transformed to potato. Characteristics of these promoters were compared to the well-studied plant pathogeninducible promoters Vst1 and Gst1. We employed conventional histochemical GUS staining and real time reverse transcriptase PCR analysis on a collection of independent transgenic potato plants to visualize kinetic and dynamic properties of these promoters.

Chapter 5 describes studies on the HR elicitor Avr9 produced by particular races of the fungal pathogen Cladosporium fulvum. The $C$. fulvum avirulence gene product Avr9 induces the HR in tomato plants carrying the complementary resistance gene Cf-9. Avr9 induces many transcriptional changes in tomato and tobacco when the $\mathrm{Cf}-9$ protein is present. To investigate the transcriptional changes induced by Avr9 in Cf-9-expressing potato leaves we conducted cDNA array hybridization experiments. Evidence is accumulating that assigns a virulence function to avirulence proteins. Therefore we conducted hybridization experiments with Avr9 treated potato plants lacking the Cf-9 gene. Genes expressed differentially in the latter case could help to elucidate the virulence function of Avr9. Expression data were analyzed using hierarchical clustering analysis resulting in the identification of distinct gene clusters. Additionally, genes were grouped according to timing, speed and levels of expression alteration.

In Chapter 6, a novel group of plant proteins is described with very potent antifungal activity against a number of plant pathogenic fungi and oomycetes in vitro. The proteins were isolated from two 
different plant species after induction with salicylic acid. Their encoding genes were cloned and the nucleotide sequences were determined. The proteins appear to possess carbohydrate oxidase activity and their antifungal activity appeared to be due to the production of hydrogen peroxide. Experiments are described were the role of these enzymes in plant disease resistance is substantiated.

In chapter 7, an overview is presented of the most important strategies presently pursued to engineer disease resistance. It is the complexity of the interaction between pathogens and the host plant that has so far delayed the introduction on the market of transgenic plants with increased pathogen resistance. However, some approaches that are pursued have great potential and it is very likely that in the coming years, the first transgenic disease resistant crops will appear on the market.

Finally, in Chapter 8, the results described in this thesis and the implications of the data for the development of disease resistance in plants are discussed. 


\section{CHAPTER 3}

\section{T-DNA TAGGING OF A PATHOGEN-INDUCIBLE PROMOTER} IN ARABIDOPSIS THALIANA

Jerôme H.H.V. Custers, Leo S. Melchers, Henk Tigelaar, Jacob B. Bade, Jennifer J.M. Spiegeler, Pieter J. van der Meijs, Bert H. Simons and Maarten H. Stuiver 
Chapter 3 


\section{SUMMARY}

Many events associated with the plant defence responses are regulated on the transcriptional level. Here we report the results of a promoter tagging approach to identify promoters that are induced upon pathogen attack in Arabidopsis thaliana. A line was identified in a T-DNA UidA tagged Arabidopsis library with induced GUS expression after Botrytis cinerea infection around the site of fungal infection. The upstream sequence was isolated and fused to the UidA gene and tested in transgenic Arabidopsis thaliana and Brassica napus plants. Promoter function was very similar to the expression pattern found in the original promoter tagged line. We found that the promoter sequence was located on Arabidopsis chromosome III and linked to a predicted open reading frame in the reverse orientation. The predicted gene codes for a putative receptor serine threonine protein kinase of 383 amino acids in size. The clone contains a protein kinase ATP binding region, a protein kinase active site, a region with similarity to motifs found in Alpha Isopropylmalate/homocitrate synthase enzymes and a putative leucine zipper motif. Analysis of the expression pattern of the gene using RT-PCR demonstrated that the putative receptor serine threonine protein kinase is upregulated after Salicylic acid treatment and Botrytis infection.

\section{INTRODUCTION}

One of the most promising strategies to engineer resistance is via controlled activation of the hypersensitive response pathway by expressing a pathogen derived avirulence gene upon pathogen challenge. Key to this strategy is the regulation of elicitor expression by a pathogeninducible promoter. Such a pathogen-inducible promoter should be strictly regulated, primarily responsive to multiple pathogens and not responsive to abiotic stress factors (Stuiver and Custers, 2001).

Expression of the defence response genes of the plant is regulated in a spatial and temporal manner (Dorey et al., 1997), and the expression pattern of these genes appears to be determined by the architecture of the promoters. A relatively small number of these promoters have been studied extensively and several different regulatory elements in these promoters have been identified (Martini et al., 1993; Fischer, 1994; Lebel et al., 1998; Petersen et al., 2000). Consensus sequences for different elements that may play a role in the regulation of the response of these promoters to pathogen attack have been described (Lois et al., 1989; Loake et al., 1992; Goldsbrough et al., 1993; Fischer, 1994; Dröge-Laser et al., 1997; Rushton and Somssich, 1998; Takeda et al., 1999; Yamamoto et al., 1999).

T-DNA gene tagging has been used as a tool to identify genes with different expression patterns or characteristics (Fobert et al., 1991; Kertbundit et al., 1991; Topping et al., 1994; Lindsey et al., 1993). This method has also been used successfully to identify plant promoters and genes that are pathogen-responsive (Barthels et al., 1997; Puzio et al., 1999). The approach makes use of a promoterless reporter gene or selectable marker gene placed close to the T-DNA border. When such a gene construct is used to transform plants, transformants with the desired expression characteristics can be selected either during or after plant transformation.

In this report we describe the identification of a promoter tagging line with Botrytis induced GUS expression using a UidA tagged Arabidopsis library (Barthels et al., 1997). Botrytis cinerea is a necrotrophic fungal pathogen that can infect many host plants including Arabidopsis (Govrin and Levine, 2000). The sequence upstream of the inserted UidA gene was isolated and its location on a 
physical map was determined. Further experiments in Arabidopsis thaliana and Brassica napus confirming the inducibility of the promoter were performed.

\section{RESULTS}

Screening of the promoter-tagging library with Botrytis cinerea and isolation of the right border flanking sequence

The Arabidopsis promoter-tagging library contained 1200 independent lines transformed with a promoterless UidA gene. All lines were prescreened for GUS expression prior to infection (Goddijn et al., 1993; Barthels et al., 1997). Lines were selected with no detectable expression of the GUS enzyme and segregation ratios on hygromycin of hygR:hygS of 3:1 or 15:1, suggesting simple TDNA integration patterns. About 500 selected lines were infected with a Botrytis cinerea spore suspension and examined for inducible GUS expression. Line 488 displayed localized GUS expression around the infection zone as shown in Figure 1A. Since Botrytis cinerea is a true necrotrophic or necrogenic fungus, the GUS staining surrounding the necrotic area corresponds quite good with the infected area.

Whole seedlings and adult plants, grown under several different culture conditions were analysed for background expression. Only minor GUS expression could be detected in the hydathodes in this line (data not shown), no expression was ever seen in any other tissue. No GUS expression could be visualised when leaves were wounded by incisions made with a knife (data not shown), suggesting that necrosis is not sufficient to induce this promoter.

The sequence flanking the right border of the T-DNA in line 488 was isolated by Inverse Polymerase Chain Reaction (IPCR). A southern blot was done to determine the number of T-DNA copies in the genome of line 488. The same sets of restriction enzymes that were used for the southern blot were used for the IPCR. This was done to be able to predict the size of the IPCR bands. About $400 \mathrm{bp}$ flanking sequence was isolated in the Hinc II digested IPCR. The DNA sequence of this fragment was determined and then fused to the UidA gene resulting in binary vector pMOG1040 in such a way that the fusion between the flanking sequence and the UidA coding region was almost identical as in the original Arabidopsis tagging line 488. For cloning purposes an Nco I restriction site was introduced downstream of the promoter overlapping the ATG of the UidA gene. A larger fragment of flanking sequence was isolated by screening a wildtype Arabidopsis genomic library with the $400 \mathrm{bp}$ IPCR fragment. A $2300 \mathrm{bp}$ genomic fragment was subcloned and the DNA sequence of the entire fragment was determined. The genomic fragment isolated contained 1781 bp promoter sequence (Genbank accession AY070236). This 1781 bp region that is located upstream of the UidA gene in PMOG553 was cloned and fused to the UidA gene resulting in binary vector pMOG1056. Both pMOG1040 and pMOG1056 were successfully transformed into Arabidopsis and pMOG1056 was additionally transformed into B. napus.

\section{Expression profiles of promoter-UidA fusions in transgenic plants after fungal infection} Transgenic Arabidopsis plants harbouring the 400 bp promoter UidA construct (pMOG1040) and the 1800 bp promoter UidA construct (pMOG1056) were infected with Botrytis cinerea.

Thirty-three plants transformed with pMOG1040 were tested in a histochemical GUS assay after infection with $B$. cinerea. None of the transgenic lines with the $400 \mathrm{bp}$ promoter element showed any detectable inducible GUS expression around the fungal infection sites. Of the Arabidopsis 
plants harbouring the 1800 bp promoter element (pMOG1056) in front of the UidA gene 14 out of 47 displayed inducible GUS expression after infection with $B$. cinerea (Figure $1 \mathrm{C}$ ) similar to that found in the original 553-488 tagging line.

Infection assays were performed on in vitro Brassica napus plantlets transgenic for the pMOG1056 construct. Plants were inoculated with a spore suspension of the Brassica napus pathogen Phoma lingam. In contrast to Botrytis cinerea, which is a necrotrophic fungus, Phoma lingam has a hemibiotrophic lifestyle. Ten out of twenty transgenic lines showed clearly inducible expression of the UidA gene localised to the sites of fungal infection (an example is shown in Figure 1D). The Phoma lingam infection was progressed until stem lesions were developing (at approx. 2 weeks after inoculation). Stem segments containing lesions were removed and tested in the histochemical GUS assay. In six lines GUS expression was visible around the stem lesions (an example is shown in Figure 1E). Botrytis inoculations were performed on detached leaves from a subset of 15 lines that were tested for Phoma responsiveness. Three lines showed local inducible expression in response to the Botrytis cinerea infection. These lines were also responsive to Phoma lingam.

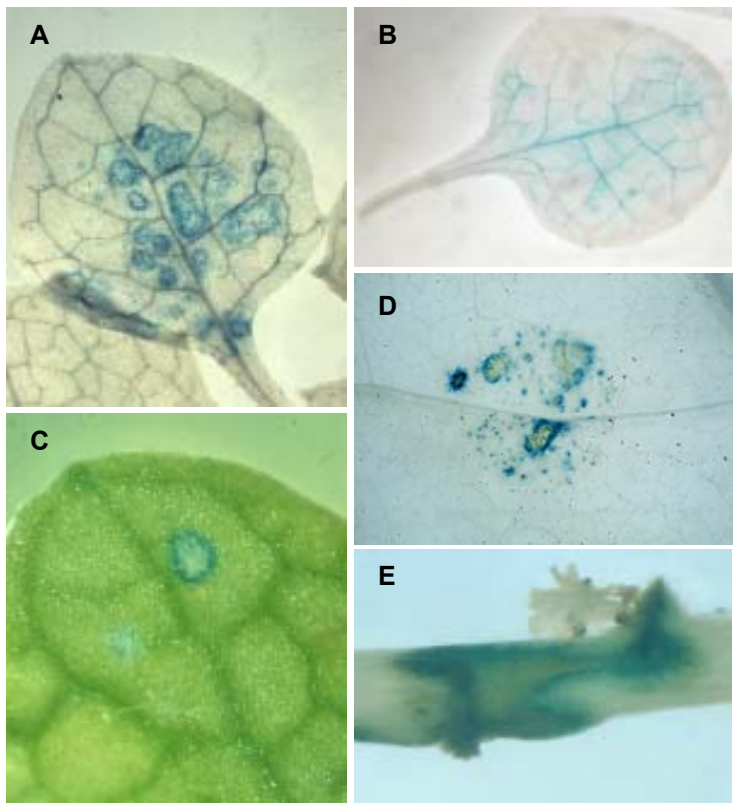

Figure 1. Histochemical staining for GUS activity in transgenic Arabidopsis and Brassica napus plants. Arabidopsis plants were infected with Botrytis cinerea and Brassica napus plantlets were infected with Phoma lingam.(A) Original Arabidopsis tagging line 488 transformed with the pMOG553 promotertagging construct containing a promoterless VidA gene. Clear GUS activity can be seen around the necrotic area's caused by the Botrytis infection. (B) GUS expression in leaf of Arabidopsis tagging line 488 treated with 5 $\mathrm{mM}$ Salicylic acid. (C) Transgenic Arabidopsis line transformed with the pMOG1056 construct carrying the long promoter element that $\mathrm{mM}$ Salicylic acid. (C) Transgenic Arabidopsis line transformed with the pMOG1056 construct carrying the long promoter element that was isolated from the Arabidopsis genome. The GUS activity around the Botrytis lesion is clearly visible. (D) Detailed image of a lingam. The nrotic lesion cansists stem lesion in pMOG1056 transgenic $B$. napus plantlet.
ste 


\section{Analysis of the 488-promoter DNA sequence}

The complete sequence of the $2.3 \mathrm{~kb}$ genomic clone was used in a BLAST (Altschul et al., 1997) homology search against the EMBL database. Two clones displaying more than $99 \%$ homology were found in the sequences of BAC MZB10 (Lin et al., 1999; AC009326) and BAC T16011 (Lin et al., 1999; AC010871). Both BAC's have an overlap of $17450 \mathrm{bp}$ at the SP6 site of the BAC's and are located near molecular marker CIC7A12R (YAC CIC7A12) on Arabidopsis chromosome III.

The T-DNA of the pMOG553 promotertagging construct in Arabidopsis line 553-488 is inserted between the predicted third and fourth open reading frame on BAC MZB10. The location of the TDNA insertion site is $398 \mathrm{bp}$ downstream of the third ORF (MZB10.3), a protein of unknown function and $1591 \mathrm{bp}$ upstream of the translation start of the putative receptor serine threonine protein kinase, the fourth ORF (MZB10.4). The situation at this chromosomal location of the T-DNA in line 553-488 is presented schematically in Figure 2 . The only difference between the sequence of the isolated genomic fragment derived from the $\mathrm{C} 24$ ecotype and the published sequence (Columbia ecotype) is a deletion of 12 nucleotides in the C24 ecotype within intron 1 of the MZB10.4 predicted ORF. When the DNA sequence of both regions in BAC MZB10 and BAC T16011 were compared, they appeared to be identical over the entire region of the putative receptor serine threonine kinase.

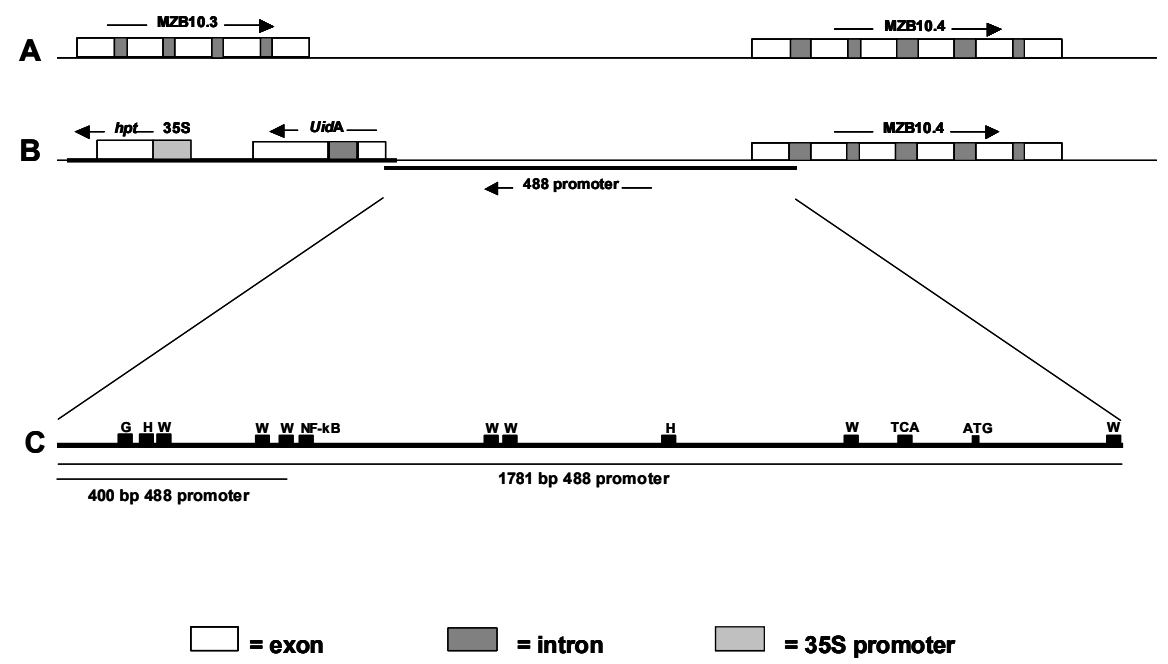

Figure 2. Comparison of the situation on chromosome III between open reading frames MZB10.3 and MZB10.4 in a wildtype Arabidopsis Col-0 plant (A) and the situation on the same location in promotertagging line 488 (B). The T-DNA is integrated upstream of MZB10.4 in the reverse orientation (as indicated by the arrows). The white boxes represent exons, introns are indictated as grey boxes and the $35 \mathrm{~S}$ promoter driving expression of the hygromycin resistance gene (hpt) is shown as a shaded box. (C) A more detailed schematic representation of the 1781 bp 488-promoter. Black boxes indicate the presence of the different promoterbox sequences. $\mathrm{G}=\mathrm{G}$-box with the sequence CAAGTG (Loake et al., 1989)), $\mathrm{H}=\mathrm{H}$-box (consensus is CCTACC, Lois et al., 1989), W = W-box (core of motif is nTGACn, Eulgem et al., 2000), NF-kB represents a putative binding site for NF-kB (Lebel et al., 1998), TCA is motif known to bind tobacco nuclear proteins upon SA treatment (Goldsbrough et al., 1993) and ATG is the translation start of MZB10.4.

The DNA sequence of the 488 Botrytis inducible promoter from Arabidopsis thaliana was analyzed for the presence of specific sequences known to be present in stress and pathogen induced genes. 
Sequences very similar to the H-box consensus as described by Lois et al. (1989) and Fischer (1994) were found in the 488-promoter (Figure 2). These boxes are known to confer fungal elicitor and wound induced expression when fused as multimers to a minimal promoter (Takeda et al., 1999). Also indicated in figure 2 are boxes similar to the so-called G-box motif (Loake et al., 1992) and several sequences similar to W-boxes known to bind the WRKY family of transcription factors (Rushton et al., 1998). A motif at position number 1344-1352 just upstream of the Hinc II restriction enzyme recognition site used for cloning of the $400 \mathrm{bp}$ promoter element has homology to the NF$\mathrm{KB}$ motif. NF-KB motifs are found in the salicylic acid and pathogen inducible Arabidopsis PR-1 promoter (Lebel et al., 1998) and promoters of genes upregulated in the constitutive SAR Arabidopsis mpk4 mutant (Petersen et al., 2000). The TCA motif at position 366-375 is found in many SA induced genes and binds a nuclear protein in tobacco upon SA induction (Goldsbrough et al., 1993). Since activation of a pathogen inducible promoter under other conditions than pathogen attack is unfavourable we analysed the 488 promoter sequence for the presence of cis-acting elements involved in the abiotic stress response. No sequences identical to the major cis elements, DRE (drought responsive element; Liu et al., 1998) and ABRE (absicic acid responsive element; Yamaguchi-Shinozaki and Shinozaki, 1994) involved in abiotic stress responses like drought, highsalt and cold were found in the sequence of the 488 promoter.

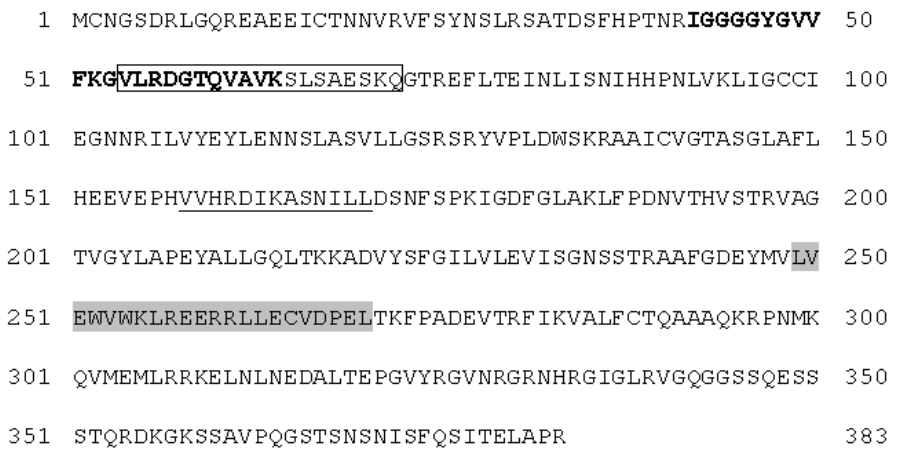

Figure 3. Predicted amino acid sequence of MZB10.4 (EMBL: AC009326). Protein kinase ATP binding region is indicated in bold, the protein kinase active site is underlined and the putative leucine zipper is highlighted in grey. The boxed motif partly overlapping the ATP binding region has similarity to motifs found in alpha isopropylmalate/homocitrate synthase enzymes.

\section{Analysis of MZB10.4 amino acid sequence and phylogeny}

Computer based prediction of the open reading frames and the subsequent translation into amino acid sequences revealed a difference between both accessions (MZB10.4, Lin et al., 1999; EMBL: AC009326 and T16011.3, Lin et al., 1999; EMBL: AC010871). The difference was found in the prediction of the splicing site between intron five and exon six, resulting in two different predicted protein sequences. The amino acid sequence of the MZB10.4 putative receptor serine threonine protein kinase is $383 \mathrm{Aa}$ in size and contains a protein kinase ATP binding region ( $\mathrm{Aa} 42$ to 64 ), a protein kinase active site (Aa 158 to 170), a Leucine zipper motif (Aa 249 to 270) and a region with similarity to motifs found in Alpha Isopropylmalate/homocitrate synthase enzymes (Aa 54 to 64) as predicted in a Procite pattern search (Figure 3). The amino acid sequence of the T16011.3 putative 
protein kinase is $384 \mathrm{Aa}$ in size and contains a protein kinase ATP binding region (Aa 42 to 64 ), a protein kinase active site (Aa 158 to 170) and a region with similarity to motifs found in Alpha Isopropylmalate/homocitrate synthase enzymes (Aa 54 to 64 ). The T16011.3 putative protein kinase differs from MZB10.4 between Aa position 254 and 259 and changing the leucine zipper motif, wihch is predicted (based on similarity) in MZB10.4 and not in T16011.3.

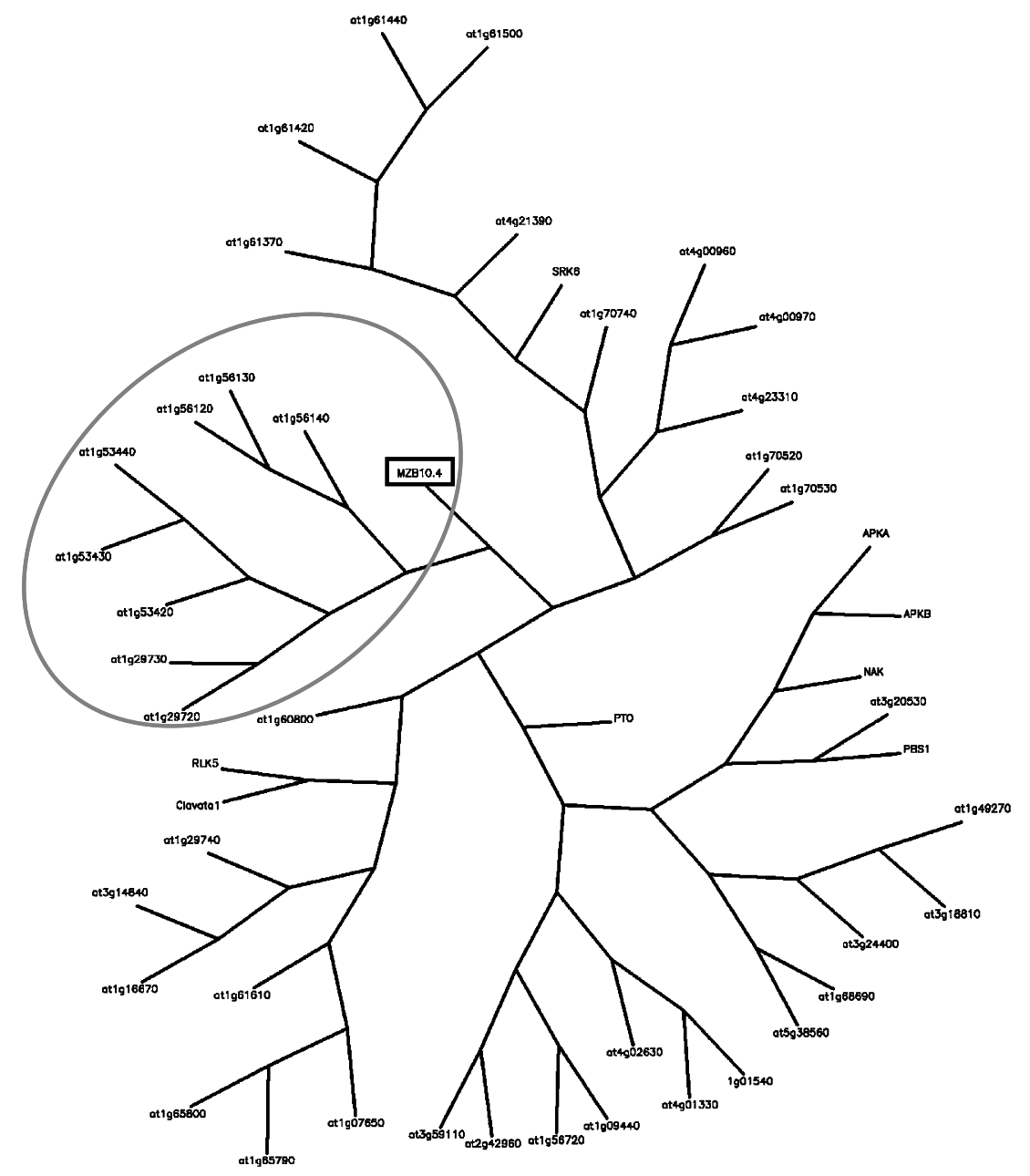

Figure 4: Relatedness of the MZB10.4 kinase to the 40 most related kinases in Arabidopsis and a selection of (receptor) kinases from Arabidopsis and other plant species with known function. The clade of the phylogenetic tree containing MZB10.4 is highlighted (gray elipse). 
Sequence analysis of the cDNA in this region showed that it encodes the 383 Aa serine threonine receptor kinase as previously predicted by Lin et al. and designated MZB10.4. To compare the MZB10.4 protein with other related sequences the MZB10.4 amino acid sequence was used in a BLAST2 search (Altschul et al., 1997) against the Arabidopsis genome sequence. The 40 best hits were used together with a selection of known kinases from Arabidopsis and other plant species to build an unrooted phylogenetic tree (Figure 4). The phylogenetic tree separates into five major clades. The MZB10.4 kinase groups together with a set of 8 Arabidopsis kinases with unknown function.

Expression of the MZB10.4 receptor kinase mRNA after treatment of Arabidopsis plants with plant hormones and Botrytis cinerea

Arabidopsis plants were treated with salicylic acid, jasmonic acid, 1-amino cyclopropane carboxylic acid (ACC, a precursor of ethylene) or inoculated with B. cinerea spores. The MZB10.4 RNA could not be detected on Northern blots, which indicates that expression of the serine/threonine kinase mRNA is too low to detect using this technique. To overcome detection difficulties a RT-PCR approach was attempted, demonstrating that the MZB10.4 transcript is indeed upregulated after infection of Arabidopsis with Botrytis cinerea and treatment with Salicylic acid (Figure 5). SAinducibility of the 488-promoter was also observed in transgenic Arabidopsis plants containing the pMOG553 T-DNA insertion (See Figure 1B). The induction by Botrytis cinerea appears relatively modest in this experiment (approximately 2 -fold), but at the time of sampling only an estimated 5$10 \%$ of the plant was infected by this fungus.

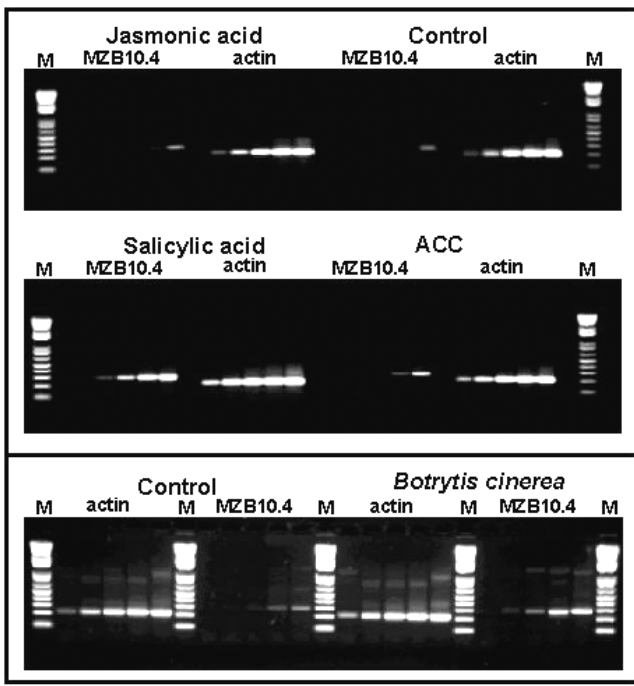

Figure 5: RT-PCR quantification of Arabidopsis mzb10.4 and actin genes in untreated plants, Botrytis infected (72 hours after inoculation), Salicylic acid treated, Jasmonic acid and ACC treated plants (24 hours after spraying). For each gene/treatment combination 5 identical PCR reactions were subjected to 22, 24, 26, 28 or 30 PCR cycles and analysed on an ethidium bromide stained $2 \%$ agarose gel. $M=1 \mathrm{kbPLUS}$ size marker (Gibco) 


\section{DISCUSSION}

It has been shown that a promoter tagging approach can be used to identify novel pathogenresponsive promoters. A promoter has been identified that is induced specifically and locally after fungal infection. An isolated promoter element of $1781 \mathrm{bp}$ exhibited a Botrytis-inducible expression pattern identical to the original 553-488 promoter tagging line.

Promoters identified using a promoter tagging approach are often not 'real' endogenous gene promoters. They may, however, be able to drive transcription of reporter genes when removed from their original context and reintroduced at another location in a plant genome. Insertion of T-DNA's in plant genomes is thought to be more or less random. However in a relatively high percentage (up to $70 \%$ ) of T-DNA integration events where a promoterless reporter gene is placed close to T-DNA borders expression of this reporter gene is found (Topping et al., 1991; Lindsey et al., 1993). This suggests that integration events occur preferentially in transcriptionally active areas, near or in expressed genes (Lindsey et al., 1993). In several cases it has been found that transcriptionally silent regions in the plant genome are activated upon insertion of a T-DNA, often referred to as cryptic promoters (Fobert et al., 1994). The ability to identify these so-called cryptic promoters by screening directly for the desired promoter activity is one of the main advantages of promoter tagging above other techniques. However, promoter tagging is not a very efficient method to clone plant promoters. Especially not since novel differential screening techniques like cDNA-AFLP and high density microarrays have become available. We have identified one Botrytis responsive promoter in the 500 lines we screened (preselection from 1200 lines). This means that in our library the tagging efficiency of Botrytis responsive promoters is below $0.1 \%$. Depending on the characteristics of the plant promoter, reporter genes, preselection procedures and early screening assays can be used to enhance the tagging efficiency. For crops where microarrays are not available but transformation technology and screening methodology are in place, T-DNA promoter tagging can be a suitable approach.

In the fungal responsive 488 tagging line the T-DNA is inserted between two predicted open reading frames of which at least one is actively transcribed. This gene codes for a putative serine threonine kinase, as predicted by BLAST similarity searching. The gene is located upstream of the promoterless UidA sequence which is on the introduced T-DNA. Enhancer sequences upstream of the MZB10.4 minimal promoter (promoter of the kinase) are probably directing the pathogen- and $\mathrm{SA}$-induced expression. Although there is an isolated report of activating sequences functioning from a position downstream from the ORF (Tremousaygue et al., 1999), most promoter architecture studies have clearly shown all activating sequences to be found upstream of the gene in plants. We therefore assume that the activating sequences identified play a role in MZB10.4, and not in MZB10.3 expression. Reports have also shown that enhancer or activator sequences can function in a bi-directional manner, also at positions more distal from the minimal promoter (Vorst et al., 1993; Leung et al., 1991). This suggests that the transcriptional activity of the 488-promoter is not a result of activation of a transcriptionally silent region. The tagging construct that was used in our experiments was designed to allow transcriptional as well as translational fusions. The T-DNA between the ATG translational start of the UidA gene and the right border sequence does not contain a minimal promoter sequence. A functional TATA box has to be present in the Arabidopsis genome upstream of the T-DNA insertion relative of the ATG translation start of the UidA gene. The regulatory region between the T-DNA insertion and the start of the MZB10.4 coding region is 
predicted to be responsible for the pathogen induced expression as observed in promotertagging line 553-488 and in transgenic Arabidopsis or Brassica napus plants transformed with the pMOG1056 construct.

The truncated promoter fragment that was used in pMOG1040 did not confer fungal-induced expression in transgenic Arabidopsis plants. From these experiments we concluded that elements necessary for pathogen induced expression of the 488-promoter are located upstream of the $400 \mathrm{bp}$ promoter element (relative to the T-DNA insertion) and the predicted minimal promoter and 5' untranslated region of the MZB10.4 putative serine threonine receptor kinase. The frequency at which the long promoter element (pMOG1056) is functional in the $A$. thaliana and $B$. napus transgenics (14 out of 47 and 10 out of 20 respectively) is comparable to what is commonly observed when producing transgenic plants with promoter-GUS fusion constructs. The GUS negative lines can be either non-expressors or expressors that are below the GUS histochemical assay detection level. This variation in transgene expression is often observed and can be either caused by the presence of multiple copies of the T-DNA resulting in co-suppression of the transgene or by the site of integration in the plant genome (Peach and Velten, 1991; Matzke and Matzke, 1998).

The promoter of the kinase contains several putative elements that drive the fungal induced expression of the UidA gene as shown in Figure 1. Elements necessary for pathogen-inducible expression or enhancement of pathogen inducible expression are probably present in the more upstream region of the long promoter element and thus more downstream in the promoter of the MZB10.4 Ser/Thr receptor kinase. This promoter stretches until the second exon of the Ser/Thr kinase. Detailed analysis of the 488-promoter sequence revealed the presence of several regulatory elements like H-boxes (Lois et al., 1989), G-boxes (Loake et al., 1993) and W-boxes (Eulgem et al., 2000; Rushton et al., 1998). Elements like these are predominantly found in the promoters of genes of which the expression is upregulated after pathogen attack, elicitor treatment or SA treatment. The W-box sequences are known to bind members of the WRKY family of transcription factors (Eulgem et al., 2000). Some members of this family in potato and parsley are induced by pathogen challenge as well (Dellagi et al., 2000; Eulgem et al., 1999). Du and Chen (2000) identified several receptor kinases in Arabidopsis that are possible targets for pathogen- and SA-induced WRKY DNA-binding proteins. A positive regulator of plant defence in Arabidopsis, the NPR1 gene, is also induced after pathogen infection and SA treatment. The promoter region of NPR1 contains W-box sequences that are essential for the function of NPR1 and these W-box sequences are recognised by SA inducible WRKY proteins (Yu et al., 2001). The TCA motif found in the 488-promoter and in the MZB10.4 promoter is present in many SA-induced genes and in tobacco this TCA motif binds a nuclear protein upon SA induction (Goldsbrough et al., 1993). The presence of a NF-KB motif also found in the Arabidopsis PR-1 promoter suggests that this element could be essential for directing pathogenand/or SA-induced expression. This motif is also found in the upstream regions of genes overexpressed in the Arabidopsis mpk4 mutant (Petersen et al. 2000). The MAP kinase 4 negatively regulates systemic acquired resistance. Both the NF- KB motif and the TCA motif are only present in the longer promoter fragment tested and thus appear to be necessary for directing pathogen inducible and SA inducible reporter gene expression. No cis elements known to confer responsiveness to abiotic stress (cold, high salt and drought) were identified in the 488 promoter. Whether the 488 promoter is indeed non-responsive to abiotic stress factors was not investigated. 
The open reading frame coupled to the region directing the expression of GUS in the original promoter tagging line codes for a serine threonine receptor kinase. Because the transcript could not be detected on northern blots the kinase transcript is probably a very low abundant messenger. We could however show, using a reverse transcriptase PCR approach, that the expression of the serine threonine protein kinase is upregulated after SA treatment and fungal infection in Arabidopsis. The gene is induced six- to eight-fold after SA treatment and we were only able to show an approximately two-fold upregulation in the case of the Botrytis infection. This difference in induction level can be explained by the fact that only a limited number of cells are directly contacted by the Botrytis infection in contrast to the SA spray that probably hits a larger number of cells that can respond to the treatment. The induction level of the mzb10.4 transcript in response to Botrytis in Arabidopsis differs somewhat from the GUS induction observed in the original tagging line. This can be explained by the fact that in the original tagging line the mzb10.4 promoter in the reverse orientation was analyzed and accumulation of the GUS enzyme was measured. When the expression of the mzb10.4 transcript in wildtype Arabidopsis is determined the activity of the native mzb10.4 promoter is measured, which can exhibit a different expression pattern than the promoter responsible for the expression of the UidA gene in the original tagging line. Furthermore, mRNA levels are determined which more directly reflect promoter activity than the $\beta$-glucuronidase activity measured in that tagging line.

The predicted amino acid sequence of the MZB10.4 kinase contains a protein kinase active site, an ATP binding region and a leucine zipper. The Arabidopsis genome contains about 1.000 serine/threonine kinase genes (The Arabidopsis Genome Initiative, 2000) where for the majority their function remains to be elucidated. Phosphorylation and dephosphorylation are very important processes in signal transduction pathways. Enzymes of the protein kinase superfamily mediate phosphorylation of target proteins and thereby activate or deactivate their targets by which signals are transduced in eukaryotic cells and which are important for a variety of different processes (Sopory and Munshi, 1998). Comparison of MZB10.4 with the 40 most related Arabidopsis kinases and other plant (receptor) kinases showed that it clustered together with 8 other kinases with unknown function. Two kinases included in the phylogenetic tree that play an important role in resistance are the PTO and PBS1 serine threonine kinases. They are required for resistance of respectively tomato and Arabidopsis to Pseudomonas (Martin, 1999; Swiderski and Innes, 2001). A possible role of the MZB10.4 kinase in plant disease resistance and the biological significance of the induction of this kinase in response to $S A$ and fungal pathogens remain unclear.

The 1781 bp 488-promoter when transferred to Brassica napus is induced very locally after infection by two different fungi including the major pathogen Phoma lingam. This makes the 488-promoter an attractive candidate to drive expression of elicitors of the hypersensitive response or antifungal proteins to engineer fungal resistance in oilseed rape and possibly in other field crops.

\section{EXPERIMENTAL PROCEDURES}

Construction Arabidopsis pMOG553 promoter tagging library

The T-DNA sequence of the promoter tagging construct pMOG553 (Goddijn et al., 1993) is available in the EMBL database under accession number X84105. 
The promoter tagging construct was introduced into Agrobacterium tumefaciens strain MOG101 (Hood et al., 1993) and used for Arabidopsis thaliana C24 root transformation. More than 1100 transgenic plants were generated, self-fertilized and the resulting $\mathrm{S} 1$ seeds were harvested.

\section{Infection of Arabidopsis plants with B. cinerea}

Three weeks old Arabidopsis seedlings were transferred to potting soil in $5.5 \mathrm{~cm}$ pots and grown for one more week at $18^{\circ} \mathrm{C}$. Prior to inoculation of the plants with Botrytis cinerea leaf samples were taken and a histochemical GUS staining was performed essentially as described in Goddijn et al. (1993). The plants were sprayed with a $B$. cinerea spore suspension of $1.2 \times 10^{6} \mathrm{spores} / \mathrm{ml}$ in $\mathrm{H}_{2} \mathrm{O}$ containing $0.2 \%(\mathrm{w} / \mathrm{v})$ sucrose/0.8\% (w/v) $\mathrm{KH}_{2} \mathrm{PO}_{4}$. Leaves that displayed disease symptoms were harvested at 24 hours and 48 hours after inoculation and subjected to a histochemical GUS assay.

\section{Infection assays on transgenic Brassica napus plants}

A detached leaf infection assay was used for Brassica napus transgenic plants. Leaves were detached and placed on wet foam. Small incissions were made and droplets of a $B$. cinerea spore suspension (method section 2.2) were applied on the incissions. Infected material was incubated at $18^{\circ} \mathrm{C}$ and high relative humidity ( $\pm 90 \%$ ) for 3 days.

Similar infection assays were performed on in vitro plantlets grown in small glass tubes. Plants were inoculated with a spore suspension of Leptosphaeria maculans (anamorph: Phoma lingam) the causal agent of Blackleg disease on Brassica napus. Small droplets of the spore suspensions were applied directly on the leaves and the disease was allowed to develop for 6 days at room temperature. When small lesions became visible, leaves were removed from the plant and tested for expression using a histochemical GUS assay. Inoculated plantlets were maintained for approximately 2 weeks until clear stem lesions developed.

\section{Isolation of Botrytis-inducible promoter by inverse PCR}

Genomic DNA was isolated from leaves of Arabidopsis (Fütterer et al., 1995). Two micrograms of genomic DNA was subjected to restriction enzyme digestion with five different enzymes, EcoR I, EcoR V, Hinc II, Mlu I and Nsp I (Gibco BRL). Half of the mixture was separated on a $0.8 \%$ agarose gel and transferred to a Hybond-N+ (Amersham Life Sciences) as described by the manufacturer. The blot was hybridized $\left(16\right.$ hours, $65^{\circ} \mathrm{C}$ ) with a $560 \mathrm{bp} \mathrm{Nco} \mathrm{I} \mathrm{-} \mathrm{EcoR} \mathrm{V} \mathrm{GUS} \mathrm{fragment} \mathrm{(pMOG18,}$ Sijmons et al., 1990) labeled with ${ }^{32} \mathrm{P}$-dCTP as a probe. Then the blot was washed twice with $0.2 \mathrm{x}$ $\mathrm{SSC} / 1 \% \mathrm{SDS}$ at $65^{\circ} \mathrm{C}$. Detection was done via 24 hour exposure to Fuji X-ray film at $-80^{\circ} \mathrm{C}$.

The remaining digested DNA was self-ligated. The ligated DNA was then linearized with SnaB I and a small portion of this DNA sample was used as a template in a PCR reaction with primer GUSINV5: 5'CTT TCC CAC CAA CGC TGA TC3' and GUS7 (5'GTA ATG CTC TAC ACC ACG CCG3') except for the ECOR I reaction were GUS8 (5'CGC ACC ATC GTC GGC TAC AGC3') was used. Twenty-five pmol of each primer, $0.5 \mu \mathrm{l}$ of a $20 \mathrm{mM}$ dNTP solution, 0.5 units Taq DNA polymerase (Gibco BRL) were used to amplify the promoter fragment $\left(1 \mathrm{cycle:} 5^{\prime} 95^{\circ} \mathrm{C}, 5^{\prime} 55^{\circ} \mathrm{C}, 5^{\prime}\right.$ $72^{\circ} \mathrm{C}$; 25 cycles: $1^{\prime} 95^{\circ} \mathrm{C}, 1^{\prime} 55^{\circ} \mathrm{C}, 2^{\prime} 72^{\circ} \mathrm{C}$; 1 cycle: $1^{\prime} 95^{\circ} \mathrm{C}, 1^{\prime} 55^{\circ} \mathrm{C}, 10^{\prime} 72^{\circ} \mathrm{C}$ ). The $0.6 \mathrm{~kb}$ Hinc II PCR fragment was isolated and cloned into the PGEM-T vector (Promega, Madison WI, USA) as described by the manufacturer. Identity of the cloned PCR fragment was determined by DNA sequence analysis. 


\section{Isolation of a larger promoter fragment using library screening}

For the isolation of a large promoter fragment from the Arabidopsis genome a genomic Arabidopsis thaliana C24 wildtype library was screened. The screening of the genomic library was done using a $401 \mathrm{bp} \mathrm{Hind} \mathrm{III} \mathrm{-} \mathrm{Hinc} \mathrm{II} \mathrm{fragment} \mathrm{from} \mathrm{the} \mathrm{T-vector} \mathrm{clone} \mathrm{harbouring} \mathrm{the} 0.6 \mathrm{~kb}$ iPCR fragment as a probe during the complete procedure.

Hybridizing bands of $\pm 4 \mathrm{~kb}$ (Sst I - Sst I fragment) of two different subclones were isolated and subcloned into high copy cloning vector pUC18 (Yanisch-Perron et al., 1985)) also digested with Sst I. Clones containing inserts of the correct size were subjected to restriction enzyme analysis, southern blotting and hybridization with the $401 \mathrm{bp} 488$ probe. A $2.3 \mathrm{~kb}$ hybridizing Sst I - EcoR V fragment was subcloned into high copy cloning vector $\mathrm{pBKS}^{+}$(Stratagene) and the DNA sequence of the insert was determined.

\section{Analysis of MZB10.4 amino acid sequence and phylogeny}

To compare the MZB10.4 protein with other related sequences the MZB10.4 amino acid sequence was used in a BLAST2 search (Altschul et al., 1997) against the Arabidopsis genome sequence. The 40 best hits were selected and aligned together using the Clustal_X programme (Thompson et al., 1997). An unrooted phylogenetic tree was build using the Clustal_X neighbour-joining method and bootstrapped 1000 times. The Drawtree programme of the Phylip Phylogeny Inference package version 3.6 (http://evolution.genetics.washington.edu/phylip.html) was used to visualise the tree.

\section{Inductions of Arabidopsis plants and expression analysis}

The expression of the MZB10.4 mRNA after treating the plants with Botrytis (72 hours after inoculation) and different plant hormones (24 hours after inoculation) was examined. For this purpose Eight to ten plants of 6- to 7- week old Arabidopsis thaliana plants (C24) were infected with a spore suspension of a Botrytis cinerea strain (methods section 4.2). Salicylic acid (5 mM), 1aminocyclopropane-1-carboxylic acid $(1 \mathrm{mM})$ and jasmonic acid $(0.1 \mathrm{mM})$ were applied by spraying the plants with an aqueous solution containing $0.01 \%$ Silwet. All agents were purchased at SigmaAldrich. The plants were maintained at $20^{\circ} \mathrm{C}, 80 \%$ relative humidity and a day/night regime of 16 hours/8 hours.

Total RNA was extracted using the hot phenol method (Pawlowski et al., 1994) and chromosomal DNA contaminations where removed by DNAse I (Life technologies) treatment Reverse transcription reactions were performed on $2 \mu \mathrm{g}$ of total RNA using an oligo(d)T primer and Superscript II RT (Life technologies). For each gene examined five PCR reactions of each treatment were perfomed $(25 \mathrm{pmol}$ of each primer, 2.5 units of Platinum Taq DNA polymerase, 0.5 $\mu \mathrm{l} 20 \mathrm{mM}$ dNTP's, $1 \times$ PCR buffer and $1.5 \mu \mathrm{l} 50 \mathrm{mM} \mathrm{MgCl}$ (Life technologies)) and subjected to 22 , $24,26,28$, and 30 cycles of $30^{\prime \prime} 92^{\circ} \mathrm{C}, 30^{\prime \prime} 55^{\circ} \mathrm{C}, 30^{\prime \prime} 72^{\circ} \mathrm{C}$. Fragments were analysed on a $2 \%$ agarose gel. Primers used to amplify a 292 bp MZB10.4 fragment (spanning intron 2); FR-MZB10.4562: 5'-GAT TTG CAC CAA CAA TGT GAG G-3' and MZB10.4-563: 5'-GGT ACT CAT AGA CAA TCC G-3', and a 218 bp actin fragment; FR-Actin-586: 5'-GAT GAT ATG GAG AAG ATT TGG CAT C-3' and FR-Actin-587: 5'-CAC AAT ACC GGT TGT ACG ACC AC-3'. 


\section{Construction of promoter-UidA fusions}

The $400 \mathrm{bp}$ promoter fragment was fused to the uidA open reading frame to mimic the original plant line 553-488. A small modification was made introducing a Nco I restriction site overlapping the ATG startcodon of the UidA gene to enable easy fusion of the promoter to different open reading frames. Primers were developed for the amplification of the fragment from the Arabidopsis genome: Primer LS259 5'CGT ACC ATG GGG GAC TGA CC3' introducing a Nco I restriction site overlapping the ATG startcodon and primer LS260 5'AGC CGA GCT CGT TGA CAA AAA AAG TAA AAT AAA GTT C3' introducing a Sst I restriction site upstream of the 400 bp promoter fragment. The PCR product was purified, digested with Sst I and Nco I and ligated into a Sst I, Nco I digested cloning vector containing UidA gene with the Stls1 intron (Jefferson et al., 1987) followed by the 3' untranslated region of the potato proteinase inhibitor II gene (An et al., 1989) forming pMOG1039. The complete expression unit was then transferred to binary vector pMOG800 (derived from pMOG23 Sijmons et al., 1990) using restriction enzymes Sst I and EcoR I. The resulting plasmid was designated PMOG1040.

For the construction of the $1800 \mathrm{bp} 488$-promoter a $1400 \mathrm{bp}$ upstream fragment of the promoter was fused to the $400 \mathrm{bp}$ fragment using the Hinc II restriction site. Therefore the $400 \mathrm{bp}$ promoter was excised from vector pMOG1039 with $\mathrm{BamH} I$ and Hinc II and ligated into a likewise digested cloning vector $\mathrm{pBKS}^{+}$(Stratagene). The resulting vector was then digested with Hinc II and the 1400 bp upstream Hinc II fragment derived from the genomic fragment was ligated into this vector. A clone with the promoter elements fused in a proper way was digested with $\mathrm{XhO} \mathrm{I}$ and $\mathrm{Bam \textrm {H } I}$ and ligated into binary vector pMOG1040 digested with Xho I and BamH I resulting in binary vector pMOG1056.

Both binary vectors were transferred by electroporation to Agrobacterium tumefaciens strain MOG101 (Hood et al., 1993) for transformation of Arabidopsis thaliana and strain MOG301 (Hood et al., 1993) for transformation of Brassica napus.

\section{Transformations of 488-promoter GUS constructs to $A$. thaliana and B. napus}

Transformations of Arabidopsis thaliana ecotype C24 were performed as described in Goddijn et al., 1993 and grown under the conditions described above. Brassica napus cv Westar transformations were performed as described by Bade and Damm (1995). Transgenic plants were grown in pots in a greenhouse under the following conditions; $21-24^{\circ} \mathrm{C}, 60-80 \%$ relative humidity and 16 hour light cycle.

\section{ACKNOWLEDGMENTS}

The authors would like to thank Bart van Wezenbeek and Stuart Harrison for critical reading of the manuscript and Anton Zonneveld for technical assistance.

\section{REFERENCES}

Altschul, S. F., Madden, T.L., Schaffer, A.A., Zhang, J., Zhang, Z., Miller, W., and Lipman, D.W. (1997) "Gapped BLAST and PSIBLAST: a new generation of protein database search programs", Nucleic Acids Res. 25, 3389-3402.

An, G., Mitra, A., Cho,i H.K., An, K., Thornburg, R.W. and Ryan, C.A. (1989) Functional analysis of the 3' control region of the potato wound-inducible proteinase inhibitor II gene. Plant Cell 1(1), 115-122.

Bade, J.B., and Damm, B. (1995) Agrobacterium-mediated transformation of Brassica napus. In Gene transfer to plants; Potrykus, I.; Spangenberg, G. Eds. Springer Verlag: Berlin, pp 32-38. 
Barthels, N., van der Lee, F.M., Klap, J., Goddijn, O.J., Karimi, M., Puzio, P., Grundler, F.M., Ohl, S.A., Lindsey, K., Robertson, L., Robertson, W.M., Van Montagu, M., Gheysen, G. and Sijmons, P.C. (1997) Regulatory sequences of Arabidopsis drive reporter gene expression in nematode feeding structures. Plant Cell 9(12), 2119-2134.

Dellagi, A., Heilbron, J., Avrova, A.O., Montesano, M., Palva, E.T., Stewart, H.E., Toth, I.K., Cooke, D.E.L., Lyon, G.D. and Birch P.R.J. (2000) A Potato Gene Encoding a WRKY-like Transcription Factor Is Induced in Interactions with Erwinia carotovora subsp. Atroseptica and Phytophthora infestans and Is Coregulated with Class I Endochitinase Expression. Mol. Plant-Microbe Interact. 13(10), 1092-1101.

Dorey, S., Baillieul, F., Pierrel, M., Saindrenan, P., Fritig, B. and Kauffmann, S. (1997) Spatial and Temporal Induction of Cell Death, Defence genes, and Accumulation of Salicylic Acid in Tobacco Leaves Reacting Hypersensitively to a Fungal Glycoprotin elicitor. Mol. Plant-Microbe Interact. 10(5), 646-655.

Dröge-Laser, W., Kaiser, A., Lindsay, W.P., Halkier, B.A., Loake, G.J., Doerner, P., Dixon, R.A. and Lamb, C.J. (1997) Rapid stimulation of a soybean protein-serine kinase that phosphorylates a novel bZIP DNA-binding protein, G/HBF-1, during the induction of early transcription dependent defences. EMBO J.16(4), 726-738.

Du, L. and Chen, Z. (2000) Identification of genes encoding receptor-like protein kinases as possible targets of pathogen- and salicylic acid- induced WRKY DNA-binding proteins in Arabidopsis. Plant J. 24(6), 837-847.

Eulgem, T., Rushton, P.J., Schmelze,r E., Hahlbrock, K. and Somssich, I. (1999) Early nulear events in plant defence signalling: rapid gene activation by WRKY transcription factors. EMBO J. 18(17): 4689-4699.

Eulgem, T., Rushton, P.J., Robatzek, S. and Somssich, I.E. (2000) The WRKY superfamily of plant transcription factors. Trends Plant Sci. 5(5): 199-206.

Fisher, R. (1994) Optimierung der heterologen expression von stilbensynthasegenen für den pflanzenschutz. Ph.D. thesis, University of Hohenheim, Germany.

Fobert, P.R., Miki, B.L. and lyer, V.N. (1991) Detection of gene regulatory signals in plants revealed by T-DNA -mediated fusions. Plant Mol. Biol. 17: 837-851.

Fobert, P.R., Labbé, H., Cosmopoulos, J., Gottlob-McHugh, S., Ouellet, T., Hattori, J., Sunohara, G., Iyer, V.N. and Miki, B.L. (1994) T-DNA tagging of seed coat-specific cryptic promoter in tobacco. Plant J. 6(4): 567-577.

Fütterer, J., Gisel, A., Iglesias, V., Klötti, A., Mittelsten Scheid, O., Neuhaus, G., Neuhaus-Url, G., Schrott, M., Shillito, R., Spangenberg, G and Wang, Z.Y. (1995) Isolation of genomic DNA from plants. In: Gene transfer to plants; Potrykus, I.; Spangenberg, G. Eds. Springer Verlag: Berlin, 1995; pp 215-218.

Goddijn, O.J.M., Lindsey, K., Van der Lee, F.M., Klap, J.C. and Sijmons, P.C. (1993) Differential gene expression in nematodeinduced feeding structures of transgenic plants harbouring promoter-UidA fusion constructs. Plant J. 4(5): 863-873.

Goldsbrough, A.P., Albrecht, H. and Stratford, R. (1993) Salicylic acid-inducible binding of a tobacco nuclear protein to a 10 bp sequence which is highly conserved amongst stress-inducible genes. Plant J. 3(4): 563-71.

Govrin, E.M. and Levine, A. (2000) The hypersensitive response facilitates plant infection by the necrotrophic pathogen Botrytis cinerea Curr Biol 10: 751-757.

Hood, E.E., Gelvin, S.B., Melchers, L.S. and Hoekema, A. (1993) New Agrobacterium helper plasmids for gene transfer to plants Transgenic res. 2: 208-218.

Jefferson, R.A., Kavanagh, T.A. and Bevan, M.W. (1987) GUS fusions: $\beta$-glucuronidase as a sensitive and versatile gene marker in higher plants. EMBO J. 6: 3901-3907.

Kertbundit, S., De Greve, H., Deboeck, F., Van Montagu, M. and Hernalsteens, J-P. (1991) In vivo random $\beta$-glucuronidase gene fusions in Arabidopsis thaliana. Proc. Natl. Acad. Sci. USA 88: 5212-5216.

Lebel, E., Heifetz, P., Thorne, L., Uknes, S., Ryals, J. and Ward, E. (1998) Functional analysis of regulatory sequences controlling PR-1 gene expression in Arabidopsis. Plant J. 16(2): 223-233.

Leung, J., Fukuda, H., Wing, D., Schell, J. and Masterson, R. (1991) Functional analysis of cis-elements, auxin response and early developmental profiles of the mannopine synthase bi-directional promoter. Mol. Gen. Genet. 230(3): 463-474.

Lindsey, K., Wei, W., Clarke, M.C., McArdle, H.F., Rooke, L.M. and Topping, J.F. (1993) Tagging genomic sequences that direct transgene expression by activation of a promoter trap in plants. Transgenic Res. 2: 33-47.

Liu, Q., Kasuga, M., Sakuma, Y., Abe, H., Miura, S., Yamaguchi-Shinozaki, K. and Shinozaki, K. (1998) Two Transcription Factors, DREB1 and DREB2, with an EREBP/AP2 DNA Binding Domain Separate Two Cellular Signal Transduction Pathways in Droughtand Low-Temperature-Responsive Gene Expression, Respectively, in Arabidopsis. Plant Cell 10: 1391-1406.

Loake, G.J., Faktor, O., Lamb, C.J. and Dixon, R.A. (1992) Combination of H-box [CCTACC(N) $\left.{ }_{7} \mathrm{CT}\right]$ and G-box (CACGTG) cis elements is necessary for feed-forwarded stimulation of a chalcone synthase promoter by the phenylpropanoid-pathway intermediate p-coumaric acid. Proc. Natl. Acad. Sci. USA 89: 9230-9234. 
Lois, R., Dietrich, A., Hahlbrock, K. and Schulz, W. (1989) A phenylalanine ammonia-lyase gene from parsley: structure, regulation and identification of elicitor and light responsive cis-acting elements. EMBO J. 8(6): 1641-1648.

Martin, G.B. (1999) Functional analysis of plant disease resistance genes and their downstream effectors. Curr. Opin. Plant Biol. 2:273-279.

Martini, N., Egen, M., Runtz, I and Strittmatter, G. (1993) Promoter sequences of a potato pathogenesis-related gene mediate transcriptional activation selectively upon fungal infection. Mol. Gen. Genet. 236:179-186.

Pawlowski, K., Kunze, R., de Vries, J. and Bisseling, T. (1994) Isolation of total, poly(A) and polysomal RNA from plant tissues. In: Plant Molecular Biology Manual, Second Edition eds. Gelvin S.B. and Schilperoort R.A. Kluwer Academic Publishers.

Petersen, M., Brodersen, P., Naested, H., Andreasson, E., Lindhart, U., Johansen, B., Nielsen, H.B., Lacy, M., Austin, M.J., Parker, J.E., Sharma, S.B., Klessig, D.F., Martienssen, R., Mattson, O., Jensen, A.B. and Mundy, J. (2000) Arabidopsis MAP Kinase 4 Negatively Regulates Systemic Acquired Resistance. Cell 103: 1111-1120.

Puzio, P.S., Lausen, J., Almeida-Engler, J., Cai, D., Gheysen, G. and Grundler, F.M.W. (1999) Isolation of a gene from Arabidopsis thaliana related to nematode feeding structures. Gene 239; $163-172$.

Rushton, P. and Somssich, I.E. (1998) Transcriptional control of plant genes responsive to pathogens. Curr. Opin. Plant Biol. 1:311315.

Sopory, S.K. and Munshi, M. (1998) Protein kinases and phosphatases and their role in cellular signalling in plants. Crit. Rev. Plant Sci. 17(3): 245-318

Sijmons, P.C., Dekker, B.M., Schrammeijer, B., Verwoerd, T.C., Van den Elzen, P.J. and Hoekema, A. (1990) Production of correctly processed human serum albumin in transgenic plants. Bio/technology 8(3): 217-212.

Stuiver, M.H. and Custers, J.H.H.V. (2001) Engineering disease resistance in plants. Nature 411; 865-868.

Swiderski, M.R. and Innes, R.W. (2001) The Arabidopsis PBS1 resistance gene encodes a member of a novel protein kinase family. Plant J. 26(1): 101-112.

Takeda, S., Sugimoto, K., Otsuki, H. and Hirochika, H. (1999) A 13-bp cis-regulatory element in the LTR promoter of the tobacco retrotransposon Tto1 is involved in responsiveness to tissue culture, wounding, methyljasmonate and fungal elicitors. Plant J. 18(4): 383-393.

The Arabidopsis Genome Initiative (2000) Analysis of the genome sequence of the flowering plant Arabidopsis thaliana. Nature 408: 796-815.

Thompson, J.D., Gibson, T.J., Plewniak, F., Jeanmougin, F. and Higgins, D.G. (1997) The Clustal X windows interface: flexible strategies for multiple sequence alignment aided by quality analysis tools. Nucleic Acids Res. 25(24): $4 \overline{8} 76-4882$

Tremousaygue, D., Manevski, A., Bardet, C., Lescure, N. and Lescure, B. (1999). Plant interstitial telomere motifs participate in the control of gene expression in root meristems. Plant J. 20(5): 553-561.

Topping, J.F., Agyeman, F, Henricot, B. and Lindsey, K. (1994) Identification of molecular markers of embryogenesis in Arabidopsis thaliana by promoter trapping. Plant J. 5(6): 895-903.

Vorst, O., Kock, P., Lever, A., Weterings, B., Weisbeek, P. and Smeekens, S. (1993) The promoter of the Arabidopsis thaliana plastocyanin gene contains a far upstream enhancer-like element involved in chloroplast-dependent expression. Plant J. 4: 933-945.

Yamaguchi-Shinozaki, K., and Shinozaki, K. (1994) A novel cis-acting element in an Arabidopsis gene is involved in responsiveness to drought, low-temperature, or high-salt stress. Plant Cell 6: 251-264

Yamamoto, S., Suzuki, K. and Shinshi, H. (1999) Elicitor responsive, ethylene-independent activation of a GCC box-mediated transcription that is regulated by both protein phosphorylation and dephosphorylation in cultured tobacco cells. Plant J. 20(5): 571579

Yu, D., Chen, C. and Chen, Z. (2001) Evidence for an Important Role of WRKY DNA Binding Proteins in the Regulation of NPR1 expression. Plant Cell 13, 1527-1539. 



\section{CHAPTER 4}

\section{ISOLATION OF TWO NOVEL PATHOGEN-INDUCIBLE PROMOTERS: EVALUATION OF PROMOTER-UIDA FUSIONS IN TRANSGENIC POTATO PLANTS USING A COMBINATION OF HISTOCHEMICAL STAINING AND QUANTITATIVE RT-PCR}


Chapter 4 


\section{SUMMARY}

Many biotechnological approaches to increase pathogen resistance in crop plants are dependent on the availability of well-characterized plant promoters that respond to pathogen attack. In this study, two novel plant promoters were isolated from genes that are induced locally after pathogen infection. Both promoter sequences were analysed for the presence of motifs common to pathogeninduced genes. Subsequently these promoters were fused to the UidA reporter gene and transformed into potato. Characteristics of these newly isolated promoters were compared with those of two well-studied plant pathogen-inducible promoters from the genes encoding Vitis stilbene synthase 1 (Vst1) and potato Glutathione-S transferase 1 (Gst1). Twenty transgenic lines of each promoter-UidA fusion were analysed using conventional histochemical staining and real time RTPCR analysis to visualize spatial, kinetic and dynamic properties of these promoters. The correlation between RT-PCR and GUS accumulation data indicate that, at least for some of the studied promoters, the $5^{\prime}$ UTR sequences may influence translational efficiencies.

\section{INTRODUCTION}

Many different biotechnological approaches to engineer pathogen resistance require the availability of promoters that respond specifically to pathogen infection. In many cases, constitutive expression of antimicrobial proteins, expression of enzymes involved in production of antimicrobial metabolites or constitutive activated resistance appears to affect plant vigour and yield, interferes with reproduction of the plant, or increases susceptibility to other pathogens (Hain et al., 1993; Cao et al., 1998; Felton et al., 1999; Osusky et al., 2000; Yalpani et al., 2001; Berrocal-Lobo et al., 2002). The use of promoters that have an expression level sufficiently low in the absence of pathogens such that they are below threshold for the adverse effect, and are only activated when plants are attacked by pathogens might reduce these negative side effects. Another advantage of using pathogen-induced promoters in transgene constructs may be in reducing exposure to non-target organisms., The constitutive production of certain plant defence components lead to increased, unwanted, exposure of non-target organisms to the transgenic product produced.

One promising way to engineer broad-spectrum disease resistance is based on the induction of a hypersensitive response (HR) after pathogen entry, by the introduction of an elicitor-producing gene under control of a pathogen-inducible promoter in plants containing the corresponding resistance (R) gene (De Wit, 1992; Stuiver and Custers, 2001). In this approach, pathogen attack induces the expression of the elicitor by the plant itself, which in presence of the cognate R-protein will trigger the HR. This approach has been successfully employed in tobacco by introducing the Phytophthora cryptogea cryptogein gene or the Ralstonia solanacearum PopA gene under control of a pathogeninducible promoter (Keller et al., 1999; Belbahri et al., 2001). Successful use of a similar approach was exemplified in the crop plant tomato by insertion of the Cladosporium fulvum Avr9 gene under control of the potato Gst1 promoter. (Stuiver et al., unpublished results). One of the aims of our group is to use this approach in potato to generate resistance to the oomycete Phytophothora infestans

For all approaches that require a pathogen-responsive promoter, certain properties of the pathogeninducible promoter are key to the success. The speed of accumulation of the antimicrobial compounds or of the elicitor protein and subsequent HR in the latter approach is central to the ability to stop the pathogen in a timely manner. Besides these kinetic properties, the dynamic 
expression range of a promoter is also important. The basic expression level should be sufficiently low to preclude a deleterious effect on vigour, yield and plant reproduction under all commonly encountered environmental conditions. However, during pathogen attack sufficiently high levels of antimicrobial compounds (or elicitor protein) need to be produced in the infected parts. Only this allows the plant to mount a timely response leading to successful restriction of pathogen infection. Another important but frequently overlooked parameter involves the frequency at which transgenic lines show the proper induction patterns. It is known also for other (e.g. constitutive) promoters that individual lines transgenic for genes under control of these promoters may vary significantly in levels of expression (Peach and Velten, 1991; Mlynarova et al., 1994). When using a pathogen-inducible promoter-dependent strategy, the ability to make sufficient well-responding lines may pose limitations on the applicability of the promoter.

Suitable pathogen-inducible promoters can be obtained from a large collection of characterized plant genes that are responsive to pathogen attack. Candidates that fit most requirements might be derived from genes that are induced as a result of the activation of one of the well-known induced resistance pathways known to be activated by many different pathogens, including viruses, bacteria, fungi, oomycetes and insects (Schenk et al., 2000; Glazebrook, 2001). Pathogen responsive genes like Glutathione S-transferases (Gst), pathogenesis-related (PR) proteins, enzymes in the phenylpropanoid pathway, enzymes required for the production of antimicrobial secondary metabolites and enzymes involved in the biosynthesis of signaling molecules with a role in pathogen resistance may yield suitable promoter candidates. Genes encoding PR proteins are induced by different pathogens and plant hormones. Their timing of induction during the infection process varies considerably. Interestingly, PR protein genes are often also expressed at during plant development in the absence of pathogen challenge. For use in antifungal strategies, the expression in uninfected plant organs or tissues poses a problem especially when expression of antimicrobial compounds or induction of the HR is not desirable (Samac and Shah, 1991; Eyal et al., 1993; Jordá and Vera, 2000).

The promoters used in this study are each derived from a different class of pathogen- responsive genes. The potato Gst1 gene is induced very early after $P$. infestans infection. The promoter region, an activator element of $239 \mathrm{bp}$, necessary and sufficient to confer Phytophthoraresponsiveness in combination with a minimal promoter has been characterized before (Martini et al., 1993; Strittmatter, 1995; Strittmatter et al., 1996). The Vst1 promoter is derived from the Vitis stilbene synthase gene that is involved in the biosynthesis of resveratrol in response to pathogens. Stilbenes have antimicrobial activity and play an important role in the defence system of some plants, and of grapevine in particular (Hain et al., 1993). The Vst1 promoter is responsive to pathogen infection as well as to wounding and high ozone concentrations, and promoter regions involved in these responses have been delineated (Fischer, 1994; Schubert et al., 1997). Over the years, many promoters of pathogen-induced genes have been analyzed for specific sequence motifs related to pathogen responsiveness. Detailed promoter deletion studies have resulted in the identification of promoter elements and some of the proteins binding these elements have been identified as well (Lois et al., 1989; Goldsbrough et al., 1993; Yang and Klessig, 1996; Schubert et al., 1997; Lebel et al., 1998; Takeda et al., 1999; Eulgem et al., 2000). Over the last years, the use 
of novel genomics and bioinformatics approaches has enabled the fast discovery of common elements in sets of co-regulated genes (Maleck et al., 2000).

In this study we cloned two novel pathogen-inducible promoters, analyzed their DNA sequences, fused them to the $\beta$-glucuronidase gene (UidA gene) and transformed them into potato. We then compared kinetic and dynamic characteristics in these transgenic potato lines, using the well defined Vst1 and Gst1 promoters as reference. We also studied frequencies of responding lines in a collection of transgenic potato lines. For analyses of both promoters driving the UidA gene expression we employed histochemical GUS staining and real-time RT-PCR.

\section{RESULTS}

\section{Induction of the Ics gene and isolation of its promoter from Catharanthus roseus}

Van Tegelen et al. (1999) have shown that the Isochorismate synthase enzyme activity in C. roseus suspension cells was strongly induced upon fungal elicitor treatment. To show whether the transcript coding for Ics is also upregulated after pathogen infection in C. roseus plants we used a competitive RT-PCR approach. The Ics transcript was induced 100 -fold after inoculation of C. roseus plants with the oomycete $P$. cactorum. No induction of the Ics transcript was found in the uninfected parts of the same leaf (see Figure 1), which is an indication that the Ics promoter in $C$. roseus is only activated locally.

\section{Infected Control}

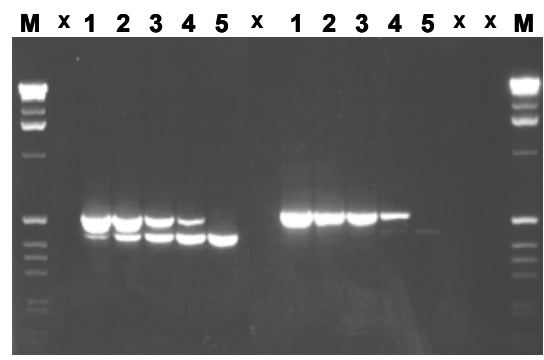

Figure 1: Typical result of a competitive RT-PCR experiment. Catharanthus roseus plants were inoculated with a Phytophthora cactorum hyphal suspension (Infected) or water (Control) and leaf discs were harvested at 48 hours after inoculation (48 hai). Catharanthus roseus CDNA was prepared and subjected to PCR with Ics specific primers in the presence of decreasing amounts of competitor (MIMIC) DNA (lanes 1 to 5). The Ics CDNA amplicon is $443 \mathrm{bp}$ (lower band) and the PCR MIMIC amplicon is $527 \mathrm{bp}$ (upper band) in size. $\mathrm{M}$ is the $1 \mathrm{~kb}$ size marker (Gibco BRL).

The Ics promoter was isolated from the C. roseus genome using an Inverse PCR approach. A 2.0 $\mathrm{kb}$ fragment upstream of the Ics Open Reading Frame was fused to the UidA reporter gene. Based on the presence of many pathogen-responsive sequence motifs in this fragment, and testing of its inducibility we assume to have successfully isolated the fully functional part of the Ics promoter (see below for details).

\section{Isolation of the $\mathrm{Ha}-\mathrm{CHOX}$ promoter from sunflower}

Competitive RT-PCR experiments in our laboratory had shown that the Helianthus annuus carbohydrate oxidase $(\mathrm{Ha}-\mathrm{CHOX})$ transcript was upregulated sharply after fungal infection in sunflower leaves (Custers et al., 2004). An inverse PCR approach was used to isolate the upstream 
regulatory sequence of the $\mathrm{Ha}-\mathrm{CHOX}$ gene. A fragment of approximately $2 \mathrm{~kb}$ was cloned and fused to the UidA reporter gene. Like for the Ics gene, analysis of the promoter sequence (see below) indicated we had most likely isolated the majority, if not all, of the regulatory elements of the Ha-CHOX promoter.

\section{Analysis of the promoter sequences used in this study}

The four promoter sequences used in our promoter analysis were compared with respect to the presence of sequence motifs known to be associated with stress and pathogen responsiveness in plants. The promoter sequences are shown schematically in Figure 2 with the different promoter elements indicated as black boxes. The chimeric Gst1/Fd promoter fragment contains one W-box motif (Eulgem et al., 2000), an ERELEE4 motif (Itxhaki et al., 1994) and one S-box motif (Kirsch et al., 2000). The $1.9 \mathrm{~kb} \mathrm{Ha-CHOX}$ promoter sequence contains three $\mathrm{W}$-box core motifs, two ERELEE4 motifs, one H-box motif (Lois et al., 1989) and one auxin responsive element (Liu et al., 1994; Ulmasov et al., 1996). The modified Vst1 promoter sequence contains a very high density of pathogen/stress responsive elements including $\mathrm{W}$-box, auxin responsive elements, $\mathrm{H}$-boxes, and an S, N (NF-KB; Lebel et al., 1998), G (Lois et al., 1989) and TCA motif (Goldsbrough et al., 1993). The Ics promoter is very rich in W-box motifs (6), contains a Myb motif (Yang and Klessig, 1996), an ERELEE4 motif and an $\mathrm{H}$-box.
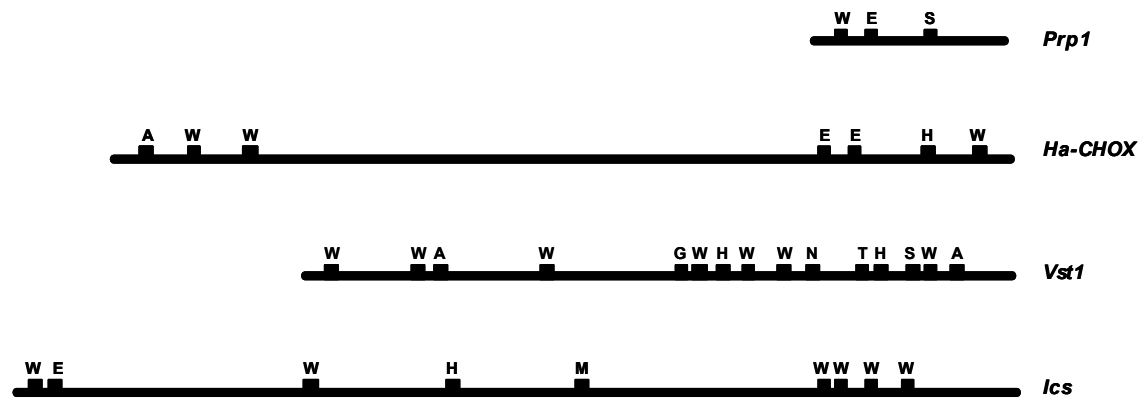

Figure 2: Schematic representations of the four promoter sequences. Putative cis elements involved in pathogen-responsiveness are indicated by black boxes; H = H-box (CCTACC, Fisher, 1994; Lois et al., 1989), W = W-box (nGTCAn, Eulgem et al., 2000), A = Auxin responsive elements (TGTCTC, Ulmasov et al., 1995), E = ERELEE4 motif (Itxhaki et al., 1994), G = G-box (CAmGTG, Lois et al., 1989), $\mathrm{S}$ = S-box (AGCCACCAnA, Kirsch et al., 2000), $\mathrm{N}=$ NFKB (GACTTTTC, Lebel et al., 1998) and T = TCA motif (TCATCTTCTT, Goldsbrough et al., 1993), M = Myb motif (Yang and Klessig, 1996).

\section{Construction of promoter-UidA fusions}

The four promoters were fused to the UidA gene with intron (Vancanneyt et al., 1990) and the terminator of the potato proteinase inhibitor II gene (An et al., 1989). The promoter fusions were made in a similar way i.e. regulatory regions, minimal promoter and 5' untranslated regions of the promoter were fused to the translation start of the UidA gene using the Nco I restriction site over the start codon ATG. This sequence is closely related to that described by Kozak (1989) for optimal translation initiation. The four promoter- UidA fusions are shown schematically in Figure 3. 


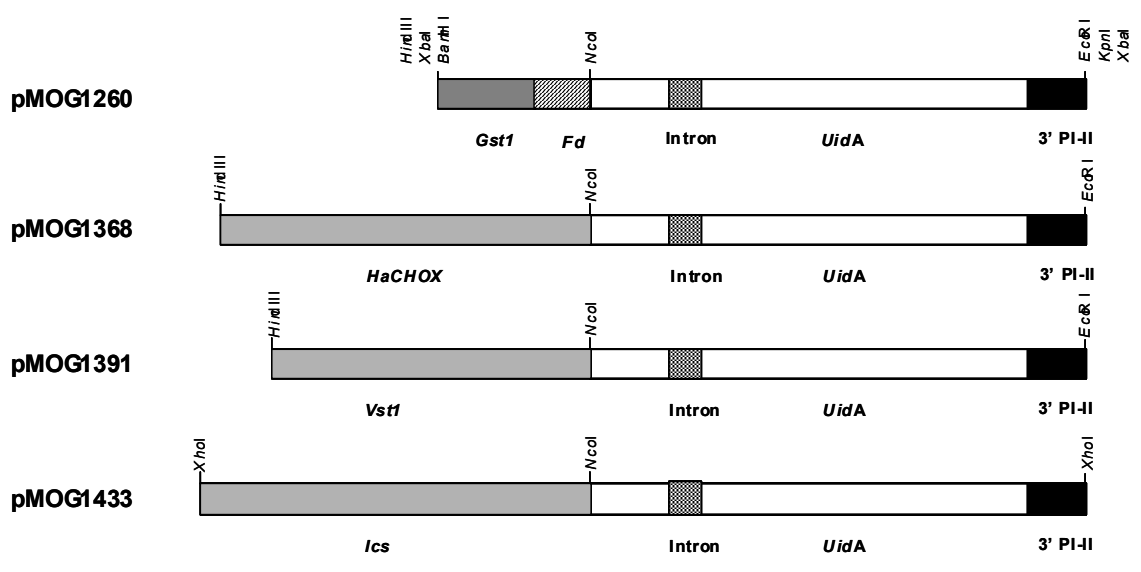

Figure 3: Promoter-UidA constructs used in this study. Promoters are indicated in grey (Gst1/Fd, Ha-CHOX, Vst1 and Ics) and the Ferredoxin minimal promoter $(F d)$ is shown as a shaded box. The UidA ORF is shown in white and the intron is depicted as a checkered box. The potato proteinase inhibitor II (3' PI-II) transcription terminator is shown in black. Restriction endonuclease sites that were used for cloning are indicated.

Response of the various promoter-UidA fusions to Phytophthora infection in transgenic potato plants

Twenty independent transgenic potato plants were made for each promoter-UidA construct and the resulting plants were inoculated with Phytophthora infestans, the causal agent of late blight of tomatoes and potatoes. Promoter activity was initially assessed using a histochemical GUS assay. GUS expression levels were monitored before and after inoculation. A summary of the performance of the various promoters is shown in Figure 4. The photographs presented show that the Vst1 and Gst1 promoters are induced very locally at the site of $P$. infestans infection. GUS expression driven by the Ics promoter in response to $P$. infestans is very low and is seen strongest in the vascular tissue of the leaf. In the potato plants containing the Ha-CHOX-UidA fusion no GUS expression could be detected by our histochemical assay. These analyses also show that the Gst1 promoter performance after Phytophthora infection is not very consistent. Even within one leaf of the best performing line, there is considerable variation in the response to $P$. infestans infection, as well as in background expression levels (data not shown). In contrast, the Vst1 promoter turns out to be a very consistent pathogen-inducible promoter. A very high percentage of the transgenic potato lines display the expression pattern as shown in Figure 4.

Properties of the Gst1, Vst1, Ha-CHOX and Ics promoters using real-time PCR

The histochemical data as described above are good for spatial analysis of expression patterns. However even quantitative GUS enzymatic analyses, such data cannot be used to determine kinetic and dynamic characteristics of the four pathogen-inducible promoters, as the GUS levels may be too low for accurate quantification in uninfected tissue, and for some promoters even after infection. Furthermore, enzymatic assays reflect the amount of enzyme product at a certain time point, which is only partly depending on promoter activity, and in addition reflects accumulation of the enzyme 
product. For this reason a real-time PCR based analysis method was used, since this is both very sensitive over a larger dynamic range and better reflects promoter activity. Please note that in our constructs, most of the reporter RNA used is identical between different promoter constructs, which reduces effects of transcript stability differences.

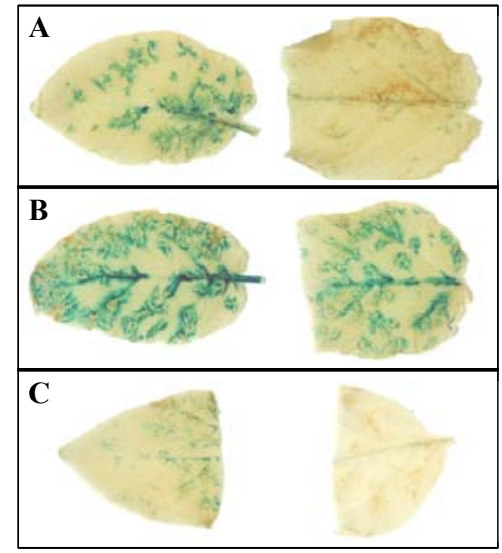

Figure 4: Figure showing examples of GUS stained potato leaves containing one of the pathogen-inducible promoter - UidA fusions. a) Gst1/Fd promoter b) Vst1 promoter c) Ics promoter. Leaves were stained for GUS expression at 48 hours after inoculation with Phytophthora infestans. Leaves from potato plants transformed with the Ha-CHOX-UidA fusion are not shown, as they did not display detectable GUS expression after infection.

Potato plants were inoculated with $P$. infestans and samples were collected at 0,12 , and 48 hours after inoculation. At all timepoints mock-inoculated controls were included in the experiment. The PCR primer combinations used in this experiment were designed not to amplify $P$. infestans-derived actin mRNA and the primer sets used were not able to generate a PCR product under the given conditions on genomic DNA extracted from $P$. infestans alone (data not shown).

The average variation between two independent PCR reactions found in our experiments corresponds to a $\mathrm{Ct}$ value of 0.5 . This translates to a change in expression level of only 2 -fold. We have performed all reactions in duplo and have averaged the $\mathrm{Ct}$ values. Thus we believe these results to provide a very careful assessment of the actual mRNA levels and induction patterns.

Table 1. Results of the histochemical GUS assay after Phytophthora infestans infections in transgenic potato plants containing the pMOG1260, pMOG1368, pMOG1391 and pMOG1433 constructs (resp. Gst1/Fd-, Ha-CHOX-, Vst1- and Ics-promoter). + = strong inducible GUS expression, \pm = weak inducible GUS expression,$-=$ no inducible GUS expression.

\begin{tabular}{lccc}
\hline & \multicolumn{3}{c}{ GUS expression } \\
& - & $+/-$ & + \\
\hline \multirow{2}{*}{ Gst1/Fd } & & & \\
Ha-CHOX & 13 & 6 & 1 \\
Vst1 & 25 & 0 & 0 \\
Ics & 2 & 8 & 15 \\
& 16 & 3 & 1 \\
\hline
\end{tabular}


The real-time PCR experiments using material derived prior to infection ( $\mathrm{t}=0 \mathrm{hr}$ ) indicate that generally the Gst1 promoter provides the highest basal expression level and the Ics promoter displays the lowest basal expression level (see Table 2). The differences between basal expression of these promoters is quite substantial. The Ics promoter construct transgenics show almost 5 times lower levels of mRNA in non-induced state than the other promoter constructs.

Table 2. Average basal expression levels and average fold induction levels of the different pathogen-inducible promoters in potato at different time points after inoculation with $P$. infestans as determined by real-time reverse transcriptase PCR.

\begin{tabular}{|c|c|c|c|c|c|}
\hline \multirow{3}{*}{ Promoter } & \multirow{3}{*}{$\begin{array}{l}\text { Basal expression } \\
\quad \mathrm{T}=0 \mathrm{hrs}\end{array}$} & \multicolumn{2}{|c|}{$\begin{array}{l}\text { Fold induction } \\
\mathrm{T}=12 \mathrm{hrs}\end{array}$} & \multicolumn{2}{|c|}{$\begin{array}{l}\text { Fold induction } \\
\mathrm{T}=48 \mathrm{hrs}\end{array}$} \\
\hline & & & & & \\
\hline & & $\begin{array}{l}\text { Average } \\
\text { induction }^{2}\end{array}$ & $\begin{array}{l}\text { Two best induced } \\
\text { lines }^{3}\end{array}$ & $\begin{array}{l}\text { Average } \\
\text { induction }^{2}\end{array}$ & $\begin{array}{l}\text { Two best induced } \\
\text { lines }^{3}\end{array}$ \\
\hline Gst1/Fd & 0.169 & 15 & $\begin{array}{l}134 \\
109\end{array}$ & 42 & $\begin{array}{c}455 \\
10\end{array}$ \\
\hline На-СHOX & 0.109 & 10 & $\begin{array}{l}52 \\
50\end{array}$ & 76 & $\begin{array}{l}982 \\
288\end{array}$ \\
\hline Vst1 & 0.107 & 28 & $\begin{array}{l}197 \\
137\end{array}$ & 120 & $\begin{array}{l}727 \\
495\end{array}$ \\
\hline Ics & 0.022 & 4 & $\begin{array}{l}22 \\
11\end{array}$ & 44 & $\begin{array}{l}267 \\
174\end{array}$ \\
\hline
\end{tabular}

${ }^{1}$ Absolute expression levels at $t=0$ relative to expression in standard line. Absolute expression levels are averages of measurements in 20 independent transgenic potato lines.

${ }^{2}$ Average induction level (fold induction) relative to mock inoculated controls $(n=20)$. Average basal expression levels $(t=0$, absolute expression levels measured) and average fold induction levels relative to the mock inoculated controls at $t=12$ and $t=48$ hours after inoculation. UidA basal and induced mRNA levels were determined using real-time RT-PCR. Induced levels were normalized to inocula lo I I N

The different Ics-UidA transgenic lines also display the lowest variation in the UidA transcript levels. The variation in basal expression levels between the Vst1 and $\mathrm{Ha}-\mathrm{CHOX}$ transgenics is comparable, while the Gst1 transgenics show substantial variations in both assays. Some lines show high mRNA levels even before infection, while they show weak GUS activity in the GUS histochemical assay. At 12 hours after inoculation clear differences can be seen between the responses of the four promoters (see Tables 1 and 2). The Vst1 promoter responds quite well to $P$. infestans infection, with an average 28-fold increase in induction classifying it as the best responding promoter. The two lines with the highest relative level of induced expression (197-fold and 137-fold) are also Vst1-transgenic lines. A few lines with the Gst1 promoter construct display greater than 10-fold induction of the UidA transcript, indicating that also this promoter can respond strongly to the infection at this time point. Only 2 out of the 18 successfully analyzed Ics-UidA lines show a substantial (>10-fold) increase in expression after infection. There are also quite marked differences in the fidelity of the promoters (Table 3). Vst1 is responding most consistent, with $42 \%$ (8/19 lines) showing over 10-fold increase in expression. Gst 1 has only 2 strong responders from 19 lines successfully analysed $(11 \%)$. In contrast to the early time point (12h), at 48 hours after inoculation, the Ics-UidA transgenics show strongly increased GUS transcript levels in many lines ( $58 \%$ of the lines show more than 10 -fold induction, with an average induction of 44 -fold), indicating 
that the promoter is consistent and strongly induced at this time point. Likewise, the $\mathrm{Ha}-\mathrm{CHOX}$ promoter comes on quite strongly at $48 \mathrm{hrs}$, with an average induction of 76 -fold. Most Vst1 promoter-transgenics show high levels of expression after infection, on average 120-fold above the basal level. Again the Gst1-UidA transgenics show high UidA transcript levels in only a few lines at 48 hours after inoculation. The Ha-CHOX promoter has a similar induction frequency as the Gst1 promoter.

Analysis of uninfected controls showed that detaching leaves and placing them in petridishes for a maximum of 48 hours had only limited effect on the UidA transcript levels (data not shown). For the Gst1 and Vst1 promoters the increase in UidA transcript levels in control samples until 48 hours is 3.5 fold, which is modest compared to the inductions seen. In the case of the Ics and Ha-CHOX promoters this increase in transcript level as a result of the control treatment is respectively 5 and 10 fold.

Table 3. Percentage responding lines (at least 10 -fold relative to actin control and UidA levels at $t=0$ ) in potato detached leaves at $=12$ and $\mathrm{t}=48$ hours after inoculation with $P$. infestans.

\begin{tabular}{ccc}
\hline Promoter & $\begin{array}{c}\text { \% responders 12 } \text { hai }^{1} \\
(>10 \text {-fold })\end{array}$ & $\begin{array}{c}\text { \% responders 48 } \text { hai }^{1} \\
(>10 \text {-fold })\end{array}$ \\
\hline Gst1/Fd & 11 & 8 \\
Ha-CHOX & 14 & 37 \\
Vst1 & 42 & 56 \\
Ics & 11 & 58 \\
\hline
\end{tabular}

${ }^{1}$ Responsive lines were selected bases on absolute expression levels at $t=12$ hai or $t=48$ hai of at least 10 -fold compared to absolute expression level at $t=0$. Absolute expression levels of UidA transcripts were determined using real time reverse transcriptase PCR relative to potato actin mRNA levels. hai = hours after inoculation.

\section{DISCUSSION}

The successful development of transgenic plants with broad-spectrum pathogen resistance requires the availability of promoters that are specifically activated after pathogen attack. Many pathogenresponsive genes have been identified but the promoters of most of them have been characterised poorly and often only in a model plant. The aim of the work described in this paper was to identify and isolate novel pathogen-inducible promoters and to make a careful assessment of their pathogen-responsiveness in the crop plant potato. This was achieved by analyzing 20 independent transgenic lines of each promoter-UidA fusion construct for basal expression levels, induced expression levels and induction over time. Furthermore, their characteristics were benchmarked against two well-characterized pathogen inducible promoters. To this end, we used a combination of histochemical GUS staining and real time reverse transcriptase PCR and were able to determine kinetic, dynamic and spatial expression properties of these promoters.

\section{Expression profiles of the promoters in potato}

\section{Ics promoter}

Catharanthus cells treated with fungal elicitors display an increased isochorismate synthase activity (Moreno et al., 1994; Van Tegelen et al., 1999). Competitive RT-PCR experiments in C. roseus plants challenged with an oomycete showed that the isochorismate synthase transcript is also induced after pathogen infection. In later studies it was shown that in Arabidopsis mutants lacking the homologue ICS enzyme activity, pathogen-inducible salicylic acid accumulation is absent 
(Wildermuth et al., 2001). The same authors have shown that Ics1 transcript accumulation in Arabidopsis is correlated with the expression of $P R 1$, a marker of systemic acquired resistance (SAR) and the accumulation of salicylic acid. When comparing their basal expression level, i.e. the expression level before infection, it is evident that the C. roseus Ics promoter has the lowest basal expression level. The expression levels of the other three promoters are in a similar range (approximately 5 times higher than for the Ics promoter). The Ics-gene product homologue from Arabidopsis is involved in synthesizing salicylic acid after pathogen challenge (Wildermuth et al., 2001). Salicylic acid is a key hormone in triggering an increased state of defence and continuous exposure of a plant to this hormone is known to affect plant growth and may even increase susceptibility to other pathogens (Felton et al., 1999; Yalpani et al., 2001). Very strict regulation of Ics gene expression might therefore be crucial. This appears to be reflected in the behaviour of our promoter test constructs.

The induction characteristics of the promoters are quite different. The Ics promoter is induced relatively weakly at the 12 hours timepoint, with an average 4-fold induction, but does increase to a quite good 44 -fold average to the 48 -hour timepoint. The best lines have 174 - and 267 -fold induced levels over mock-treated controls at that timepoint. The Ics promoter classifies itself as a relatively late and reliable promoter with extremely low background expression.

\section{Ha-CHOX promoter}

One line harbouring the $\mathrm{Ha}-\mathrm{CHOX}$ promoter displays the strongest induction of all lines tested (982fold). On average this promoter is performing well which was not expected regarding the results of the histochemical GUS assay. We have no explanation why these potato lines do not show detectable GUS expression (since the basal expression level is comparable to Gst1 and Vst1). It seems very likely that the translation efficiency is very low due to sequences in the 5 ' untranslated region (UTR) of the $\mathrm{Ha}-\mathrm{CHOX}$ promoter. Alternatively there is a strong effect of the leader sequences on the translatability of the heterologous reporter gene. The sunflower $\mathrm{Ha}-\mathrm{CHOX}$ gene is induced after pathogen infection and treatment with high concentrations of Salicylic acid. The protein it codes for, $\mathrm{Ha}-\mathrm{CHOX}$, a carbohydrate oxidase, has a hydrogen peroxide generating role in response to pathogen infection (Custers et al., 2004). It is not clear whether the hydrogen peroxide produced by this enzyme is contributing to pathogen resistance in sunflower but the same authors have shown that overexpression of the enzyme in tobacco enhances resistance to pathogenic bacteria.

\section{Vst1 promoter}

The stilbene synthase gene isolated from grapevine codes for the enzyme involved in the production of the phytoalexin precursor resveratrol (Wiese et al., 1994; Coutos-Thevenot et al., 2001). Generally, phytoalexin synthesis and also PR-protein expression are not part of the initial responses but these compounds accumulate later during pathogen infection (Van Camp et al., 1998). Expression of the SBS open reading frame under control of a heterologous promoter in tobacco and grapevine results in increased resistance to fungal pathogens (Hain et al., 1993; Coutos-Thevenot et al., 2001). Interestingly, it comes on very strongly at the earliest timepoint after infection and is induced up to 727 -fold in the best line, and thus shows a very high dynamic range of expression. The behaviour in these transgenic lines is not entirely consistent with the late 
accumulation of phytoalexins, and one is left to wonder whether the RNA accumulation does not proceed in a dramatic way as the accumulation of stilbene synthase protein.

\section{Gst1/Fd promoter}

Gst1, member of the group of genes encoding Glutathione S-transferases, respond to various stress conditions amongst which oxidative stress. The plant oxidative burst in response to pathogen infection is one of the earliest responses and consists of a pulse of active oxygen species (AOS) and the first Gst mRNA can already be detected 1 hour after infection (Van Camp et al., 1998). One would expect that the Gst1 promoter should be able to respond to pathogen infection very fast.

In line with the rapid induction known for this class of genes we see rapid and somewhat transient induction. Although the average induction at 48 hours is significantly higher than that at 12 hours, this effect is only caused by one line that has a 455 -fold induced level at the latter timepoint. The second best line has only a 10 -fold induced level. It is hard to say whether this one line represents the 'typical' performance of the Gst1 promoter, or whether this line has an aberrant expression due to a very unusual chromosomal location of the T-DNA insert. Since the 'Gst1 promoter' constitutes only part of the native promoter (Martini et al., 1993), which according to Martini et al. performed better than the native Gst1 promoter, it is unclear whether the native promoter behaves similarly.

\section{Translational regulation}

We do note that our relative induction of mRNA accumulation is much higher than that measured by other research published on the promoters. The maximum induction factor observed for the native Vst1 promoter tested in tobacco is 72 -fold (Fischer, 1994) and we scored a maximum induction of RNA levels of more than 700 -fold. In these previous reports, however, induction characteristics of the promoters were in each case determined using quantitative GUS enzyme assays that are a poor reflection of promoter activity at a certain timepoint as this only measures enzyme synthesis and accumulation. As stated above, we also measured a relatively low GUS accumulation in the Vst1derived lines, which could reflect the poor translatability of the UidA sequences following the 5'UTR. Also in the case of the Ha-CHOX promoter, the level of mRNA accumulation does not seem to reflect the level of protein/GUS stain accumulation. For the Ics promoter also, we expected to have seen GUS staining, especially when the RNA accumulation data is compared with that of Gst1.

Since this effect is observed in most of the promoters tested, we anticipate significant regulation with pathogen-inducible promoters at the level of translation, most likely mediated by the $5^{\prime}$ UTR sequences. The four transformation vectors containing the pathogen-inducible promoters that were compared in potato were all cloned in a similar way. Fusion to the UidA ORF was in each case accomplished by introduction of the Nco I endonuclease recognition site overlapping the ATG translation start. For this purpose only limited nucleotide changes were introduced in the upstream sequences at positions -1 and -2 relative to the translation start to facilitate introduction of this Nco I site. The translation initiation sequences around the ATG startcodon for all four promoter-UidA fusions closely match the optimal translation initiation consensus sequence as proposed by Kozak (1989). This approach was chosen also because the transcription start sites have not been mapped in detail. Also, initiator sequences around the transcription start may interfere with the level of expression, and we did not want to interfere with these. The mRNAs in the different constructs from 
the ATG start codon to the poly-A tail are identical, and we believe this study in that respect to be as thorough as technically possible.

Note that we did not find this apparent discrepancy between high transcript level and low protein/stain accumulation in case of the Gst1 promoter, which has heterologous minimal promoter and 5'UTR sequences. Our choice for this variant was based on the work of Martini et al. (1993). The UidA and 3'UTR sequences are identical for all reporter constructs. Therefore we anticipate the translational control most likely due to sequences within the 5'UTR. Leader sequences have been shown to be able to suppress gene expression, in some cases due to the presence of uORFs (Curie and McCormick, 1997; David-Assael et al., 2005). Computer prediction of the transcription start of the $\mathrm{Ha}-\mathrm{CHOX}$ promoter and analysis of the predicted 5'UTR revealed possible uORFs in the $\mathrm{Ha}$ CHOX 5'UTR (data not shown). In this case, the translational regulation might be part of a tight enzyme expression control mechanism of the carbohydrate oxidase in plants. Since the enzyme is able to catalyse the conversion of a number of commonly occurring sugars, leading to the formation of hydrogen peroxide, this translational control may be an additional safeguard for the plant A direct comparison of our data with these of others is somewhat complicated by the fact that most other reports describe a very limited number of independent transgenic lines. We have used 20 independent transgenic lines in our study and thus have been able to make a careful assessment of promoter performance and the consistency of the specific promoter-reporter gene constructs.

\section{Variability in expression between plant lines}

For transgenic approaches to be efficiently applied, consistency and predictability of transgene expression is crucial. The genomic location where the construct is inserted is of major importance. Sequences flanking the T-DNA, and especially in our case were the promoter is positioned at the right border repeat, can influence promoter performance significantly (Breyne et al., 1992; Matzke and Matzke 1998).

The number of T-DNA copies present in a transgenic line can have an effect on promoter performance as well. When more than one T-DNA copy is present, promoter function measured can be a combination of the expression patterns driven by the different T-DNA loci or expression can be affected by cosuppression (Hobbs et al., 1993; Matzke and Matzke, 1998). The transgenic lines tested in this study where not tested for T-DNA copy number and may therefore contain multiple copies of T-DNA. Assessment of T-DNA copy numbers may reveal a relationship between expression levels/patterns and the number of T-DNA copies present. However, for molecular resistance breeding in potato, mostly performed through clonal propagation, multiple T-DNA copies are all expected to be passed on to next generations and consequently the specific expression characteristics will be maintained.

We assume that the distribution of different copy number lines over the population used is similar, because of the size of the population. Nevertheless, we do see marked differences between the sets of transformants made with different constructs.

The Gst1 promoter, e.g. has very high variability between lines. The best line showed massive induction, (450 fold), the second best significantly lower (10x) and many of the lines show no induction at all. The Vst1 promoter, on the other hand, shows good induction in 5 of the lines made, and also the maximal level of induction between these 5 are quite similar. We assume that the larger size of the promoter, maybe in combination with the number of binding sites for transcription 
factors may influence this increased stability in expression between individual lines. We therefore would propose to use longer promoters with more binding sites wherever possible.

\section{Potential use of the pathogen-inducible promoters}

The availability of suitable pathogen-inducible promoters is crucial for the development of biotechnological strategies for pathogen resistance. The promoters analysed in this paper all have different characteristics in potato and may therefore be suitable for diverse applications. The potato Gst1 promoter has been used successfully in our company to engineer broad-spectrum pathogen resistance in tomato in combination with the C. fulvum Avr9 gene (Stuiver et al., unpublished results) and has also been used to drive expression of the Bacillus amyloliquefaciens barnase gene to trigger pathogen-induced cell death (Strittmatter et al., 1995). This promoter can respond strongly and quickly to pathogen infection but seems to be rather unreliable. The $\mathrm{Ha}-\mathrm{CHOX}$ promoter has a high dynamic range but seems to be activated later than Gst1. A higher percentage of lines do show Phytophthora-responsiveness, though. The grapevine Vst1 promoter is a very reliable and fast pathogen-inducible promoter. The fact that it is also wound responsive and very sensitive to other stress conditions makes it less suitable for driving expression of elicitor genes (Fischer, 1994; Schubert et al., 1997). However, Vst1 might be very suited to express antipathogenic proteins like plant defensins or proteins that are able to degrade fungal cell walls (e.g. chitinases, glucanases) upon pathogen infection. The Ics promoter is upregulated rather slow but has a good dynamic range and has the lowest basal expression level of the four promoters tested. This promoter might be an excellent choice in combination with HR elicitors with a very high specific activity or could also be used for the pathogen-induced production of antimicrobial compounds that are highly phytotoxic.

The combination of histochemical GUS assays and real time RT-PCR analysis described in this paper are excellent tools for analysing promoter-UidA fusions. In contrast to the often-used fluorimetric GUS assays, this combination of techniques can accurately measure mRNA levels at a certain timepoint and can give qualitative and quantitative information about promoter performance. We did see some inconsistency when the results of the histochemical assays were compared with the real time PCR data. This was not unexpected because two completely different parameters are measured here (protein accumulation levels vs. mRNA levels) and the limits of detection are quite different as well. A drawback of the methods described here is that they are both destructive to the plant, which makes measurements over time in one sample impossible. An alternative method is the use of non-destructive markers like the firefly luciferase enzyme (LUC) or the jellyfish green fluorescent protein (GFP) to facilitate measurements in a single plant or leaf during a certain period of time. Especially the relatively unstable and sensitive luciferase enzyme would be suited to measure expression changes over a certain time period (Jordá and Vera, 2000; Van Leeuwen et al., 2000). Drawback of using luciferase, is that in some cases the substrate Luciferin is able to induce expression of PR-genes and therefore interferes with the analysis (Jordá and Vera, 2000).

We have shown that using a combination of a real time RT-PCR approach and conventional histochemical GUS analysis it is possible to analyse and compare different pathogen-inducible promoter-UidA fusions with respect to qualitative properties, basal expression levels, dynamic characteristics, kinetics and reliability. Two novel pathogen-inducible promoters were cloned and 
characterized in potato and compared to the Gst 1 and Vst1 promoters. This was shown in the crop plant potato in combination with the oomycete Phytophthora infestans. The newly identified and characterized pathogen-inducible promoters will aid in the development of transgenic potato plants with enhanced resistance against Late blight. Evaluation of these promoters driving effect genes, e.g. elicitors of the HR, in pathogen resistance trials will provide crucial information about the predictive value of such an analysis. A promoter analysis as described in this paper can be applied to analyse other promoters as well, will be important in the development of transgenic plants with various traits and will improve and accelerate the testing and design of plant promoters with diverse characteristics.

\section{MATERIALS AND METHODS}

\section{Competitive RT-PCR on Catharanthus roseus plant material}

C. roseus plants $(50 \mathrm{~cm}$ in size) were inoculated with a droplet of a Phytophthora cactorum hyphal suspension on a small incision in the leaf. Pathogen infection was allowed to proceed at $18^{\circ} \mathrm{C}$ at $90 \% \mathrm{RH}$. Leaf disks $(13 \mathrm{~mm})$ were harvested at 2 and 6 days after inoculation from the infected zone and distal, non-infected areas. Poly-A+ RNA was harvested from 3 such leaf disks (100 mg of leaf tissue), from independent infections, using the Quickprep Micro mRNA purification Kit (Amersham Pharmacia Biotech, Uppsala, Sweden). Poly-A+ RNA (100 ng) was used to synthesize cDNA using Superscript II (RNAse H-free) reverse transcriptase (Gibco BRL) and 0.1 nmole oligo(dT)12-18 primers (Gibco BRL). Samples were analysed by competitive PCR (Siebert and Larrick, 1992). The PCR MIMIC, which served as a competitor in the CRT-PCR experiments, was constructed as follows. A fragment of 527 bp from the plasmid pUC18 (Yanisch-Perron et al., 1985) was amplified using primers 5'ATA GAA ACG AGG ACA CTT CCA CGT TAA GGG ATT TTG G3' and 5'ATA AGC ACG GAT TAA TGG GCC GGA GCT GAA TGA AGC C3'. This MIMIC was then further amplified with primers 5'ATA GAA ACG AGG ACA CTT CC3' and 5'ATA AGC ACG GAT TAA TGG GC3'. These latter two primers will amplify a band of $443 \mathrm{bp}$ from the Isochorismate synthase (Ics) CDNA and $527 \mathrm{bp}$ of the MIMIC template. PCR MIMIC serial dilutions were made in a range of $0.1 \mathrm{pg}, 10 \mathrm{fg}, 1 \mathrm{fg}$ and $0.1 \mathrm{fg}$ and combined with cDNA derived from $10 \mathrm{ng}$ Poly-A+-RNA per $50 \mu \mathrm{IPCR}$ reaction. Amplification of CDNA and MIMIC was performed using $10 \mu \mathrm{M}$ of the primers described above, and using $0.2 \mathrm{mM}$ dNTPs and $2.5 \mathrm{U}$ recombinant Taq DNA polymerase (Gibco BRL) and was allowed to proceed for 35 cycles, $1^{\prime} 95^{\circ} \mathrm{C}, 1^{\prime} 55^{\circ} \mathrm{C}, 2^{\prime} 72^{\circ} \mathrm{C}$.

\section{Isolation of the Ics promoter from C. roseus}

PCR primers were developed based on the sequence of the Ics CDNA (Genbank accession number: AJ006065). Primers 5'TGG TGA TCC AAG AGC TCC GG3' and 5'CCT GGT TGA AAG GTC TGT G3' were used for inverse PCR (iPCR) using primer 5'GCA ACA CAA TGC CCT GTG3' for a second round 'nested' amplification. C. roseus genomic DNA was isolated (Fütterer et al., 1995) and subjected to restriction enzyme digestion with five different enzymes, Dde I, Kpn I, Msc I, Nco I or Nla IV. The fragmented DNA was circularised by DNA ligation and used as a template in a PCR reaction with 25 pmol primers as described above. Then the reaction was used for 'nested' PCR. The resulting PCR bands from the Kpn I, Nco I and Nla IV digestions were cloned and sequenced. PCR primers were developed based on the DNA sequence of the cloned IPCR fragments. These primers were located at the far upstream part of the promoter and at the ATG 
translational startcodon of the lcs open reading frame (ORF). Primer 5'GCA AGC TTC ATG TAC CTT ATC TTG GCC3' is located upstream of the promoter and introduces a Hind III restriction site and primer 5'TAG ATG CCA TGG GAT GGG AG3' is located at the startcodon of the Ics ORF introducing a Nco I restriction site overlapping the ATG codon of the translational start. Using these primers a promoter fragment of approximately $3 \mathrm{~kb}$ was cloned. A $2 \mathrm{~kb}$ lcs promoter fragment was cloned in front of the UidA reporter gene containing an intron using Xho I and Nco I (Vancanneyt et al., 1990). The UidA ORF is followed by the 3 ' untranslated region of the potato proteinase inhibitor Il gene (An et al., 1989). This expression cassette was susbsequently cloned in a binary vector (Sijmons et al., 1990). The sequence of the Ics promoter can be found in GenBank under accession number AY555149.

\section{Isolation of the $\mathrm{Ha}-\mathrm{CHOX}$ promoter from sunflower}

The isolation of the Ha-CHOX promoter from the sunflower genome was essentially done in a similar manner as described for the Ics promoter. Genomic sunflower DNA was digested with the restriction enzyme Hind III. Primers 5'CAG GCA GCT GTG GTT TGT GGC3' and 5' CGG GAA GTT GCA GAA GAT TGG GTT G3' were used in Inverse PCR reactions. Nested PCR was performed as described but now with nested primers 5'ACG TAG ATA TCG AAC AAG AAA CCG C3' and 5'GAG CAA GAG AAG AAG GAG AC3'. A $1.9 \mathrm{~kb}$ iPCR band was isolated from gel and the DNA sequence was determined. Based on the DNA sequence, new primers were designed for the amplification of the Ha-CHOX promoter region from the sunflower genome. Primer 5'GCA AGC TTT ATA GTT TAC GAT CC3' is located in the upstream part of the Ha-CHOX promoter region overlapping the Hind III restriction site. Primer 5'TTG CCA TGG TGC ATG GTT TAG CG3' overlaps the translational start introducing an $\mathrm{Nco}$ I restriction site over the ATG startcodon. A Ha-CHOX promoter-UidA fusion and binary vector was made essentially as described for the Ics promoter. The sequence of the Ha$\mathrm{CHOX}$ promoter can be found in GenBank under accession number AF472609.

\section{Construction of the Gst1/Fd chimeric promoter}

To construct the Gst1/Fd chimeric pathogen-inducible promoter the Gst1 transcription regulation domain (-402 till -165) Genbank accession number: J03679; (Martini et al., 1993) was linked to the minimal promoter and leader sequence from the Arabidopsis ferredoxin gene Fd2 (Genbank accession number: X51370; Vorst et al, 1990) containing nucleotides -40 to +50 relative to the transcription start. The two regions were joined by overlap extension PCR (Horton et al., 1990). The promoter region was fused to the UidA reporter gene and the 3' untranslated region of the potato proteinase inhibitor II gene (An et al., 1990) and subsequently transferred to a binary vector as described above.

\section{Construction of the Vst1 promoter}

The Vst1 promoter was assembled from two different regulatory domains, removing the identified ozone-responsive element, which is present between -280 and -430 relative to the start of transcription (Schubert et al., 1997). To construct this Vst1 promoter, the 2 different fragments of the Vst1 promoter were amplified using primers 5' CCG AAG CTT CCC CGG ATC ACA TTT CTA TG 3' and 5' GCG AGA TCT ACG TAA CAT GTC ATT TAA C 3' to amplify the -1500/-430 fragment and primers 5' GCG GAT CCA GGG GCT CGA AAA GTC TTT ATC 3' and 5' GAA GCC ATG GTT CCT 
AGC TAC 3' to amplify element -280/+70 pEV5+ which contains 1570 bp Vst1 upstream sequence. The underlined nucleotides in the primers represent restriction sites that were used to clone the Vst1 promoter fragments. The fragments were joined using the $\mathrm{Bgl} I \mathrm{I}$ and $\mathrm{BamH} I$ restriction sites. The Nco I site was used for fusion of the promoter directly to the translation start of the UidA-gene and was transferred to a binary vector as described above for the other promoters.

\section{Agrobacterium-mediated transformation of potato}

Binary vectors were transferred to Agrobacterium tumefaciens strain EHA105 (Hood et al., 1993) by electroporation. The binary vectors pMOG1260 (Gst1/Fd), pMOG1368 (Ha-CHOX), pMOG1391 (Vst1) and pMOG1433 (Ics) were transferred into potato (Solanum tuberosum c.v. Russet Burbank) using stem explants as described by Bade et al. (2003).

\section{$P$. infestans infection assays on detached potato leaves}

Promoter induction was tested using GUS histochemical staining in the leaves of full-grown (4week-old) potato plants after inoculation with $P$. infestans. Before inoculation, some leaves were detached and stained for expression of GUS in the absenc of pathogen. Then the plants were sprayed with a zoospore suspension of $5 \times 10^{5} \mathrm{spores} / \mathrm{ml}$ and the infection was allowed to develop for 2 days (48 hours). Again leaves were detached and stained for the expression of GUS. Histochemical GUS assays were basically performed as described by Bade et al. (2003).

For real time PCR experiments, twenty independent potato (cv. Russet Burbank) plants transformed with pMOG1260, pMOG1368, pMOG1391 or pMOG1433, were grown for 5 weeks in the greenhouse. Two adjacent leaves per plant were detached and placed in a Petri dish with a moist piece of paper in the cover in order to reach a high level of relative humidity. One of the leaves was spray-covered with a suspension of $40.000 P$. infestans zoospores $/ \mathrm{ml}$ and the other leaf sprayed with water served as an uninfected control. Leaves were incubated in an 8 hours dark, 16 hours light regime at $18^{\circ} \mathrm{C}$ and leaf samples were taken directly after spraying ( $\mathrm{t}=0 \mathrm{hrs}$ ) and at 12 and 48 hours after spraying.

\section{Real-time cDNA PCR experiments}

Leaf samples were ground in the Retsch MM300 Mixer Mill and RNA was isolated using the RNeasy 96 kit from Qiagen. Contaminating DNA was removed by Deoxyribonuclease I (DNase I from Gibco BRL) treatment, as described by the manufacturer. Equal volumes of RNA (10 $\mu \mathrm{l})$ were used to synthesize cDNA using 200 units of Superscript II RT RNAse H- reverse transcriptase (Gibco BRL) and $1 \mu \mathrm{l}$ oligo(dT)12-18 primers $(500 \mu \mathrm{g} / \mathrm{ml}$, Gibco BRL) as described by the manufacturer.

The Taqman experiments were performed with the following primers for Gus: GusC: 5'AGG TGC ACG GGA ATA TTT CG3'; GusRC: 5'ACG CGT CGG GTC GAG TT3'; GusCprobe: 5'CCA CTG GCG GAA GCA ACG CG3'. This probe has been labeled with a 6-FAM fluorescent dye for fluorometric detection. For amplification of the actin cDNA we used: ActinforwardC: 5'TGA AGG AGA AGT TGT CTT ACA TTG CT3'; ActinreverseC: 5'GAA GCT CAT AGC TCT TCT CAA CAG AT3'; ActinCprobe: 5'TGA CTA TGA ACA AGA AAT TGA AAC AGC TAA GAC CAG3'. This probe has been labeled with a VIC fluorescent dye for fluorometric detection. Relative abundance of the cDNAs from these transcripts was determined by Taqman analysis. Each sample was measured 
twice, in different runs. The Taqman assays were run on an ABI7700 with the following thermal cycler conditions: 1 cycle $2^{\prime} 50^{\circ} \mathrm{C}, 10^{\prime} 95^{\circ} \mathrm{C} ; 40$ cycles $0.15^{\prime} 95^{\circ} \mathrm{C}, 1^{\prime} 60^{\circ} \mathrm{C}$.

In every run cDNA from a control transgenic 35S-UidA plant (in triplicate) was included and the mean outcome obtained by this analysis was used to normalise the reactions. The relative UidA vs. actin expression in this line was set at 1.0. With this method relative expression levels were determined allowing different plants to be compared, even those analysed in different runs of the analysis. For the determination of expression levels, mock-infected leaves were also consistently analysed for UidA and actin expression. Only measurements where both actin and UidA levels could be determined for the mock- and pathogen-infected samples were included in the final analysis. Therefore, for some time points, data of less than 20 plants could only be incorporated in the final computational analysis, although they were all tested.

\section{ACKNOWLEDGMENTS}

The authors would like to thank Professor Pierre de Wit for reading the manuscript and for helpful suggestions. Dr. Marianne Verberne, Leiden University is thanked for providing the Catharanthus roseus plants. Dr. Carol Stanger, Syngenta Jealott's Hill International Research Centre, UK, is thanked for assistance with the development of the UidA and actin specific real time PCR assays.

\section{REFERENCES}

An, G., Mitra, A., Choi, H.K., An, K., Thornburg, R.W. and Ryan, C.A. 1989. Functional analysis of the 3' control region of the potato wound-inducible proteinase inhibitor II gene. Plant Cell 1(1): 115-122.

Bade, J., Van Grinsven, E., Custers, J., Hoekstra, J. and Ponstein, A. 2003. T-DNA tagging in Brassica napus as an efficient tool for the isolation of new promoters for selectable marker genes. Plant Mol. Biol. 52: 53-68.

Belbahri, L., Boucher, C., Candresse, T., Nicole, M., Ricci, P. and Keller, H. 2001. A local accumulation of the Ralstonia solanacearum PopA protein in transgenic tobacco renders a compatible plant-pathogen interaction incompatible. Plant J. 28(4): 419430 .

Berrocal-Lobo, M., Molina, A. and Solano, R. 2002. Constitutive expression of ETHYLENE-RESPONSE-FACTOR1 in Arabidopsis confers resistance to several necrotrophic fungi. Plant J. 29(1): 23-32.

Breyne, P., Gheysen, G., Jacobs, A., Van Montagu, M. and Depicker, A. 1992. Effect of T-DNA configuration on transgene expression. Mol Gen Genet. 235(2-3): 389-396

Cao, H., Li, X. and Dong, X. 1998. Generation of broad-spectrum disease resistance by overexpression of an essential regulatory gene in systemic acquired resistance. Proc. Natl. Acad. Sci. USA 95: 6531-6536.

Coutos-Thevenot, P., Poinssot, B., Bonomelli, A., Yean, H., Breda, C., Buffard, D., Esnault, R., Hain, R. and Boulay, M. 2001. In vitro tolerance to Botrytis cinerea of grapevine 41B rootstock in transgenic plants expressing the stilbene synthase Vst1 gene under the control of a pathogen-inducible PR 10 promoter. J Exper. B. 52(358): 901-910.

Curie C. and McCormick S., 1997.A strong inhibitor ofgene expression in the 5' untranslated region of the pollen-specific LAT59 gene of tomato. Plant Cell 9: 2025-2036.

Custers J.H.H.V., Harrison S.J., Sela-Buurlage M.B., Van Deventer E., Lageweg W., Howe P.W., Van der Meijs P.J., Ponstein A.S., Simons L.H., Melchers L.S. and Stuiver M.H., 2004. Isolation and characterisation of a class of carbohydrate oxidases from higher plants, with a role in active defence. Plant J. 39(2): 147-160.

David-Assael O., Saul H., Saul V., Mizrachy-Dagri T., Berezin I., Brook E. and Shaul O., 2005. Expression of AtMHX, an Arabidopsis vacuolar metal transporter, is repressed by the $5^{\prime}$ untranslated region of its gene. $\mathrm{J}$ Exp Bot. 56(413): 1039-1047.

De Wit, P.J.G.M. 1992. Molecular characterisation of gene-for-gene systems in plant-fungus interactions and the application of avirulence genes in control of plant pathogens. Ann. Rev. Phytopathol. 30: 391-418.

Eulgem, T., Rushton, P.J., Robatzek, S. and Somssich, I.E. 2000. The WRKY superfamily of plant transcription factors. Trends Plant Sci. 5(5): 199-206.

Eyal, Y., Meller, Y., Lev-Yadun, S. and Fluhr, R. 1993. A basic-type PR-1 promoter directs ethylene responsiveness, vascular and abscission zone-specific expression. Plant J. 4(2): 225-234. 
Felton G.W., Korth K.L., Bi J.L., Wesley S.V., Huhman D.V., Mathews M.C., Murphy J.B., Lamb C. and Dixon R.A. 1999. Inverse relationship between systemic resistance of plants to microorganisms and to insect herbivory. Curr. Biol. 9: 317-320.

Fisher, R. 1994. Optimierung der heterologen expression von stilbensynthasegenen für den pflanzenschutz. Ph.D. thesis, University of Hohenheim, Germany.

Fütterer, J., Gisel, A., Iglesias, V., Klötti, A., Mittelsten Scheid, O., Neuhaus, G., Neuhaus-Url, G., Schrott, M., Shillito, R., Spangenberg, G. and Wang, Z.Y. 1995. Isolation of genomic DNA from plants. In: Gene transfer to plants; Potrykus, I.; Spangenberg, G. Eds. Springer Verlag: Berlin, 1995; pp 215-218.

Glazebrook, J. 2001. Genes controlling expression of defence responses in Arabidopsis - 2001 status. Curr. Opin. Plant Biol. 4: 301-

Goldsbrough, A.P., Albrecht, H. and Stratford, R. (1993) Salicylic acid-inducible binding of a tobacco nuclear protein to a $10 \mathrm{bp}$ sequence which is highly conserved amongst stress-inducible genes. Plant J. 3(4): 563-71.

Hain, R., Reif, H.J., Krause, E., Langebartels, R., Kindl, H., Vornam, B., Wiese, W., Schmelzer, E., Schreier, P.H. and Stocker, R.H. 1993. Disease resistance results from foreign phytoalexin expression in a novel plant. Nature 14: 153-156.

Hobbs, S.L.A., Warkentin, T.D. and Delong, C.M.O. 1993. Transgene copy number can be positively or negatively associated with transgene expression. Plant Mol. Biol. 21: 17-26.

Hood, E.E., Gelvin, S.B., Melchers, L.S. and Hoekema, A. 1993. New Agrobacterium helper plasmids for gene transfer to plants. Transgenic res. 2: 208-218

Horton, R.M., Cai, Z.L., Ho, S.N. and Pease, L.R. 1990. Gene splicing by overlap extension: tailor-made genes using the polymerase chain reaction. Biotechniques 8(5): 528-535.

Itxhaki, H., Maxson, J.M. and Woodson, W.R. 1994. An Ethylene-responsive enhancer element is involved in the senescence-related expression of the carnation Glutathione-S tranferase (GST-1) gene. Proc. Natl. Acad. Sci. USA 91: 8925-8929.

Jordá, L. and Vera, P. 2000. Local and systemic induction of two defence-related subtilisin-like protease promoters in transgenic Arabidopsis plants. Luciferin induction of PR gene expression. Plant Physiol. 124: 1049-1057.

Keller, H., Pamboukdjian, N., Ponchet, M., Poupet, A., Delon, R., Verrier, J-L., Roby, D. and Ricci, P. 1999. Pathogen-induced elicitin production in transgenic tobacco generates a hypersensitive response and non-specific disease resistance. Plant Cell 11: 223-235.

Kirsch, C., Logemann, E., Hahlbrock, K., Rushton, P. and Somssich, I. 2000. Chimeric promoters capable of mediating gene expression in plants upon pathogen infection and uses thereof. International Patent Publication WO 00/29592.

Kozak, M. 1989. The scanning model for translation: An update. J. Cell Biol. 108: 229-241.

Lebel, E., Heifetz, P., Thorne, L., Uknes, S., Ryals, J. and Ward, E. 1998. Functional analysis of regulatory sequences controlling PR1 gene expression in Arabidopsis. Plant J. 16(2): 223-233.

Liu, Z.B., Ulmasov, T., Shi, X., Hagen, G. and Guilfoyle, T.J. 1994. Soybean GH3 promoter contains multiple auxin-inducible elements. Plant Cell 6(5): 645-657.

Lois, R., Dietrich, A., Hahlbrock, K. and Schulz, W. 1989. A phenylalanine ammonia-lyase gene from parsley: structure, regulation and identification of elicitor and light responsive cis-acting elements. EMBO J. 8(6): 1641-1648.

Maleck, K., Levine, A., Eulgem, T., Morgan, A., Schmid, J., Lawton, K.A., Dangl, J.L. and Dietrich, R.A. 2000. The transcriptome of Arabidopsis thaliana during systemic acquired resistance. Nat. Gen. 26: 403-410.

Martini, N., Egen, M., Runtz, I. and Strittmatter, G. 1993. Promoter sequences of a potato pathogenesis-related gene mediate transcriptional activation selectively upon fungal infection. Mol Gen Genet 236: 179-186.

Matzke, A.J. and Matzke, M.A. 1998. Position effects and epigenetic gene silencing of plant transgenes. Curr. Opin. Plant Biol. 1(2): $142-148$.

Mlynarova, L., Loonen, A., Heldens, J., Jansen, R.C., Keizer, P., Stiekema, W.J. and Nap, J-P. 1994. Reduced position effect in mature transgenic plants conferred by the chicken lysozyme matrix-associated region. Plant Cell 6: 417-426.

Moreno, P.R.H., Van der Heijden, R. and Verpoorte, R. 1994. Elicitor- mediated induction of isochorismate synthase and accumulation of 2,3-dihydroxy benzoic acid in Catharanthus roseus cell suspensions and shoot cultures. Plant Cell Rep. 14: 188-191.

Osusky, M., Zhou, G., Osuska, L., Hancock, R.E., Kay, W.E. and Misra, S. 2000. Transgenic plants expressing cationic peptide chimeras exhibit broad-spectrum resistance to phytopathogens. Nature Biotechnology 18: 1162-1166.

Peach, C. and Velten, J. 1991. Transgene expression variability (position effect) of CAT and GUS reporter genes driven by linked divergent T-DNA promoters. Plant Mol. Biol. 17: 49-60.

Samac, D.A. and Shah, D.M. 1991. Developmental and pathogen-induced activation of the Arabidopsis acidic chitinase promoter. Plant Cell 3: 1063-1072. 
Schenk, P.M., Kazan, K., Wilson, I., Anderson, J.P., Richmond, T., Sommerville, S.C. and Manners, J.M. 2000. Coordinated plant defence responses in Arabidopsis revealed by microarray analysis. Proc. Natl. Acad. Sci. USA 97(21): 11655-11660.

Schubert, R., Fischer, R., Hain, R., Schreier, P.H., Bahnweg, G., Ernst, D. and Sandermann, H. Jr. 1997. An ozone-responsive region of the grapevine resveratrol synthase promoter differs from the basal pathogen-responsive sequence. Plant Mol Biol. 34(3): 417-426.

Sijmons, P.C., Dekker, B.M., Schrammeijer, B., Verwoerd, T.C., Van den Elzen, P.J. and Hoekema, A. 1990. Production of correctly processed human serum albumin in transgenic plants. Bio/technology 8(3): 217-212.

Strittmatter, G. 1995. Chimeric genes comprising a fungus-responsive element. International Patent Publication WO 96/28561.

Strittmatter, G., Janssens, J., Opsomer, C. and Botterman, J. 1995. Inhibition of fungal disease development in plants by engineering controlled cell death. Bio/Technology 13: 1085-1088.

Strittmatter, G., Geysen, G., Gianinazzi-Pearson, V., Hahn, K., Niebel, A., Rohde, W. and Tacke, E. 1996. Infection with various types of organisms stimulate transcription from a short promoter fragment of the potato Gst1 gene. Mol. Plant Microbe Interact. 9(1): 68-73.

Stuiver, M.H. and Custers, J.H.H.V. 2001. Engineering disease resistance in plants. Nature 411; 865-868.

Takeda, S., Sugimoto, K., Otsuki, H. and Hirochika, H. 1999. A 13-bp cis-regulatory element in the LTR promoter of the tobacco retrotransposon Tto 1 is involved in responsiveness to tissue culture, wounding, methyljasmonate and fungal elicitors. Plant J. 18(4): 383-393

Ulmasov, T., Liu, Z.B., Hagen, G. and Guilfoyle, T.J. 1995. Composite structure of auxin response elements. Plant Cell 7(10): 16111623.

Van Camp, W., Van Montagu, M. and Inze, D. 1998. H2O2 and NO: redox signals in disease resistance. Trends Plant Sci. 3(9): 330334

Vancanneyt, G., Schmidt, R., O'Connor-Sanchez, A., Wilmitzer, L. and Rocha-Rosa, M. 1990. Construction of an intron containing marker gene: Splicing of the intron in transgenic plants and its use in monitoring early events in Agrobacterium mediated plant transformation. Mol Gen Genet 220: 245-250.

Van Tegelen, L.J.P., Moreno, P.R.H., Croes, A.F., Verpoorte, R. and Wullems, G.J. 1999. Purification and cDNA cloning of Isochorismate synthase from elicited cell cultures of Catharanthus roseus. Plant Phys. 119: 705-712.

Vorst, O., van Dam, F., Oosterhoff-Teertstra, R., Smeekens, S. and Weisbeek, P. 1990. Tissue-specific expression directed by an Arabidopsis thaliana pre-ferredoxin promoter in transgenic tobacco plants. Plant Mol Biol 14: 491-499.

Yalpani, N., Altier, D.J., Barbour, E., Scigan, A.L. and Scelonge, C.J. 2001. Production of 6-Methylsalicylic Acid by expression of a fungal polyketide activates disease resistance in tobacco. Plant Cell 13: 1401-1409.

Yang, Y. and Klessig, D.F. 1996. Isolation and Characterization of a tobacco mosaic virus-inducible myb oncogene homolog from tobacco. Proc Natl Acad Sci. USA 93: 14972-14977.

Yanisch-Perron, C., Vieira, J. and Messing, J. 1985. Improved M13 phage cloning vectors and host strains: nucleotide sequences of the M13mp18 and pUC19 vectors. Gene 33(1): 103-119.

Van Leeuwen, W., Hagendoorn, M.J.M., Ruttink, T., Van Poecke, R., Van der Plas, L.H.W. and Van der Krol, A.R. 2000. The use of the luciferase reporter system for in planta gene expression studies. Plant Mol. Biol. Rep. 18: 143a-143t.

Wiese, W., Vornam, B., Krause, E. and Kindl, H. 1994. Structural organization and differential expression of three stilbene synthase genes located on a 13 kb grapevine DNA fragment. Plant Mol Biol., 26(2):667-677.

Wildermuth, M.C., Dewdney, J., Wu, G. and Ausubel, F.M. 2001. Isochorismate synthase is required to synthesize salicylic acid for plant defence. Nature 414: 562-565. 
Supplementary data

Graphs displaying the results of the real-time RT-PCR experiments. On the X-axis the individual plant lines tested of pMOG1260, pMOG1368, pMOG1391 and pMOG1433 are listed and on the Y-axis the expression level is given. cDNA levels are normalised using potato actin genes as an internal control. Expression levels are normalised relative to CDNA prepared from a transgenic potato line containing the UidA gene with a GUS expression level just detectable in a histochemical assay. Independent lines are ordered based on expression levels at $\mathrm{t}=48 \mathrm{hr}$.

$\mathrm{t}=0 \mathrm{hr}$

$\mathrm{t}=12 \mathrm{hr}$
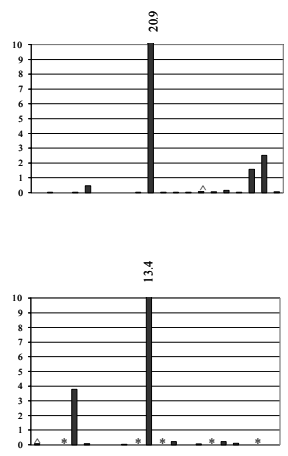

$\frac{\underline{0}}{\text { 음 }}$

कू
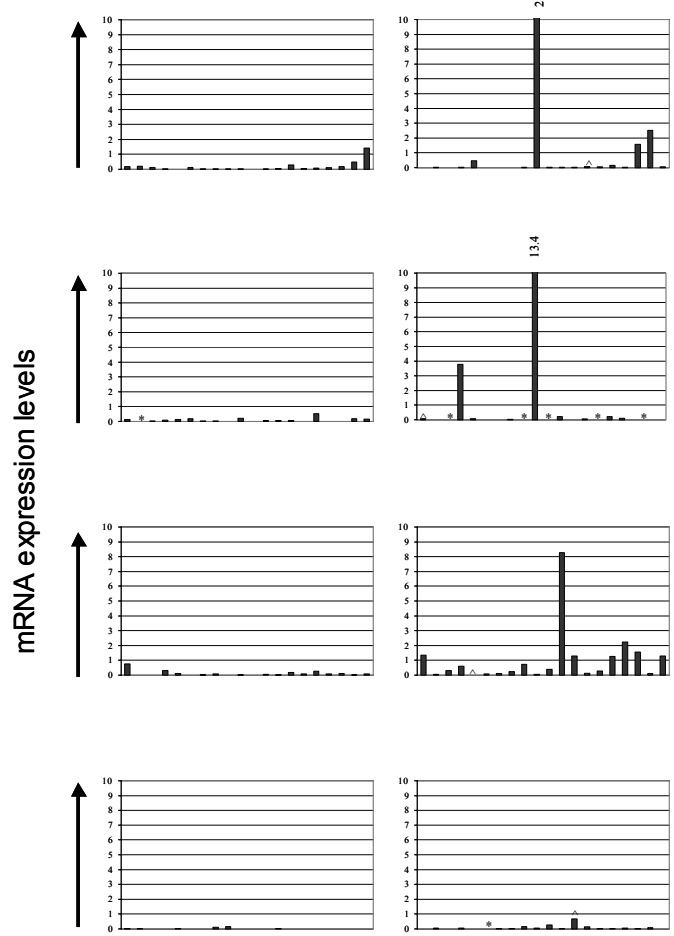

ndependent transgenic plantlines $\mathrm{t}=48 \mathrm{hr}$
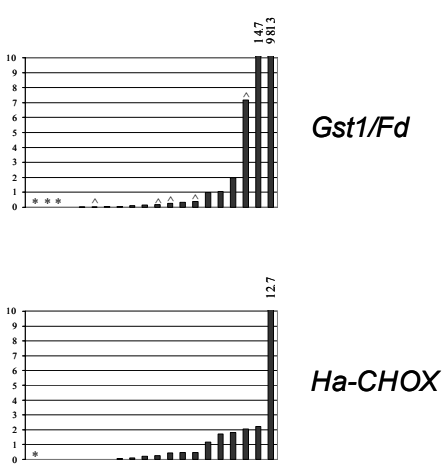

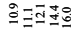

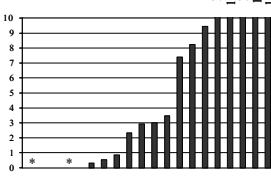

Vst1

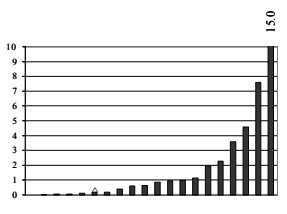

Ics 


\section{CHAPTER 5}

TRANSCRIPTIONAL REPROGRAMMING IN POTATO LEAVES FOLLOWING INFILTRATION OF THE CLADOSPORIUM FULVUM AVIRULENCE PROTEIN AVR9

Jerôme H.H.V. Custers, Stuart J. Harrison, Els van Deventer, Rhian Howells, John Ray, Mireille Oostdam, Sonja Kerkhoff, Bert H. Simons, Pierre J.G.M. De Wit and Maarten H. Stuiver 
Chapter 5 


\section{SUMMARY}

cDNA microarray technology was used to study transcriptional reprogramming in potato leaves in response to treatment with the Cladosporium fulvum Avr9 avirulence protein. Avr9 is able to trigger a hypersensitive response (HR) in plants containing the resistance gene Cf-9 and is assumed to have a function in virulence of the fungus as well. To study the transcriptional response of potato to the Avr9 elicitor protein and the function of this protein in compatible and incompatible interactions a synthetic Avr9 protein preparation was infiltrated in leaves of Solanum tuberosum cultivar Bintje plants that were either untransformed or transformed with the cognate tomato R-gene, Cf-9. At least 510 potato genes on the array have been shown to respond to Avr9 infiltration in potato. These genes were designated Solanum tuberosum Avr9 responsive (STAR) genes. We observed limited alteration in gene expression after infiltration of the Avr9 protein in leaves of untransformed potato plants but the few upregulated genes might point at a role of Avr9 during fungal infection. In Cf-9transformed potato plants major changes in gene expression were observed, which might point to genes involved in the defence of plants against fungal infection. Data presented in this paper provide a basis for further exploration of the virulence function of Avr9 and Cf-9-mediated Avr9induced defence responses.

\section{INTRODUCTION}

Plants have to respond actively to a large variety of potential pathogens by switching on defence pathways. One very effective induced resistance response results from a gene-for-gene interaction between a plant-derived resistance gene and a pathogen-derived avirulence gene. The main characteristics of the induced response involves the activation of local and systemic defence and the development of localized cell death, also known as the hypersensitive response (HR), and ultimately results in resistance (Bonas and Lahaye, 2002; Dangl and Jones, 2002). Transcriptional responses to infection or HR induction is expected to encompass major changes in gene expression which have been shown to be readily detectable using microarray technology (Maleck et al., 2000; Schenk et al., 2000; Scheideler et al., 2002; Tao et al., 2003; Glazebrook et al., 2003).

The intrinsic function of most pathogen avirulence proteins currently identified is still largely unknown. However, increasing evidence emerges that they contribute to virulence of pathogens (Lauge et al., 1997; Gassman et al., 2000; Abramovitch et al., 2003). For most avirulence proteins, including Avr9, no strong contribution to pathogen virulence has been observed so far. This is largely due to the fact that pathogens produce many such proteins, and just lack of one of them may only slightly impair virulence under controlled conditions. In some cases it has been shown that these (a)virulence factors are involved in binding or processing of a plant pathogenicity target likely contributing to disease (AvrPto/AvrPtoB - Pto, Shan et al., 2000, Pedley and Martin, 2003; AvrRpm1/AvrB/AvrRpt2 - Rin4, Mackey et al., 2002; Mackey et al., 2003; Axtell and Staskawicz, 2003; Avr2/Rcr3, Rooney et al., 2005).

The tomato $\mathrm{Cf}-9$ gene confers resistance to races of the tomato fungal pathogen Cladosporium fulvum expressing the Avr9 protein. Avr9 is produced as a 63 amino acid precursor and is processed by fungal and plant proteases to a mature 28 amino acid secreted peptide (Van den Ackerveken et al., 1993). Extensive structural analysis provided evidence that Avr9 resembles cystine knotted peptides which often function as protease inhibitors or ion-channel inhibitors (Vervoort et al., 1997; Van den Hooven et al., 2001). However, no carboxypeptidase inhibiting 
activity of Avr9 could be found so far (Van den Hooven et al., 2001). Mutational analysis of the Avr9 protein has identified a number of amino acids required for biological activity (Kooman-Gersman et al., 1997), but not much is known about the mode of action or the binding partner of Avr9 and until now no direct interaction between Cf-9 and Avr9 could be shown (Luderer et al., 2001). Additionally, the Avr9 peptide is able to bind to a high affinity binding site present in membrane fractions of several plant species independent of the presence of the Cf-9 gene (Kooman-Gersmann et al., 1996). The Cf- 9 receptor-like protein (RLP) consists of 27 extracellular leucine rich repeats and is anchored in the plant cell membrane. The structure of Cf- 9 and the localization of Avr9 suggest that perception of Avr9 by Cf- 9 occurs in the leaf apoplast. Cf- 9 is interacting with a thioredoxin homolog in the cytoplasm through its cytoplasmic tail. This thioredoxin appears to be a negative regulator of Cf-9-mediated cell death and defence (Rivas et al., 2004). However, the identity of the plant component responsible for binding Avr9 and consequently might represent the virulence target for Avr9 remains to be determined.

It has been shown that the Avr9/Cf-9 interaction is able to provoke an HR in potato in a similar way as it does in tomato (Hammond-Kosack et al., 1998; Van der Hoorn et al., 2000). In addition, a high affinity binding site for Avr9 is not only present in microsomal fractions from tomato but also in those of potato (Kooman-Gersman et al., 1996). Therefore, the potato system was considered, also in view of the availability of potato cDNA arrays, to be a suitable model to study transcriptional responses to Avr9 both in the absence and the presence of the cognate resistance gene Cf-9.

Here we describe the analysis of the transcriptional changes in potato leaves after infiltration of the C. fulvum Avr9 protein. We observed more than 510 genes whose expression was changed after infiltration with the Avr9 protein. The changes in expression found in Cf-9 expressing potato might point to defence mechanisms effective against fungi. Alternatively, analysis of alterations in gene expression of untransformed potato plants infiltrated with Avr9 might point to a virulence of Avr9. Both types of genes and their possible roles in defence and virulence are discussed.

\section{RESULTS AND DISCUSSION}

\section{Plant treatments, hybridization experiments and analysis of expression data}

To study the transcriptional reprogramming in potato in response to treatment with Avr9 we conducted gene expression profiling making use of cDNA arrays from potato. Avr9 preparations were infiltrated in potato leaves of untransformed potato plants and transgenic plants containing the tomato resistance gene $C f-9$ (Cf-9 potato). Infiltration of Avr9 preparations in Cf-9 potato resulted in rapid necrosis in the infiltrated area (Figure $1 \mathrm{~A}$ ). In untransformed plants no necrosis could be observed upon Avr9 infiltration (Figure 1B). Two different Avr9 concentrations were infiltrated to study differences in transcriptional responses between necrosis-inducing (100 nM) and nonnecrosis inducing $(15 \mathrm{nM})$ concentrations. Optimal Avr9 concentrations were determined experimentally and matched with previously described Avr9 concentrations that did induce necrosis (Kooman-Gersmann et al., 1997). Probes prepared from Avr9 infiltrated leaves were labeled with Cy3 and probes prepared from water-infiltrated leaves (controls) were labeled with Cy5. Corresponding probes were mixed and hybridized to glass cDNA arrays and Cy 3 and Cy 5 signals were detected. 


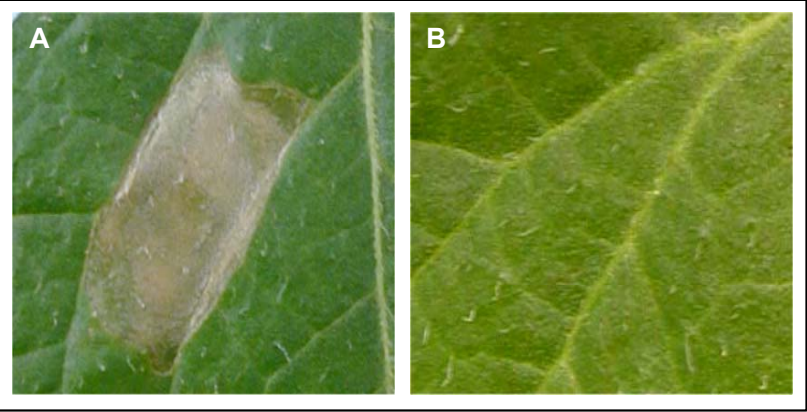

Figure 1. Symptoms developed after infiltration of Avr9 (100nM) in Cf-9 transgenic potato plant c.v. Bintje (A) and in untransformed potato c.v. Bintje (B). Leaves were photographed 24 hours after infiltration.

The glass cDNA arrays used in this study included approximately 10.000 potato expressed sequence tags (ESTs). ESTs were generated from different potato tissue cDNA libraries. These tissues included organs from Solanum tuberosum cv. Desiree plants including roots, stolon tissue, tubers, leaves infected by the oomycete Phytophthora infestans, uninfected leaves of various growth stages and roots from plants infected with the nematodes Meloidogyne incognita and Globodora pallida. Transcriptional responses were visualized using various approaches. Firstly, scatter plots of Cy3 and Cy5 signal values were made to show that transcriptional responses were readily detectable using this technology (Figure $2 a$ and $2 b$ ). These figures clearly show that infiltration of Avr9 in Cf-9 potato results in strong changes in gene expression.

A.

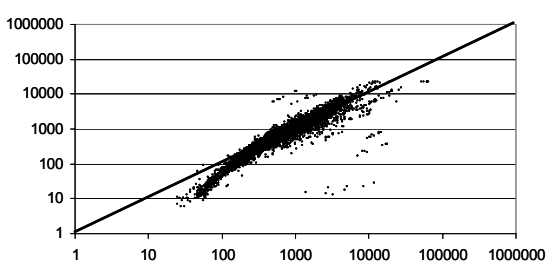

B.

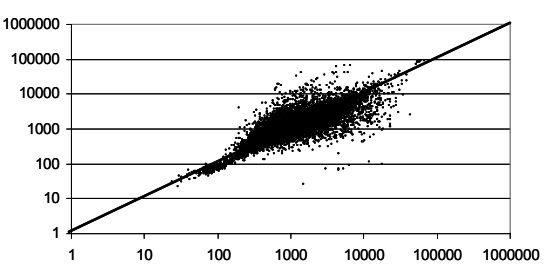

Figure 2. Scatter plots of individual micro array hybridization experiments. All elements on the array are plotted, including the control genes $(n=192)$. ). The cy3 signal values (X-axis) against the balanced cy5 signal values ( $Y$-axis) are plotted on a logarithmic scale. A. Micro array hybridization experiment executed with sample derived from Cf-9 potato leaves treated with $100 \mathrm{nM}$ Avr9 at 1 hour after infiltration. B. The same treatment as in (A.) but now at 5 hours after infiltration. 


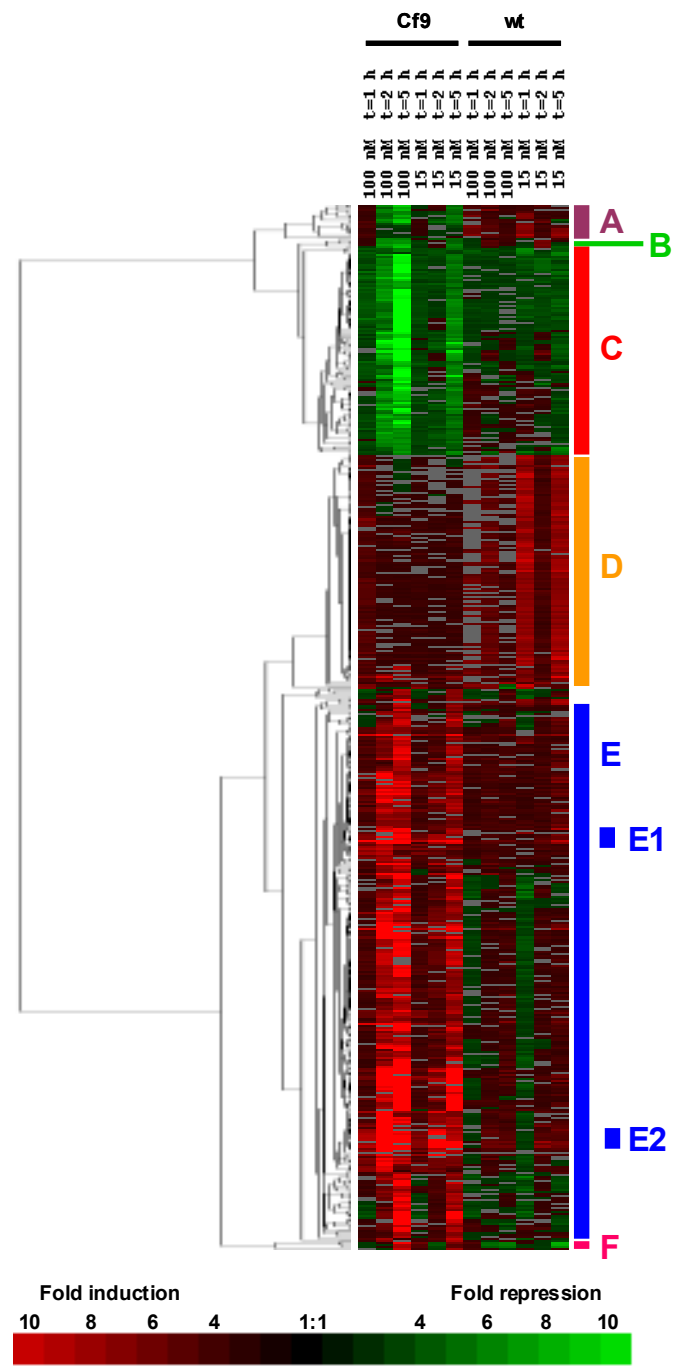

Figure 3A. Image of the clustergram containing the 510 STAR genes that are differentially expressed after treatment of potato leaves with Avr9. Genes changed in expression in at least 2 of the 12 treatments of 2.5 -fold or more were included in the analysis. Genes displaying differential expression as a result of presence of the Cf-9 gene in potato compared to wild type potato were omitted from the analysis (see material and methods). Genes are in rows, treatments are in columns. Red means transcriptional activation and green means downregulation when Avr9 treated plants were compared with water controls. Grey indicates no datapoint available. The scale is shown at the bottom. The phylogenetic tree at the left shows the relationship between the different genes with respect to their expression profiles in the different treatments as determined by hierarchical clustering. 


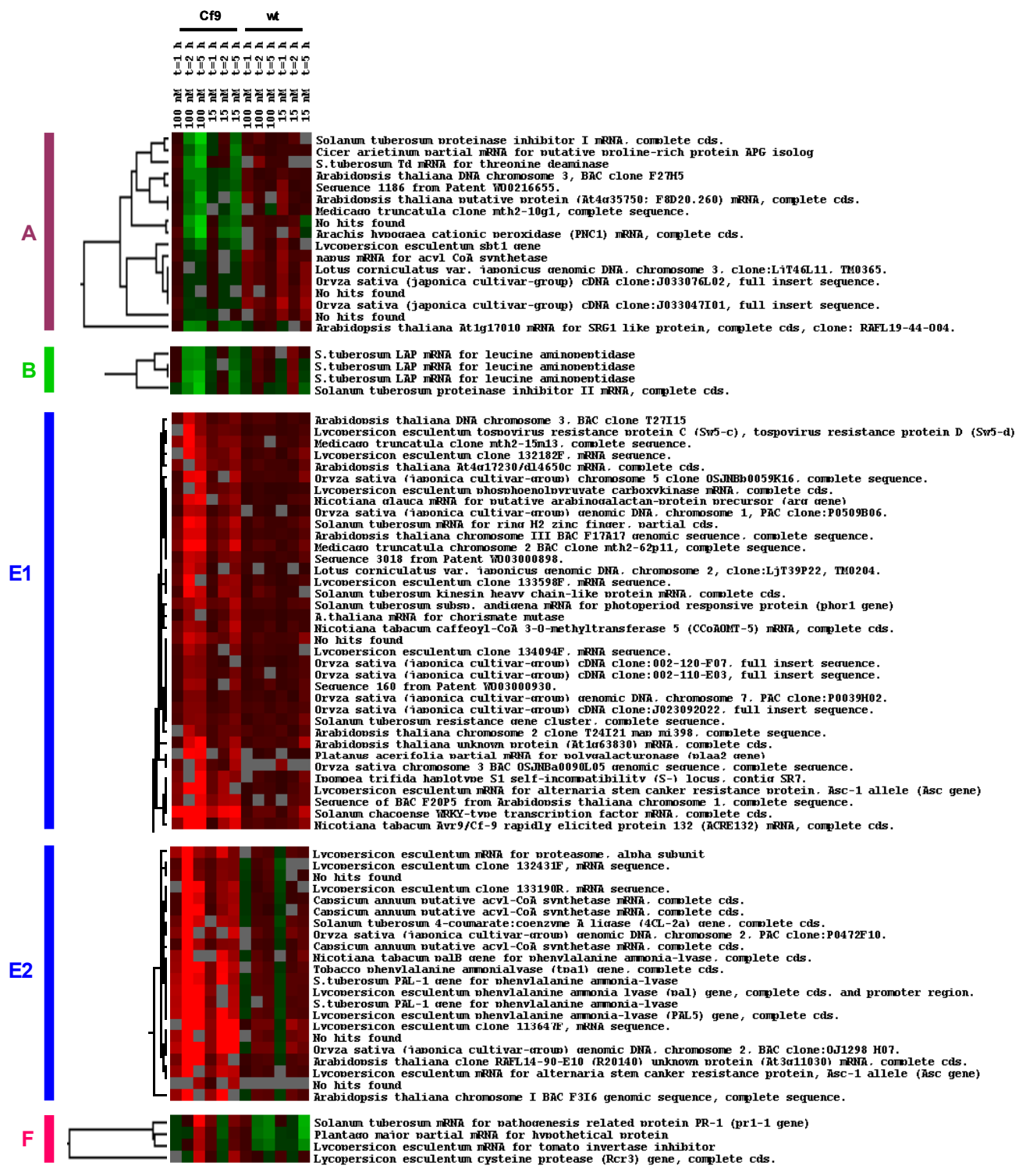

Figure 3B. Zoomed images of gene clusters shown in Figure 3A. Annotation is shown at the right. Arrays are in a fixed order. Colorcoding of clusters and sub clusters correspond to color-coding of clusters presented in Figure $3 \mathrm{~A}$. 
Transcriptional responses to Avr9 in Cf-9 potato increased over time and show a dose response effect. Responses in untransformed plants were very limited. Avr9-responsive genes were selected according to the following criteria. Genes were selected that changed at least 2.5 -fold in at least 2 of the 12 treatments as a result of Avr9 treatment. Genes that changed only as a result of the Cf-9 transgene being present in the genome of $\mathrm{Cf}-9$ potato plants were omitted from the analysis (for filtering and selection criteria see experimental procedures). Of the approximately 10.000 gene fragments present on the array, 510 met the criteria described and were designated as Solanum tuberosum Avr9-responsive (STAR) genes. STAR genes were grouped according to expression profiles over the different treatments by cluster analysis. Cluster analysis was performed using Cluster software (http://rana.lbl.gov/EisenPublications.htm) with the arrays in a fixed order (Eisen et al., 1998). Gene clusters and phylogenetic trees were visualized using Treeview software (http://rana.lbl.gov/EisenPublications.htm, Eisen et al., 1998). Clustering analysis of the 510 STAR genes revealed distinct gene clusters with respect to gene expression changes in the different treatments (Figure $3 \mathrm{~A}$ and $3 \mathrm{~B}$ ). Subsequently, genes were ranked based on highest (and lowest) differential expression levels at one and 5 hours, respectively, after infiltration in $\mathrm{Cf}-9$ potato in order to examine timing and level of gene expression (Figure 4 and 5 respectively). In addition, strongest responding genes in untransformed plants were filtered out to study Avr9 responses independent from Cf-9 expression (Figure 6).

\section{Global changes in gene expression}

Cluster analysis identified gene clusters with distinct mRNA expression patterns over the different treatments. Figure $3 A$ displays the 510 STAR genes grouped in clusters. Six major gene clusters could be identified ( $A$ to $F$ ). Figure $3 B$ displays zoomed images of a selection of clustergrams derived from Figure $3 \mathrm{~A}$. Cluster $\mathrm{A}$ contains genes downregulated in the Avr9-treated leaves including a proteinase inhibitor, a threonine deaminase, a cationic peroxidase and an Sbt1 gene. Cluster B contains, like cluster C, genes that are downregulated by Avr9 in Cf-9 potato. The majority of the genes in cluster $C$ (Figure $3 \mathrm{~A}$ ) are involved in photosynthesis and primary metabolism. Concurrent with the downregulation of this set of genes, a large set of potato genes was strongly induced in response to Avr9 infiltration (cluster E, Figure $3 \mathrm{~A}$ ). The genes in cluster E are all somewhat upregulated in Avr9-treated Cf-9 potato and their transcription is not affected by Avr9 infiltration in untransformed potato. Two subclusters, E1 and E2, were identified that contain genes induced early in Avr9-treated Cf-9 potato (Figure 3B). These clusters include genes with similarity to WRKY transcription factors, ACRE genes (cluster E1), Asc1 genes (cluster E1 and E2) and genes involved in the phenylpropanoid biosynthetic pathways (cluster E2). The tomato Asc1 gene mediates the plant insensitive to the fungal AAL and fumonisin B1 toxins (Brandwagt et al., 2000). Asc1 is a homologue of the longevity assurance gene (LAG1) in yeast that is associated with life span (D'mello et al., 1994). Homologs have also been found in mammals and seem to be involved in ceramide synthesis and even confer fumonisin B1 resistance in human cells (Riebeling et al., 2003). It is not known whether Asc1 in tomato is upregulated during an HR or even after application of AAL- or fumonisin $\mathrm{B} 1$ toxins. It is possible that sphingolipid-like components accumulating during the Avr9/Cf-9-mediated HR activate Asc1 expression. Several genes with similarity to phenylalanine ammonia-lyase (PAL) and 4-coumarate-CoA ligase that are functioning in the same biosynthetic pathway (phenylpropanoid metabolism) are clustered and are specifically induced in the 
"incompatible" interaction. Phenylpropanoid metabolism (PAL and 4-CL expression) is activated during plant defence and intermediate metabolites play a role in the synthesis of salicylic acid (SA), phytoalexins and the lignification of plant tissue (Chong et al., 2001). Cluster $F$ contains genes that are upregulated in Cf-9 potato and downregulated in untransformed potato. This cluster contains 4 STAR-genes including a $P R-1$ gene, an invertase inhibitor and an Rcr3-like cysteine protease. Tomato Rcr3, a cysteine protease, is required for Cf-2-mediated resistance in tomato and its protease activity is inhibited by avirulence protein Avr2, resulting in the induction of HR (Rooney et al., 2005).

\section{HR-related gene expression alteration: level and timing}

$\mathrm{HR}$ comprises a set of events that results in resistance to mostly biotrophic pathogens including the generation of reactive oxygen species (ROS), the death of a few cells at the site of attempted infection, the reinforcement of cell walls around the site of infection and the accumulation of antimicrobial compounds, both of phenolic and proteinaceous nature (Dorey et al., 1997). Analysis of the Avr9-mediated HR was achieved by arraying genes with respect to timing and amplitude of the transcriptional changes. Figure 4 displays a selection of STAR genes (81 out of 364) with the highest differential expression levels (up and down) at 5 hours after infiltration of $100 \mathrm{nM} \mathrm{Avr9}$ in Cf9 potato. The gene with the highest induction rate (>19-fold) is a lipid desaturase-like gene. Lipid desaturases are implicated to play a role in fatty acid metabolism as part of the jasmonate biosynthetic pathway. Lipid desaturases have been shown to be upregulated after $P$. infestans elicitor treatment in potato (Göbel et al., 2001). Furthermore in relation to fatty acid metabolism, a lipoxygenase-3, a phospholipase $\mathrm{D}$, an oleate desaturase and a fatty acid hydroperoxide lyase are upregulated as well. A number of $P R$-genes, germacrene $C$ synthase a phytoalexin biosynthesis gene, SA-responsive genes and an $\mathrm{HR} \mathrm{Ca}{ }^{2+}$ binding protein encoding gene are strongly induced (Figure 4). Additional genes that are strongly upregulated are an ascorbic acid oxidase and an oxygenase both associated with oxidative stress in plants and an $/ \mathrm{dh} 1$ gene induced during oxygen deficiency (Germain et al., 1997). Several copies of the HR-associated genes $h s r 201, h s r 203 j$ and hsr515 are induced during Cf-9-mediated HR in potato and shown to be HR-responsive in tobacco as well (Czernic et al., 1996; Pontier et al., 1999).

In order to differentiate between genes that respond early and late, leaves were collected at one, two and five hours after treatment with Avr9 or water. In Cf-9 tobacco suspension cultures already at 30 minutes after Avr9 treatment altered gene expression is detectable (Durrant et al., 2000). At one hour after infiltration of the $100 \mathrm{nM}$ Avr9 into Cf-9 potato we observed very strong changes in expression of approximately 75 genes of which 69 are induced (Figure 5). The two fastest responding genes are transcription factors, one belonging to the class of WRKY transcription factors and one similar to ZPT2 transcription factors. In addition, several other genes with homology to WRKY transcription factors are upregulated in response to treatment with Avr9. Members of this very large family of transcription factors have been shown to bind to W-box elements found in many pathogen-responsive genes (Eulgem et al., 2000) and are enriched in Arabidopsis promoters of genes involved in systemic acquired resistance (Maleck et al., 2000). Some WRKY genes analyzed in potato and parsley are induced by pathogen challenge (Dellagi et al., 2000; Eulgem et al., 1999). Asai et al. (2002) have shown that in Arabidopsis some WRKY genes play an essential role in genefor-gene pathogen resistance. The very fast response of the N. tabacum WRKY1 gene suggests an 
important role for this transcription factor in activating defence gene expression. Similarly, a ZPT2like transcription factor gene is strongly and early activated in Avr9 treated Cf-9 potato. A direct involvement of ZPT2 in pathogen resistance has not been reported but a role in other stress responses like drought and wounding has been described (Takatsuji, 1999; Sugano et al., 2003). Presumably, expression of distinct subsets of genes are activated by WRKY1 and ZPT2 in response to the Avr9-mediated HR. Amongst the fast responding sequences are also phenylalanine-ammonia lyase ( $P A L)$ genes, histidine decarboxylase genes, different proteases, kinases, genes involved in ethylene biosynthesis, lipid desaturases and hsr203j-like genes. The selection of fast responding genes includes homologues of genes formerly identified in tobacco as Avr9/Cf-9 rapidly elicited (ACRE) genes (Durrant et al., 2000). For most of the early-induced STAR genes, a role in pathogen defence has been described. However, to our knowledge this is the first report where histidine decarboxylase genes are associated with the plant defence response. It has been shown that a specific histidine decarboxylase is upregulated during fruit ripening in tomato and microarray analysis has shown that histidine decarboxylase genes are induced by nitrate in Arabidopsis (Picton et al., 1993; Wang et al., 2000). Histidine decarboxylase utilizes the amino acid histidine to produce histamine and $\mathrm{CO}_{2}$. In mammalian systems histamine has been shown to be involved in regulating an allergic response and inflammation (Bachert, 1998).

\section{Avr9-induced responses in untransformed potato plants}

The Avr9 protein structurally resembles cystine knotted peptides, which are implicated to function as protease inhibitors or ion-channel blockers (Van der Hooven et al., 2001). So far no virulence function has been assigned to Avr9 and no prove has been provided that the protein has protease inhibitory or ion-channel blocking activity. When Avr9 would induce specific shifts in gene expression in the host in the absence of the Cf- 9 protein these genes could point to possible functions in virulence to Cladosporium or identify possible host targets of Avr9. In order to investigate this possibility we infiltrated concentrations of $100 \mathrm{nM}$ and $15 \mathrm{nM}$ Avr9 into leaves of untransformed potato plants and performed expression profiling. The analysis revealed that treatment with Avr9 results in very limited changes in gene expression in the absence of Cf-9 (Figure 6). Five genes show a tendency of being downreguled and include a putative pathogenesisrelated protein, a tomato invertase inhibitor like gene, a hydroxyacid dehydrogenase, a PR1-like gene and one sequence without any similarity to annotated sequences. At five hours after infiltration 14 genes are upregulated 2-fold or more with the strongest responder being a receptor kinase homolog. However, most of these genes are responsive to Avr9 infiltration irrespective of the presence of the $\mathrm{Cf}-9$ protein. One of the genes, a homolog of potato $P R 1-1$, was strongly induced in the Avr9/Cf-9 interaction but downregulated in untransformed potato leaves. PR1-1 is a well-known and extensively studied marker for SAR in tobacco and Arabidopsis. Induction of systemic acquired resistance (SAR) is expected during HR formation and is completely dependent on functional SA signaling, also in potato (Yu et al., 1997; Coquoz et al., 1998; Dorey et al., 2000). Down regulation of this gene after Avr9 treatment in the absence of Cf-9 suggests SAR is inhibited. 
GeneName

Lesculentum mRNA for lipid desaturase-like protein. Nicotiana tabacum immediate-early salicylate-induced glucosyltran epidermal germacrene $C$ synthase L.esculentum mRNA for lipid desaturase-like prote-

Putative histidine decarboxylase

Solanum tuberosum class II chitinase (ChtA3) mRNA, partial cds. N.tabacum mRNA for HSR515 prote

(ChtA2) mRNA, complete od hypersensitive reaction associas

4-coumarate-CoA ligase-like protein

gentative integral membrane protein

S.melongena CYP76A2 mRNA for hydroxylase.

putative PTS protein

Incyte EST

Capsicum annuum ascorb

Contains similarity to an unknown protein T10D 10.8 gil6730756 fro

D12 oleate desaturas
Lycopersicon esculen

lentum Idh1 gene.

Solanum tuberosum germin-like protein (OXAOXA) mRNA, compl
contains similarity to Pfam family PFO0070 - Pyridine nucleotide-d fatty acid hydroperoxide lyase

S.tuberosum mRNA for formate dehydrogenase.

EST AU070346(S12172) corresponds to a region of the predicted cytochrome P450

contains similarity to Pfam family PF00070 - Pyridine nucleotide-

ATAF

glucosyltransferase-like protein
contains similarity to protein kinase domains (Pfam F00069, Score S.tuberosum mRNA for formate dehydrogenase

Lycopersicon esculentum light dependent NADH:protochlorophy L.esculentum DNA for CAB11 gene.

PSI-N

S.tuberosum mRNA for T subunit of glycine decarboxylase multi-e Incyte EST

hypothetical protein

thioredoxin pero
unknown protein

Tomato photosystem I (PS I) reaction center protein subunit II ( $p$ S Tomato CAB-8 gene (constucted from mRNA and DNA) for type Potato mRNA for light inducible tissue-specific ST-LS1 gene.

Incyte EST

hypothetical protein

S.tuberosum rbcS2b gene for ribulose-(1,5)-bisphosphate carbox Chlorophyll a/h-binding protein CP29 precursor
Medicago sativa clone MS28 unknown mRNA.

putative protein

Tomato CAB-8 gene (constucted from mRNA and DNA) for type Solanum $m$

core protein
photosystem I subunit II

Potato mRNA for starch phosphorylase (EC 2.4.1.1).

N.sylvestris psaH gene for photosystem I psaH protei

acid phosphatase

thaizole biosynthetic enzmye

S.tuberosum rbcS3 gene for ribulose-(1,5)-bisphosphate carboxyla Solanum tuberosum mRNA for extensin-like protein, partial.

(n)

N.tabacum mRNA for aquaporin acid phosphatase

Ther ferredoxin-1.
Clone ID

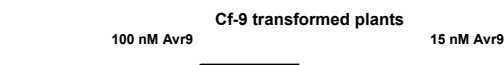

702311429
703036269
703035886

703052527
703033927

703033927
703026370
703041319

703051660

70304727

703053387
703043457
702324473

702324473
703026480

70232435

702313586
703026129

702311140
703130418

703042813

703035830

70231986

702324848

70236408

702300769

702300769
702364353

703132753
702322813
70232422

70231819

702300494
702362271
70232455

703038741

703026105
703048294

703048294
702309542

703061373

(203034920

702293364
702302376

70236553

70230143

703142918
703053912

(702293328

70292945

702320543

702304323
70230185
702302073

(0314316

702304760
702295955

702295955
702303854

702294449

702309541

702302654

702295817
702325361
702300728

703142250
702322179

702322179
702293318

(229338

703025876
702298289

702295991

702298793

702298142
702295926

70229874

702294933
702293779 $\mathrm{t}=1 \quad \mathrm{t}=2 \quad \mathrm{t}=5$

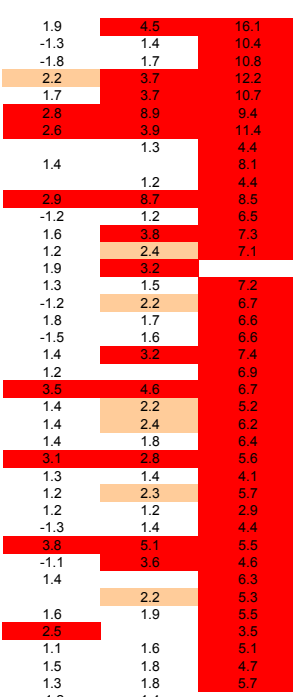

\begin{tabular}{rr|r}
1.3 & 1.8 & 5.7 \\
-1.2 & 1.4
\end{tabular}

$\begin{array}{ll}-1.2 & 1.4 \\ -1.3 & -1.1 \\ -1.3 & -1.4 \\ -1.6 & -1.2\end{array}$

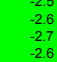

-2.6
-2.7
-2.6
-2.4
-2.6

-2.4
-2.6
-2.5
-3.1
-2.7

-2.7
-2.6
-2.4
-2.3

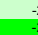

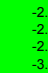

-2.7
-2.
-3.
-2.
-2.5
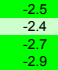

-2,
-2,
-2.7
-3

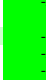

-3.1
-2.8
-3.2
-2.8
-3.1
-2.9

-3.2
-3.1
-2.8
-2.8

-2.
-4
-2
-4.7
-2.7

-2.7
-3.4
-4.9
-3.2
-3.2

Figure 4: Gene induction as a result of the Avr9-induced Cf-9 mediated hypersensitive response in potato. List of 81 STAR genes that respond to Avr9 treatment in Cf-9 potato ordered based on gene induction/repression levels at $t=5$ hours after treatment with $100 \mathrm{nM}$ Avr9 (boxed column). Red marks gene induction, green gene repression. Gene names are based on initial gene annotation using assembled sequences (left column). Reannotation based on single component sequences present on the array is shown in table S1, supplementary data. 
GeneName

Nicotiana

Capsicum annuum ascorbic acid oxidase mRNA, partial cds.

Incyte EST

nine ammonia-lyase (PAL5)

Lycopersicon esculentum phenylalanine ammonia lyase (pal) gene

S.tuberosum PAL-1 gene for phenylalanine ammonia-lyase.

Incyte EST

PAL-1 gene for phenylalanine ammonia-lyase.

histidine decarboxylase
Lycopersicon esculentum mRNA for proteasome, alpha subunit.

S.tuberosum PAL-1 gene for phenylalanine ammonia-lyase.

es from this gene.

Lycopersicon esculentum ASC1 (Asc) gene, Asc-1 allele, comple

N.tabacum (Samsun NN) mRNA for

Incyte EST
Incyte EST

Incyte EST

gene_id:MWL2.19-unknown protein

Incyte EST

RING-H2 finger protein RHY1

Lycopersicon esculentum 1-amino-cyclopropane-1-carboxylate sy

histidine decarboxylase

gene_id:MSH12.19 unknown protein

Capsicum annuum MAP kinase 1 (MK1) gene, complete cds.

putative receptor protein kinase
putative D-isomer specific 2-hydroxyacid dehydrogenase

similar to zinc metalloproteinases

Lycopersicon esculentum expansin precursor (Exp5) mRNA, com cytochrome P4

Incyte EST

hypothetical protei
unknown protein

Nicotiana tabacum harpin inducing protein (hin1) gene, complete Lycopersicon esculentum DNA, similar to hsr203J, complete cd.

axi 1-like protein

putative protein kinase

Incyte EST

putative calmodu
putative protein

gb|AAD25781.1 1 gene_id:MAG2.5 - strong similarity to unknown prc 4-coumarate-CoA ligase-like protein

Solanum tuberosum 4-coumarate:coenzyme A ligase (4CL-2a) ger Incyte EST

putative giberellin beta-hydroxylas

hypothetical protein

RNA for lipid desaturase-like protein.

putative protein

5 (CCoAO

gb|AAC14530.1 gene id:MHM17 13 -strong similarity to unknown

Incyle EST

N.tabacum NTP303 pollen specific mRNA.

putative protein

Unknown protein
Similar to Synechocystis hypothetical protein (gb|D90908)

PSIN

Tomato photosystem I (PS I) reaction center protein subunit II (pSa
Potato (S.tuberosum) ribulose bisphosphate carboxylase (rbcS) $\mathrm{mI}$
Clone ID

Cf-9 transformed plants

$15 \mathrm{nM}$ Avr9

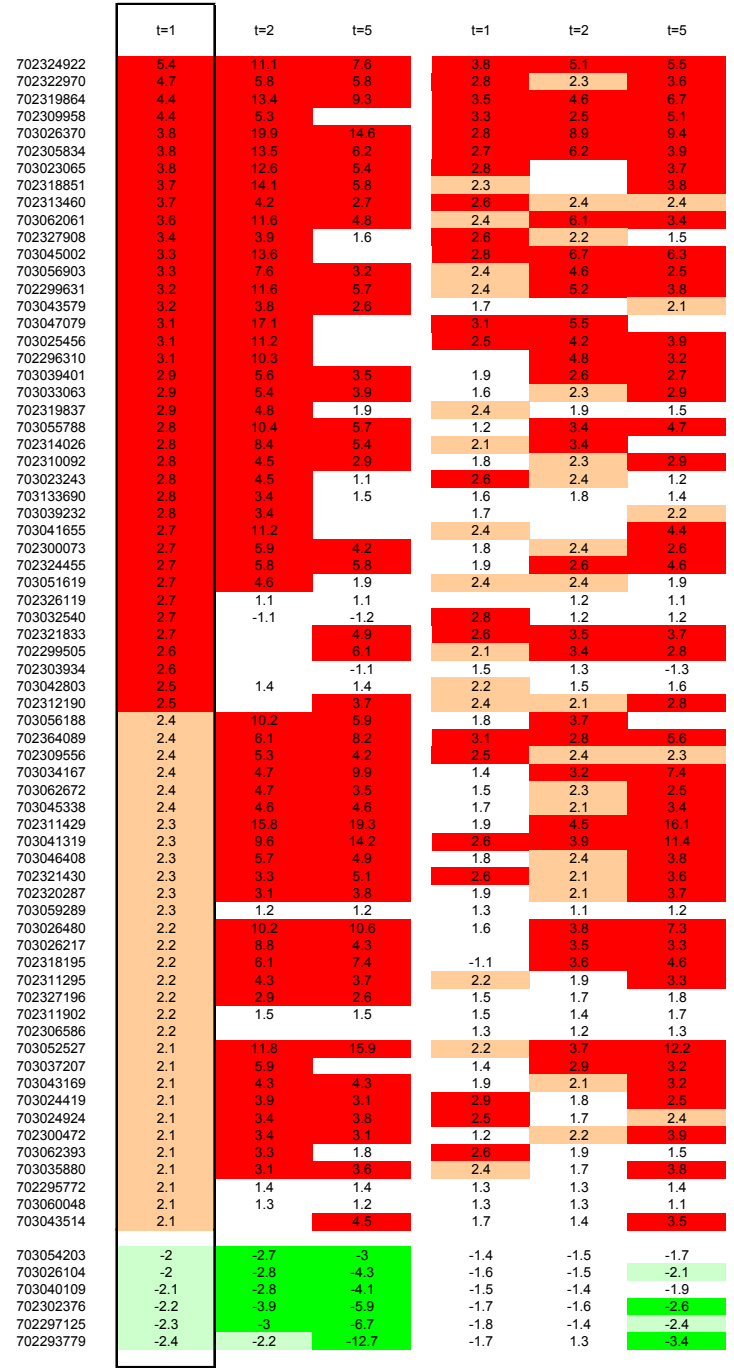

Figure 5: Kinetics of gene induction following Avr9 infiltration in Cf-9 potato. List of STAR genes that respond early to Avr9 treatment (100 nM Avr9) of Cf-9 potato ordered based on gene induction/repression levels at $t=1$ hour after treatment (boxed column). Red marks gene induction and green gene repression. Gene names are based on initial gene annotation using assembled sequences (left column). Reannotation based on single component sequences present on the array is shown in table S1, supplementary data. 
Furthermore, we have observed down regulation of a gene similar to invertase inhibitors. Often, plant apoplastic invertases are induced upon fungal infection enabling pathogens to utilize sucrose (Herbers et al., 2000; Chou et al., 2000). In addition, plant pathogenic fungi, especially biotrophic fungi, display increased expression of hexose transporters and invertases in specific infection structures (Hahn and Mendgen, 2001). Specific down regulation of invertase inhibitors by Avr9 might point at a potential use of invertases and hexose transporters by the fungus to utilize momosacharides from the apoplast of the host plant. Some potato invertase inhibitors are not only able to inhibit the activity of invertases but also able to inhibit the activity of plant, fungal and bacterial enzymes like, polygalacturonases, pectinases, pectin lyases, alpha-Larabinofuranosidases and beta-glucosidases of which some play an important role in pathogenicity of bacterial and fungal plant pathogens (Isla et al., 2002). It is unknown whether $C$. fulvum requires these enzymes to colonize the host apoplast but this fungus might produce Avr9 to protect itself against the action of invertase inhibitors.

GeneName

receptor-like protein kinase homolog RK20-1 Capsicum annuum ascorbic acid oxidase mRNA, partial cds. unknown protein Putative histidine decarboxylase Putative histidine decarboxylase desaturase-like protein Incyte EST PDR5-like ABC transporter PDR5-like ABC transporter Putative monosum mRNA for NtWRKY1, complete cds. putative pathog Lycopersicon esculentum mRNA for tomato invertase inhibitor. putative D-isomer specific 2-hydroxyacid dehydrogenase Solanum tub
Incyte EST
Clone ID
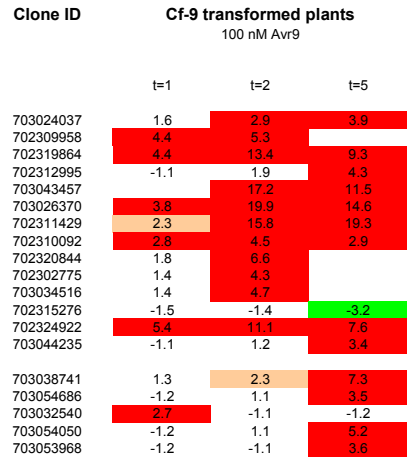

Untransformed plants 100 nM Avr9

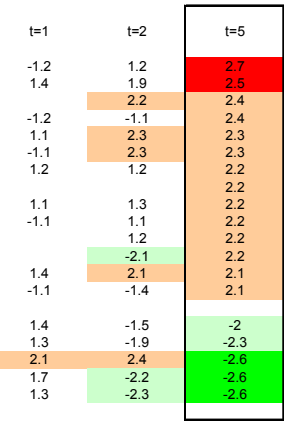

Figure 6: Listing of STAR genes that display differential gene expression of at least 2-fold in the $100 \mathrm{nM}$ Avr9 treated untransformed potato leaves (boxed column). On the left, induction/repression levels in Cf-9 potato. Gene names are based on initial gene annotation using assembled sequences (left column). Reannotation based on single component sequences present on the array is shown in table $\mathrm{S} 1$, supplementary data.

In conclusion, Avr9-induced, Cf-9-mediated HR in potato results in major shifts in gene expression. Potato redirects its gene expression profile from general maintenance to defence as concluded from the down-regulation of the expression of genes involved in primary metabolism and photosynthesis and simultaneous upregulation of pathogen defence-associated genes. Moreover, some genes have not been linked to pathogen defence or the HR before and are therefore interesting candidates for further research. Infiltration of Avr9 in untransformed potato resulted in very limited alterations in gene expression profiles. Three genes are downregulated and 14 genes are upregulated. Down regulation of some PR-genes and apoplastic invertase inhibitors suggest that Avr9 might have a role in suppression of parts of the plant defence system. Altogether, the data presented reveal interesting leads for further research. 


\section{EXPERIMENTAL PROCEDURES}

\section{Generation of Cf-9 transgenic potato plants}

Binary vectors were transferred to Agrobacterium tumefaciens strain EHA105 (Hood et al., 1993) by electroporation. The binary vector pMOG1096 containing the NPT II gene conferring kanamycin resistance and containing a $7.5 \mathrm{~kb}$ Pst I fragment, harbouring the Cf-9 promoter, the Cf-9 coding region and polyadenylation sequences (Hammond-Kosack et al., 1998), was transformed to potato c.v. Bintje essentially as described by Bade et al. (2003). Transgenic line 1096-03 was selected as reliably responsive to Avr9 infiltration as judged by necrotic responses in several different experiments under various conditions with different plants. Untransformed Bintje plants were maintained in tissue culture under equal conditions as the transgenic plants but without antibiotic selection. These untransformed potato $\mathrm{cv}$. Bintje plants did not develop visible necrotic lesions in response to Avr9 infiltration.

\section{Generation of probe material and array hybridizations}

For the infiltration experiments, 7-week-old Cf-9 or untransformed potato plants were used (cv. Bintje, line pMOG1096-3). The Avr9 preparations that were used were based on a synthetic Avr9 peptide with the Serine at position 5 replaced by an Alanine and the Arginine at position 8 replaced by a Lysine. These mutations render an active Avr9 elicitor with a higher specific activity (R8K mutation) and the S5A mutation removes an $\mathrm{N}$-linked glycosylation site and slighltly reduces the specific activity (Kooman-Gersman et al., 1997). Avr9 peptides were synthesized and refolded as described previously (Van der Hooven et al., 1999). Avr9 concentrations of $100 \mathrm{nM}$ and $15 \mathrm{nM}$, respectively, were infiltrated. The Avr9 preparations and mock samples (solvent, water) were infiltrated into mature fully expanded leaves using a $1 \mathrm{ml}$ syringe resulting in $50-70 \%$ of the leaf infiltrated with Avr9 or water. For each sample three plants and three infiltrated leaves per plant were used. The leaves were detached and collected at 1, 2 and 5 hours after infiltration and snap frozen in liquid nitrogen. For each treatment, nine leaves were pulverized in liquid nitrogen, mixed and one gram of pulverized tissue was used for RNA extraction. Total RNA was isolated using the Trizol reagent (Gibco BRL) as recommended by the manufacturer. In short, one gram of pulverized leaf material was homogenized with $10 \mathrm{ml}$ Trizol reagent and after centrifugation the water phase was removed. Poly- $\mathrm{A}^{+}$RNA was extracted using the Qiagen OligoTex mini mRNA kit (Qiagen). Further probe production (Cy5 and Cy3 labeling during cDNA synthesis), array hybridizations, array scanning and data mining were perfomed by Incyte Genomics basically as described in Yue et al. (2001).

\section{Data analysis}

Quality of microarray hybridisations, spot intensities and spot area were analysed by Incyte Genomics. Scatter plots of all data points were made using Microsoft Excel of Cy3 and balanced Cy5 signal values measured of spots meeting all the criteria defined by Incyte Genomics (Yue et al., 2001). Signal balancing was performed to correct for differential incorporation of Cy3 and Cy5 fluorophores based on control DNA on each array.

Genes included in the analysis described in this paper were selected based on the following parameters. Genes with a differential expression level of 2.5 -fold or more (induction and repression) in at least 2 out of 12 hybridization experiments were included in the analysis. This threshold of 2.5- 
fold seems rather conservative since Incyte Genomics considers a differential expression threshold of 1.74-fold to be significant (Yue et al., 2001). A threshold value of $+/-2.5$-fold ensures that the genes included in the analysis reflect true changes in expression. This selection was achieved by using the sort and formula options in Microsoft Excel.

Initial gene annotations are included in the tables (Figures 4, 5 and 6) and were obtained by tBLASTx similarity searching (Altschul et al., 1997) against the EMBL plant sequence database of sequences assembled from components with overlapping sequences. Recent annotation of the 510 selected Avr9-responsive gene components has been performed by tBLASTx similarity searching against the EMBL plant sequence database as well.

Genes that changed as a result of expression of the Cf- 9 transgene, transformation of the potato plants or insertion in the potato genome of the Cf-9 transgene, were omitted from the analysis. To achieve this, the control gene set present on each array $(n=192)$ was used to normalize the absolute signal values of all genes present on the array. The normalized absolute signal values measured of the 6 arrays probed with $C f-9$ transgenic material were averaged and compared to the likewise averaged normalized absolute signal values of the genes on the arrays probed with untransformed material. Genes that displayed a difference in absolute signal values of 2.0-fold or more between arrays probed with untransformed of $C f-9$ potato (infiltrated with $\mathrm{H}_{2} \mathrm{O}$ ) were discarded from the analysis. As a result, a subset of 184 genes was removed from the analysis that might display differential expression levels as a result of the $C f-9$ transgene, plant genetic transformation and/or insertion of the T-DNA in the potato genome. A resulting set of 510 genes changed in more than two treatments at least 2.5 -fold and is unlikely changing as a result of the Cf-9 transgene insertion. This Solanum tuberosum Avr9-responsive (STAR) gene set of 510 genes was used for cluster analysis using the "Average Linkage Clustering" feature of the Cluster programme (default settings) and displayed using Treeview (Eisen et al., 1998). For analysis of levels and timing of alteration in expression, genes were ordered using Microsoft Excel. Genes were ordered in tables and colour coded accordingly.

\section{ACKNOWLEDGEMENTS}

The authors would like to thank Dr. Jacques Vervoort, Wageningen University, for the Avr9 (S5A/R8K) protein preparation.

\section{REFERENCES}

Abramovitch R.B., Kim Y.J., Chen S., Dickman M.B. and Martin G.B., 2003. Pseudomonas type III effector AvrPtoB induces plant disease susceptibility by inhibition of host programmed cell death. EMBO J. 22(1): 60-69.

Altschul S.F., Madden T.L., Schaffer A.A., Zhang J., Zhang Z., Miller W. and Lipman D.W., 1997. Gapped BLAST and PSI-BLAST: a new generation of protein database search programs. Nucleic Acids Res. 25: 3389-3402.

Asai T., Tena G., Plotnikova J., Willmann M.R., Chiu W., Gomez-Gomez L., Boller T., Ausubel F.M. and Sheen J., 2002. MAP Kinase signaling cascade in Arabidopsis innate immunity. Nature 415: 977-983.

Axtell M.J. and Staskawicz B.J., 2003. Initiation of RPS2-specified disease resistance in Arabidopsis is coupled to the AvrRpt2directed elimination of RIN4. Cell 112: 369-377.

Bachert C., 1998. Histamine - a major role in allergy? Clin. Exp. Allergy 28: 15-19.

Bade J., Van Grinsven E., Custers J., Hoekstra S. and Ponstein A. (2003) T-DNA tagging in Brassica napus as an efficient tool for the isolation of new promoters for selectable marker genes. Plant Mol. Biol. 52: 53-68.

Bonas U. and Lahaye T., 2002. Plant disease resistance triggered by pathogen-derived molecules: refined models of specific recognition. Curr. Opin. Microbiol. 5: 44-50. 
Brandwagt B.F., Mesbah L.A., Takken F.L.W., Laurent P.L., Kneppers T.J.A., Hile J. and Nijkamp J., 2000. A longevity assurance gene homolog of tomato mediates insensitivity to AAL toxins and fumonisin B1. Proc. Natl. Acad. Sci. USA 97: 4961-4966.

Cai, X., Takken, F.L.W., Joosten, M.H.A. and De Wit, P.J.G.M., 2001. Specific recognition of AVR4 and Avr9 results in distinct patterns of hypersensitive cell death in tomato, but similar patterns of defence-related gene expression. Mol. Plant Pathol. 2(2): 7786.

Chong J., Pierrel M-A., Atanassova R., Werck-Reichhart D., Fritig B. and Saindrenan P., 2001. Free and conjugated Benzoic acid in tobacco plants and cell cultures. Induced accumulation upon elicitation of defence responses and role as Salicylic Acid precursor. Plant Physiol. 125: 318-328.

Chou H., Bundock N., Rolfe S.A. and Scholes J.D. (2000) Infection of Arabidopsis thaliana leaves with Albugo candida (white blister rust) causes a reprogramming of host metabolism. Mol. Plant Path. 1(2): 99-103.

Coquoz J-L., Buchala A. and Metrauz J-P. (1998) The biosynthesis of salicylic acid in potato plants. Plant Physiol. 117: 1095-1101.

Czernic, P., Huang, H.C. and Marco, Y., 1996. Characterization of hsr201 and hsr515, two tobacco genes preferentially expressed during the hypersensitive reaction provoked by phytopathogenic bacteria. Plant Mol. Biol. 31(2): 255-265.

Dangl J.L. and Jones J.D.G., 2001. Plant pathogens and integrated defence responses to infection. Nature 411: 826-833.

Dellagi A., Heilbron J., Avrova A.O., Montesano M., Palva E.T., Stewart H.E., Toth I.K., Cooke D.E.L., Lyon G.D. and Birch P.R.J., 2000. A Potato Gene Encoding a WRKY-like Transcription Factor Is Induced in Interactions with Erwinia carotovora subsp. Atroseptica and Phytophthora infestans and Is Coregulated with Class I Endochitinase Expression. Mol. Plant-Microbe Interact. 13(10), 1092-1101.

D'mello N.P., Childress A.M., Franklin D.S., Kale S.P., Pinswasdi C. and Jazwinski S.M., 1994. Cloning and characterization of LAG1, a longevity-assurance gene in yeast. J Biol Chem. 269(22): 15451-15459.

Dorey S., Baillieul F., Pierrel M., Saindrenan P., Fritig B. and Kauffmann S., 1997. Spatial and Temporal Induction of Cell Death, Defence genes, and Accumulation of Salicylic Acid in Tobacco Leaves Reacting Hypersensitively to a Fungal Glycoprotein elicitor. Mol. Plant-Microbe Interact. 10(5), 646-655.

Durrant, W.E., Rowland, O., Piedras, P., Hammond-Kosack, K.E. and Jones, J.D.G., 2000. cDNA-AFLP reveals striking overlap in race-specific resistance and wound response gene expression profiles. Plant Cell 12: 963-977.

Eisen M.B., Spellman P.T., Brown P.O. and Botstein D., 1998. Cluster analysis and display of genome-wide expression patterns. Proc. Natl. Acad. Sci. USA 95: 14863-14868.

Eulgem T., Rushton P.J., Schmelzer E., Hahlbrock K. and Somssich I., 1999. Early nuclear events in plant defence signaling: rapid gene activation by WRKY transcription factors. EMBO J. 18(17): 4689-4699.

Eulgem T., Rushton P.J., Robatzek S. and Somssich I.E., 2000. The WRKY superfamily of plant transcription factors. Trends Plant Sci. 5(5): 199-206.

Gassmann W., Dahlbeck D., Chesnokova O., Minsavage G.V., Jones J.B. and Staskawicz B.J., 2000. Molecular evolution of virulence in natural field strains of Xanthomonas campestris pv. vesicatoria. J. of bacteriol. 182: 7053-7059.

Germain V., Raymond P. and Ricard B., 1997. Differential expression of two tomato lactate dehydrogenase genes in response to oxygen deficit. Plant Mol. Biol. 35(6):711-721.

Glazebrook J., Chen W., Estes B., Chang H.S., Nawrath C., Metraux J.P., Zhu T. and Katagiri F., 2003. Topology of the network integrating salicylate and jasmonate signal transduction derived from global expression phenotyping. Plant J. 34(2): 217-228.

Göbel C., Feussner I., Schmidt A., Scheel D., Sanchez-Serrano J., Hamberg M. and Rosahl S., 2001. Oxylipin profiling reveals the preferential stimulation of the 9-lipoxygenase pathway in elicitor-treated potato cells. J. Biol. Chem. 278(9): 6267-6273.

Hahn M. and Mendgen K., 2001. Signal and nutrient exchange at biotrophic plant-fungus interphases. Curr. Opin. Plant Biol. 4: 322327.

Hammond-Kosack, K.E., Tang S., Harrison, K. and Jones, J.D.G., 1998. The tomato Cf-9 disease resistance gene functions in tobacco and potato to confer responsiveness to the fungal avirulence gene product Avr9. Plant Cell 10: 1251-1266.

Herbers K., Takahata Y., Melzer M., Mock H.P., Hajorezaei M. and Sonnewald U., 2000. Regulation of carbohydrate partitioning during the interaction of potato virus $Y$ with tobacco. Mol. Plant Path. 1(1): 51-59.

Isla M.I., Ordonez R.M., Moreno M.I., Sampietro A.R. and Vattuone M.A., 2002. Inhibition of hydrolytic enzyme activities and plant pathogen growth by invertase inhibitors. J. Enzyme Inhib. Med. Chem. 17(1): 37-43.

Kooman-Gersmann M., Honee G., Bonnema G. and De Wit P.J.G.M., 1996. A high-affinity binding site for the Avr9 peptide elicitor of Cladosporium fulvum is present on plasma membranes of tomato and other solanaceous plants. Plant Cell 8: 929-938.

Kooman-Gersmann M., Vogelsang R., Hoogendijk E.C. and De Wit P.J.G.M., 1997. Assignment of amino acid residues of the Avr9 peptide of Cladosporium fulvum that determine elicitor activity. Mol Plant Microbe Interact. 10(7): 821-829. 
Lauge R.., Joosten M.H.A.J., Van den Ackerveken G.F.J.M., Van den Broek H.W.J. and De Wit P.J.G.M., 1997. The In planta produced extracellular proteins ECP1 and ECP2 of Cladosporium fulvum are virulence factors. Mol. Plant-Microbe-Interact. 10: $725-$ 734.

Li H., Burkhardt C., Heinrich U.R., Brausch I., Xia N. and Forstermann U., 2003. Histamine upregulates gene expression of endothelial nitric oxide synthase in human vascular endothelial cells. Circulation 107(18): 2348-2354.

Luderer R., Rivas S., Nurnberger T., Mattei B., Van der Hooven H.W., Van der Hoorn R.A.L., Romeis T., Wehrfritz J-M.,Blume B., Nennstiel D., Zuidema D., Vervoort J., De Lorenzo G., Jones J.D.G., De Wit P.J.G.M. and Joosten M.H.A.J., 2001. No evidence for binding between resistance gene product Cf-9 of tomato and avirulence gene product Avr9 of Cladosporium fulvum. Mol. PlantMicrobe Interact 14: $867-876$.

Mackey D., Holt B.F., III, Wiig A. and Dangl J.L., 2002. RIN4 interacts with Pseudomonas syringae type III effector molecules and is required for RPM1-mediated disease resistance in Arabidopsis. Cell 108: 743-754.

Mackey D., Belkhadir Y., Alonso J.M., Ecker J.R. and Dangl J.L., 2003. Arabidopsis RIN4 is a target of the type III virulence effector AvrRpt2 and modulates RPS2-mediated resistance. Cell 112: 379-389.

Maleck K., Levine A., Eulgem T., Morgan A., Schmid J., Lawton K.A., Dangl J.L. and Dietrich R.A., 2000. The transcriptome of Arabidopsis thaliana during systemic acquired resistance. Nat. Gen. 26: 403-410.

Pedley K.F. and Martin G.B., 2003. Molecular basis of Pto-mediated resistance to bacterial speck disease in tomato Annu Rev Phytopathol. 41:215-243.

Pontier D., Gan S., Amasino R.M., Roby D. and Lam E., 1999. Markers for the hypersensitive response and senescence show distinct patterns of expresson. Plant Mol. Biol. 39: 1243-1255.

Riebeling C., Allegood J.C., Wang E., Merrill A.H. Jr and Futerman A.H., 2003. Two mammalian longevity assurance gene (LAG1) family members, trh1 and trh4, regulate dihydroceramide synthesis using different fatty acyl-CoA donors. J Biol Chem. 278(44): $43452-43459$.

Rivas S., Rougon-Cardoso A., Smoker M., Schauser L., Yoshioka H. and Jones J.D., 2004. CITRX thioredoxin interacts with the tomato Cf-9 resistance protein and negatively regulates defence. EMBO J. 23(10): 2156-2165.

Rooney H.C.E., Van 't Klooster J.W., Van der Hoorn R.A.L., Joosten M.H.A.J., Jones J.D.G. and De Wit P.J.G.M., 2005. Cladosporium Avr2 Inhibits tomato Rcr3 Protease required for Cf-2-dependent disease resistance. Science 308: 1783-1786.

Rowland O., Ludwig A.A., Merrick C.J., Baillieul F., Tracy F.E., Durrant W.E., Frutz-Laylin L., Nekrasov V., Sjolander K., Yoshioka H. and Jones J.D.G., 2005. Functional analysis of Avr9/Cf-9 rapidly elicited genes identifies a protein kinase, ACIK1, that is essential for full Cf-9-dependent disease resistance in tomato. Plant Cell 17(1): 295-310.

Scheideler M., Schlaich N.L., Fellenberg K., Beissbarth T., Hauser N.C., Vingron M., Slusarenko A.J. and Hoheisel J.D., 2002. Monitoring the switch from housekeeping to pathogen defence metabolism in Arabidopsis thaliana using cDNA arrays. J. Biol. Chem. 277(12): 10555-10561.

Schenk P.M., Kazan K., Wilson I., Anderson J.P., Richmond T., Sommerville S.C. and Manners J.M., 2000. Coordinated plant defence responses in Arabidopsis revealed by microarray analysis. Proc. Natl. Acad. Sci. USA 97(21): 11655-11660.

Shan L., He P., Zhou J.M. and Tang X., 2000. A cluster of mutations disrupt the avirulence but not the virulence function of AvrPto. Mol Plant Microbe Interact 13(6): 592-598.

Sugano S., Kaminaka H., Rybka Z., Catala R., Salinas J., Matsui K. Ohme-Takagi M. and Takatsuji H., 2003. Stress-responsive zinc finger gene ZPT2-3 plays a role in drought tolerance in petunia. Plant J. 36(6): 830-841

Swidzinski J.A., Sweetlove L.J. and Leaver C.J., 2002. A custom microarray analysis of gene expression during programmed cell death in Arabidopsis thaliana. Plant J. 30(4): 431-446.

Takatsuji H., 1999. Zinc-finger proteins: the classical zinc finger emerges in contemporary plant science. Plant Mol. Biol. 39(6): 10731078.

Tao Y., Xie Z., Chen W., Glazebrook J., Chang H.S., Han B., Zhu T., Zou G. and Katagiri F., 2003. Quantitative Nature of Arabidopsis Responses during Compatible and Incompatible Interactions with the Bacterial Pathogen Pseudomonas syringae. Plant Cell 15(2): $317-330$

Van der Biezen E.A. and Jones J.D.G., 1998. Plant disease-resistance proteins and the gene-for-gene concept. Trends Biochem. Sci. 23: $454-456$

Van der Hoorn R.A.L., Laurent F., Roth. R. and De Wit P.J.G.M., 2000. Agroinfiltration is a versatile tool that facilitates comparative analysis of Avr9/Cf-9-induced and Avr4/Cf-4-induced necrosis. Mol. Plant-Microbe Interact. 13: 439-446.

Van den Hooven H.W., Appelman A.W., Zey T., de Wit P.J.G.M. and Vervoort J., 1999. Folding and conformational analysis of AVR9 peptide elicitors of the fungal tomato pathogen Cladosporium fulvum. Eur J Biochem. 264(1): 9-18.

Van den Hooven H.W., Van den Burg H.A., Vossen P., Boeren S., De Wit P.J.G.M., Vervoort J., 2001. Disulfide bond structure of the Avr9 elicitor of the fungal tomato pathogen Cladosporium fulvum: evidence for a cystine knot. Biochemistry 40(12): 3458-3466. 
Vervoort J., Van den Hooven H.W., Berg A., Vossen P., Vogelsang R., Joosten M.H.A.J. and De Wit P.J.G.M., 1997. The racespecific elicitor Avr9 of the tomato pathogen Cladosporium fulvum: a cysteine knot protein. Sequence-specific $1 \mathrm{H}$ NMR assignments, secondary structure and global fold of the protein. FEBS Lett 404(2-3): 153-158.

Yu D., Liu Y., Fan B., Klessig D.F. and Chen Z., 1997. Is the high basal level of salicylic acid important for disease resistance in potato? Plant Physiol. 115: 343-349.

Yue H., Eastman P.S., Wang B.B., Minor J., Doctolero M.H., Nuttal R.L., Stack R., Becker J.W., Montgomery J.R., Vainer M. and Johnston R., 2001. An evaluation of the performance of cDNA microarrays for detecting changes in global mRNA expression. Nucleic Acids Res. 29(8): E41-1.

\section{Supplementary data}

Table S1 (page $113-120$ ). List of 510 STAR genes with initial annotation, and reannotation March 2005. Reannotation was performed using tBLASTx similarity searching of single component sequences present on the array against the EMBL plant sequence database. Differential expression data are shown for each hybridization experiment. 
†

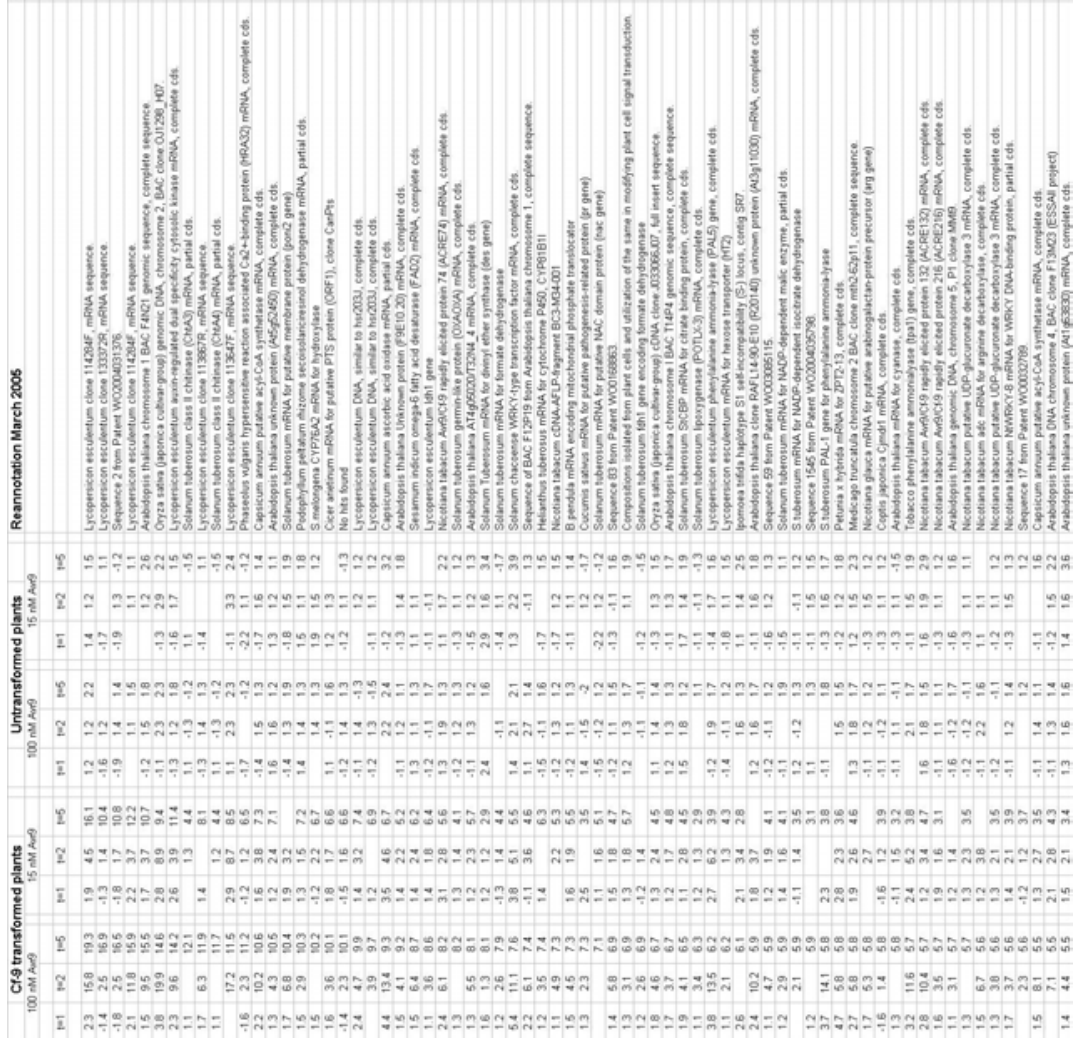

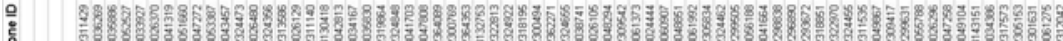

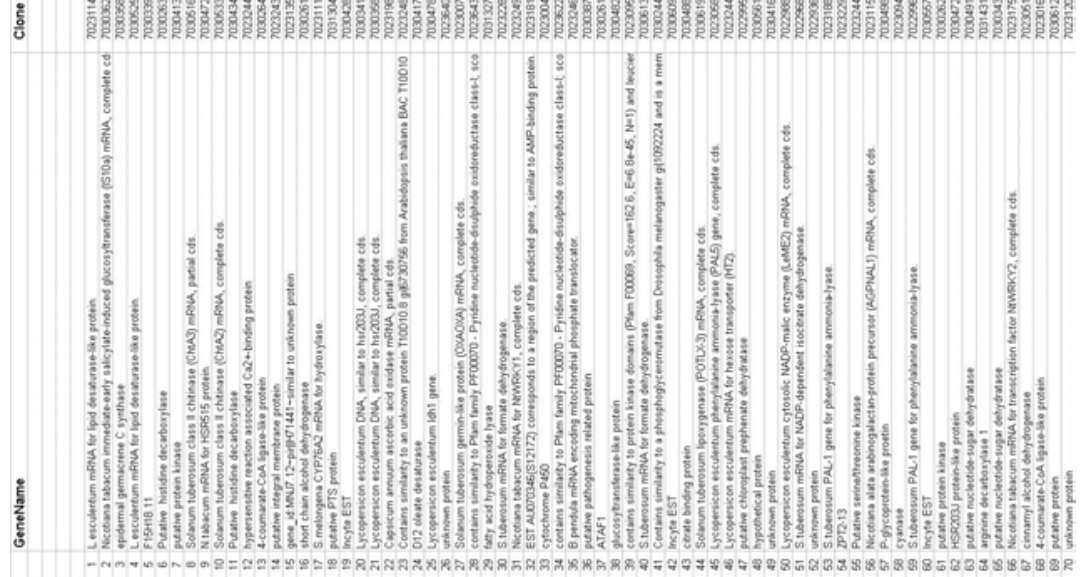


B.
3.
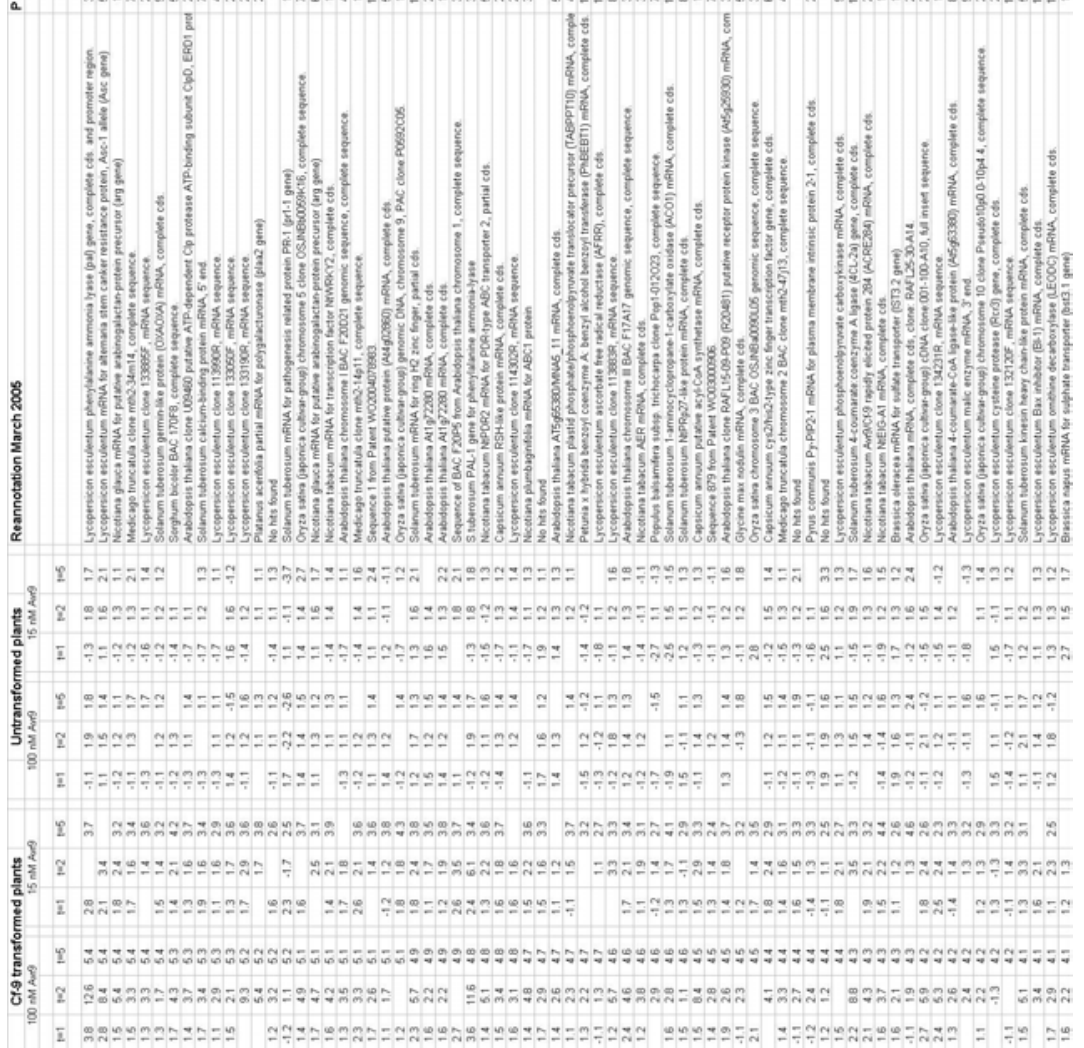

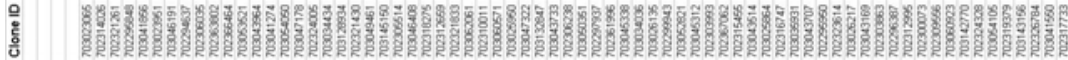

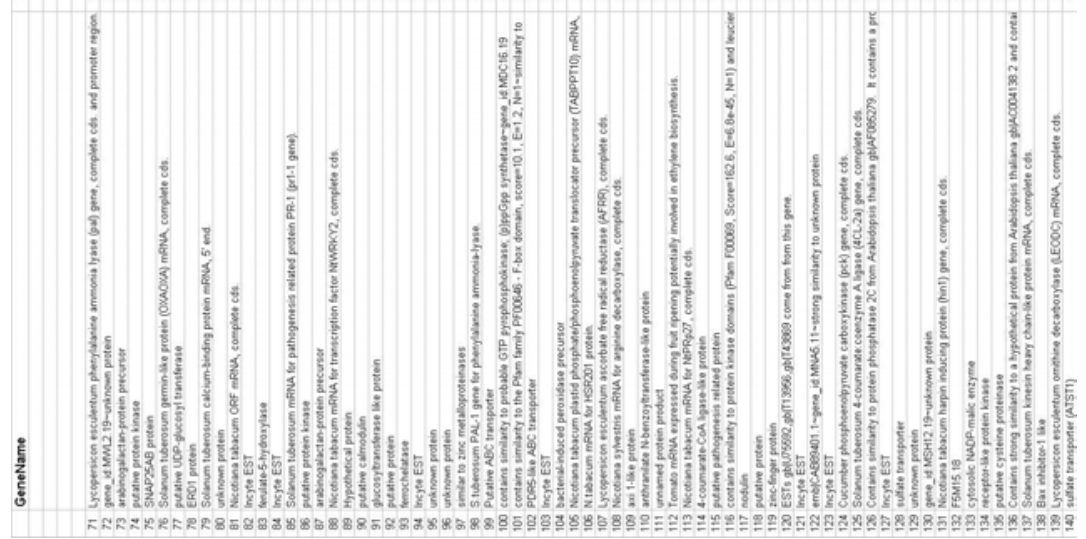




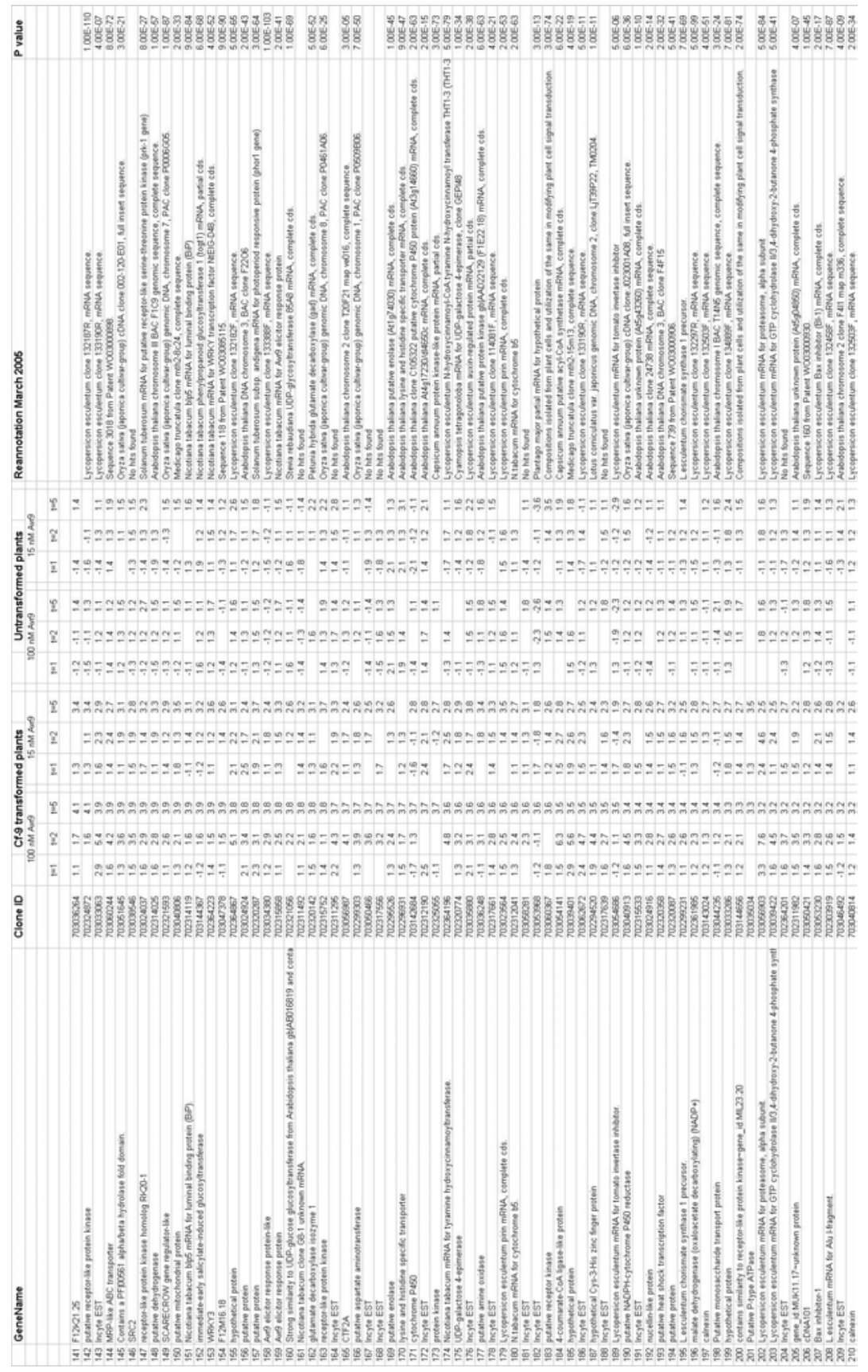




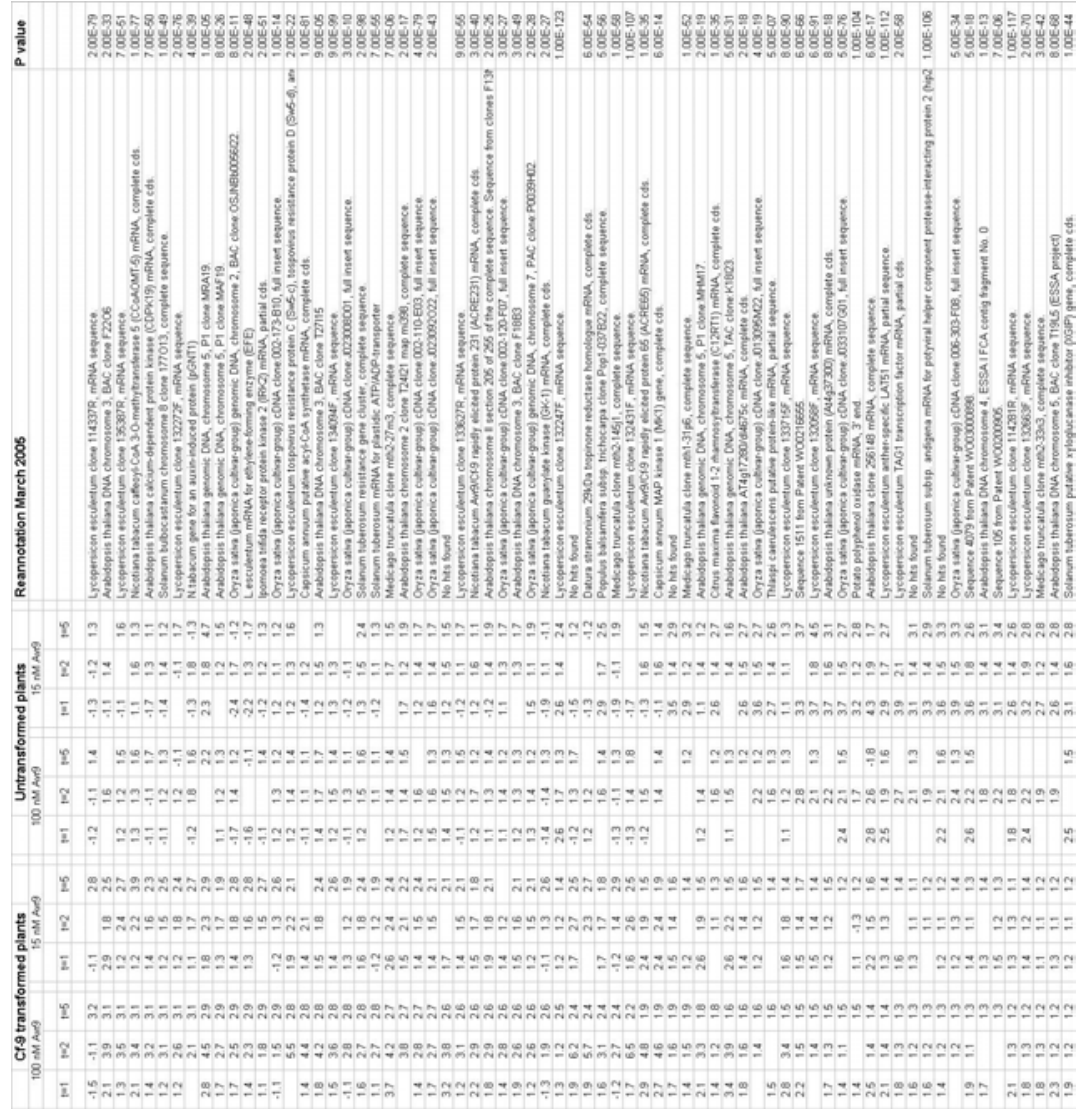

i

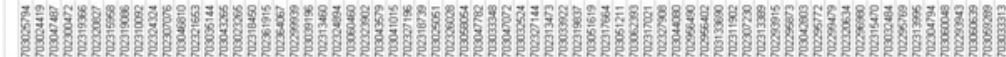

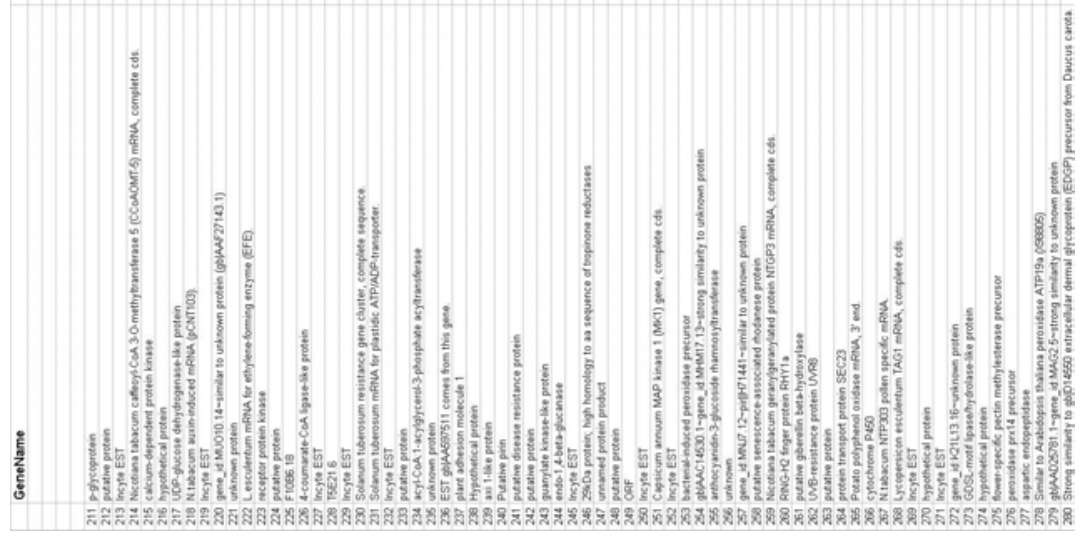



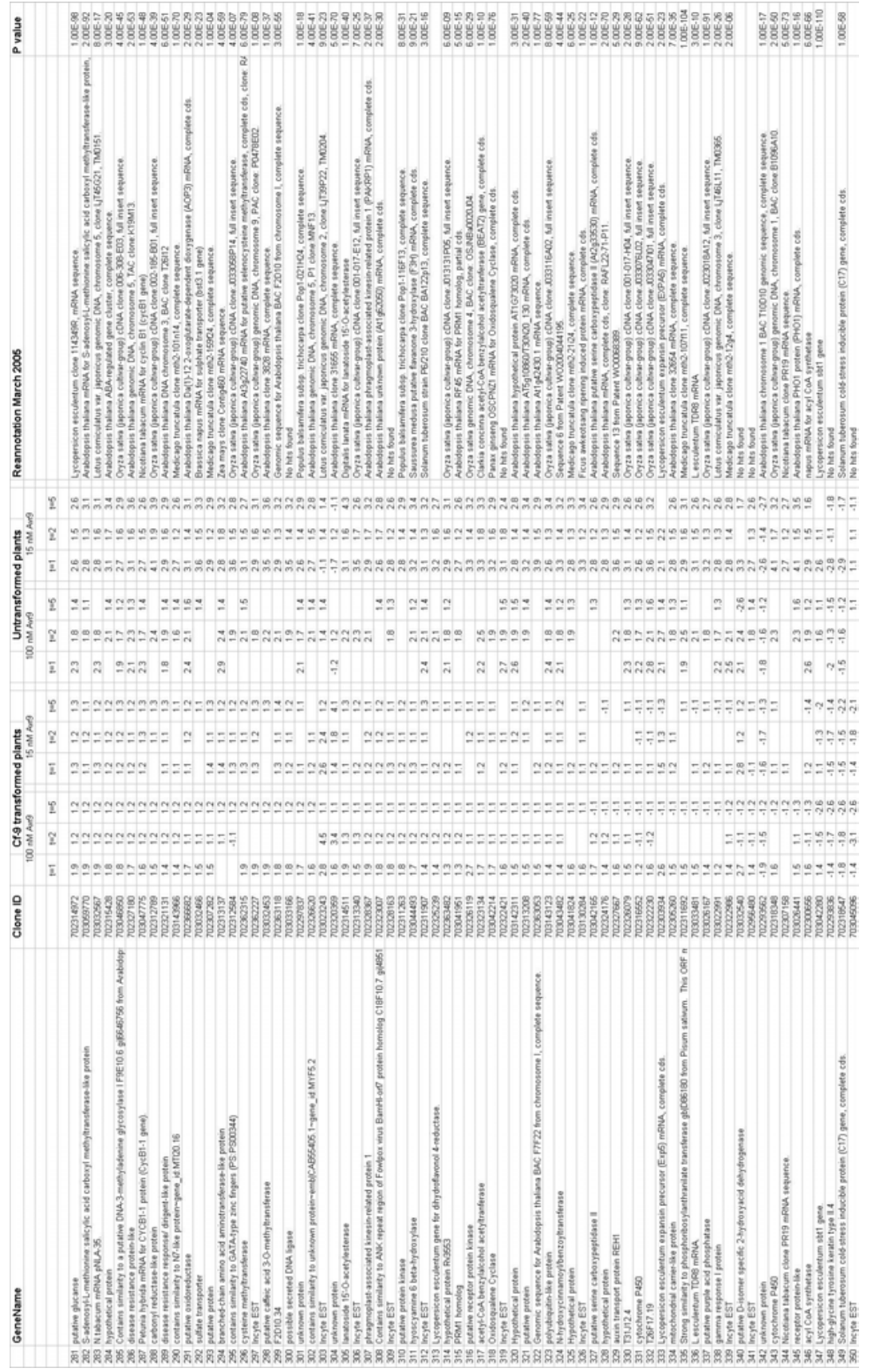


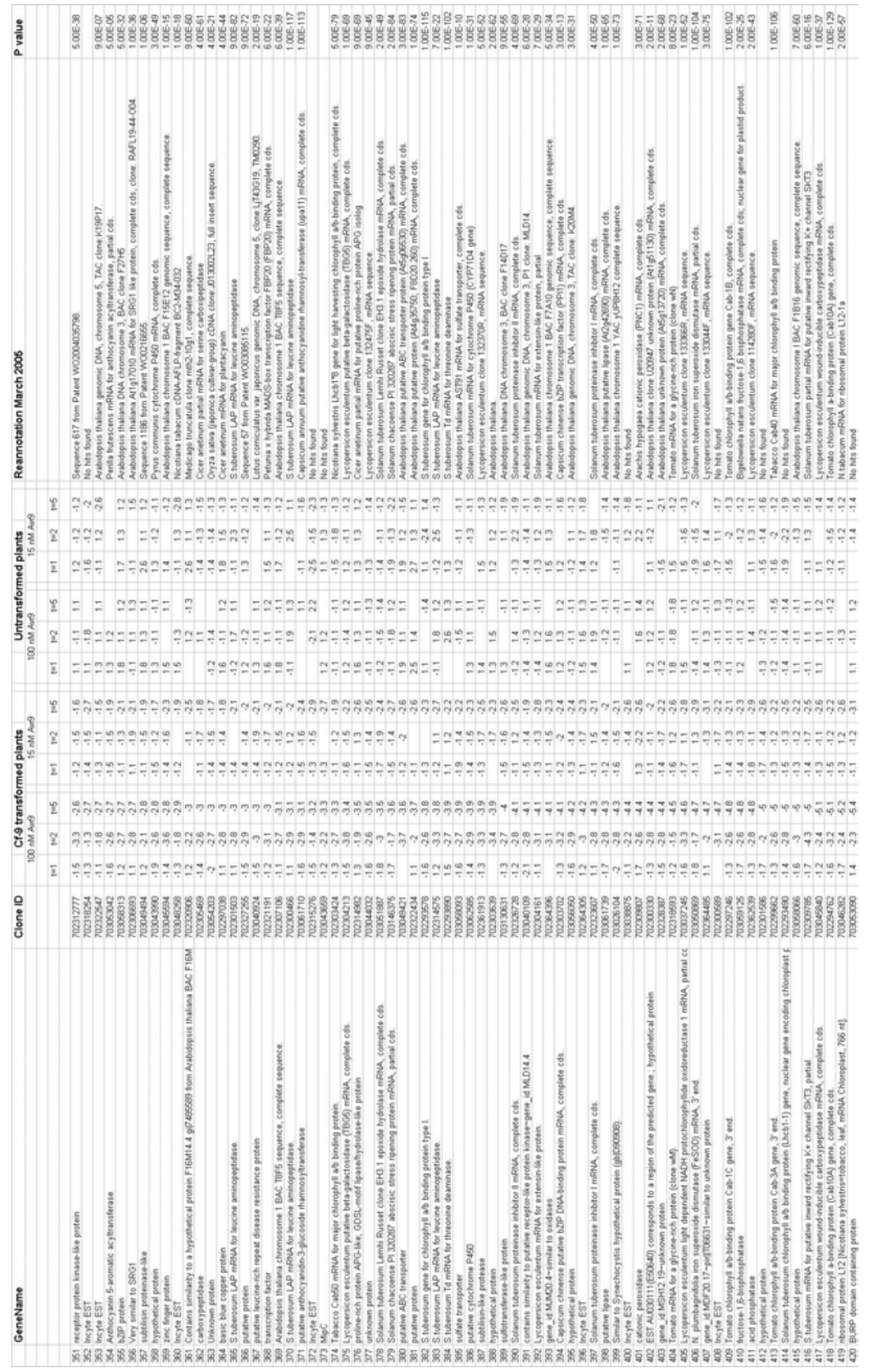




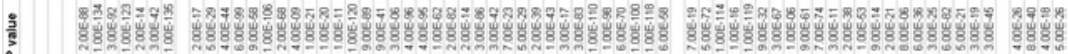

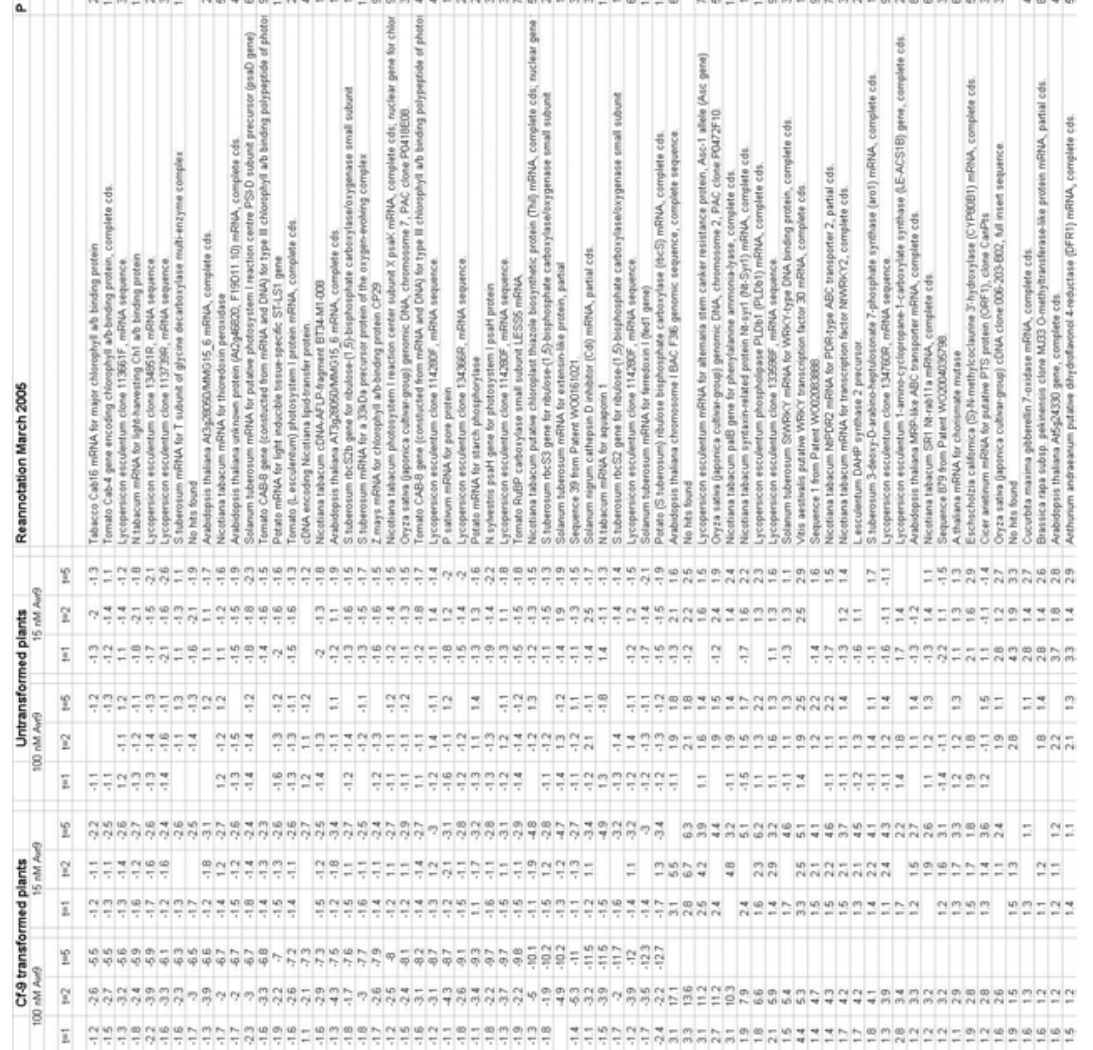

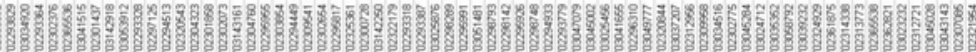

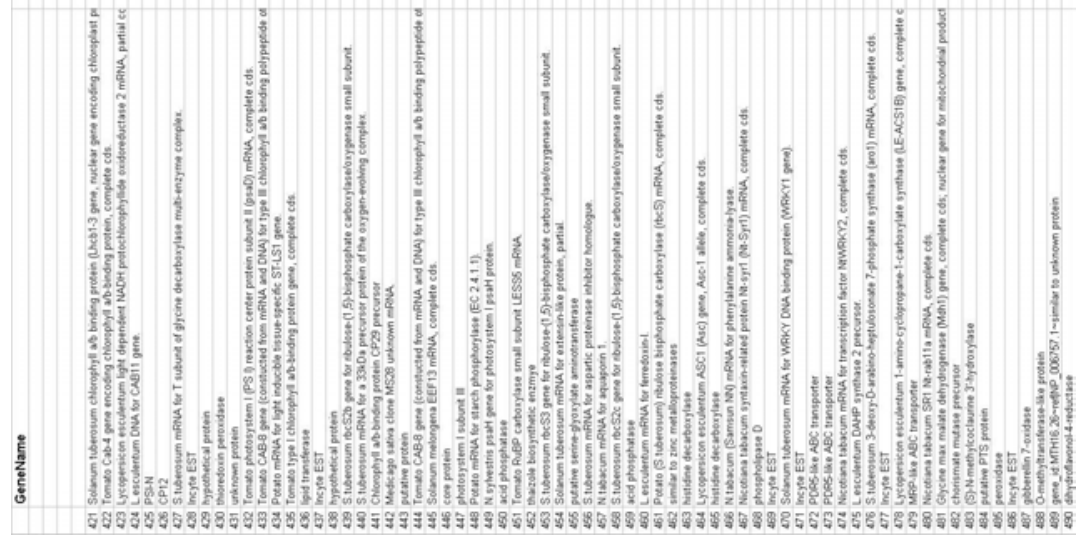



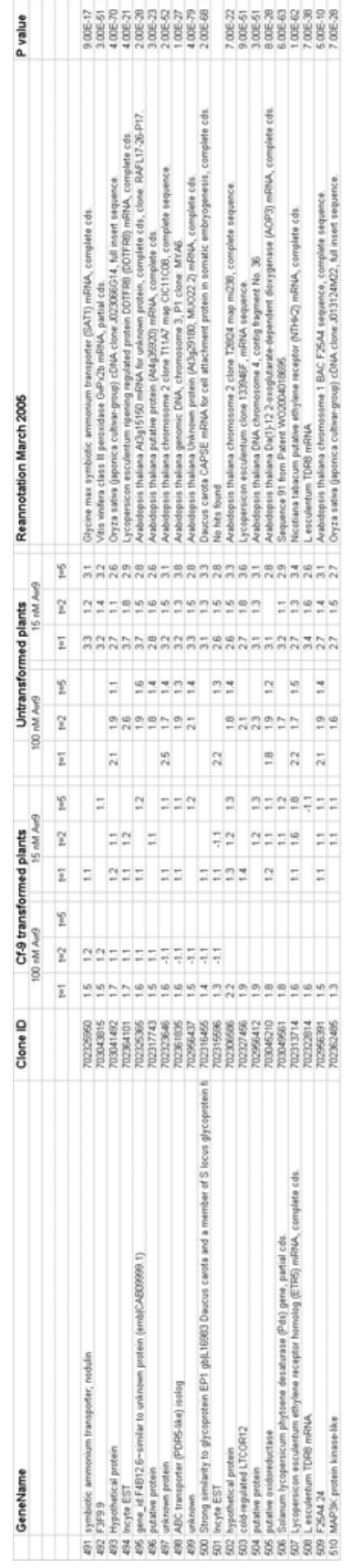


\section{CHAPTER 6}

\section{ISOLATION AND CHARACTERISATION OF A CLASS OF CARBOHYDRATE OXIDASES FROM HIGHER PLANTS, WITH A ROLE IN ACTIVE DEFENCE}

Jerôme H.H.V. Custers, Stuart J. Harrison, Marianne B. Sela-Buurlage, Els van Deventer, Peter W. Howe, Wessel Lageweg, Pieter J. van der Meijs, Anne S. Ponstein, Bert H. Simons, Leo S.

Melchers and Maarten H. Stuiver 
Chapter 6 


\section{SUMMARY}

In a search for novel plant derived antimicrobial proteins we screened extracts from salicylic acid treated lettuce and sunflower leaves. These extracts displayed very potent antimicrobial activity against a set of phytopathogens. Characterization of these extracts revealed that in both extracts proteins of approximately $60 \mathrm{kDa}$ were responsible for the antimicrobial activity. Further characterization of these proteins and cloning of the respective cDNAs revealed close homology to a range of (plant) oxidases. Dissection of the enzymatic activity of both proteins revealed them to be carbohydrate oxidases ( $\mathrm{Ha}-\mathrm{CHOX}$ and Ls-CHOX) with broad substrate specificity and with hydrogen peroxide as one of the reaction products. The sunflower transcript was, in addition to SA inducible, also inducible by fungal pathogens but not by ethylene and jasmonate. To determine whether $\mathrm{Ha}-\mathrm{CHOX}$ plays a role in pathogen defence it was transformed into tobacco and the effect of resistance to Pectobacterium carotovorum subsp. carotovorum was examined. Transgenic plants overexpressing $\mathrm{Ha}-\mathrm{CHOX}$ displayed enhanced resistance to infection by this pathogen, and the resistance level was proportional to enzyme expression.

\section{INTRODUCTION}

Plants have developed a complex defence system to combat invading pathogens, which includes both preformed and induced components. One of the earliest induced responses following attempted infection by pathogens is the rapid formation of active oxygen species (AOS), known as the oxidative burst. The main AOS, hydrogen peroxide $\left(\mathrm{H}_{2} \mathrm{O}_{2}\right)$ and superoxide $\left(\mathrm{O}_{2}^{-}\right)$, have been shown to play a role in several parts of the defence response for three reasons. Firstly, the AOS have a direct antimicrobial effect on the pathogen. Secondly, they are involved in the oxidative cross-linking of cell walls around the site of infection (Bradley et al., 1992). And thirdly, these AOS have been implicated as inducers/activators of defence genes and have a role in the development of cell death during the Hypersensitive Response (HR) (Orozco-Cardenas et al., 2001; Alvarez et al., 1998; Grant and Loake, 2000).

The main source of AOS production in plants in response to pathogen infection is still unknown (Bolwell, 1999; Wojtaszek, 1997). In mammalian systems, plasma membrane-localised NADPHand NADH oxidase complexes are responsible for the generation of the so-called 'respiratory burst'. Plant homologues of components of these enzyme complexes have been identified in rice and Arabidopsis $\left(g p 91^{\text {phox }}\right)$, but it is unclear whether these plant homologues play a key role in the plant oxidative burst (Groom et al., 1996; Angel Torres et al., 1998). Other possible sources of extracellular $\mathrm{H}_{2} \mathrm{O}_{2}$ production in response to biotic stress are $\mathrm{pH}$-dependent cell-wall peroxidases, oxalate oxidases and amine oxidases. The role of $\mathrm{pH}$-dependent cell-wall peroxidases in the generation of $\mathrm{H}_{2} \mathrm{O}_{2}$ is most clearly shown for the interaction between Colletotrichum lindemuthianum and French bean, where they appear to be the sole source of $\mathrm{H}_{2} \mathrm{O}_{2}$ production in the oxidative burst (Bolwell et. al., 1995). In germinating barley and wheat seeds as well as in barley leaves challenged with powdery mildew, oxalate oxidase activity has been identified as a generator of $\mathrm{H}_{2} \mathrm{O}_{2}$ (Lane et al., 1993; Zhou et al., 1998). Oxalate oxidase utilises oxalic acid and oxygen as substrates producing $\mathrm{H}_{2} \mathrm{O}_{2}$ and $\mathrm{CO}_{2}$. For certain necrotrophic fungi such as Sclerotinia sclerotiorum, oxalic acid is a major pathogenicity determinant, significantly altering environmental $\mathrm{pH}$ (Cessna et al., 2000). Pathogen-inducible oxalate oxidase acts both as a generator of $\mathrm{H}_{2} \mathrm{O}_{2}$, killing the invading pathogen, and simultaneously detoxifying the acid, which is phytotoxic at high concentrations. 
Sunflower plants expressing a wheat oxalate oxidase accumulate enhanced levels of salicylic acid and PR1 even in the absence of pathogen infection and display improved tolerance to Sclerotinia infection (Bidney et al., 1999). This effect is most likely due to the production of $\mathrm{H}_{2} \mathrm{O}_{2}$ from endogenous oxalic acid. Amine oxidases are a class of enzymes mainly found in the plant apoplast that act on a variety of amine substrates, including mono-, di- and polyamines and release the corresponding aldehyde as well as $\mathrm{NH}_{3}$ and $\mathrm{H}_{2} \mathrm{O}_{2}$. Amines are present in the plant apoplast and accumulate in response to environmental stress (Bolwell and Wojtaszek, 1997). Thus in plants several systems are available that can produce $\mathrm{H}_{2} \mathrm{O}_{2}$ following pathogen attack.

The importance of $\mathrm{H}_{2} \mathrm{O}_{2}$ in plant defence has clearly been shown by several groups who have reported increased pathogen resistance in transgenic plants by introducing either, $\mathrm{H}_{2} \mathrm{O}_{2}$-generating systems or by inhibiting $\mathrm{H}_{2} \mathrm{O}_{2}$-degrading systems. The expression of a fungal glucose oxidase resulted in enhanced resistance to Phytophthora infestans and Erwinia carotovora in potato (Wu et al., 1995). Similarly, the prevention of $\mathrm{H}_{2} \mathrm{O}_{2}$ breakdown resulted in higher levels of $\mathrm{H}_{2} \mathrm{O}_{2}$ and increased disease resistance (Chamnongpol et al., 1998). Whether this improved pathogen tolerance is due to the direct antimicrobial effect of $\mathrm{H}_{2} \mathrm{O}_{2}$, or due to the fact that the plant defence system is induced by the increased levels of $\mathrm{H}_{2} \mathrm{O}_{2}$, was in either case not investigated.

Here we describe the identification of a novel plant enzyme that plays a role in plant defence. The enzyme was identified in leaves of two members of the Compositae family after treatment with salicylic acid. The cDNAs were cloned and the protein sequence displayed high similarity to the berberine bridge enzymes (reticuline oxidases) found in certain species of the Papaveraceae (Dittrich and Kutchan, 1991). Expression of the gene encoding the sunflower variant was also induced by fungal infection. The isolated enzyme can utilize a range of reducing sugars, most notably hexoses that accumulate in plants upon pathogen infection, resulting in the production of $\mathrm{H}_{2} \mathrm{O}_{2}$. Transgenic tobacco plants constitutively expressing high levels of this carbohydrate oxidase displayed enhanced resistance to infection by the soft rotting bacterium Pectobacterium carotovorum subsp. carotovorum.

\section{RESULTS}

\section{Isolation of an antimicrobial protein from SA-induced sunflower and lettuce leaves}

Protein extracts from sunflower (Helianthus annuus) and lettuce (Lactuca sativa) leaves treated repeatedly with high doses of Salicylic Acid (SA), displayed high levels of antifungal activity, when assayed against a panel of phytopathogenic fungi. The active component from both extracts was purified to apparent homogeneity using successive column chromatography coupled with fungal inhibition assays. The active fractions from each purification step of the active lettuce component are shown in Figure 1. The active fraction shown in lane 5 of figure 1 still contained multiple proteins, which were separated by native PAGE under acidic conditions.

Proteins were eluted from the gel, and half used in an in vitro antifungal assay and the remained separated by SDS-PAGE (data not shown). Examination of the active eluted band from the native PAGE analysis by SDS-PAGE revealed a $64 \mathrm{kDa}$ protein as the most likely candidate for the lettuce antifungal protein. The active component of sunflower was isolated using similar techniques, however a different order was used to purify the protein. Following desalting of the extract, anion and cation exchange purifications were performed $(\mathrm{pH} \mathrm{6)}$ followed by hydrophobic interaction all coupled antifungal assays to follow activity at each step. A final gel filtration chromatography step 
and native (basic conditions) PAGE analysis revealing a $59 \mathrm{kDa}$ protein to be responsible for the antifungal activity (data not shown).

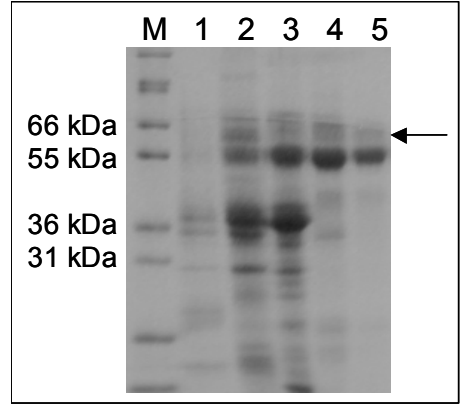

Figure 1. SDS Page gel displaying the purification of the lettuce antimicrobial protein and the enrichment for protein following each stage of purification. (1: Lettuce leaf extract. 2: Active fraction following hydrophobic interaction chromatography. 3: Active fraction following cation exchange chromatography. 4: Active fraction following anion exchange chromatography. 5: Active fraction following gel filtration). The arrow marks the band corresponding to the lettuce AMP.

Both proteins were separated by SDS-PAGE and excised from the gel to allow $\mathrm{N}$-terminal sequencing. The sunflower Anti-Microbial Protein (AMP) was subjected to $\mathrm{N}$-terminal sequencing by Edman degradation, however no sequence could be retrieved from the mature protein, indicating that the $\mathrm{N}$-terminus was potentially blocked. The amino acid sequences of tryptic fragments of this protein were determined, allowing the cloning of the encoding gene from sunflower (AF472609). In the case of the lettuce AMP, amino acid sequence was obtained from the $\mathrm{N}$-terminus and tryptic fragments of the protein, allowing a cDNA encoding the protein to be cloned (AF472608). To clone both genes degenerate primers were designed based on the peptide sequences and RACE PCR performed on cDNA made from poly ${ }^{+}$RNA extracted from SA treated leaves. The lettuce AMP was found to be highly similar in its amino acid sequence to the sunflower AMP. Although the sunflower and lettuce proteins migrated at 59 and $64 \mathrm{kDa}$ respectively the predicted molecular weight of the two proteins were $60.9 \mathrm{kDa}$ and $60.7 \mathrm{kDa}$, respectively.

\section{The sunflower and lettuce AMPs display homology to several oxidases}

A BLAST (Altschul et al., 1990) search against Genbank revealed that the predicted amino acid sequences of the sunflower and lettuce AMPs contain high sequence similarity to the berberine bridge enzymes (BBE) from Californian poppy (Eschscholtzia californica) and Opium poppy (Papaver somniferum). These berberine bridge enzymes or reticuline oxidases catalyse the formation of the berberine bridgehead carbon in the production of $(S)$-scoulerine from $(S)$-reticuline at the branchpoint leading to formation of benzophenanthridine alkaloids (Dittrich and Kutchan, 1991). Cytotoxic benzophenanthridine alkaloids accumulate in certain species of the Papaveraceae and Fumaraceae in response to pathogen attack and are presumed to be phytoalexins (Dittrich and Kutchan, 1991; Dixon, 2001). Weaker sequence similarities were found with other oxidoreductases, 6-hydroxy-D-nicotine oxidase (HDNO) from Arthrobacter oxidans, mitomycin radical oxidase (MCRA) from Streptomyces lavendulae and to a hexose oxidase ( $\mathrm{CcHox}$ ) from the red seaweed Chondrus crispus. An alignment of the amino acid sequences of sunflower and lettuce AMPs, together with EcBBE and CcHox, HDNO and MCRA is shown in Figure 2. The conserved flavin- 
binding site of oxidoreductases as indicated in Figure 2 is thought to bind the FAD cofactor at the histidine in position 104 in EcBBE (Kutchan and Dittrich, 1995). The sunflower and lettuce AMP amino acid sequences each contain a predicted signal sequence of 28 and 27 amino acid residues, respectively, indicating that the proteins are secreted (Von Heijne, 1985).

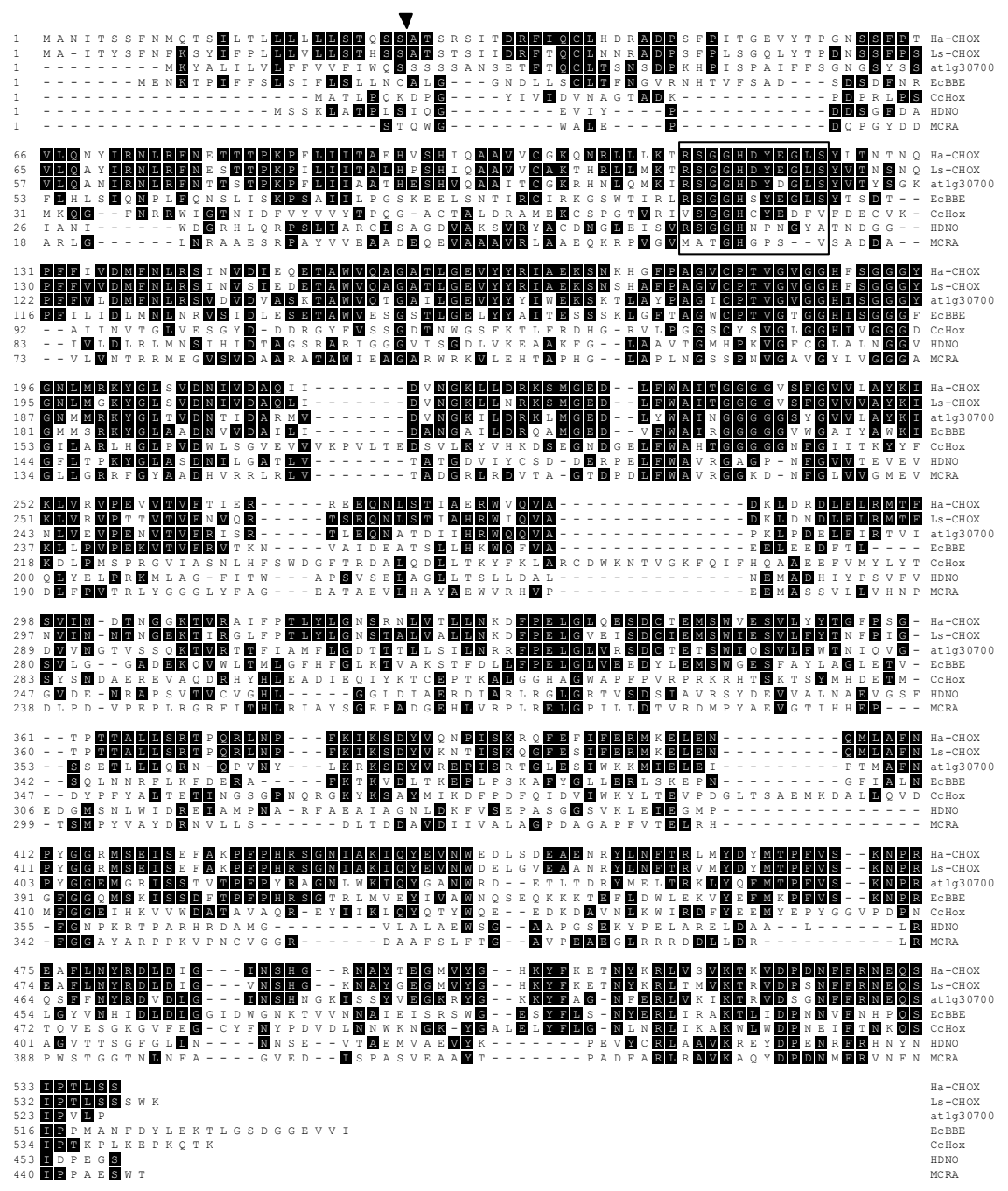

Figure 2: Amino acid sequence alignment of the sunflower and lettuce AMPs with homologous sequences constructed with the ClustalX programme (Thompson et al., 1997) and displayed using MEGALIGN (DNAstar, Madison, WI). The black-boxed area indicates the putative flavin binding site consensus (Dittrich and Kutchan, 1991). The black triangle indicates the putative cleavage site of the N-terminal signal sequences of the AMPs. The Genbank accession numbers for the protein sequences are; Sunflower AMP. AF472609: Lettuce AMP. AF472608; ECBBE (Eschscholtzia californica berberine bridge enzyme): P30986; HDNO (Arthrobacter oxidans 6-hydroxy-d-nicotine oxidase): X05999; MCRA (Streptomyces lavendulae mitomycin radical oxidase): 129247 ; CcHox (Chondrus crispus hexose oxidase): P79076. 
The Arabidopsis genome contains at least 27 genes with high similarity to the sunflower AMP. In an attempt to classify these Arabidopsis homologs we performed phylogenetic analysis of the (predicted) amino acid sequences of these 27 Arabidopsis genes, together with sunflower and lettuce AMPs, E. californica BBE, and C. crispus hexose oxidase. The resulting phylogenetic tree (Figure 3a) clearly shows that this group of protein sequences can be divided into 7 major clades. The sunflower and lettuce AMPs group together with the Arabidopsis predicted protein at $1 \mathrm{~g} 30700$ and this group is marked with a grey elipse (Figure 3a). E. californica BBE and C. crispus Hexose oxidase are on separate branches. When phylogenetic analysis was performed on these three protein sequences together with the sunflower and lettuce AMPs, At1g30700, 6-hydroxy nicotine oxidase and mitomycin radical oxidase (Figure $3 b$ ) it clearly shows that the BBE is the most related characterised protein to the sunflower and lettuce AMPs. When the sequences of the sunflower and lettuce AMPs were subjected to BLAST searches against plant EST databases, similarities were found in the majority of dicot and monocot species for which sequence was available (data not shown).

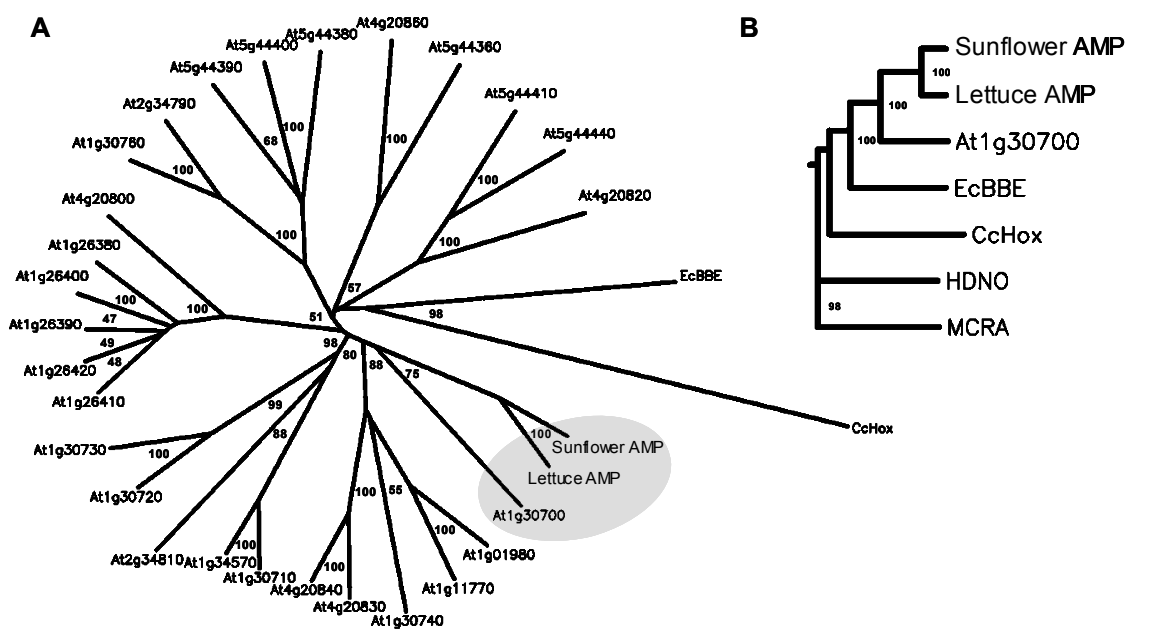

Figure 3. Phylogenetic trees showing the relationship of the sunflower and lettuce AMPs to other oxidases. (A) An unrooted phylogenetic tree showing the relationship between the AMPs, EcBBE, CcHox, and the 27 closest homologs from the Arabidopsis genome. The tree was constructed using the neighbour-joining method of the ClustalX programme (Thompson et al., 1997). The tree is based on complete (predicted) protein sequences. Numbers at branch tips indicate Arabidopsis database accession numbers (TAIR: http://www.arabidopsis.org/). Confidence values are displayed at internal branches as a percent of 1000 times bootstrap. (B) Phylogenetic tree displaying the relationship of the AMPs to oxidases from different organisms. This phylogenetic tree is as in Figure 3a based on complete protein sequences. Sequences are as in Figure 2. Confidence values are displayed at internal branches as a percent of 1000 times bootstrap.

Due to the high level of sequence similarity and presence of relevant active site residues, it is presumed that both the sunflower and lettuce AMPs are oxidases. Similarly, due to the high level of sequence identity it was presumed that both the sunflower and lettuce AMPs have identical activity and therefore all further characterisation has been performed on the sunflower antimicrobial protein. 
Induction of the sunflower AMP after treatment with biotic and abiotic elicitors

To further study the inducibility of the sunflower AMP promoter, the induction of the AMP mRNA in sunflower plants to various plant signalling molecules and pathogenic fungi was examined. The transcript levels determined by competitive RT-PCR are listed in Table 1 relative to the gapC (glyceraldehyde 6-phosphate dehydrogenase endogenous control gene) transcript levels measured in the same samples. Treatment of sunflower plants with a high concentration of SA $(5 \mathrm{mM}$, the concentration used to induce the antifungal activity in sunflower), induced the sunflower AMP transcript at least 40 fold relative to the gapC control. Treatments with a lower concentration SA (1 $\mathrm{mM}$ ), Jasmonic acid or ACC did not have an effect on sunflower AMP transcript levels relative to gapC transcript levels. The sunflower AMP was induced approximately 10-20 fold when normalized for gapC expression after sunflower plants were challenged with Sclerotinia sclerotiorum, Botrytis cinerea and Diaporthe helianthi. During infection by $B$. cinerea and S. sclerotiorum the induction was restricted to the lesion in contrast to infection by $D$. helianthi. After infection by the hemibiotrophic fungus $D$. helianthi a 100-fold induction of the sunflower AMP transcript was observed outside the necrotic zone.

Table 1: Expression profiles of sunflower AMP and glyceraldehyde 6-phospate dehydrogenase $(g a p C)$ transcripts as determined by competitive RT-PCR relative to an untreated control. Relative sunflower AMP induction is calculated by normalisation to the gapC transcript leve.

\begin{tabular}{lccc}
\hline Treatment & AMP induction & gapC induction & Relative AMP induction \\
\hline mM Salicylic acid & 2000 & 500 & 40 \\
$1 \mathrm{mM} \mathrm{Salicylic} \mathrm{acid}$ & 100 & 100 & 1 \\
$1 \mathrm{mM} \mathrm{ACC}$ & 500 & 500 & 1 \\
$0.1 \mathrm{mM} \mathrm{Jasmonic} \mathrm{acid}$ & 100 & 100 & 1 \\
Botrytis cinerea local $^{1}$ & 1000 & 100 & 10 \\
Diaporthe helianthi local $^{1}$ & 1000 & 100 & 20 \\
Sclerotinia sclerotiorum local $^{1}$ & 1000 & 50 & 1 \\
Botrytis cinerea distal $^{2}$ & 1 & 5 & 100 \\
Diaporthe helianthi distal $^{1}$ & 500 & 5 & 1 \\
Sclerotinia sclerotiorum distal $^{1}$ & 1 & 1 & 10 \\
\hline
\end{tabular}

${ }^{1}$ local means induction in leaf disk of $13 \mathrm{~mm}$.

${ }^{2}$ distal means induction in leaf ring removed around leaf disk of $13 \mathrm{~mm}$ until $25 \mathrm{~mm}$.

Heterologous overexpression of the sunflower AMP in Escherichia coli

Purification of the protein from SA-treated sunflower leaves yielded limited amounts of pure protein. To allow sufficient characterisation of both the enzymatic and antifungal properties, the protein was overexpressed in E. coli. The sequence encoding the predicted mature protein of the sunflower AMP was cloned into the pET32c (Novagen) expression vector. A $10 \mathrm{~L}$ batch culture was prepared and the antifungal protein was purified from the soluble protein fraction using a combination of metal affinity chromatography, cation exchange chromatography, and a final step of gel filtration. This procedure resulted in purification to apparent homogeneity of the recombinant protein with identical antifungal activity to that of the plant-derived protein.

\section{Enzymatic properties of the recombinant sunflower antifungal protein}

Due to the high sequence similarity between the sunflower enzyme and the BBE class of enzymes, it was tested for reticuline oxidase activity. No reticuline oxidase activity could be measured from the enzyme at a range of enzyme and substrate concentration, when measured by $\mathrm{H}_{2} \mathrm{O}_{2}$ release (data 
not shown). Since sequence homology was also found with several other oxidases and since it was isolated as a protein with antifungal activity, a fungal cell wall suspension was prepared to function as a substrate for the putative oxidase activity. A crude cell wall suspension was prepared from Rhizoctonia solani by sonication (Jijakli and Lepoivre, 1998) and an oxidase assay performed. Oxidase activity, shown by the release of $\mathrm{H}_{2} \mathrm{O}_{2}$, was clearly detected when the purified enzyme was incubated in the presence of a cell wall suspension (data not shown). The major cell wall components of $R$. solani are $\beta$-1,3-glucan and chitin, polymers of glucose and $\mathrm{N}$-acetylglucosamine, respectively. In order to determine which of the components in fungal cell walls was acting as a substrate, the non-polymerised sugars comprising the wall were utilised as substrates in oxidase assays. The recombinant enzyme (100nM) was able to utilise glucose, but not $\mathrm{N}$-acetyl glucosamine as a substrate when tested at a range of substrate concentrations from $1 \mu \mathrm{M}$ to $1 \mathrm{mM}$ (data not shown).

To characterise the glucose-oxidising activity further, the enzymatic properties of the sunflower AMP ( $\mathrm{Km}$ and $\mathrm{Vmax}$ ) were determined along side those of glucose oxidase and pyranose oxidase, both of which share the ability to utilise glucose as a substrate. Two hundred nanograms of the sunflower AMP, glucose oxidase (Sigma) and pyranose oxidase (Biozyme laboratories) were incubated with a range of glucose concentrations $(0.125-2 \mathrm{mM})$ at $\mathrm{pH} 6.5$ and the enzyme activity monitored by the release of $\mathrm{H}_{2} \mathrm{O}_{2}$. As can be seen in Table 2, the three enzymes possess different characteristics, with the AMP most closely resembling pyranose oxidase in activity characteristics, sharing a similar $\mathrm{Km}$ and $\mathrm{Vmax}$ value for glucose.

Table 2. Enzymatic properties of Glucose oxidase, Pyranose oxidase and the recombinant sunflower AMP when utilising glucose as a substrate. Pure enzyme samples were incubated in the presence of varying concentrations of glucose and hydrogen peroxide production was monitored using a colour reaction measured spectrophotometrically at $510 \mathrm{~nm}$. Reaction rates were used to calculate both $\mathrm{Km}$ and Vmax values.

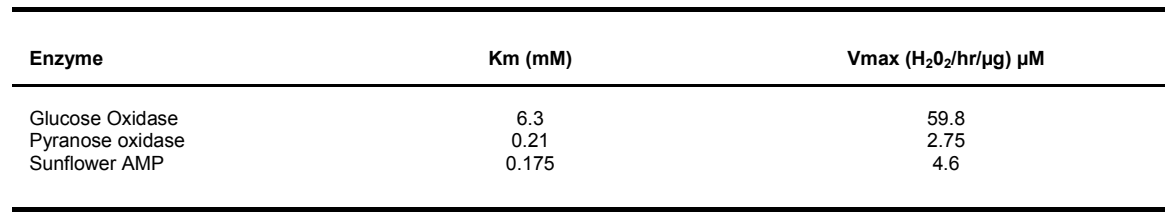

To perform a preliminary investigation into the substrate specificity of the enzyme, its ability to utilise a range of mono- and polysaccharides as substrates was examined. Glucose oxidase and pyranose oxidase were again included in these experiments as controls as their enzyme characteristics have been extensively examined. The three enzymes were incubated with Dglucose, L-glucose, D-galactose, D-mannose, D-altrose, maltose, lactose, sucrose, fructose, cellobiose, cellotriose, cellotetriose, cellopentaose, cellulose and $\mathrm{N}$-acetyl-glucosamine, at a concentration of substrate 10-fold exceeding the Km for glucose for the sunflower AMP (2 mM of substrate). Most likely, these concentrations represent saturating substrate conditions for at least pyranose oxidase and the AMP. As a defined molecular weight could not be obtained for cellulose, the same weight was added as for the cellopentaose. The rate of each reaction was monitored over 30 minutes and activity is represented as hydrogen peroxide production per hour. The sunflower enzyme was able to convert the majority of the mono- and disaccharide substrates tested, whereas 
glucose and pyranose oxidase displayed limited ability to utilise the substrates tested (Figure 4a). It is clear that the protein is able to use different carbohydrates as a substrate in an oxidation reaction. Therefore the sunflower and lettuce AMPs have been renamed Ha-CHOX (Helianthus annuus carbohydrate oxidase) and Ls-CHOX (Lactuca sativa carbohydrate oxidase) respectively.

A

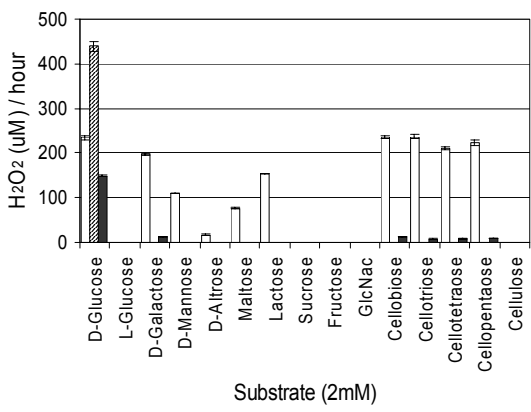

B

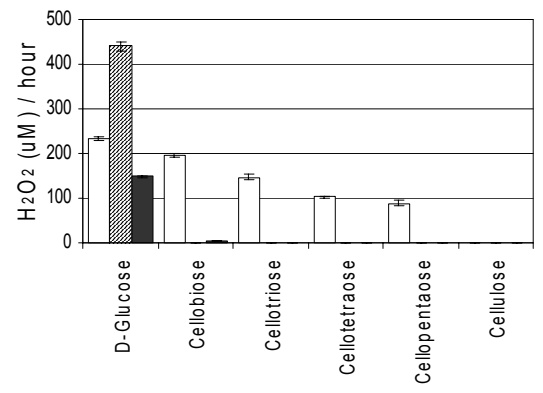

Substrate $(1.8 \mathrm{mg} / \mathrm{mL})$

Figure 4. Specific activity of the recombinant sunflower AMP ( $\mathrm{Ha}-\mathrm{CHOX}$, white bars) as compared to Glucose oxidase (hatched bars) and pyranose oxidase (black bars), utilising a range of mono and disaccharides. (A) Displays the specific activity $\left(\mathrm{H}_{2} \mathrm{O}_{2} / \mathrm{mM} / \mathrm{hr}\right.$ ) of the three enzymes when utilising a range of substrates at fixed molar concentrations (mM). (B) Displays the specific activity $\left(\mathrm{H}_{2} \mathrm{O}_{2} / \mathrm{mM} / \mathrm{hr}\right)$ of the three enzymes when utilizing a range of cellulose oligomers at fixed concentrations $(\mathrm{mg} / \mathrm{mL})$.

The activity of Ha-CHOX against polysaccharides was further investigated using the selection of cellulose oligomers. Unlike the experiment performed above, the polysaccharides were added at equal weights rather than equal molarity. As can be seen in Figure $4 \mathrm{~b}$, hydrogen peroxide production drops with each additional glucose moiety, suggesting that $\mathrm{Ha}-\mathrm{CHOX}$ is acting only on the terminal reducing sugar molecule of each polymer.

\section{Dissection of the reaction catalysed by Ha-CHOX}

The BLAST search indicated the most closely related hexose oxidase to be one from Chondrus crispus, which possesses a similar substrate range to Ha-CHOX (Groen et al., 1997). This enzyme is a 1-oxidoreductase (identical catalytic reaction to glucose oxidase), which converts D-glucose and oxygen to $\delta$-glucono 1,5-lactone and $\mathrm{H}_{2} \mathrm{O}_{2}$. Pyranose oxidase, a 2-oxidoreductase converts Dglucose and oxygen to 2-dehydro-D-glucose and $\mathrm{H}_{2} \mathrm{O}_{2}$. To determine the end product of the oxidation of glucose by $\mathrm{Ha}-\mathrm{CHOX}$, the enzyme (100 $\mathrm{ng}$ ) was incubated with glucose (1 mM) overnight (room temperature) and the products of the reactions were analysed by RP-HPLC. The products of the Ha-CHOX catalysed reaction were then compared with those of glucose oxidase and pyranose oxidase treated in a similar manner. The oxidised product of the $\mathrm{Ha}-\mathrm{CHOX}$ reaction shared the same elution time with the reaction product of glucose oxidase, previously identified as $\delta$-glucono-1-5-lactone (Figure 5) and thus we conclude that $\mathrm{Ha}-\mathrm{CHOX}$ is a 1-oxidoreductase with a reaction scheme similar to glucose oxidase. The reaction product of $\mathrm{Ha}-\mathrm{CHOX}$ was subsequently injected together with that of the glucose oxidase and pyranose oxidase and co-elution with the glucose oxidase product, $\delta$-glucono-1,5 lactone supported the above result (data not shown). 


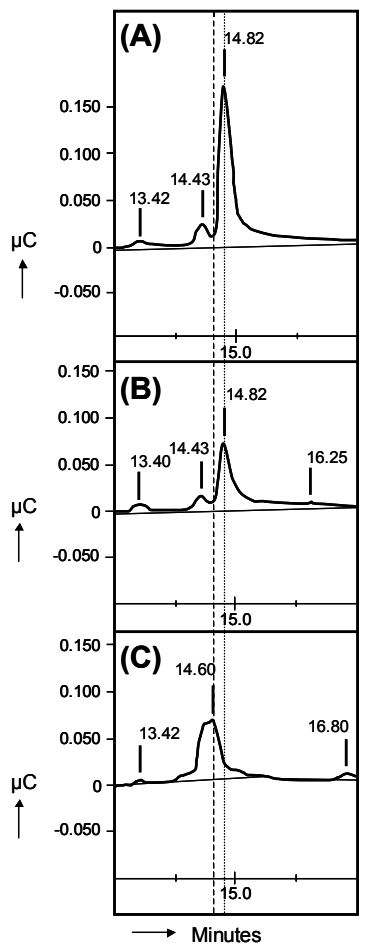

Figure 5. Analysis of the carbohydrate end products of the oxidation of glucose by $\mathrm{Ha}-\mathrm{CHOX}(\mathrm{A})$, glucose oxidase (B) and pyranose oxidase (C) by RP-HPLC. The dotted lines overlaying the chromatogram show the end products peaks of Ha-CHOX and glucose oxidase sharing a similar elution time, whereas the end product of the reaction catalysed by pyranose oxidase elutes 0.22 minutes earlier.

To confirm the RP-HPLC co-elution experiments the product of Ha-CHOX was examined by NMR and the structure compared to that of product of glucose oxidase and glucose, $\delta$-glucono 1,5 lactone. Five hundred nanograms of $\mathrm{Ha}-\mathrm{CHOX}$ and glucose oxidase (Sigma) were incubated overnight with $5 \mathrm{mM}$ glucose $(\mathrm{pH} 6.5)$. Following the overnight incubation, the reaction mixtures were measured by NMR and compared to that of the expected end product. The enzyme reaction mixtures displayed a similar peak pattern when the $1 \mathrm{D}{ }^{1} \mathrm{H}$ NMR spectra were overlaid, confirming they contained identical components (data not shown). Further analysis of the $\mathrm{Ha}-\mathrm{CHOX}$ reaction mixture before and after the addition of gluconic acid (the hydrolysis product of $\delta$-glucono 1,5 lactone) confirmed that the product peaks are from gluconic acid and that $\mathrm{Ha}-\mathrm{CHOX}$ is a 1oxidoreductase (Supplementary data).

\section{Characterisation of the antimicrobial activity of the Ha-CHOX enzyme}

$\mathrm{Ha}-\mathrm{CHOX}$ inhibited the growth of all tested Oomycete, fungal and bacterial plant pathogens in an in vitro assay (Table 3 ). Even though the enzyme can utilize fungal cell walls as substrates, we 
believe that the glucose present in the assay medium was the main substrate for the enzyme. The end products of the reaction (when utilizing glucose as a substrate), $\mathrm{H}_{2} \mathrm{O}_{2}$ and $\delta$-glucono 1,5-lactone were tested for their ability to inhibit fungal growth. As can be seen in Table 3 , hydrogen peroxide efficiently inhibits all fungal pathogens, however $\delta$-glucono 1,5-lactone also acted as a strong inhibitor of the growth of $P$. carotovorum.

Table 3. Antimicrobial activity of $\mathrm{Ha}-\mathrm{CHOX}$, hydrogen peroxide $\left(\mathrm{H}_{2} \mathrm{O}_{2}\right)$ and $\delta$-gluconolactone against a range of oomycete, fungal and bacterial phytopathogens. Microbial growth was visually assessed to determine the concentration required for $50 \%$ growth inhibition.

\begin{tabular}{lccc}
\hline Pathogen & Ha-CHOX (mM) & $\mathbf{H}_{2} \mathbf{O}_{2}(\mathbf{m M})$ & ठ-gluconolactone (mM) \\
\hline Phytophthora infestans & 0.0025 & 0.19 & $>25$ \\
Botrytis cinerea & 0.049 & 9 & $>25$ \\
Pyricularia oryzae & 0.0066 & 2.2 & $>25$ \\
Fusarium graminearum & 0.01 & 1.2 & $>25$ \\
Rhizotonia solani & 0.0051 & 0.39 & $>25$ \\
Pectobacterium carotovorum subsp. carotovorum & 0.0019 & 0.036 & 0.55 \\
\hline
\end{tabular}

\section{Role of Ha-CHOX in defence against pathogen attack.}

Transgenic tobacco ( $N$. tabacum CV. SR1) plants overexpressing the Ha-CHOX protein were generated to assess a potential role in the defence response. Ha-CHOX under the control of the 'Super-promoter' (Ni et al., 1995) starting at the $2^{\text {nd }}$ ATG (includes the signal peptide) was transformed into tobacco using A. tumefaciens. The protein was produced in an active form and was found exclusively in the apoplast (data not shown). The expression level of 30 plants (4 weeks after germination) from each of 9 lines was assessed by determination of $\mathrm{Ha}-\mathrm{CHOX}$ enzyme activity. Thirty plants were selected for further analysis from the initial screen representing high, medium and low expressing lines. All plants were then reassessed for expression level after 8 weeks. Many of the plants displayed inconsistent expression across a leaf, which was also observed in potato, tomato and Brassica napus GUS expressing lines when using the same promoter (Data not shown). Lines were selected for consistent expression levels, with 6 plants displaying constant expression across the leaf, which also represented a range of different enzyme expression levels.

To analyse the effect of $\mathrm{Ha}-\mathrm{CHOX}$ overexpression on the ability of plants to accumulate hydrogen peroxide after pathogen attack, we exposed these 6 selected plants to various substrates and assessed $\mathrm{H}_{2} \mathrm{O}_{2}$ production in planta. Firstly, glucose was used as the internal standard, which was used to rank the plants (Figure 6a). Secondly, invertase was infiltrated to provide a source of free glucose for the enzyme. Plants secrete apoplastic invertase upon infection by pathogens and likewise, pathogens utilize the same enzymatic activity in order to utilize plant-derived sucrose (Hall and Williams, 2000). Invertase infiltration clearly resulted in an elevated $\mathrm{H}_{2} \mathrm{O}_{2}$ production proportional to the expression level (Figure 6a). The bacterial plant pathogen Pectobacterium carotovorum makes large amounts of cell wall degrading enzymes upon infection, and consequently the hexoses released during the interaction may act as substrate sources for $\mathrm{Ha}-\mathrm{CHOX}$. The culture filtrate of Pectobacterium carotovorum was therefore also infiltrated and $\mathrm{H}_{2} \mathrm{O}_{2}$ production assessed. $P$. carotovorum was grown in a synthetic growth medium supplemented with macerated tobacco 
leaves to induce enzyme production prior to infiltration. Using a gel diffusion assay it was confirmed that the $P$. carotovorum culture filtrate possessed both cellulase and polygalacturonase activity (data not shown), the two main cell wall-degrading enzymes produced by $P$. carotovorum (Chatterjee et al., 1995). Infiltration of culture filtrate containing such enzymes also resulted in a significant accumulation of hydrogen peroxide in transgenic plants expressing high levels of Ha$\mathrm{CHOX}$, with significantly lower levels in a low expressor (Figure 6a). Estimates of protein expression levels from Western blots indicated a clear relationship of protein to enzymatic activity (data not shown), consistent with the finding that non-transgenic tobacco plants had no significant endogenous enzymatic activity converting glucose to hydrogen peroxide.

\section{A}

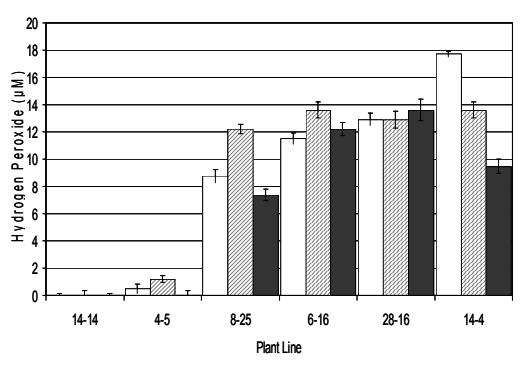

B

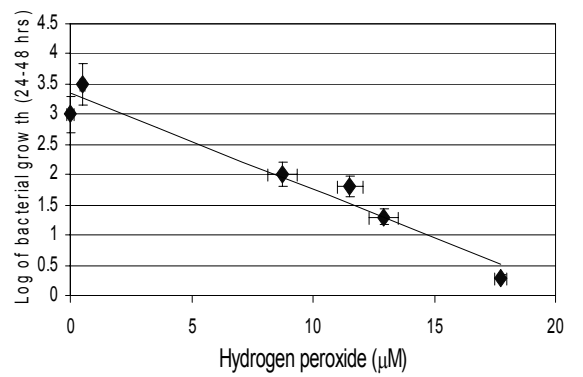

Figure 6: Analysis of 6 independent $\mathrm{Ha}-\mathrm{CHOX}$ transgenic tobacco lines for production of $\mathrm{H}_{2} \mathrm{O}_{2}$ upon application of substrate and resistance to infection by Pectobacterium carotovorum. The 6 plants represented a subset of transgenics whose protein levels were consistent both across and between leaves. (A) In planta determination of hydrogen peroxide production in $\mathrm{Ha}-\mathrm{CHOX}$ transgenic tobacco plants following the application of various sources of glucose. Glucose (white bars), Invertase (shaded bars) and Pectobacterium carotovorum culture filtrate (black bars). (B) Analysis of resistance to infection by Pectobacterium carotovorum (Log of bacterial growth between 24 and 48 hours after inoculation) as compared to enzyme expression level (In planta measurement of right, low expressers to high expressers) as in Figure 6A. From this picture it is clear that the lines expressing a high level of carbohydrate oxidase activity display enhanced tolerance to bacterial infection.

The final assessment for the importance of $\mathrm{Ha}-\mathrm{CHOX}$ in plant defence was to infect the panel of 6 overexpressing lines with $P$. carotovorum to determine whether $\mathrm{Ha}-\mathrm{CHOX}$ expression level correlates with resistance. Plants were infected with $P$. carotovorum grown to a logarithmic growth phase and infiltrated into the leaves at a cell density of $10^{8}$ cells per $\mathrm{mL}$. Plants were then sampled at 24 and 48 hours after inoculation, bacteria isolated from the leaves and colony counts performed. As can be seen clearly from the graph in Figure $6 \mathrm{~b}$ bacterial growth in that period clearly correlates negatively with the level of $\mathrm{Ha}-\mathrm{CHOX}$ expression.

\section{DISCUSSION}

This is the first report that describes the identification of a carbohydrate oxidase from higher plants. Until now enzymes with a comparable activity and substrate range have only been found in the red seaweed C. crispus (hexose oxidase) and in fungi, particularly the Basidiomycetes (pyranose oxidase). The activity has also been described for several citrus species, but the enzyme responsible for these activities has not been isolated (Bean et al., 1961). 


\section{Dissection of the function of Ha-CHOX}

Based on the high level of sequence homology with reticuline oxidase the obvious first assay was to determine whether $\mathrm{Ha}-\mathrm{CHOX}$ could oxidise reticuline, however, no such activity was observed. All other sequence similarities with $\mathrm{Ha}-\mathrm{CHOX}$ (Figure 2) were weak, with the highest region of identity associated with a conserved region of the sequence known to bind a flavin molecule in a range of oxidases (Brandsch et al., 1987; Dittrich and Kutchan, 1991). Sequence similarity to other oxidases together with various enzyme assays allowed the putative classification of carbohydrate oxidase to be assigned.

Plants accumulate increased amounts of soluble sugars in the apoplast after pathogen infection. These increased concentrations of sucrose and simultaneous induction of plant apoplastic invertases result in increased amounts of glucose and fructose (Herbers et al., 2000; Chou et al., 2000). The increased glucose concentration may serve as a substrate for the pathogen induced $\mathrm{Ha}-\mathrm{CHOX}$ enzyme to generate $\mathrm{H}_{2} \mathrm{O}_{2}$ to inhibit pathogen growth and to trigger plant defence.

Despite having a very similar activity there is very limited similarity at the protein sequence level between $\mathrm{Ha}-\mathrm{CHOX}$ and hexose oxidase. As described earlier, the $\mathrm{Ha}-\mathrm{CHOX}$ protein is more closely related to berberine bridge enzymes found in Opium poppy and Californian poppy where they are involved in alkaloid biosynthesis. These berberine bridge enzymes or reticuline oxidases, catalyse the formation of $(S)$-scoulerine from $(S)$-reticuline at the branchpoint leading to benzophenanthridine alkaloids. Benzophenanthridine alkaloids are accumulated in species of the Papaveraceae and Fumaraceae in response to pathogen attack and are supposed to be phytoalexins (e.g. sanguinarine in Californian poppy; Dittrich and Kutchan, 1991). There is not much known regarding alkaloid and phytoalexin production in sunflower and lettuce. The main alkaloids produced in members of the Compositeae are the sesquiterpene lactones. These sesquiterpene lactones have strong antifungal activity and are thought to play a role in the plant defence response (Wedge et al., 2000). The biosynthetic pathway leading to the production of sesquiterpene lactones has yet to be elucidated and as a result it is unknown whether an oxidase is involved. Similarly it is not known what other substrates can be utilised by reticuline oxidases, which may well be multifunctional oxidases.

The genome of Arabidopsis thaliana contains a large gene family with high similarity to both berberine bridge enzymes and Ha-CHOX (The Arabidopsis Genome Initiative, 2000). Until now, none of these putative enzymes have been characterised so their enzymatic activity remains unclear. Phylogenetic analysis of the 27 closest Arabidopsis Ha-CHOX homologs revealed that the Arabidopsis gene family could be separated into 7 different clades. Arabidopsis gene At1g30700 displays the highest level of similarity at the amino acid level to $\mathrm{Ha}-\mathrm{CHOX}$ and potentially has a similar enzymatic activity and potentially may function in a similar manner in Arabidopsis as HaCHOX does in sunflower. The tree displayed in Figure 3a contains two groups with a close relationship to EcBBE containing 2 and 3 gene family members respectively. When searched against previously characterised proteins, $\mathrm{Ha}-\mathrm{CHOX}$ shows the strongest similarity to $\mathrm{EcBBE}$, but there are a large number (22) of Arabidopsis homologues that are more closely related to $\mathrm{Ha}-\mathrm{CHOX}$. It appears that $\mathrm{EcBBE}$ and $\mathrm{Ha}-\mathrm{CHOX}$ represent members of a superfamily of plant oxidases that may play a role in numerous pathways. It is possible that sunflower may encode further $\mathrm{Ha}-\mathrm{CHOX}$ genes that display even greater similarity to EcBBE. High stringency southern blot analysis was used to 
demonstrate that only a single $\mathrm{Ha}-\mathrm{CHOX}$ gene is present in the sunflower genome (data not shown), however under these conditions only genes with approximately $80 \%$ sequence identity or higher at the nucleotide level can be detected (Sambrook et al., 1989).

\section{Role for HA-CHOX in the defence response}

Enzyme activity of the berberine bridge enzyme in cell suspension cultures of $E$. californica is induced by methyl jasmonate and elicitor challenge (Dittrich and Kutchan, 1991; Kutchan, 1993) and the $\mathrm{Ha}-\mathrm{CHOX}$ transcript is induced in sunflower leaves after treatment with high levels of salicylic acid and after fungal inoculation (Table 1). These observations, taken together with the identification of a signal peptide indicate that $\mathrm{Ha}-\mathrm{CHOX}$ is an extracellular hydrogen peroxide generating enzyme induced upon fungal infection. This leads to the speculation that $\mathrm{Ha}-\mathrm{CHOX}$ might be one of the enzymes that is responsible for the generation of extracellular hydrogen peroxide in response to pathogen attack. As can be seen in Figure 6a, hydrogen peroxide synthesis was induced following the infiltration of the culture filtrate of $P$. carotovorum in $\mathrm{Ha}-\mathrm{CHOX}$ overexpressing plants. Therefore, if in a natural infection $\mathrm{Ha}-\mathrm{CHOX}$ would be induced upon infection and targeted to the apoplast, the cellulases and polygalacturonases of the invading bacterium would provide the substrate needed for the enzyme to produce hydrogen peroxide. The production of these cell wall degrading enzymes is not restricted to bacteria. Fungal pathogens including Colletotrichum, Rhizoctonia, Fusarium and Stagonospora have all been shown to produce significant quantities of cell wall-degrading enzymes during infection (Shi et al., 2000; Wei et al., 2002; Lisker et al., 1975; Guo et al., 1995; Carlile et al., 2000). As Ha-CHOX-like genes have been shown to be so widely spread in the plant kingdom, this class of oxidases may contribute to the production of $\mathrm{H}_{2} \mathrm{O}_{2}$ as part of the defence response in the vast majority of these plants.

A role for $\mathrm{Ha}-\mathrm{CHOX}$ in the defence response is most clearly demonstrated in Figure 6, where resistance to infection by $P$. carotovorum was found to be proportional to the enzyme expression level. These results complement previous data where overexpression of glucose oxidase from fungal sources enhances resistance to pathogens in potato, canola and cotton (Wu et al., 1995; Kazan et al., 1998; Murray et al., 1999). In the case of potato the induced $\mathrm{H}_{2} \mathrm{O}_{2}$ was shown not only to provide a direct antimicrobial effect, but also to result in an elevated defensive state in uninfected plant material and a slight stunting (Wu et al., 1997). Similarly in cotton plants overexpressing the Talaromyces flavus glucose oxidase, enhanced resistance was obtained but reduced plant growth, slow germination and reduced seed set also resulted from this overexpression. There are no obvious phenotypic differences observed in tobacco plants overexpressing $\mathrm{Ha}-\mathrm{CHOX}$, which may be explained by enzyme activity. The $\mathrm{Km}$ of $\mathrm{Ha}-\mathrm{CHOX}$ suggests it would be a much better enzyme at the very early stages of infection, where only low concentrations of free glucose will be available as a substrate. In this sense it would be more efficient than glucose oxidase. The Vmax is significantly lower, producing a maximum of $4.6 \mu \mathrm{M}$ of $\mathrm{H}_{2} \mathrm{O}_{2} \mu \mathrm{gg}^{-1}$ of protein, approximately 10 times less than glucose oxidase. Therefore it is possible that $\mathrm{Ha}-\mathrm{CHOX}$ may play a dual role in defence. For pathogens such as Pectobacterium carotovorum and potentially oomycete and fungal pathogens such as Phytophthora infestans and Rhizoctonia solani all of which are highly susceptible to $\mathrm{H}_{2} \mathrm{O}_{2}$, the main role of $\mathrm{Ha}-\mathrm{CHOX}$ may be in direct inhibition resulting from $\mathrm{H}_{2} \mathrm{O}_{2}$ production. For the remaining fungal pathogens that were tested for sensitivity to $\mathrm{H}_{2} \mathrm{O}_{2}$ the concentration required for 
inhibition is high and therefore it is unclear whether $\mathrm{Ha}-\mathrm{CHOX}$ could produce concentrations of $\mathrm{H}_{2} \mathrm{O}_{2}$ high enough to result in complete growth inhibtion. Possibly, $\mathrm{Ha}-\mathrm{CHOX}$ produced $\mathrm{H}_{2} \mathrm{O}_{2}$ can have a function in signalling in the defence response, or alternatively functions as a substrate for the lignin forming peroxidases.

As resistance is proportional to expression level, its inducibility in response to infection is also as important as the enzyme characteristics. The native gene was shown to be induced in sunflower in response to fungal pathogens, being most pronounced in response to the infection of Diaporthe helianthi. Similarly, Arabidopsis plants infected with Pseudomonas syringae display induction of a number of homologues of Ha-CHOX (Jane Glazebrook, personal communication). Likewise, EcBBE was induced by both elicitors and jasmonic acid and shown to play a role in the production of phytoalexins (Dittrich and Kutchan, 1991; Kutchan, 1993). The isolation of Ha-CHOX and Ls-CHOX from sunflower and lettuce has helped to further elucidate the role of oxidases in the plant defence response. We have shown that when constitutively expressed, these carbohydrate oxidases are able to confer resistance to bacterial infection in tobacco. The analysis of Arabidopsis plants with mutations in ortholog(s) of $\mathrm{Ha}-\mathrm{CHOX}$ will provide further evidence for the role of this class of oxidases in the defence system of higher plants.

\section{EXPERIMENTAL PROCEDURES}

\section{Treatment and extraction of plant tissue}

Leaves of 7 to 8 week old plants were sprayed daily for 5 days with $10 \mathrm{mM}$ sodium salicylate. Three hours after each spray, leaves were washed with water to remove residual sodium salicylate. Three days after the final spray leaves were harvested, frozen in liquid nitrogen and homogenised in a Waring blender in the presence of $0.5 \mathrm{M} \mathrm{NaOAc} \mathrm{pH} 5.2\left(4^{\circ} \mathrm{C}\right)$, and $8 \mathrm{~g} / \mathrm{L}$ activated carbon. The homogenate was filtered using cheesecloth, and subsequently centrifuged for 50 minutes at 20,000 $\mathrm{g}\left(4^{\circ} \mathrm{C}\right)$. The protein extract was desalted by passage through a Sephadex $\mathrm{G} 25$ column equilibrated in $40 \mathrm{mM} \mathrm{NaOAc} \mathrm{pH} 5.2$.

\section{Cation exchange chromatography}

Active protein extracts were loaded onto a cation exchange column (FPLC Mono-S HR 5/5, Pharmacia) previous equilibrated with $40 \mathrm{mM} \mathrm{NaOAc} \mathrm{pH}$ 5.2. Protein was eluted with a linear gradient from 0 to $400 \mathrm{mM} \mathrm{NaCl}$ and fractions were collected. Fractions were dialysed to $50 \mathrm{mM}$ MES $\mathrm{pH} 6$ and were assessed for antifungal activity.

\section{Hydrophobic interaction chromatography}

Protein from active fractions were pooled and dialysed to $1 \mathrm{M}$ ammonium sulphate in $50 \mathrm{mM}$ potassium phosphate, $\mathrm{pH} 7$. The pooled and dialysed fractions were applied to a hydrophobic interaction chromatography column (FPLC Phenyl Superose HR 5/5, Pharmacia) equilibrated in the same buffer. The column was eluted with a linear decreasing gradient from 1 to $0 \mathrm{M}$ ammonium sulphate in $50 \mathrm{mM}$ potassium phosphate, $\mathrm{pH} 7$ and fractions were collected. Fractions were dialysed to $50 \mathrm{mM}$ MES pH 6 and were assessed for antifungal activity. 


\section{Gel Filtration Chromatography}

The active fractions were independently dialysed to $50 \mathrm{mM}$ MES $(\mathrm{pH} 6), 0.2 \mathrm{M} \mathrm{NaCl}$ and applied to a gel filtration column (FPLC Superdex 75 HR 10/30 column, Pharmacia) previously equilibrated with the same buffer. Proteins were eluted in an isocratic gradient in the same buffer. Samples were dialysed against $50 \mathrm{mM}$ MES $(\mathrm{pH} 6)$ to remove the $\mathrm{NaCl}$ and assayed for antifungal activity.

\section{Amino acid sequencing}

Bands corresponding to active proteins were excised from SDS-PAGE gels and submitted for automated Edman degradation $\mathrm{N}$-terminal sequencing (Applied Biosystems Inc.). For sequencing of internal fragments, in gel tryptic (Roche) digests were performed according to the manufacturers instructions. The products were analysed by RP-HPLC and submitted for Edman degradation sequencing (EuroSequence, Groningen, The Netherlands).

\section{HPLC detection of carbohydrate oxidase end products}

Reactions were prepared containing the test oxidase $(100 \mu \mathrm{g})$ together with glucose $(1 \mathrm{mM})$ and incubated overnight at room temperature. Samples were then centrifuged through a Centricon YM-3 ( $3 \mathrm{kDa}$ cut off) column (Millipore), and the flow-through analysed for reaction end products. Samples were applied to a Carbopac $\mathrm{PA}_{1}$ anion exchange column attached to a Dionex HPLC system. A linear gradient was run from $\mathrm{pH} 3$ to 9 and eluted products detected by pulsed electrochemical detection. Peaks were identified by co-elution with either glucose and $\delta$-glucono-1,5-lactone.

\section{NMR analysis of carbohydrate oxidase end products}

Samples were prepared for NMR by adding $10 \% \mathrm{D}_{2} \mathrm{O}$ and $0.005 \% d_{4}$-Trimethylsilylpropionate (TSP). NMR spectra were recorded on a Varian Inova $500 \mathrm{MHz}$ NMR spectrometer using a $5 \mathrm{~mm}$ ${ }^{1} \mathrm{H}\{\mathrm{X}\}$ probe at $24^{\circ} \mathrm{C} .1 \mathrm{D}{ }^{1} \mathrm{H}$ spectra used a $30^{\circ}$ excitation pulse and a relaxation delay of $3.1 \mathrm{~s}$ including a $1.9 \mathrm{~s}$ presaturation pulse, to suppress residual water.

\section{Transgenic plant sampling and oxidase activity assays}

Leaf samples $(50 \mathrm{mg})$ were taken and lyophilised in 96 well microtitre plates. Samples were homogenised in a Retsch Mill (Qiagen) according to the manufacturers instructions. Samples were resuspended in $150 \mu \mathrm{L}$ of cold PBS buffer and centrifuged for $10 \mathrm{~min}$ at $2000 \mathrm{xg}$ to remove cellular debris.

Oxidase assays were performed by determining the amount of $\mathrm{H}_{2} \mathrm{O}_{2}$ produced during carbohydrate oxidation in a modification of the methods described by Machida and Nakanishi (1984). The standard assay mixture contained $50 \mathrm{mM}$ pyrophosphate, $6 \mathrm{mM} \mathrm{2,4,6-Tribromo-3-hydroxy-benzoic}$ acid, $25 \mu \mathrm{M}$ FAD, $10 \mathrm{mM}$ sodium azide, $0.01 \%$ Triton X100, $20 \mathrm{U} / \mathrm{mL}$ horseradish peroxidase and 2 $\mathrm{mM} 4$-aminoantipyrine in a total volume of $150 \mu \mathrm{L}$. This mixture was added to $50 \mu \mathrm{L}$ of sample and $50 \mu \mathrm{L}$ of substrate and the reaction monitored for 60 minutes at room temperature at $510 \mathrm{~nm}$. 


\begin{abstract}
Antifungal assays
Antifungal bioassays to assess antimicrobial activity were adapted from described methods (Broekaert et al., 1990) and conducted at $22^{\circ} \mathrm{C}$ for 96 hours except for Pectobacterium carotovorum, which was grown at $29^{\circ} \mathrm{C}$ for 48 hours. The test organisms were suspended in PDB using a cell, spore or hyphal fragment concentration of 10000 per $\mathrm{mL}$. A $50 \mu \mathrm{L}$ aliquot of the test organism was placed in a microtitre plate and incubated at room temperature for 4 hours following which $50 \mu \mathrm{L}$ of test solution or water was added. All samples were measured in duplicates for each test solution. Growth inhibition was monitored visually using a microscope.
\end{abstract}

\title{
Isolation of the Ha-CHOX and Ls-CHOX cDNA's
}

Total RNA was extracted from $10 \mathrm{~g}$ sunflower leaf material (that was induced by spraying 5 times with a $10 \mathrm{mM}$ sodium salicylate solution) using a hot phenol method (Pawlowski et al., 1994) and purified using the Qiagen RNA buffer set and tip-100 columns (Qiagen). Contaminating DNA was degraded using Dnase I (Gibco BRL). Poly- $\mathrm{A}^{+}$containing RNA was isolated using mRNA purification push columns (Stratagene). CDNA was prepared and 5' and 3' RACE PCR reactions were performed as described in the instructions of the Marathon ${ }^{\mathrm{TM}}$ kit (Clontech). PCR fragments were cloned into the pGEM-T vector (Promega) and verified by DNA sequencing.

Protein sequence alignments and construction of phylogenetic trees

The Ha-CHOX amino acid sequence was used in a BLASTP (Altschul et al., 1997) search against the SWISSPROT protein database. Sequences were extracted and aligned using the ClustalX programme (Thompson et al., 1997). Alignments were loaded into the MegAlign programme (DNAStar package) and modified for output quality. The Arabidopsis homologs were extracted from The Arabidopsis Information Resource database (TAIR: http://www.arabidopsis.org/) and aligned using the ClustalX programme. The phylogenetic tree was build using the ClustalX NeighbourJoining method and the tree was bootstrapped 1000 times. The resulting trees were visualized using the Drawtree and Drawgram programmes from the Phylip Phylogeny Inference package version 3.6 (http://evolution.genetics.washington.edu/phylip.html). Confidence values were determined of bootstrap support as a percentage of 1000 replicates and mapped on the tree using TreeView 1.6.6 (Roderick Page, 2001).

\section{Expression of $\mathrm{Ha}-\mathrm{CHOX}$ in E.coli and purification of the recombinant protein}

A 270 bp Ha-CHOX PCR fragment generated using primers: FR-Ha-CHOX-64; 5'CCTCATGACTTCCCGTTCCATTACAGATC-3' (introducing a methionine at the amino terminus of the presumed mature protein) and FR-Ha-CHOX-12; 5'GTCCACAATGAAGAAGGGTTGG-3' containing the 5'part of $\mathrm{Ha}-\mathrm{CHOX}$ and the remaining 3' part of $\mathrm{Ha}-\mathrm{CHOX}$ using $\mathrm{BspH} \mathrm{I}$ and $\mathrm{BamH} \mathrm{I}$ were ligated into expression vector pET32c (Novagen, Madison, $\mathrm{WI}$ ) digested with $\mathrm{Nco}$ I and BamH I. Using this vector a fusion protein will be expressed containing a thioredoxinA tag and a $6 x$ Histidine tag. The plasmid was introduced into expression host E. coli AD494 (DE3) pLysS (Novagen, Madison, WI). Expression of Ha-CHOX was induced by adding IPTG to the bacterial culture in a final concentration of $1 \mathrm{mM}\left(\mathrm{OD}_{600}=0.5\right)$. The soluble protein fraction was isolated and applied to a nickel affinity column. Following elution of the bound fraction using a block gradient, the sample was dialysed to remove the imidazole and the purification tag was cleaved from $\mathrm{Ha}-\mathrm{CHOX}$ 
using enterokinase (Roche). The sample was dialysed to $50 \mathrm{mM}$ MES (pH 6) and applied to a cation exchange column with the eluting fractions assessed for antifungal activity. A final gel filtration step allowed the protein to be purified to apparent homogeneity.

\section{Expression of Ha-CHOX in transgenic plants}

PCR primers were developed based on the sequence around the $2^{\text {nd }}$ ATG start codon and the TGA stop codon for cloning of the open reading frame (ORF). A Nco I restriction site was introduced at the $2^{\text {nd }}$ ATG start codon for fusion to the constitutive $3 \mathrm{x}$ ocs $/ 1 \mathrm{x}$ mas hybrid promoter (Ni et al., 1995) by PCR using primer FR-Ha-CHOX-66: 5' CC GCC ATG GAG ACT TCC ATT CTT ACT C 3'. The second codon of the ORF was changed from caa $(Q)$ to gag $(E)$ as a result of the introduced Nco I restriction site. Downstream of the TGA stop codon a BamH I restriction site was introduced by PCR using primer FR-HA-CHOX-47: 5' GCC GGA TCC TCA AGA TGA CAA AGT TGG GAT GCT 3'. Using a PCR reaction with Pfu DNA polymerase (Stratagene) the entire ORF was amplified. The integrity of the DNA sequence was confirmed by sequencing. After the ORF a 3' untranslated region of the potato proteinase inhibitor II (An et al., 1989) was introduced. The chimeric gene produced was introduced into binary vector pMOG800 (pMOG23 derivative, Sijmons et al., 1990) the resulting clone pMOG1180, was transformed to Agrobacterium tumefaciens strain MOG101 (Hood et al., 1993) using electroporation for transformation of tobacco. Tobacco transformations were carried out using co-cultivation of tobacco leaf disks essentially as described by Horsch et al., (1985).

\section{Ha-CHOX expression analysis in sunflower}

Leaves of 7 to 8 weeks old Sunflower plants (Helianthus annuus c.v. Zebulon) were induced either by spraying 5 times with $5 \mathrm{mM}$ salicylic acid (SA), or once with $1 \mathrm{mM}$ salicylic acid, or once with 0.1 $\mathrm{mM}$ jasmonic acid (JA) and once with $1 \mathrm{mM}$ ACC (1-aminocyclopropane-1-carboxylic acid, a precursor of the plant hormone ethylene). Leaf samples were harvested from induced leaves after 24 hours ( $1 \mathrm{mM} \mathrm{SA}, 0.1 \mathrm{mM} \mathrm{JA}, 1 \mathrm{mM} \mathrm{ACC}$ ) and after 5 days ( $5 \mathrm{mM} \mathrm{SA})$. Control samples were taken at 24 hours after induction in non-induced plants.

Fungal infections were performed on plants of 7 to 8 weeks old. Small droplets (15-20 $\mu$ l) of a Botrytis cinerea spore suspension (in $\mathrm{H}_{2} \mathrm{O}$ containing $0.2 \%$ (w/v) sucrose/0.8\% (w/v) $\mathrm{KH}_{2} \mathrm{PO}_{4}$ ) Diaporthe helianthi (PH9905) hyphal fragment suspension or a Sclerotinia sclerotiorum hyphal fragment suspension (both in $\mathrm{H}_{2} \mathrm{O}$ ) were applied on small incisions made in the leaf to enable the fungi to penetrate the plant. Inoculated plants were placed at $18^{\circ} \mathrm{C}$ and a high relative humidity $( \pm$ $90 \%$ ). Leaf disks (diameter $=13 \mathrm{~mm}$ ) harbouring the site of infection were harvested at approximately 4 days after inoculation. Around the hole of the $13 \mathrm{~mm}$ leaf disk, a leaf ring of $12 \mathrm{~mm}$ $(25-13 \mathrm{~mm})$ was harvested. Leaf disks were also harvested in non-infected leaves around leaf incisions as a control.

\section{Analysis of samples by competitive RT-PCR}

Transcript levels of $\mathrm{Ha}-\mathrm{CHOX}$ were determined using the competitive RT-PCR as described by Siebert and Larrick, 1992. Poly- $\mathrm{A}^{+}$RNA was harvested from $100 \mathrm{mg}$ of leaf tissue using the Quickprep Micro mRNA purification Kit (Amersham Pharmacia Biotech, Uppsala, Sweden). The relative amount of mRNA was determined using ethidium bromide fluorescence as indicator. Equal amounts of Poly- $\mathrm{A}^{+}$RNA (100 ng) were used to synthesize cDNA using 200 units of Superscript II 
RT RNAse $\mathrm{H}^{-}$reverse transcriptase (Gibco BRL) and $1 \mu \mathrm{l}$ oligo(dT) $)_{12-18}$ primers $(500 \mu \mathrm{g} / \mathrm{ml}$, Gibco $B R L)$ as described by the manufacturer.

For construction of a PCR MIMIC the following primers were developed; FR-pUC-208 5' GTT CCG GAG GTT GTG ACC GTG GGA TGT GCT GCA AGG CG3', FR-pUC-209 5' CTG GGG AAG CCC GTG TAG TAA AGC CCC CGC GCG TTG GCC GAT TC3', FR-HA-CHOX-47 5' CTG GGG AAG CCC GTG TAG TAA AGC3' and FR-HA-CHOX-77 5' GTT CCG GAG GTT GTG ACC GTG3'. Primers FR-pUC-208 and FR-pUC-209 were used to amplify a fragment of $387 \mathrm{bp}$ from the plasmid pUC18 by PCR $\left(10\right.$ cycles of $\left.1^{\prime} 95^{\circ} \mathrm{C}, 1^{\prime} 55^{\circ} \mathrm{C}, 2^{\prime} 72^{\circ} \mathrm{C}\right)$. From this PCR product $1 \mu \mathrm{l}$ was amplified using primers FR-HA-CHOX-47 and FR-HA-CHOX-77 by PCR to produce a large amount of PCR MIMIC (30 cycles of $1^{\prime} 95^{\circ} \mathrm{C}, 1^{\prime} 55^{\circ} \mathrm{C}, 2^{\prime} 72^{\circ} \mathrm{C}$ ). PCR MIMIC dilutions were made in a range of 100 $\mathrm{ng} / \mu \mathrm{l}$ to $0.01 \mathrm{ag} / \mu \mathrm{l}$ in $\mathrm{H}_{2} 0$ containing $0.2 \mu \mathrm{g} / \mu \mathrm{l}$ glycogen as a carrier.

As an internal control for the quality and amount of cDNA used in the Ha-CHOX competitive RTPCR, a cRT-PCR on the housekeeping gene glyceraldehyde 6-phosphate dehydrogenase (gapC) was included. For the construction of a gapC PCR MIMIC the following primers were developed; FR-pUC-224 5' CCA TGG GCT CAA ACT GGA GCC GGC CGG GAG CAG ACA AGC CCG 3', FRpUC-225 5' CGA GAC GTC AAC AGT CGG GAC CCA CTC ATT AGG CAC CCC AGG C3', FRgapC-211 5' CCA TGG GCT CAA ACT GGA GCC G3' and FR-gapC-212 5' CGA GAC GTC AAC AGT CGG GAC C3'. Primers FR-pUC-224 and FR-pUC-225 were used to amplify a fragment of 527 bp from the plasmid pUC18 by PCR $\left(10\right.$ cycles of $\left.1^{\prime} 95^{\circ} \mathrm{C}, 1^{\prime} 55^{\circ} \mathrm{C}, 2^{\prime} 72^{\circ} \mathrm{C}\right)$. From this PCR product $1 \mu \mathrm{l}$ was amplified using primers FR-gapC-211 and FR-gapC-212 by PCR to produce a large amount of PCR MIMIC (30 cycles of $1^{\prime} 95^{\circ} \mathrm{C}, 1^{\prime} 55^{\circ} \mathrm{C}, 2^{\prime} 72^{\circ} \mathrm{C}$ ). GapC PCR MIMIC dilutions were made in a range of $100 \mathrm{ng} / \mu \mathrm{l}$ to $0.01 \mathrm{ag} / \mu \mathrm{l}$ in $\mathrm{H}_{2} \mathrm{O}$ containing $0.2 \mu \mathrm{g} / \mu \mathrm{l}$ glycogen as a carrier. The cDNA samples were analysed in a competitive RT-PCR. Therefore $2 \mu \mathrm{l}$ of each sample was combined in a $0.5 \mathrm{ml}$ tube with $1 \mu \mathrm{l}$ diluted PCR MIMIC $(0.1 \mathrm{pg}, 10 \mathrm{fg}, 1.0 \mathrm{fg}, 0.1 \mathrm{fg}, 10$ ag and 1.0 ag). Amplification of CDNA and MIMIC was performed using $10 \mu \mathrm{M}$ of primers, $0.5 \mu \mathrm{l} 20 \mathrm{mM}$ dNTP's, $1 \mathrm{x}$ PCR buffer, $\mathrm{MgCl}_{2}$ and 2.5 units recombinant Taq DNA polymerase (Gibco BRL) and was allowed to proceed for 35 cycles, $1^{\prime} 95^{\circ} \mathrm{C}, 1^{\prime} 55^{\circ} \mathrm{C}, 2^{\prime} 72^{\circ} \mathrm{C}$. PCR products were separated on a $2 \%$ agarose gel and visualized by staining with ethidium bromide and a UV illuminator.

Pectobacterium carotovorum resistance assay in $\mathrm{Ha}-\mathrm{CHOX}$ transgenic tobacco plants.

An overnight culture of Pectobacterium carotovorum bacteria was diluted 100 fold in standard LB medium and grown at $29^{\circ} \mathrm{C}$ to an $\mathrm{OD}_{600}$ of 0.5 . Bacteria were washed twice with sterile tap water, dissolved in sterile tap water and infiltrated into the leaves of transgenic tobacco plants with a $1 \mathrm{ml}$ needleless syringe. Five identical leaves of each transgenic plant were infiltrated. In each leaf four infiltrations were done for each time point ( 24 hours and 48 hours). Plants were maintained at $20^{\circ} \mathrm{C}$, $70-80 \%$ relative humidity and a 16 hours light cycle. Leafdisks covering the four infiltrated patches were harvested, pooled, homogenized in $120 \mu \mathrm{l} 0.1 \mathrm{mM} \mathrm{MgSO}_{4}$ and 10 -fold serial dilutions were made. Dilutions ranging from $10^{-3}$ to $10^{-7}$ were plated and after two days of culturing bacterial colonies were counted. 


\section{ACKNOWLEDGMENTS}

The authors would like to thank Pierre de Wit and Bart van Wezenbeek for critically reading the manuscript. Jane Glazebrook, Torrey Mesa Research Institute, is thanked for sharing unpublished data and Eline Voogd is thanked for assistance with the RP-HPLC analysis.

\section{REFERENCES}

Altschul, S. F., Madden, T.L., Schaffer, A.A., Zhang, J., Zhang, Z., Miller, W., and Lipman, D.W., 1997. "Gapped BLAST and PSIBLAST: a new generation of protein database search programs", Nucleic Acids Res. 25, 3389-3402.

Alvarez M.E., Pennel R.I., Meijer P., Ishikawa A., Dixon R.A. and Lamb C., 1998. Reactive Oxygen Intermediates Mediate a Systemic Signal network in the establishment of Plant Immunity. Cell 92; 773-784.

An, G., Mitra, A., Cho,i H.K., An, K., Thornburg, R.W. and Ryan, C.A., 1989. Functional analysis of the 3' control region of the potato wound-inducible proteinase inhibitor II gene. Plant Cell 1(1), 115-122.

Angel Torres M., Onouchi H., Hamada S., Machida C., Hammond-Kosack and Jones J.D.G., 1998. Six Arabidopsis homologues of the human respiratory burst oxidase ( $g p 91^{\text {phox }}$ ), Plant J. 14(3): 365-370

Bean R.C., Porter G.G. and Steinberg B.M., 1961. Carbohydrate metabolism of citrus fruits. II. Oxidation of sugars by an aerodehydrogenase from young orange fruits. J. Biol. Chem. 236: 1235-1240.

Bidney D.L., Charne D.G., Coughlan S.L., Falak I., Mancl M.K., Nazarian K.A.P., Scelonge C.J. and Yalpani N., 1999. Production of pathogen resistant plants. International patent application WO 99/04012

Bolwell G.P., Butt V.S., Davies D.R. and Zimmerlin A., 1995. The origin of the oxidative burst in plants. Free Radic. Res. 23(6): 517532.

Bolwell P.G., 1999. Role of active oxygen species and NO in plant defence responses, Curr. Opin. Plant Biol. 2: 287-294.

Bolwell G.P. and Wojtaszek P. 1997 Mechanisms for the generation of reactive oxygen species in plant defence - a broad perspective, Physiol. Mol. Plant Path. 51: 347-366.

Bradley D.J., Kjellbom P. and Lamb C.J., 1992. Elicitor and wound induced oxidative cross-linking of a proline-rich plant cell wall protein: A novel, rapid defence response. Cell 70: 21-30.

Brandsch R., Bichler V. and Nagursky H., 1987. Covalent flavinylation of 6-hydroxy-D-nicotine oxidase analysed by partial deletions of the gene. Eur. J. Biochem. 165(3): 559-564.

Broekaert W.F., Terras F.R.G., Cammue B.P.A. and Vanderleyden J., 1990. An automated quantitative assay for fungal growth inhibition. FEMS Microbial. Lett. 69: 55-59.

Cessna S.G., Sears V.E., Dickman M.B. and Low P.S., 2000. Oxalic Acid, a pathogenicity factor for Sclerotinia sclerotiorum, suppresses the oxidative burst of the host plant. Plant Cell 12: 2191-2199.

Chamnongpol S., Willekens H., Moeder W., Langebartels C., Sandermann H., Van Montagu M., Inze D. and Van Camp W., 1998. Defence activation and enhanced pathogen tolerance induced by $\mathrm{H}_{2} \mathrm{O}_{2}$ in transgenic tobacco. Proc. Natl. Acad. Sci. USA 95: 58185823.

Chatterjee A., Cui Y., Liu Y., Dumenyo K. and Chatterjee A.K., 1995. Inactivation of rsmA Leads to Overproduction of Extracellular Pectinases, Cellulases and Proteases in Erwinia carotovora subsp. carotovora in the absence of the starvation/Cell Desity-Sensing Signal, N-(3-Oxohexanoyl)---Homoserine Lactone. Appl. Environm. Microbiol. May: 1959-1967.

Chou H., Bundock N., Rolfe S.A. and Scholes J.D., 2000. Infection of Arabidopsis thaliana leaves with Albugo candida (white blister rust) causes a reprogramming of host metabolism. Mol. Plant Path. 1(2): 99-103.

Dittrich H. and Kutchan T.M., 1991. Molecular cloning, expression, and induction of berberine bridge enzyme, an enzyme essential to the formation of benzophenanthridine alkaloids in the response of plants to pathogen attack. Proc. Natl. Acad. Sci. USA 88: 9969the form 9973.

Dixon R.A., 2001. Natural products and plant disease resistance. Nature 411: 843-847

Grant J.J. and Loake G.J., 2000. Role of Reactive Oxygen Intermediates and Cognate Redox Signaling in Disease Resistance. Plant Physiol. 124: 21-29

Groen B.W., De Vries S. and Duine J.A., 1997. Characterization of hexose oxidase from the red seaweed Chondrus crispus. Eur J Biochem. 244(3): 858-861.

Groom Q.J., Torres M.A., Fordham-Skelton A.P., Hammond-Kosack K.E., Robinson N.J. and Jones J.D.G., 1996. rbohA, a rice homologue of the mammalian gp91phox respiratory burst oxidase. Plant J. 10(3): 515-522. 
Guo W., Gonzalez-Candelas L. And Kolattukudy P.E., 1995. Cloning of a novel constitutively expressed pectate lyase gene pelB from Fusarium solani f. sp. Pisi (Nectria haematococca, mating type VI) and characterization of the gene product expressed in Pichia pastoris. J. Bacteriol. 177(24): 7070-7077.

Hall J.L. and Williams L.E., 2000. Assimilate transport and partitioning in fungal biotrophic interactions. Aust. J. Plant Physiol. 27: 549-560.

Herbers K., Takahata Y., Melzer M., Mock H.P., Hajorezaei M. and Sonnewald U., 2000. Regulation of carbohydrate partitioning during the interaction of potato virus $Y$ with tobacco. Mol. Plant Path. 1(1): 51-59.

Hood E.E., Gelvin S.B., Melchers L.S. and Hoekema A., 1993. New Agrobacterium helper plasmids for gene transfer to plants. Transgenic res. 2: 208-218.

Horsch R.B., Rogers S.G. and Fraley R.T., 1985. Transgenic plants. Cold Spring Harb Symp Quant Biol 50:433-437.

Jijakli M.H. and Lepoivre P., 1998. Characterization of an Exo-Beta-1,3-Glucanase Produced by Pichia anomala strain K, Antagonist of Botrytis cinerea on Apples. Phytopathology 88: 335-343.

Kazan K., Murray F.R., Goulter K.C., Llewellyn D.J. and Manners J.M., 1998. Induction of Cell death in Transgenic Plants Expressing a Fungal Glucose Oxidase. Mol. Plant Microbe Interact. 11(6): 555-562.

Kutchan T.M., 1993. 12-Oxo-phytodienoic acid induces accumulation of berberine bridge enzyme transcript in a manner analogous to methyl jasmonate. J. Plant Physiol. 142: 502-505.

Kutchan T.M. and Dittrich H., 1995. Characterization and Mechanism of the Berberine Bridge Enzyme, a Covalently Flavinylated Oxidase of Benzophenanthridine Alkaloid Biosynthesis in Plants. J. Biol. Chem. 270(41): 24475-24481.

Lane B.G., Dunwell J.M., Ray J.A., Schnitt M.R. and Cuming A.C., 1993. Germin, a protein marker of early plant development, is an oxalate oxidase. J. Biol. Chem. 268(17): 12239-12242

Lisker N., Katan J. and Henis Y., 1975. Sequential production of polygalacturonase, cellulase and pectine lyase by Rhizoctonia solani. Can. J. Microbiol. 21(9): 1298.

Machida Y. and Nakanishi T., 1984. Purification and properties of pyranose oxidase from Coriolus versicolor. Agric. Biol. Chem. 48: 2463-2470.

Murray F., Llewellyn D., McFadden H., Last D., Dennis E.S. and Peacock W.J., 1999. Expression of the Talaromyces flavus glucose oxidase gene in cotton and tobacco reduces fungal infection, but is also phytotoxic. Mol. Breeding 5: 219-232.

Ni M., Cui D., Einstein J., Narasimhulu S., Vergara C.E. and Gelvin S.B., 1995. Strength and tissue specificity of chimeric promoters derived from the octopine and mannopine synthase genes. Plant Journal 7(4): 661-676.

Orozco-Cardenas M., Narvaez-Vasquez J. and Ryan C., 2001. Hydrogen peroxide acts as a second messenger for the induction of defence genes in tomato plants in response to wounding, systemin and methyl jasmonate. Plant Cell 13(1): 179-191.

Pawlowski, K., Kunze, R., de Vries, J. and Bisseling, T., 1994. Isolation of total, poly(A) and polysomal RNA from plant tissues. In: Plant Molecular Biology Manual, Second Edition eds. Gelvin S.B. and Schilperoort R.A. Kluwer Academic Publishers.

Sambrook J., Fritsch E.F. and Maniatis T., 1989. Molecular cloning: A Laboratory Manual, $2^{\text {nd }}$ Edition; Cold Spring Harbor Laboratory Press: Cold Spring Harbor, NY.

Shi J., Wei Y. and Goodwin P.H., 2000. A comparison of the pectate lyase genes pel-1 and pel-2 of Colletotrichum gloeosporioides f.sp. malvae and the relationship between their expression inculture and during necrotrophic infection. Gene 243(1-2): 139-150

Siebert P.D. and Larrick J.W., 1992. Competitive PCR. Nature 359: 557-558

Sijmons P.C., Dekker B.M., Schrammeijer B., Verwoerd T.C., Van den Elzen P.J. and Hoekema A., 1990. Production of correctly processed human serum albumin in transgenic plants. Bio/technology 8(3): 217-212.

The Arabidopsis Genome Initiative, 2000. Analysis of the genome sequence of the flowering plant Arabidopsis thaliana. Nature 408: $796-815$

Thompson J.D., Gibson T.J., Plewniak F., Jeanmougin F. and Higgins D.G., 1997. The Clustal X windows interface: flexible strategies for multiple sequence alignment aided by quality analysis tools. Nucleic Acids Res. 25(24): 4876-4882.

Von Heijne G., 1985. Signal sequences. The limits of variation. J. Mol. Biol. 184(1): 99-105.

Wedge D.E., Galindo J.C.G. and Macias F.A., 2000. Fungicidal activity of natural and synthetic sesquiterpene lactone analogs. Phytochemistry 53: 747-757.

Wei Y., Shi J., Li J. And Goodwin P.H., 2002. Two pectin lyase genes, pnl-1 and pnl-2, from Colletotrichum gloeosporioides f.sp. malvae differ in a cellulose-binding domain and their expression during infection of Malva pusilla. Microbiology 148(7): 2149-2157.

Wojtaszek P., 1997. Oxidative Burst: an early plant response to pathogen infection. Biochem. J. 322: 681-692. 
Wu G., Shortt B.J., Lawrence E.B., Levine E.B., Fitzsimmons C. and Sha D., 1995. Disease Resistance Conferred by Expression of a Gene Encoding $\mathrm{H}_{2} \mathrm{O}_{2}$-Generating Glucose Oxidase in Trangenic Potato Plants. Plant Cell 7: 1357-1368.

Wu G., Shortt B.J., Lawrence E.B., Leon J., Fitzsimmons C., Levine E.B., Raskin I. and Sha D., 1997. Activation of Host Defence Mechanisms by Elevated Production of $\mathrm{H}_{2} \mathrm{O}_{2}$ in Transgenic Plants. Plant Physiol. 115: 427-435.

Zhou F., Zhang Z., Gregersen P.L., Mikkelsen J.D., De Neergaard E., Collinge D.B. and Thordal-Christensen H., 1998. Molecular Characterization of the Oxalate Oxidase Involved in the Response of Barley to the Powdery Mildew Fungus. Plant Physiol. 117: 3341.

\section{Supplementary Data}

The figure below shows $1 \mathrm{D}^{1} \mathrm{H}$ NMR spectra of the reaction mixture of $\mathrm{Ha}-\mathrm{CHOX}$ and glucose before (lower spectrum) and after adding gluconic acid (upper spectrum), which is produced by the hydrolysis of -glucono-1,5-lactone. Isolated protons from the product are marked 'P'; others are in the range $3.7-3.9 \mathrm{ppm}$ so overlap with protons from glucose. This confirms that the product peaks are from gluconic acid

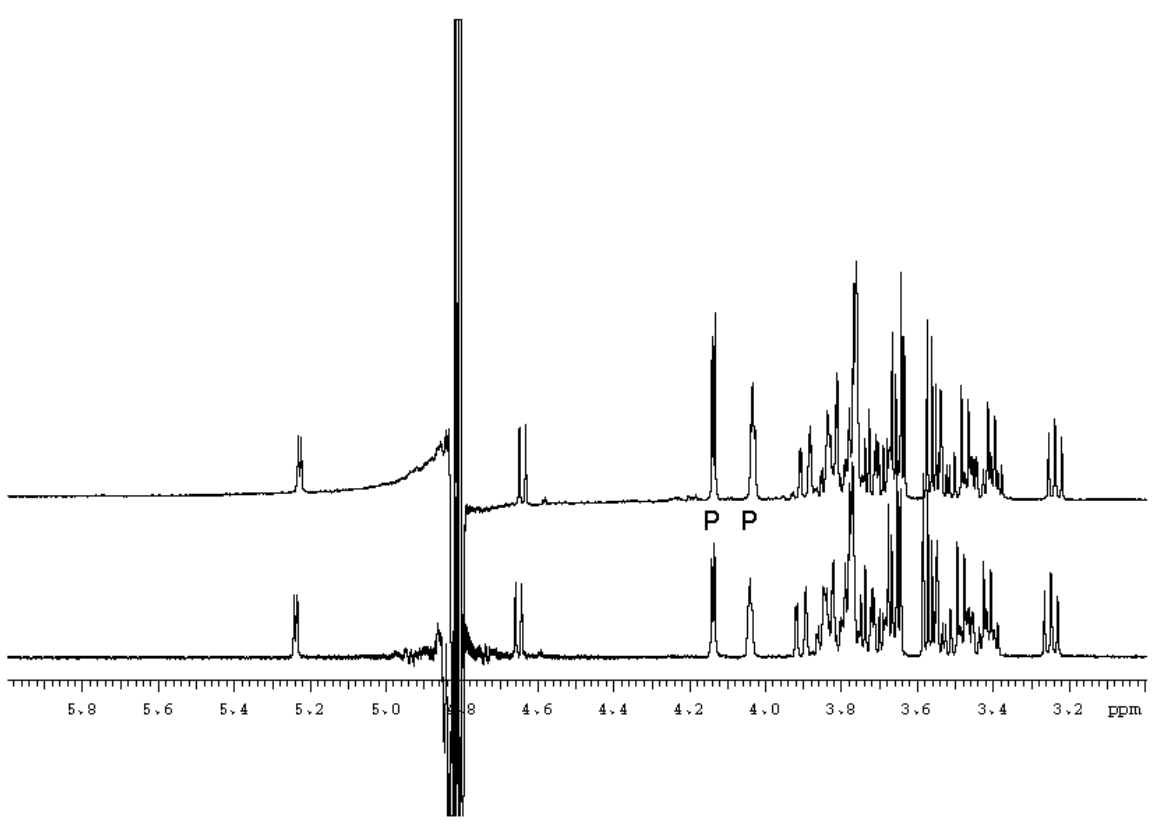




\section{CHAPTER 7}

ENGINEERING DISEASE RESISTANCE IN PLANTS

Maarten H. Stuiver and Jerôme H.H.V. Custers

Published in 2001, Nature 411: 865-868. 


\section{ENGINEERING DISEASE RESISTANCE IN PLANTS}

Ever since the initial discovery of the molecules and genes involved in disease resistance in plants, attempts have been made to engineer durable disease resistance in economically important crop plants. Unfortunately, many of these attempts have failed, owing to the complexity of diseaseresistance signalling and the sheer diversity of infection mechanisms that different pathogens use. Although disease-resistant transgenic plants or seeds are not yet available commercially, future product development seems likely as our current level of understanding of pathogenesis and plant defence improves.

One cannot study plant defence without being impressed by the complex and sophisticated systems that plants have evolved to withstand a variety of pathogens. It is often mentioned that plants successfully withstand infection by the vast majority of pathogens that attack them. It is the sheer diversity of the infection mechanisms that these pathogens use that makes this feat truly remarkable.

Plant defence must be adapted to combat two different types of pathogen. Necrotrophs are pathogens that produce toxic enzymes and metabolites that kill the tissue directly upon invasion. In contrast, hemibiotrophs or biotrophs initially feed on the plants parasitically initially, keeping the cells in infected plant tissue alive for a significant fraction of the pathogen's lifecycle; this is sometimes followed by a more necrotrophic existence during the later stages of infection. The number of different plant toxic compounds and proteins that have been isolated from plant pathogens and contribute to virulence is enormous (Walton, 1996; White et al., 2000).

\section{USING DEFENCE PATHWAYS TO ENGINEER RESISTANCE}

During the past few years, the identification of key regulatory genes in plant defence, has provided evidence that plants use several different defence pathways against different pathogens (Delaney et al., 1994; Thomma et al., 2001; Pieterse et al., 1999). In general, these pathways are characterized by the signalling molecules that are crucial in the regulation of expression of defence proteins. The best-known signalling molecule is salicylic acid. Treatment of plants with salicylic acid or analogues of salicylic acid induces expression of a subset of plant defence responses (Uknes et al., 1992), which results in warding off certain, but not all, pathogens (Gorlach et al., 1996; Thomma et al., 1998). Other pathways seem to use the small signalling molecules jasmonic acid and ethylene for their activation. Activation of either these pathways also induces resistance, but to a different group of pathogens than that associated with salycilic acid (Thomma et al., 1998, Feys and Parker, 2000). In addition to these three pathways, evidence suggests that additional signalling molecules might be involved, most likely including reactive oxygen species (Grant et al., 2000; Pieterse et al., 1998).

Treatment of plants with one or more of these signalling molecules causes the coordinated induction of antifungal proteins, phytoalexins, enzymes involved in plant cell wall re-inforcement or breakdown of pathogen infection structures. Most known antifungal proteins identified from 
pathogen-infected plants (Stintzi et al., 1993) can be induced by either of these stimuli, alone or combination (Penninckx et al., 1998), indicating that at least the crude outline of the plant defence potential has been established.

The wide spectrum of defence responses caused by treatment with each of these signalling molecules has prompted research to identify and use signal transduction 'master switches' to engineer disease resistance. This has been successful in some cases. The Arabidopsis NIM1/NPR1 gene seems to be crucial in salicylic acid-mediated resistance, and overexpression leads to resistance against several pathogens (Cao et al., 1998). Other enhanced disease resistance (edr) mutants have been identified (Bowling et al., 1994; Frye et al., 2001). But engineering resistance through use of these master switches is generally not without drawbacks. Most mutants possessing constitutive expression of a defence pathway show reduced yield or plant vigour. And there seems to be antagonism between the different defence pathways (Doares et al., 1995, Leslie and Romani, 1988), which leads to increased susceptibility to other pathogens (Hoffman et al., 1999).

But these effects may not prevent this approach from being taken to engineer resistance. Plants have a finely tuned defence (both with respect to resistance to different classes of pathogens and to the amount of energy devoted to pathogen resistance and yield), which has contributed to survival in the wild. In modern agriculture, it may be acceptable to shift this balance to provide for resistance to the most problematic pathogens, with the threat posedwby other pathogens being removed by adoption of, for example, growing conditions. Barley culture provides a good example of this technique. Most modern barley cultivars possess the naturally occurring mutant mlo gene, which provides durable and broad-spectrum resistance to powdery mildew, one of the main pathogens in barley. The use of the mlo gene leads to a small decrease in yield (Paul Schulze-Lefert, pers. comm.), and makes barley more susceptible to another fungal pathogen, Magnaporthe grisea (Jarosch et al., 1999). But this pest is not a significant problem in modern barley culture. The loss in yield is also acceptable, as yield stability (the ability to harvest a stable yield from year to year) is much more important to growers than absolute yield, especially for crops in which diseases can cause heavy losses. The possibility of using key regulators of defence pathways to 'tweak' resistance to the most pressing problems in agriculture provides an exciting opportunity, which is now starting to be realized.

One of the oldest strategies in the engineering of pathogen resistance is the overexpression of antifungal (or antipathogenic) proteins. In some respects this is very similar to the pathwaymodulating approach described above, only much more specific, as only one or a few genes from the entire defence system are transferred simultaneously to a new transgenic crop. In contrast to the pathway-modulating approach, the impact on yield or the interference/antagonism with other defence pathways is most likely limited or absent. The limitation of this approach is that in many cases it will be highly specific for only a few pathogens, and generally does not provide broad- 
spectrum control (Alexander et al., 1993). These constraints, however, do not undermine the usefullness of this strategy, as often only a small number of pathogens are truly important per crop. One of the more significant practical problems encountered with this strategy is that the effect of the antifungal proteins is influenced by the endogenous defence mechanism already present in wildtype plants - the newly introduced proteins have to fit with the plant's endogenous defence compounds. And although all plants studied so far seem to have defence systems induced by salicylic acid, jasmonic acid and ethylene, the effector antipathogenic proteins and compounds differ considerably. In an elegant demonstration of the difficulty of this strategy, Punja and Raharjo (1996) showed that transfer of a chitinase gene, which encodes a protein that degrades the cell wall of many fungi, to two different crops resulted in a resistance-elevating effect in carrot, but not in cucumber, even when the same pathogen was used to challenge the crops. But with the ongoing genome sequencing of key agricultural crops, and advances in the study of antimicrobial gene expression (Maleck et al., 2000), it will probably be possible to identify the 'gaps' in pathogen defence of certain plant species, and so complement these systems more effectively.

Phytoalexins can be important in plant defence (Dixon, 2001), but in general the specific activity of these compounds is relatively limited, and where they are found to be a key factor in disease resistance (for example, resveratrol in grapes), the amounts accumulated are extremely high. Accumulation of such high levels of resveratrol is usually not possible when the appropriate genes required for synthesis are transferred to other crops (Hain et al., 1993). Attempts to engineer resistance using this strategy have worked in tobacco and alfalfa (Hain et al., 1993; He and Dixon, 2000; Hipskind and Paiva, 2000), but the number of successes has remained low, and the level of resistance relatively modest. It is questionable whether this strategy will ever be widely used.

\section{RESISTANCE GENES AND THE HYPERSENSITIVE RESPONSE}

The hypersensitive response is the most powerful defence system plants have. It is a highly concerted (both temporally and spatially), complex defence response that involves local cell death, high local accumulation of phenolic compounds and cell wall reinforcements in cells surrounding the area of cell death, and a more distal induction of general induced defence, which prevents further infections on distal parts of the plant (Dorey et al., 1997; Costet et al., 1999; Morel and Dangl, 1997; Melchers and Stuiver, 2000; Lam et al., 2001). For details about the hypersensitive response please see the review by Dangl and Jones (2001).

Although the defence response is powerful, and may stop infection by viruses, nematodes, bacteria and fungi, its limitations are that it is normally triggered only by the highly specific recognition (through means of a resistance gene) of a (pathogen-associated) elicitor molecule (Dangl and Jones, 2001). No response is induced even when closely related pathogens lacking this particular elicitor infect the plant. 
Breeders have often used resistance genes to introduce resistance in their crops, and with a few exceptions, all introgressed resistance genes have been shown to lack durability in the field (Pink and Puddephat, 1999). Pathogens are usually able to overcome resistance gene-mediated recognition either by shedding the corresponding elicitor gene, or by accumulating mutations in the gene, which prevents the gene product from being recognized, and thus fails to trigger the hypersensitive response (Joosten et al., 1994; Gassmann et al., 2000).

The use of most known resistance genes is therefore limited in plant biotechnology for disease resistance. For those rare genes that can provide durable resistance, the possibility of transfer to commercially relevant crops is often limited, as resistance genes frequently fail to work when transferred between plant species, especially when the species are not closely related (Rommens and Kishore, 2000).

\section{Non-host resistance}

An exception to such pessimistic assessments occurs where resistance genes recognize molecules that are so important to the pathogen that they can neither be shed nor mutated. This may explain the ability of certain plant species to withstand infection to all known isolates of a given pathogen. There are doubtless several reasons why pathogens cannot infect most plant species, but in some cases of non-host resistance it has been shown that such a generic hypersensitive response provides the most important barrier to infection (Heath, 2000). These findings have rekindled interest in the use of resistance genes to engineer pathogen resistance.

One of the most striking examples of non-host resistance based on the hypersensitive response is found in tobacco (Nicotiana) species against Phytophthora infestans, the causal agent of the devastating late blight in potato and tomato. The Phytophthora-derived INF1 gene product triggers a hypersensitive response reaction in these tobacco non-host plants, and targeted INF1 deletions in $P$. infestans make the pathogen capable of infecting one of the tobacco species (Kamoun et al., 1998). Although INF1 deletion did not affect pathogenicity of $P$. infestans on potato, the deletion is found at an extremely low frequency, suggesting the gene has an important role for this pathogen. This in part might explain the durability of non-host resistance.

The Arabidopsis Eds1 gene is an essential component in the downstream signalling pathway mediated by resistance-gene loci conferring race-specific disease resistance to several Peronospora parasitica isolates and Pseudomonas syringae bacteria (Aarts et al., 1998). Mutation of the Eds1 gene in Arabidopsis thaliana made the plants susceptible to the pathogen Albugo candida and several isolates of $P$. parasitica, which are not normally pathogenic on Arabidopsis, but infect Brassica oleracea subspecies (cabbages) (Parker et al., 1996). This suggests that on nonmutated Arabidopsis, these pathogens can be prevented from infecting the plant through an effective hypersensitive response. If so, it should be possible to isolate such resistance genes and transfer them to other crops. But the question remains as to why such resistance gene-mediated resistance is more durable than that found normally in wild relatives and varieties used by breeders. 


\section{Using HR to generate broad-spectrum disease resistance}

It is extremely tempting to make use of the hypersensitive response pathway and try to trigger this sort of defence after infection by different pathogens. Based on an idea originally advanced by Pierre de Wit (1992), both our research team at Syngenta-MOGEN (in collaboration with de Wit's group, unpublished results) and the research group of Ricci and co-workers (Keller et al., 1999) have successfully engineered broad-spectrum disease resistance in plants. This involves transfer of a pathogen-derived elicitor gene to the plant, expression of which is made conditional on pathogen infection by putting it under control of a tightly regulated pathogen-inducible plant promoter (Fig. 1). Both teams have used this technology to create transgenic plants (tomato and tobacco, respectively) that show broad-spectrum and high-level fungal control and our team has shown that the transgenic tomato plants can stop virus (tomato spotted wilt virus) infection.

The key issue in this strategy is the tight regulation of the pathogen-inducible promoter. The elicitor triggers local cell death and a large array of defence responses, and leakiness of the promoter can and will influence plant vigour and yield. Nevertheless, both teams have produced transgenic plants that show no sign of spontaneous firing of the hypersensitive response in the absence of pathogen challenge. This is therefore one of the more promising approaches to engineer broad-spectrum disease resistance using the endogenous defence components of plants.

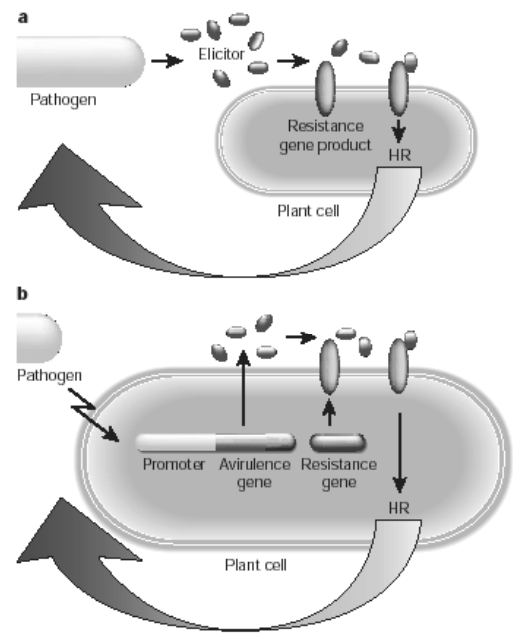

Figure 1. Generating broad-spectrum disease resistance using an elicitor and resistance gene. (A) The hypersensitive response (HR) is triggered by the highly specific recognition of a pathogen-derived elicitor by a plant resistance gene product. The powerful and concerted defence (see text) that constitutes the hypersensitive response stops the pathogen. (B) The components involved in the basic switch of the hypersensitive response can be used to create a more nonspecific defence system. A plant-derived pathogeninducible promoter drives expression of a pathogen elicitor gene. The elicitor formed will trigger the hypersensitive response if the
plants also contain the resistance gene. 
Despite the huge induction of defence components that results from triggering the hypersensitive response, there are reports indicating that not all pathogens are stopped. Infection by Botrytis cinerea, a necrotrophic fungal pathogen of many plants, seems to be enhanced when a hypersensitive response is triggered in Arabidopsis (Govrin and Levine, 2000) and tomato (Hennin et al., unpublished results). We have also found no evidence of increased resistance (but also no evidence of increased susceptibility) to Alternaria solani, another necrotrophic fungal pathogen of tomato, although in the transgenic tobacco plants mentioned above (Keller et al., 1999), there is clearly increased resistance to this class of pathogens. Research by Bonnet et al. (1996) indicates clearly that necrotrophic pathogens can be stopped by a hypersensitive response, so it seems that this strategy may have the potential to engineer resistance to necrotrophic pathogens.

\section{INTERFERENCE WITH PATHOGENESIS}

Most fungal and bacterial pathogens possess a diverse range of enzymes, proteins and metabolites that assist in the infection process of the plant. Although many such compounds seem to be dispensable for the pathogen without compromising pathogenicity (Schafer, 1993), key factors have been identified for a small number of pathogens that are crucial in the infection process (Proctor et al., 1995; Johal and Briggs, 1992; Tanaka et al., 1999; Daub and Ehrenschaft, 2000). The identification of these factors enables the design of strategies to neutralize them, and so interfere with pathogenesis.

For example, the necrotrophic fungus Sclerotinia sclerotiorum synthesizes large amounts of oxalic acid when infecting a plant. This compound is thought to be crucial for Sclerotinia infection, as mutants that loose the ability to synthesize oxalic acid are invariably non-pathogenic, whereas those that regain the ability to make this compound recover their virulence (Cessna et al., 2000). Oxalic acid serves as a co-factor needed to degrade plant cell wall structures, which enable the fungus to colonize the plant, but it was also found recetly to inhibit the onset of plant defence (Cessna et al., 2000).

The dependence of the fungus on oxalic acid can be used to engineer efficient resistance (Hartman et al., 1992). Using oxalic acid oxidase, an enzyme naturally occurring in, for example, germinating wheat and barley (both plants have a significant level of resistance against $S$. sclerotiorum), the oxalate can be broken down to carbon dioxide and hydrogen peroxide, which disable the main fungal pathogenicity factor. The hydrogen peroxide may serve a second function, as it is a signalling molecule involved in inducing plant defence. Thus, oxalic acid oxidase serves a dual role: it disables fungal pathogenicity, and with the breakdown product it could boost plant defence (Charne et al., 1999). Overexpression of another enzyme that breaks down oxalate, oxalate decarboxylase, also leads to increased resistance to Sclerotinia infection (Kesarwani et al., 2000), although the reaction does not lead to accumulation of hydrogen peroxide, or other known signalling molecules. This suggests that the breakdown of the pathogenicity factor is sufficient to engineer resistance.

Proteins with a key role in pathogenicity have been discovered for other pathogens (Lauge et al., 1998, Gassmann et al., 2000), and this is prompting strategies to counteract or interfere with their function (Lauge et al., 1998). Another interesting strategy that has recently been reported is interference with pathogen-induced apoptosis (programmed cell death). Several pathogens are known to induce apoptotic cell death through secreted toxin molecules, and interference with apoptosis through expression of apoptosis-inhibiting proteins makes these transgenic plants more 
resistant to several unrelated necrotrophic pathogens and isolated toxins (Dickman et al., 2000; Gilchrist et al., 2000). It should be added, however, that the current knowledge of the molecules involved in pathogenicity represents only the tip of the iceberg. For many fungi, even those of significant economic importance, the molecular basis of pathogenicity is poorly understood.

\section{LOOKING FORWARD}

Engineering resistance to diseases has proven much more recalcitrant than to insects. Whereas a significant proportion of crops grown today has been engineered to express insect resistance (although exclusively through the use of Bt insect toxin genes), no commercial transgenic product with enhanced disease resistance is currently available. At this moment our knowledge of pathogenesis and defence is still relatively primitive, but as engineering resistance becomes more sophisticated and successful in the coming years, we will no doubt see the first disease-resistant genetically modified crops appear on the market.

The current sequencing of crop plant genomes, together with comprehensive gene expression and functional gene analysis, will no doubt boost the development of transgenic disease-resistant plants. In particular, strategies using general defence pathways and antifungal protein overexpression will benefit from a thorough understanding of the defence arsenal of crop plants. It will provide indications of how to either complement defence or 'tweak' it. In addition, pathogen-responsive promoters, needed for development of a non-pathogen-specific hypersensitive response, will be readily identified. It is even possibly that some non-host resistance genes might be uncovered, which can then be tested for durability.

Slightly lagging behind these developments is pathogen genome analysis. For several pathogens, sequencing of genomes or expressed sequence tags has already been initiated. Once pathogenicity genes have been identified, strategies aimed at interference with the disease process will become apparent. However, functional gene analysis (such as making knockout mutants) is technically challenging for some pathogens, such that this process might be relatively slow.

With increased public concerns about fungicide use on food crops, there is a clear need for alternatives, including biotechnology. Many of the described approaches can provide a high level of protection, and because they are based on a plant's own defence arsenal, they are likely to provide a durable resistance as well.

\section{ACKNOWLEDGEMENTS}

The authors thank all colleagues in Syngenta and especially the team at Syngenta-MOGEN for helpful discussions and suggestions, and B. van Wezenbeek for critically reading the manuscript. It is impossible to include all approaches in a complex field such as this and we apologize to all colleagues whose work was not referred to.

\section{REFERENCES}

Aarts N., Metz M., Holub E., Staskawicz B.J., Daniels M.J. and Parker J.E., 1998. Different requirements for EDS1 and NDR1 by disease resistance genes define at least two R gene-mediated signaling pathways in Arabidopsis. Proc. Natl. Acad. Sci. USA 95: 10306-10311.

Alexander D. Goodman R.M., Gut-Rella M., Glascock C., Weymann K., Friedrich L., Maddox D., Ahl-Goy P., Luntz T., Ward E. and Ryals J., 1993. Increased tolerance to two oomycete pathogens in transgenic tobacco expressing pathogenesis-related proteon 1a. Proc. Natl. Acad. Sci. USA 90: 7327-7331.

Bonnet P., Bourdon E., Ponchet M., Blein J.P. and Ricci P., 1996. Acquired resistance triggered by elicitins in tobacco and other plants. Eur. J. Plant Pathol. 102: 181-192. 
Bowling S.A., Guo A., Cao H., Gordon A.S., Klessig D.F. and Dong X., 1994. A mutation in Arabidopsis that leads to constitutive expression of systemic acquired resistance. Plant Cell 6: 1845-1857.

Cao H., Li X. and Dong X., 1998. Generation of broad-spectrum disease resistance by overexpression of an essential regulatory gene in systemic acquired resistance Proc Natl Acad Sci U S A. 95(11): 6531-6536.

Cessna S.G., Sear V.E., Dickman M.B. and Low P.S., 2000. Oxalic acid, a pathogenicity factor for Sclerotinia sclerotiorum, suppresses the oxidative burst of the host plant. Plant Cell 12(11): 2191-2200.

Charne D.G., Falak I, Nazarian K.A.P., Bidney D.L., Coughlan S.L., Mancl M.K., Yalpani N. and Scelonge C., 1999. Production of pathogen resistant plants. Patent application WO 99/04012.

Costet L., Cordelier S., Dorey S., Baillieul F., fritig B. and Kauffmann S., 1999. Relationship between localized acquired resistance (LAR) and the hypersensitive response (HR): HR is necessary for LAR to occur and salicylic acid is not sifficient to trigger LAR. Mol. Plant-Microbe Interact. 12: 655-662.

Dangl J.L. and Jones J.D.G., 2001. Plant pathogens and integrated defence responses to infection. Nature 411: 826-833. Daub M.E. and Ehrenshaft M., 2000. The photoactivated Cercospora toxin cercosporin: contributions to plant disease and

Delaney T.P., Uknes S., Vernooij B., Friedrich L., Weymann K., Negrotto D., Gaffney T., Gut-Rella M., Kessmann H., Ward E. and Ryals J., 1994. A central role of salicylic acid in plant disease resistance. Science 266: 1247-1250.

De Wit P.J.G.M., 1992. Molecular Characterization of gene-for-gene systems in plant-fungus interactions and the application of avirulence genes in control of plant pathogens. Annu. Rev. Phytopathol 30: 391-418.

Dickman M.B., 2000. Trans-species transfer of apoptotic genes and transgenic plants developed thereby. Patent application WO00/26391.

Dixon R.A., 2001. Natural products and plant disease resistance. Nature 411: 843-847.

Doares S.H., Narvaez-Vazquez J., Conconi A. and Ryan C.A., 1995. Salicylic acid inhibits synthesis of proteinase inhibitors in tomato leaves induced by systemin and jasmonic acid. Plant Physiol. 108: 1741-1746.

Dorey S., Baillieul F., Pierrel M., Saindrenan P., Fritig B. and Kauffmann S., 1997. Spatial and temporal induction of cell death, defence genes, and accumulation of salicylic acid in tobacco leaves reacting hypersensitively to a fungal glycoprotein elicitor. Mol. Plant-Microbe Interact 10: 646-655.

Feys B.J. and Parker J.E., 2000. Interplay of signaling pathways in plant disease resistance. Trends Genet. 16(10): 449-455.

Frye C.A., Tang D. and Innes R.W., 2001. Negative regulation of defence responses in plants by a conserved MAPKK kinase. Proc. Natl. Acad Sci. USA 98(1): 373-378.

Gassmann W., Dahlbeck D., Chesnokova O., Minsavage G.V., Jones J.B. and Staskawicz B.J., 2000. Molecular evolution of virulence in natural field strains of Xanthomonas campestris pv. vesicatoria. J. Bacteriol. 182: 7053-7059.

Gilchrist D. G., Lincoln J., Richael C., Pan Z., Overduin B., Fan X., Smith K., Li J., Haworth R. and Bostock R., 2000. Disease after death: concept and consequence. In Biology of Plant-Microbe Interactions, Edited by P. J. M. de Wit, T. Bisseling \& W. J. Stiekema. St. Paul, MN: International Society for Molecular Plant-Microbe Interactions. pp. 406-410.

Gorlach J., Volrath S., Knauf-Beiter G., Hengy G., Beckhove U., Kogel K.H., Oostendorp M., Staub T., Ward E., Kessmann H. and Ryals J., 1996. Benzothiadiazole, a novel class of inducers of systemic acquired resistance, activates gene expression and disease resistance in wheat. Plant Cell 8(4): 629-643.

Govrin E.M. and Levine A., 2000. The hypersensitive response facilitates plant infection by the necrotrphic pathogen Botrytis cinerea. Curr. Biol. 10: 751-757.

Grant J.J., Yun B.W. and Loake G.J., 2000. Oxidative burst and cognate redox signalling reported by luciferase imaging: identification of a signal network that functions independently of ethylene, SA and Me-JA but is dependent on MAPKK activity. Plant J. 24(5): 569-

Hain R., Reif H.J., Krause E., Langbartels R., Kindl H., Vornam B., Wiese W., Schmelzer E., Schreier P.H., Stocker R.H. and Stenzel K., 1993. Disease resistance results from foreign phytoalexin expression in a novel plant. Nature 361: 153-156.

Hartman C.L., Sarjit J. and Schmitt M.S., 1992. Newly characterised oxalate oxidase and uses therefor. Patent application WO $92 / 14824$

He X.Z. and Dixon R.A., 2000. Genetic manipulation of isolflavone 7-O-methyltransferase enhances biosynthesis of 4'-O-methylated isoflavonoid phytoalexins and disease resistance in alfalfa. Plant Cell 12 (9): 1689-1702.

Heath M.C., 2000. Nonhost resistance and non-specific plant defences. Curr Opin. Plant Biol. 3(4): 315-319.

Hipskind J.D. and Paiva N.L., 2000. Constitutive accumulation of a resveratrol-glucoside in transgenic alfalfa increases resistance to Phoma medicaginis. Mol. Plant Microbe Interact. 13 (5): 551-562. 
Hoffman T., Schmidt J.S., Zheng X and Bent A.F., 1999. Isolation of ethylene-insensitive soybean mutants that are altered in pathogen susceptibility and gene-for-gene disease resistance. Plant Physiol. 119: 935-949.

Jarosch B., Kogel K.-H. and Schaffrath U., 1999. The ambivalence of the barley Mlo locus: Mutations conferring resistance against powdery mildew (Blumeria graminis f. sp. Hordei) enhance susceptibility to the rice blast fungus Magnaporthe grisea. Mol. Plant Microbe Interact. 12(6): 508-514.

Johal G.S. and Briggs S.P., 1992. Reductase activity encoded by the Hm1 resistance gene in maize. Science 258: 985-987.

Joosten M.H.A.J., Cozijnsen T.J. and De Wit P.J.G.M., 1994. Host resistance to fungal tomato pathogen lost by a single base pair change in an avirulence gene. Nature, 367: 384-386.

Kamoun S., van West P., Vleeshouwers V.G.A.A., de Groot K.E. and Govers F., 1998. Resistance of Nicotiana benthamiana to Phytophthora infestans is mediated by the recognition of the elicitor protein INF1. Plant Cell 10: 1413-1425.

Keller H., Pamboukjian N., Ponchet M., Poupet A., Delon R., Verrier J.L., Roby D. and Ricci P., 1999. Pathogen induced elicitin production in transgenic tobacco generates a hypersensitive response and nonspecific disease resistance. Plant Cell 11: 223-235.

Kesarwani M., Azam M., Natarajan K and Datta A., 2000. Oxalate decarboxylase from Collybia velutipes. Molecular cloning and its overexpression to confer resistance to fungal infection in transgenic tobacco and tomato. J. Biol. Chem. 275(10): 7230-7238.

Lam E., Kato N. and Lawton M., 2001. Programmed cell death, mitochondria and the plant hypersensitive response. Nature 411: 848853

Lauge R., Joosten M.H., Haanstra J.P., Goodwin D.H., Lindhout P. and De Wit P.J., 1998. Successful search for a resistance gene in tomato targeted against a virulence factor of a fungal pathogen. Proc. Natl. Acad. Sci. USA 95 (15): 9014-9018.

Leslie C.A. and Romani R.J., 1988. Inhibition of ethylene biosynthesis by salicylic acid. Plant Physiol. 88: 833-837.

Maleck K., Levine A., Eulgem T., Morgan A., Schmid J., Lawton K.A., Dangl J.L. and Diettrich R.A., 2000. The transcriptome of Arabidopsis thaliana during systemic acquired resistance. Nature Genetics 26: 403-410.

Melchers L.S. and Stuiver M.H., 2000. Novel genes for disease-resistance breeding. Curr. Opin. Plant Biol. 3: 147-152.

Morel J-B. and Dangl J.L., 1997. The hypersensitive response and the induction of cell death in plants. Cell death and Differentiation 4: $671-683$.

Parker J.E., Holub E.B., Frost L.N., Falk A., Gunn N.D. and Daniels M.J., 1996. Characterization of eds1, a mutation in Arabidopsis suppressing resistance to Peronospora parasitica specified by several different RPP genes. Plant Cell 8 (11): 2033-2046.

Penninckx I.A.M.A, Thomma B.P.H.J., Buchala A, Metraux J.-P. and Broekaert W.F., 1998. Concomitant activation of jasmonate and ethylene response pathways is required for induction of a plant defensin gene in Arabidopsis. Plant Cell 10: 2103-2113.

Pieterse C.M., van Wees S.C., van Pelt J.A., Knoester M., Laan R., Gerrits H, Weisbeek P.J. and van Loon L.C., 1998. A novel signaling pathway controlling induced systemic resistance in Arabidopsis. Plant Cell 10(9): 1571-1580

Pieterse C.M. and Van Loon, L.C., 1999. Salicylic acid-independent plant defence pathways. Trends Plant Sci. 4(2): 52-58.

Pink D. and Puddephat I., 1999. Deployment of disease resistance genes by plant transformation-a 'mix and match' approach. Trends. Plant Sci. 4(2): 71-75

Proctor R.H., Hohn T.M. and McCormick S.P., 1995. Reduced virulence of Gibberella zeae caused by disruption of a trichothecene toxin biosynthetic gene. Mol. Plant Microbe Inter. 8(4): 593-601.

Punja Z.K. and Raharjo S.H.T., 1996. Response of transgenic cucumber and carrot plants expressing different chitinase enzymes to inoculation with fungal pathogens. Plant Disease 80 (9): 999-1005.

Rommens C.M. and Kishore G.M., 2000. Exploiting the full potential of disease-resistance genes for agricultural use. Curr. Opin. Biotechnology 11: 120-125.

Schafer W., 1993. The role of cutinase in fungal pathogenesis. Trends Microbiol. 1(2): 69-71.

Stintzi A., Heitz T., Prasad V., Wiedemann-Merdinoglu S., Kauffmann S., Geoffroy P., Legrand M. and Fritig B., 1993. Plant 'pathogenesis-related' proteins and their role in defence against pathogens. Biochimie 75(8): 687-706.

Tanaka A., Shiotani H., Yamamoto M and Tsuge T., 1999. Insertional mutagenesis and cloning of the genes required for biosynthesis of the host-specific AK-toxin in the Japanese pear pathotype of Alternaria alternata. Mol. Plant Microbe Interact. 12(8): 691-702.

Thomma B.P., Eggermont K., Penninckx I.A., Mauch-Mani B., Vogelsang R., Cammue B.P. and Broekaert W.F., 1998. Separate jasmonate-dependent and salicylate-dependent pathways in Arabidopsis are essential for resistance to distinct microbial pathogens. Proc. Natl. Acad Sci. USA 95: 15107-15111.

Thomma B.P., Penninckx I.A., Broekaert W.F. and Cammue, B.P., 2001. The complexity of disease signaling in Arabidopsis. Curr. Opin. Immunol. 13(1): 63-68 
Uknes S., Mauch-Mani B. Moyer M. Potter S., Williams S. Dincher S., Chandler D., Slusarenko A., Ward E. and Ryals J., 1992. Acquired Resistance in Arabidopsis. Plant Cell 4: 645-656.

Walton J.D., 1996. Host-selective toxins: Agents of Compatibility. Plant Cell 8: 1723-1733.

White F.F., Yang B. \& Johnson L.B., 2000. Prospects for understanding avirulence gene function. Curr. Opin. Plant Biol. 3(4): 291298. 


\section{CHAPTER 8}

SUMMARIZING DISCUSSION 
Chapter 8 


\section{SUMMARIZING DISCUSSION}

Studies on plant-pathogen interactions have been a challenge for plant biologists and plant pathologists for decades. A profound understanding of the interaction between the host plant and its microbial attacker is crucial for the successful molecular breeding of crops with increased pathogen resistance. Commonly pursued strategies to engineer disease resistance are based on modifications of plants endogenous defence systems. Many approaches to engineer resistance have been evaluated but valorisation has been performed in limited cases. In many cases initial results were encouraging but transgenic plants had often poor agronomic properties due to negative side effects of the inserted transgenes (Hammond-Kosack and Parker, 2003). Expression of components that provide pathogen resistance only when strictly required (i.e. only at the moment of pathogen attack) by using pathogen-inducible promoters might avoid the majority of these problems.

In this thesis the isolation and characterization of pathogen-inducible promoters that are key to the genetic engineering of disease resistant plants have been described. In addition, studies are presented on the hypersensitive response (HR)-inducing Avr9 elicitor from Cladosporium fulvum and its ability to induce transcriptional changes in potato. Also the identification, cloning and characterization of a novel class of antimicrobial proteins from sunflower and lettuce have been described.

\section{USE OF THE HYPERSENSITIVE RESPONSE TO ENGINEER DISEASE RESISTANCE}

The holy grail of molecular disease resistance breeding is the development of a system that is able to confer broad-spectrum pathogen resistance, is silent in the absence of pathogens and does not affect plant growth and development. A promising strategy involves the pathogen-induced expression of elicitor genes that induce the HR in plants under controlled conditions (De Wit, 1992; Keller et al., 1999; Belbahri et al., 2001; Chapter 7).

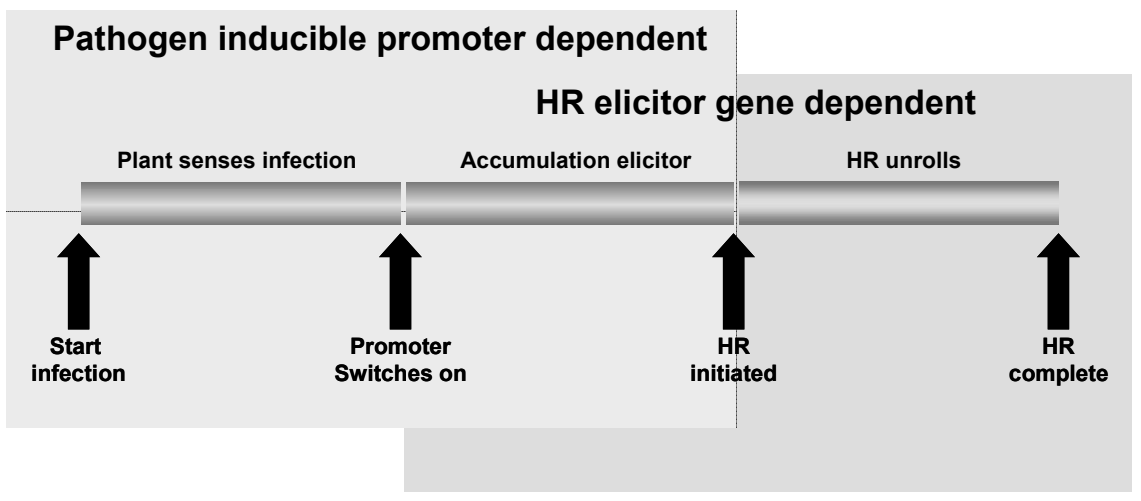

Figure 1. Schematic representation of the chain of events leading to execution of the hypersensitive response when a pathogeninducible promoter drives expression of an elicitor of the HR. A timely activation and completion of the HR is crucial in the engineering of broad-spectrum pathogen resistance. The two main components of this system, the pathogen-inducible promoter and the elicitor gene, determine the speed and the efficacy of the system. Improvements in each of these components could increase the efficacy of this system. 
This strategy requires tightly regulated pathogen-inducible promoters to ensure precise activation of the HR in time and space. Pathogen-inducible promoters are crucial but also the activity and stability of the expressed elicitor protein is important. The characteristics of the elicitor protein determine whether some level of leakiness of the promoter is acceptable as negative effects on plant growth and yield are not acceptable. Also, data on the specific activity, i.e. the threshold level of protein required to trigger the HR are important. In Figure 1, the different components of the system are presented. The speed of induction of the HR is determined by (i) the time needed for the pathogen-inducible promoter to respond to pathogen infection, (ii) the kinetic properties of the pathogen-inducible promoter resulting in accumulation of the elicitor protein and (iii) the time needed for the HR, once initiated, to be completed (Figure 1).

\section{Identification and assaying suitability of pathogen-inducible promoters}

Pathogen-inducible promoters can be derived from a large collection of plant genes that are pathogen-responsive. However, many of these genes also respond to other stress factors or are expressed in a developmental or tissue-specific manner. Presumably, only a very limited number of genes might be expressed exclusively after infection and, in addition, are responsive to multiple pathogens. Many different approaches can be pursued to identify suitable candidates. In chapter 3 and 4 the isolation of novel pathogen-inducible promoters and assaying their ability to drive pathogen-induced gene expression in planta have been described. The Arabidopsis 488 promoter was identified in a promoter-tagging library (chapter 3 ). The promoter was isolated and appeared to be linked to a gene coding for a putative serine threonine kinase in Arabidopsis. Isolation and transfer of the promoter to plants showed that it had retained its pathogen-responsiveness. Promoter-tagging has proven to be a suitable method to identify pathogen-inducible promoters in plants (Barthels et al., 1997; Puzio et al., 1999; chapter 3). However, the efficiency of promotertagging largely depends on the availability of efficient plant transformation protocols and (highthroughput) screening assays. New technologies like mRNA expression profiling using DNA or oligo arrays, cDNA AFLP analysis or other transcript profiling methods, can substantially accelerate the selection of novel candidate promoters, especially when expression-profiling results are extended to detailed in-silico analysis of promoters of co-regulated genes (Maleck et al., 2000; Eulgem et al., 2004). By using these technologies it is fairly straightforward to pre-select genes that have promoters with the required characteristics. Subsequently, selected candidate genes can be investigated more extensively before their promoters are cloned and tested in further detail. In chapter 4 the cloning of two novel pathogen-inducible promoters and the analysis and their comparison to two well-known promoters in the crop plant potato have been described. A panel of 20 transgenic lines containing each promoter construct has been investigated for responsiveness to the oomycete pathogen Phytophthora infestans and for basal expression levels. Pathogen responsiveness of these promoters was assayed using GUS staining combined with real-time quantitative RT-PCR. Pathogen-inducible promoters can be characterized in some detail using reporter genes but the accurate designation of promoter requirements and the translation of promoter characteristics from reporter to candidate gene and vice versa are extremely difficult. Frequently, extensive promoter discovery and testing programmes are preceding the selection of promoters in prototype transgenic products. During these research phases, promoters are characterized extensively using reporter genes and testing of selected promoters in combination 
with candidate genes is performed at later stages of product development. The early evaluation of promoters fused to candidate genes under field conditions (breeding approach) might accelerate development of potential products. When using pathogen-inducible promoters to drive expression of elicitors of the HR, a number of promoter characteristics are extremely important for successful employment of this strategy. Firstly speed and specificity of the pathogen-inducible promoter will have a large impact on the efficacy of the system. In addition, the pathogen-inducible promoter should only be activated very locally at the site of attempted pathogen penetration. Furthermore, activation of such a promoter by abiotic stress factors like wounding, drought, salinity stress or other commonly encountered environmental conditions should not result in activation of the HR. Additional characteristics of a pathogen-inducible promoter include the expression level in noninduced state (basal expression level), and the level in induced state as they determine the efficacy of induction when a plant is exposed to a virulent pathogen (Figure 2). The dynamics are important since for some elicitors it is known that only at a particular concentration the HR is initiated (Kooman-Gersman et al., 1997). It is therefore essential that the basal expression level is well below this HR-threshold level whereas the threshold level is reached very fast. Often, native plant promoters do not meet these criteria. Improvement of existing pathogen-inducible promoters or building synthetic promoters might be achievable. Hence, extensive knowledge of cis-acting elements important for pathogen-responsiveness is essential for the directed design of improved pathogen-inducible promoters. Rushton et al. (2002) have constructed several synthetic pathogeninducible promoters by combining or by multimerizing cis-acting elements. Testing of these promoters in planta revealed that responsiveness to elicitors and pathogens could be maintained and even improved. However, responsiveness to elicitors, pathogens and wounding appeared extremely hard to separate.

Thus more research is required to identify promoter elements driving pathogen-responsive gene expression but of equal importance, promoter elements that negatively regulate gene expression in the absence of pathogens.

A.

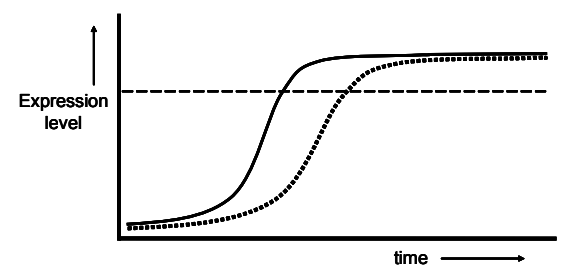

B.

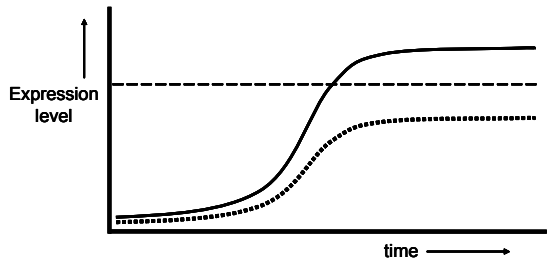

Figure 2. Graphs explaining promoter kinetics (A) and promoter dynamics (B) in the two component HR-inducing system. The horizontal dashed line represents the threshold expression level of a theoretical elicitor of HR that is required to initiate the HR. In panel A, the promoter activity profile represented by the dotted line reaches the elicitor threshold expression level later in time compared to the promoter activity profile represented by the solid line, but similar levels of expression are reached. In panel B both promoters driving expression of the elicitor protein result in a maximum expression level after approximately the same time but the promoter activity profile represented by the dotted line never results in an elicitor threshold expression level required to initiate the HR. 
Gene expression profiling of Avr9 responses in potato plants

Increasing experimental evidence is emerging that avirulence genes contribute to virulence of a pathogen. Avirulence proteins are anticipated to have a plant target by which they exert their virulence function. It is postulated that when the complementary R-protein is present, it guards the plant target and defence is initiated to arrest pathogen growth (Van der Biezen and Jones 1998). Pathogens are expected to contain multiple virulence factors, contributing to full virulence of the pathogen (Wichmann and Bergelson, 2004). For Avr9, such virulence function has not been assigned nor has the virulence target been cloned. Avr9 recognition is mediated by the tomato $R$ gene Cf-9 and results in a typical HR. The HR mechanism in plants has been subject of many investigations. It is known that the expression of many genes changes during the course of HR development. The Avr9/Cf-9-mediated HR and concurrent changes in transcription have been studied by two groups. Durrant et al. (2000) have studied the response of Cf-9-transgenic tobacco cell suspensions to treatment with Avr9 elicitor/Cf-9 and wounding using a CDNA-AFLP approach. Cai et al. (2001) investigated the expression characteristics of a fixed set of genes in tomato seedlings. We have employed a cDNA array profiling approach to analyze the transcriptional changes after an Avr9/Cf-9-mediated HR in potato. We also studied transcriptional changes in potato as a result of Avr9 expression in the absence of the Cf- 9 gene. The purpose of the latter study was to identify possible targets for Avr9 in potato that might affect expression of plant genes important for virulence of $C$. fulvum. However, in the absence of Cf-9 limited changes in gene expression were observed. Fourteen genes were up- and five genes were downregulated (Figure 3). No obvious leads were uncovered to a possible virulence function of Avr9. The slight downregulation of two defence genes might point at a role for Avr9 in suppressing basal plant defence. Further functional studies are required to assign a role for Avr9 in virulence of $C$. fulvum, and the genes identified in chapter 5 might be interesting candidates to be included in such studies. Infiltration of Avr9 in Cf-9 expressing potato plants resulted in massive changes in gene expression. A striking shift from general expression of housekeeping genes towards defence genes was observed. Similar shifts in gene expression have been described during development of an HR in Arabidopsis (Scheideler et al., 2002; De Torres et al., 2003). As shown in Figure 3, many defence genes are strongly induced in the Avr9/Cf-9 interaction. Early responding genes included two transcription factor genes that might activate defence gene expression. Some overlap has been observed between genes induced in the two different treatments. Whether these genes specifically respond to the Avr9 protein (irrespective of the presence of the Cf-9 gene) remains to be seen. No potato genes related to the four pathogen-inducible promoters were induced by the Avr9/Cf- 9 interaction. This supports their suitability to drive Avr9 expression in potato. The results described in chapter 5 also demonstrate that execution of HR can have a considerable effect on growth-related gene expression. This supports the hypothesis that a continuous elevation of defence gene activation is undesirable and that strictly regulated pathogen-inducible promoters are required for exploiting the HR to engineer disease resistant plants.

Whether the newly engineered resistance, using pathogen-induced expression of elicitors of the $H R$, will be durable under field conditions remains to be seen. It is expected that the responses associated with HR, can in principle give durable resistance. Unlike natural gene-for-gene resistance, shedding or mutating elicitor genes by the pathogen will not prevent the induction of the $\mathrm{HR}$, but the characteristics of the pathogen-inducible promoter will largely determine the durability of 
the resistance. In order to circumvent induction of the HR, pathogens need to avoid activation of the pathogen-inducible promoter. Whether this is likely to occur remains to be seen. Selected promoters should on the one hand preferably be broadly activated and should be responsive to very general pathogen stress factors, whereas on the other hand the system should be strictly regulated. It is not easy and straightforward to achieve these requirements. The results described in chapter 3,4 and 5 illustrate that components required for the exploitation of the HR to engineer disease resistance are available. This will bring the commercial application of this technology in crop plants like potato closer, but fine-tuning of the system under field conditions is still needed.
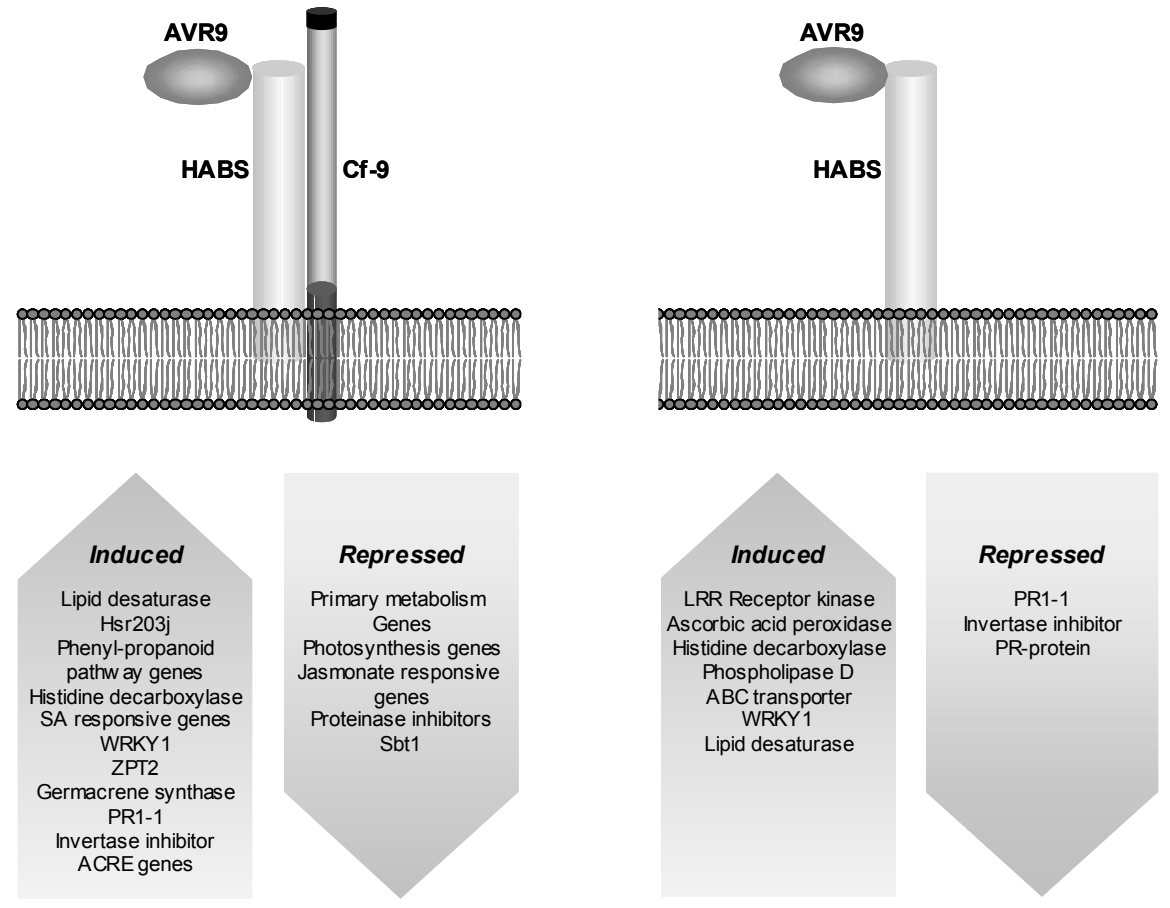

HR/defence

Disease

Figure 3. Model summarizing the transcriptional responses downstream of perception of the $C$. fulvum Avr9 protein in potato using cDNA microarrays. A selection of genes up- and downregulated in response to Avr9 infiltration in the presence and absence of the Cf-9 protein is shown 


\section{CARBOHYDRATE OXIDASE GENES IN PLANT DEFENCE}

In search for plant proteins with growth inhibiting activity against fungal and oomycete pathogens, two antimicrobial proteins were identified in extracts of lettuce and sunflower plants (Chapter 6; Custers et al., 2004). This inhibitory activity was only present when plants were repeatedly treated with SA, suggesting that the antimicrobial proteins are part of the regular defence machinery in these plants. Purification of the proteins and subsequently cloning of their encoding genes revealed that the proteins from sunflower and lettuce are almost identical with high similarity to plant oxidases. Strongest sequence similarity was found with the enzyme reticuline oxidase, also known as berberine bridge enzyme that functions at the branch point of synthesis of the phytoalexin sanguinarine in Eschscholtzia californica (Californian poppy; Kutchan and Dittrich, 1993). However, extensive analysis of the sunflower enzyme revealed that it is unable to utilize reticuline as a substrate. Studies on the sunflower protein expressed in $E$. coli showed that it utilizes carbohydrates as a substrate and produced hydrogen peroxide as one of the reaction products. Further testing of activity of the antimicrobial proteins in vitro on media containing sugars revealed that the antifungal action most probably originates from $\mathrm{H}_{2} \mathrm{O}_{2}$ released during oxidation of glucose. The enzyme was also able to utilize glucans present in fungal cell walls. It is hypothesized that upon pathogen attack in plants the action of carbohydrate oxidases might have the effects illustrated in Figure 5. The $\mathrm{H}_{2} \mathrm{O}_{2}$ produced in each of the three proposed scenarios can have different effects. $\mathrm{H}_{2} \mathrm{O}_{2}$ is known to have direct antimicrobial activity, is involved in defence signaling and is involved in cell wall strengthening through lignification. Plants generate $\mathrm{H}_{2} \mathrm{O}_{2}$ and other active oxygen species during pathogen attack. Neutrophil NADPH oxidase homologues, amine oxidases or $\mathrm{pH}$-dependent cell wall peroxidases have all been shown to be responsible for $\mathrm{H}_{2} \mathrm{O}_{2}$ production in particular plantpathogen interactions (Bolwell, 1999). The carbohydrate oxidases might be the ultimate source of $\mathrm{H}_{2} \mathrm{O}_{2}$ production in sunflower and lettuce in response to pathogen attack.

Enzymes with carbohydrate or glucose oxidase activity are not specific for the family of Compositae. This activity has also been observed in citrus (Bean et al., 1961), and recently a protein with glucose oxidase activity of approximately $60 \mathrm{kD}$ has been identified in nectar of ornamental tobacco (Carter and Thornburg, 2004). The tobacco gene shows homology to berberine bridge enzymes and biochemical characterization revealed that the enzyme contains a covalently bound flavin. Expression of this protein is confined to the nectary gland during late stages of flower development (Carter and Thornburg, 2004). Expression of a carbohydrate oxidase-like gene has also been detected in transgenic sunflower plants expressing oxalate oxidase. These plants displayed, next to increased disease resistance, constitutive enhanced expression of a set of defence genes, including a homologue of the sunflower carbohydrate oxidase (Hu et al., 2003). High sequence similarity was also found to the enzyme $\Delta^{1}$-tetrahydrocannabinolic acid synthase from Cannabis sativa $\mathrm{L}$. that is involved in the synthesis of THCA, a precursor of THC, the well known psychoactive component found in marijuana (Sirikantaramas et al., 2004). However, it is not known whether this enzyme possesses carbohydrate oxidase activity. The similarity of the sunflower and lettuce carbohydrate oxidases with enzymes involved in secondary metabolite synthesis suggests that the carbohydrate oxidase activity might not be the only enzymatic activity of these enzymes. Figure 4 displays a phylogenetic tree of a number of sequences recently identified with strong similarity to the sunflower/lettuce carbohydrate oxidase enzymes. 


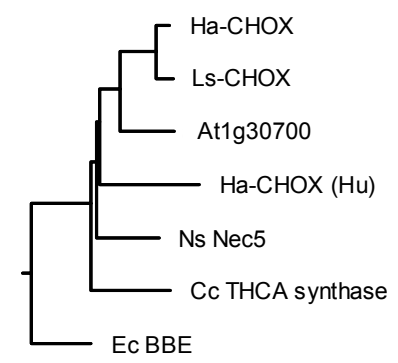

Figure 4. Phylogenetic tree showing the relatedness of the sunflower and lettuce carbohydrate oxidase protein sequence (Ha-CHOX AF472609 and Ls-CHOX, AF472608) to the sunflower carbohydrate oxidase-like sequence identified by Hu et al. (2003) (Ha-CHOX (Hu), AF364866), the tobacco Nectarin-V protein sequence (Ns NEC5, assembled from AAP30840/ AAP30841; Carter and Thornburg, 2004), the Californian poppy berberine bridge enzyme sequence (Ec BBE, P30986; Dittrich and Kutchan, 1991), the Cannabis sativa THCA synthase protein sequence (Cs THCA, BAC41356; Sirikantaramas et al., 2004) and the Arabidopsis protein Phylogeny Inference package version 3.6 .

Many reports have appeared describing increased pathogen resistance in plants by elevating $\mathrm{H}_{2} \mathrm{O}_{2}$ levels (Wu et al., 1995; Wu et al., 1997; Chamnongpol et al., 1998; Kazan et al., 1998; Murray et al., 1999; Kachroo et al., 2003; Custers et al., 2004). It is important to know what factors exactly trigger the resistance mechanisms observed in these plants. In none of these reports it is explained what is exactly responsible for the observed resistance. As discussed above, $\mathrm{H}_{2} \mathrm{O}_{2}$ can have multiple effects on plant resistance, and at least one of the proposed scenarios is responsible for the observed $\mathrm{H}_{2} \mathrm{O}_{2}$-mediated pathogen resistance. From the results described in these reports it is clear that constitutive high levels of $\mathrm{H}_{2} \mathrm{O}_{2}$ are not preferred to engineer disease resistance as they will result in detrimental effects on plant growth and development as was found for $A$. niger glucose oxidase (Murray et al., 1999; Kachroo et al., 2003).

Carbohydrate oxidases and glucose oxidases can be used to engineer disease resistance in plants, especially when expression is tightly regulated in time and space during pathogen infection. Alternatively, carbohydrate oxidases might have industrial applications. Aspergillus niger glucose oxidase is widely used for a broad range of industrial applications. It is used in biosensors, bakery industry, and beer and wine industry. Glucose oxidase is generally applied to improve shelf life and to maintain flavour and colour stability. This is achieved by either the reduction of glucose content or by exhausting the oxygen present. Often addition of glucose oxidase is combined with the addition of catalase to prevent $\mathrm{H}_{2} \mathrm{O}_{2}$ accumulation (Pickering, 2000; Malherbe et al., 2003; Garcia et al., 2004). The newly identified plant carbohydrate oxidases might provide suitable alternatives for microbial glucose oxidase used so far, since they have a broader substrate range and different enzymatic properties (lower Km and a lower Vmax). In addition, they are of plant origin, and thus already present in the food chain, which is an advantage for food or cosmetic purposes. 
A.

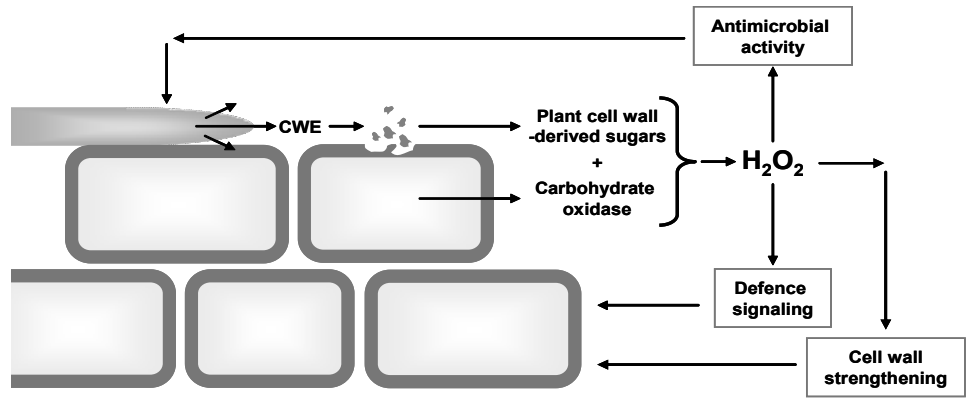

B.

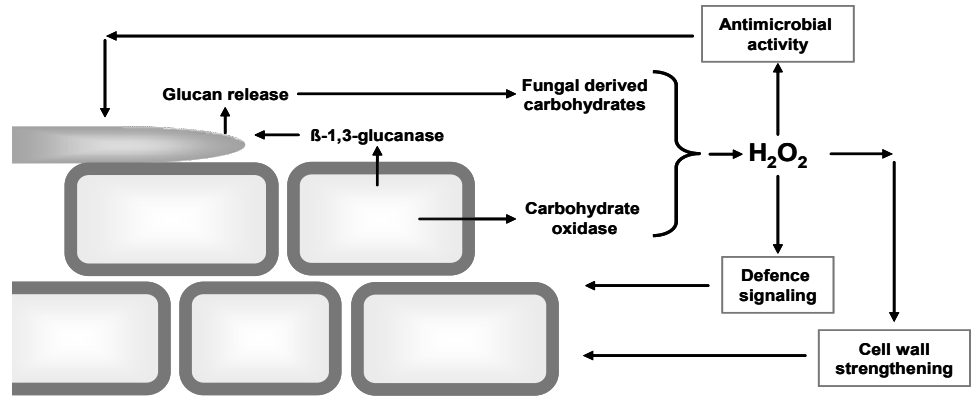

C.

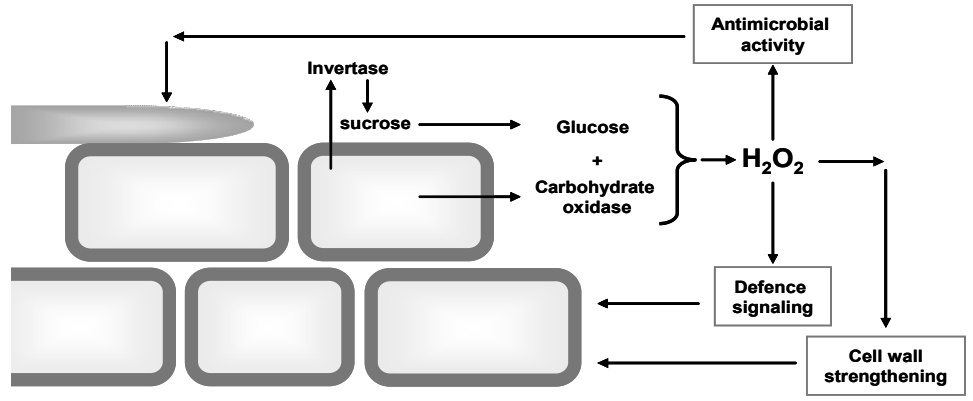

Figure 5. Three possible scenarios for a role of carbohydrate oxidases in the plant defence response: A) The pathogen produces cell-wall degrading enzymes releasing carbohydrates from plant cell walls that might serve as a substrate for the carbohydrate oxidase resulting in $\mathrm{H}_{2} \mathrm{O}_{2}$ production. B) The plant induces apoplastic $\beta$-1,3-glucanases which can act on fungal cell walls releasing substrate for the carbohydrate oxidase. C) Plant apoplastic invertases are upregulated during pathogen infection and glucose is released that serves as a substrate for the carbohydrate oxidase that is also present in the apoplast after pathogen infection. In all scenarios $\mathrm{H}_{2} \mathrm{O}_{2}$ production can result in three actions. i) $\mathrm{H}_{2} \mathrm{O}_{2}$ has direct antimicrobial activity, ii) $\mathrm{H}_{2} \mathrm{O}_{2}$ levels are perceived by the plant and this leads to further defence gene activation, iii) $\mathrm{H}_{2} \mathrm{O}_{2}$ induces the strengthening of plant cell walls near the site of plant and this leads to fl 


\section{CONCLUDING REMARKS}

Molecular breeding for disease resistance by genetic engineering has already been pursued for many years. However, no crop plants with enhanced disease resistance have reached the market except for transgenic corn and cotton plants with increased insect resistance through expression of $B t$ genes. The enormous complexity of mechanisms underlying disease resistance in plants has prevented the commercialisation of plants or seeds that are resistant to fungal or bacterial pathogens. Increased understanding of the molecular basis of plant-pathogen interactions and downstream events leading to disease or resistance will be required to successfully introduce transgenic plants. It leaves no doubt that plant promoters, and especially pathogen-responsive promoters, are key elements in many approaches to genetically engineer disease resistance. Over the years too little attention has been given to the identification, characterization and redesign of pathogen-inducible promoters. Even when introducing candidate genes that have no apparent effect on plant development and growth, activation of defence signaling pathways or parts thereof, might have a cost in terms of growth and yield or resistance levels to other pathogens. We have described three novel pathogen-inducible promoters that are suited to develop pathogen-resistant plants. Furthermore we have presented a method to analyse (pathogen-inducible) promoters in transgenic crop plants for various characteristics. This method will support the development of transgenic crops with improved disease resistance. Extensive knowledge of the processes that occur downstream of $\mathrm{R}$ protein-mediated recognition of Avrs will be indispensable when using Avr- and R-genes for molecular resistance breeding. We have shown that massive transcriptional reprogramming occurs after Avr9 treatment of Cf-9 expressing potato plants. This reprogramming includes shifts from general maintenance to defence gene expression and activation of genes previously not associated with the HR. Treatment of potato plants lacking the $C f-9$ gene show minor changes in gene expression but the genes induced could suggest roles of Avr9 in C. fulvum virulence. Furthermore, in a screen for antimicrobial proteins in plant extracts, enzymes have been identified with carbohydrate oxidase activity. The genes encoding these enzymes have been cloned from sunflower and lettuce and are related to oxidoreductases. These genes might be used to engineer disease resistance in plants. Alternatively, the enzymes might be used in the food processing industry to improve food quality. The studies described in this thesis have added further insight to support the development and market introduction of transgenic plants with broad-spectrum disease resistance.

\section{REFERENCES}

Barthels N., van der Lee F.M., Klap J., Goddijn O.J., Karimi M., Puzio P., Grundler F.M., Ohl S.A., Lindsey K., Robertson L., Robertson W.M., Van Montagu M., Gheysen G. and Sijmons P.C., 1997. Regulatory sequences of Arabidopsis drive reporter gene expression in nematode feeding structures. Plant Cell 9(12): 2119-2134.

Bean, R.C., Porter, G.G. and Steinberg, B.M., 1961. Carbohydrate metabolism of citrus fruits. II. Oxidation of sugars by an aerodehydrogenase from young orange fruits. J. Biol. Chem. 236: 1235-1240.

Belbahri, L., Boucher, C., Candresse, T., Nicole, M., Ricci, P. and Keller, H. 2001. A local accumulation of the Ralstonia solanacearum PopA protein in transgenic tobacco renders a compatible plant-pathogen interaction incompatible. Plant J. 28(4): 419-

Bolwell P.G., (1999). Role of active oxygen species and NO in plant defence responses. Curr. Opin. Plant Biol. 2: 287-294

Cai, X., Takken, F.L.W., Joosten, M.H.A. and De Wit, P.J.G.M., 2001. Specific recognition of AVR4 and Avr9 results in distinct patterns of hypersensitive cell death in tomato, but similar patterns of defence-related gene expression. Mol. Plant Pathol. 2(2): 7786. 
Carter C.J. and Thornburg R.W., 2004. Tobacco nectarin V is a flavin-containing berberine bridge enzyme-like protein with glucose oxidase activity. Plant Physiol. 134(1): 460-469.

Chamnongpol S., Willekens H., Moeder W., Langebartels C., Sandermann H., Van Montagu M., Inze D. and Van Camp W. (1998) Defence activation and enhanced pathogen tolerance induced by $\mathrm{H}_{2} \mathrm{O}_{2}$ in transgenic tobacco. Proc. Natl. Acad. Sci. USA 95: 58185823.

Custers J.H.H.V., Harrison S.J., Sela-Buurlage M.B., Van Deventer E., Lageweg W., Howe P.W., Van der Meijs P.J., Ponstein A.S., Simons L.H., Melchers L.S. and Stuiver M.H., 2004. Isolation and characterisation of a class of carbohydrate oxidases from higher plants, with a role in active defence. Plant J. 39(2): 147-160.

De Torres M., Sanchez P., Fernandez-Delmond I. and Grant M., 2003. Expression profiling of the host response to bacterial infection: the transition from basal to induced defence responses in RPM1-mediated resistance. Plant J. 33(4): 665-676.

De Wit P.J.G.M., 1992. Molecular characterisation of gene-for-gene systems in plant-fungus interactions and the application of avirulence genes in control of plant pathogens. Ann. Rev. Phytopathol. 30: 391-418.

Dittrich H. and Kutchan T.M. (1991) Molecular cloning, expression, and induction of berberine bridge enzyme, an enzyme essential to the formation of benzophenanthridine alkaloids in the response of plants to pathogen attack. Proc. Natl. Acad. Sci. USA 88: 99699973.

Durrant, W.E., Rowland, O., Piedras, P., Hammond-Kosack, K.E. and Jones, J.D.G., 2000. cDNA-AFLP reveals striking overlap in race-specific resistance and wound response gene expression profiles. Plant Cell 12: 963-977.

Eulgem T., Weigmen V.J., Chang H-S., McDowell J.M., Holub E.B., Glazebrook J., Zhu T. and Dangl J.L., 2004. Gene expression signatures from three genetically separable resistance gene signaling pathways for downey mildew resistance. Plant Physiol. 135(2): 1129-1144

Garcia R., Rakotozafy L. and Nicolas J., 2004. Analysis and modeling of the ferulic Acid oxidation by a glucose oxidase-peroxidase association. Comparison with a hexose oxidase-peroxidase association. J Agric Food Chem. 52(12): 3946-3953.

Hammond-Kosack K.E. and Parker J.E., 2003. Deciphering plant-pathogen communication: fresh perspectives for molecular resistance breeding. Curr. Opin. Biotechnol. 14(2): 177-193.

Hu X., Bidney D.L., Yalpani N., Duvick J.P., Crasta O., Folkerts O. and Lu G., 2003. Overexpression of a gene encoding hydrogen peroxide-generating oxalate oxidase evokes defence responses in sunflower. Plant Physiol. 133(1): 170-181.

Kachroo A., He Z., Patkar R., Zhu Q., Zhong J., Li D., Ronald P., Lamb C. and Chattoo B.B., 2003. Induction of H2O2 in transgenic rice leads to cell death and enhanced resistance to both bacterial and fungal pathogens. Transgenic Res. 12(5): 577-586.

Kazan K., Murray F.R., Goulter K.C., Llewellyn D.J. and Manners J.M. (1998) Induction of Cell death in Transgenic Plants Expressing a Fungal Glucose Oxidase. Mol. Plant Microbe Interact. 11(6): 555-562.

Keller H., Pamboukdjian N., Ponchet M., Poupet A., Delon R., Verrier J-L., Roby D. and Ricci P., 1999. Pathogen-induced elicitin production in transgenic tobacco generates a hypersensitive response and non-specific disease resistance. Plant Cell 11: $223-235$.

Kooman-Gersmann M., Vogelsang R., Hoogendijk E.C. and De Wit P.J.G.M., 1997. Assignment of amino acid residues of the Avr9 peptide of Cladosporium fulvum that determine elicitor activity. Mol Plant Microbe Interact. 10(7): 821-829.

Kutchan T.M. and Dittrich H. (1995) Characterization and Mechanism of the Berberine Bridge Enzyme, a Covalently Flavinylated Oxidase of Benzophenanthridine Alkaloid Biosynthesis in Plants. J. Biol. Chem. 270(41): 24475-24481.

Maleck K., Levine A., Eulgem T., Morgan A., Schmid J., Lawton K.A., Dangl J.L. and Dietrich R.A., 2000. The transcriptome of Arabidopsis thaliana during systemic acquired resistance. Nat. Gen. 26: 403-410.

Malherbe D.F., du Toit M., Cordero Otero R.R., van Rensburg P. and Pretorius I.S, 2003. Expression of the Aspergillus niger glucose oxidase gene in Saccharomyces cerevisiae and its potential applications in wine production. Appl Microbiol Biotechnol. 61(5-6): 502511

Murray F., Llewellyn D., McFadden H., Last D., Dennis E.S. and Peacock W.J. (1999) Expression of the Talaromyces flavus glucose oxidase gene in cotton and tobacco reduces fungal infection, but is also phytotoxic. Mol. Breeding 5: 219-232.

Pickering G.J., 2000. The use of glucose oxidase in winemaking. Proceedings of the $1^{\text {st }}$ EIT Oenology and Viticulture seminar series. Eastern Institute of Technology, New Zealand. G.J Pickering (ed.) Campus Press, New Zealand, 11-21.

Puzio P.S., Lausen J., Almeida-Engler J., Cai D., Gheysen G. and Grundler F.M.W., 1999. Isolation of a gene from Arabidopsis thaliana related to nematode feeding structures. Gene 239: 163-172.

Rushton P.J., Reinstädler A., Lipka V., Lippok B. and Somssich I.E., 2002. Synthetic plant promoters containing defined regulatory elements provide novel insights into pathogen- and wound-induced signaling. Plant Cell 14: 749-762.

Scheideler M., Schlaich N.L., Fellenberg K., Beissbarth T., Hauser N.C., Vingron M., Slusarenko A.J. and Hoheisel J.D., 2002. Monitoring the switch from housekeeping to pathogen defence metabolism in Arabidopsis thaliana using cDNA arrays. J. Biol. Chem. 277(12): 10555-10561. 
Sirikantaramas S., Marimoto S., Shoyama Y., Ishikawa Y., Wada Y., Shoyama Y. and Taura F., 2004.The gene controlling Marijuana psychoactivity: Molecular cloning and heterologous expression of $\Delta^{1}$-tetrahydrocannabinolic acid synthase from Cannabis sativa L. J. Biol. Chem. 279: 39767-39774.

Van der Biezen E.A. and Jones J.D.G., 1998. Plant disease-resistance proteins and the gene-for-gene concept. Trends Biochem. Sci. 23: $454-456$

Wichmann G. and Bergelson J., 2004. Effector genes of Xanthomonas axonopodis pv. vesicatoria promote transmission and enhance other fitness traits in the field. Genetics 166: 693-706.

Wu G., Shortt B.J., Lawrence E.B., Levine E.B., Fitzsimmons C. and Sha D., 1995. Disease Resistance Conferred by Expression of a Gene Encoding $\mathrm{H}_{2} \mathrm{O}_{2}$-Generating Glucose Oxidase in Trangenic Potato Plants. Plant Cell 7: 1357-1368.

Wu G., Shortt B.J., Lawrence E.B., Leon J., Fitzsimmons C., Levine E.B., Raskin I. and Sha D., 1997. Activation of Host Defence Mechanisms by Elevated Production of $\mathrm{H}_{2} \mathrm{O}_{2}$ in Transgenic Plants. Plant Physiol. 115: 427-435. 



\section{SUMMARY}

The genetic engineering of plants for increased pathogen resistance has engaged researchers and companies for decades. Until now, the number of crops with genetically engineered disease resistance traits which have entered the market are limited to products displaying virus and insect resistance. Development and registration of plants with increased broad-spectrum resistance to bacteria or fungi have failed due to limited efficacy or poor agronomic properties. This is largely due to the high diversity of pathogens that are able to attack plants, the strategies they use and the complexity of the plant signaling networks underlying natural resistance mechanisms. Generally, plant resistance is composed of multiple defence layers, jointly able to resist the majority of pathogens. Induced resistance responses are often the final layer of defence. At this stage, plants employ an active defence mechanism to stop pathogen invasion. Upon attempted pathogen ingress, plants activate distinct defence pathways to prevent the pathogen from causing disease. These active defence responses are very effective, refined and are based on very specific recognition mechanisms. In the case of gene-for-gene resistance, plant $R$-genes are able to provide resistance to pathogens carrying the matching Avr-gene. This natural occurring system can be turned into a genetic engineering strategy by transferring an Avr-gene to a plant containing the matching $R$-gene and by placing the Avr-gene under control of a pathogen-responsive promoter, the system is only activated when the plant is attacked by pathogens. Crucial for this approach is the pathogen-inducible promoter since activation of this system in the absence of pathogens can be very detrimental to plant growth and yield (Chapter 1). Apart from this particular approach, many other biotechnological applications to increase pathogen resistance in crop plants also depend on the availability of such pathogen-responsive promoters. For example, the expression of antimicrobial proteins or enzymes that synthesize antimicrobial compounds can have a negative effect on plant vigour and yield as well and therefore conditional expression of the transgene, only in the presence of pathogens is key. Chapter 3 and 4 describe the isolation of novel plant pathogeninducible promoters and the characterization of these promoters in transgenic plants. Different approaches can be applied to identify appropriate pathogen-inducible promoters. In Chapter 3 we have reported the results of a promoter tagging approach to identify promoters that are induced upon pathogen attack in Arabidopsis thaliana. One candidate out of 500 screened tagging lines displayed the desired phenotype. The tagged promoter was cloned in front of a reporter gene and was shown to be functional in transgenic Arabidopsis and Brassica napus plants. The isolated promoter sequence appeared to be linked to a predicted serine threonine kinase gene in the reverse orientation. Expression of the kinase messenger RNA was shown to be upregulated in response to pathogen infection and SA treatment, similar to the activity of the isolated promoter and the original tagging line.

Furthermore, two novel plant promoters were isolated from genes that display a local response after pathogen infection (Chapter 4). These promoters were fused to the UidA reporter gene as well and transformed into potato. Characteristics of these newly isolated promoters were compared with two well-studied plant pathogen-inducible promoters isolated from the genes encoding Vitis stilbene synthase 1 (Vst1) and potato Glutathione-S transferase 1 (Gst1). Twenty transgenic lines of each promoter-UidA fusion were analysed using conventional histochemical staining and real time RTPCR analysis to visualize spatial, kinetic and dynamic properties of these promoters. All promoterUidA fusions were shown to be responsive to an oomycete pathogen in the crop plant potato and 

frequency of induction.

Apart from the pathogen-inducible promoter, properties of the pathogen-derived Avr-gene are of importance as well. It is expected that the development of an HR stimulates strong transcriptional changes. In Chapter 5, the ability of the Cladosporium fulvum Avr9 avirulence protein to induce transcriptional changes in potato was investigated. Multiple expression profiling experiments using cDNA microarrays were performed to follow the expression profile of approximately 10.000 potato genes in response to Avr9 application. Avr9 protein preparations were manually infiltrated in leaves of potato plants that were either untransformed or transformed with the complementary tomato $R$ gene, Cf-9. At least 510 potato gene elements on the array have been shown to respond to Avr9 infiltration in potato. These genes were designated Solanum tuberosum Avr9-responsive genes (STAR genes). In Cf-9 expressing plants, strong shifts in gene expression were observed. Concurrent with an apparent induction of many defence and stress-associated genes, genes related to primary metabolism and photosynthesis were repressed. Limited gene expression alteration was observed in untransformed potato plants after infiltration with the Avr9 protein.

An alternative approach to engineer disease resistance in plants includes the expression of antimicrobial proteins. Chapter 6 describes the identification of novel plant derived antimicrobial proteins in extracts from salicylic acid treated lettuce and sunflower leaves. Proteins of approximately $60 \mathrm{kDa}$ in both extracts were found to be responsible for the observed antimicrobial activity. Further characterization of these proteins and cloning of the respective cDNAs revealed close homology to various plant oxidases. Dissection of the enzymatic activity of the proteins revealed them to be carbohydrate oxidases with broad substrate specificity and with hydrogen peroxide as one of the reaction products. Characterization of the mode of action of these proteins revealed that the hydrogen peroxide produced was responsible for the observed antimicrobial activity. Tobacco plants overexpressing $\mathrm{Ha}-\mathrm{CHOX}$ displayed increased resistance to Pectobacterium carotovorum subsp. carotovorum and the resistance level was proportional to the $\mathrm{Ha}-\mathrm{CHOX}$ enzymatic activity, which exemplifies the utility of these enzymes to engineer disease resistance. Finally in chapter 7 , different strategies are discussed that plants employ to resist pathogen infection and the strategies that are currently under development to engineer disease resistance in plants.

The applied research described in this thesis has provided novel components, tools and knowledge which will contribute to the quality and efficacy of genetically modified crops with increased pathogen resistance and to a better understanding of the mechanisms plants employ to recognize and resist microbial pathogens. 


\section{SAMENVATTING}

De wetenschap houdt zich al tientallen jaren bezig met het ontwikkelen van gewassen met verhoogde ziekteresistentie door middel van genetische modificatie. Tot op heden is het aantal genetisch gemodificeerde gewassen met ziekteresistentie dat op de markt is gebracht, beperkt gebleven tot gewassen met ingebouwde virus- of insecten-resistentie. De ontwikkeling en registratie van gewassen met verhoogde resistentie tegen bacteriën en schimmels zijn tot op heden minder succesvol door hun beperkte agronomische eigenschappen en geringe effectiviteit. Dit wordt voornamelijk veroorzaakt door de grote diversiteit aan pathogene schimmels en bacteriën, de infectiemechanismen die ze gebruiken en de complexiteit van de signaaltransductieroutes die ten grondslag liggen aan deze natuurlijk ontwikkelde resistentiemechanismen in planten. In het algemeen is ziekteresistentie in planten opgebouwd uit meerdere verdedigingslagen, die gezamenlijk in staat zijn een merendeel van de potentiële ziekteverwekkers te weerstaan. Geïnduceerde resistentie is meestal de laatste verdedigingslinie. In dit stadium maken planten gebruik van een actief verdedigingsmechanisme om pathogeeninfectie te weerstaan. Deze actieve afweervormen zijn effectief, verfijnd en gebaseerd op zeer specifieke herkenningsmechanismen. In het geval van gen-om-gen interacties zijn plantresistentiegenen in staat om resistentie te genereren tegen ziekteverwekkers die het bijpassende avirulentie-gen dragen. Dit natuurlijk voorkomende afweersysteem kan worden omgevormd tot een resistentiestrategie. Door middel van genetische modificatie wordt het avirulentie-gen, afkomstig van de pathogeen, ingebracht in een plant dat het passende resistentiegen bevat. Voorwaarde is wel dat het avirulentie-gen wordt gefuseerd met trancriptiecontrole elementen die genexpressie activeren, alleen als er pathogeeninfectie plaatsvindt. Cruciaal voor deze strategie is de kwaliteit van de pathogeen activeerbare promoter, want activering van avirulentiegenexpressie onder normale groeiomstandigheden kan een negatief effect hebben op de ontwikkeling en groei van de plant (Hoofdstuk 1). Naast deze specifieke aanpak zijn er ook andere resistentiestrategieën die afhankelijk zijn van beschikbaarheid van pathogeen activeerbare promoteren. Bijvoorbeeld, expressie van antimicrobiële eiwitten of enzymen die antimicrobiële stoffen produceren kan ook een negatief effect hebben op de ontwikkeling en groei van de plant. Daarom is expressie van dit soort componenten, alleen in de aanwezigheid van plantpathogenen essentieel. In hoofdstuk 3 en 4 wordt de isolatie van nieuwe pathogeen induceerbare promotoren en de typering van deze promotoren in transgene planten beschreven. Geschikte pathogeen induceerbare promotoren kunnen worden geïdentificeerd door gebruik te maken van verschillende strategieën. In hoofdstuk 3 hebben we een "promoter tagging" procedure toegepast met als doel promotoren te identificeren die geactiveerd worden als gevolg van een pathogeeninfectie in Arabidopsis thaliana. Het gewenste fenotype werd gevonden in één van de 500 "tagging" lijnen die zijn getest. De promoter werd geïsoleerd en gefuseerd met een reportergen. Testen in Arabidopsis thaliana en Brassica napus hebben aangetoond dat de promoter functioneel is. De promotersequentie bleek gekoppeld te zijn aan een gebied dat codeert voor een receptor serine threonine kinase in de omgekeerde oriëntatie. Het eiwit kinase boodschapper RNA kon worden geinduceerd door salicylzuurbehandeling en Botrytis infectie, vergelijkbaar met de activiteit van de geïsoleerde promoter en de oorspronkelijke "tagging" lijn.

Naast deze Arabidopsis promoter zijn nog twee nieuwe plantpromotoren geïsoleerd van genen die lokaal worden geactiveerd door pathogeeninfectie (Hoofdstuk 4). Deze promotoren zijn ook gefuseerd met het UidA reportergen. Vervolgens werden transgene aardappelplanten gegenereerd 
met deze promoter-reportergenconstructen. De eigenschappen van deze twee nieuwe promotoren werden vergeleken met twee bekende promotoren geïsoleerd van de vitis stilbene synthase (Vst1) en aardappel glutathion-S transferase (Gst1). Van elke promoter-reportergenfusie zijn twintig transgene aardappellijnen gegenereerd en geanalyseerd met behulp van conventionele histochemische kleuringstechnieken en real-time PCR analyse om de eigenschappen van de promotoren te bepalen. $\mathrm{Er}$ is aangetoond dat alle promoter-reportergenfusies werden geactiveerd door een oomyceet pathogeen in aardappel. De promotoren vertoonden verschillende pathogeen induceerbare expressie patronen met betrekking tot plaats, snelheid, niveau en frequentie van activatie.

Naast het feit dat de pathogeen induceerbare promoter enorm belangrijk is voor het succesvol toepassen van de gen-om-gen strategie, is ook het avirulentie-gen van essentieel belang. Naar verwachting brengt de ontwikkeling van een hypersensitieve respons grote veranderingen teweeg in het transcriptieprofiel van de plant.

In hoofdstuk 5 werden aardappelplanten onderzocht op transcriptionele veranderingen als gevolg van het toedienen van het AVR9 eiwit afkomstig van de schimmel Cladosporium fulvum. Verschillende expressie typeringsexperimenten zijn gedaan met behulp van cDNA microarrays om het expressieprofiel van ongeveer 10.000 genen in bladeren van aardappelplanten te volgen als gevolg van deze AVR9 toediening. Het AVR9 eiwit werd handmatig geïnfiltreerd in bladeren van aardappelplanten die het complementaire resistentiegen Cf-9 bevatten en in bladeren van aardappelplanten die dit resistentiegen niet bevatten. Tenminste 510 aardappelgenen bleken te reageren op AVR9 infiltratie. Deze genen zijn STAR genen genoemd ( Solanum tuberosum AVR9 Responsive). Grote transcriptionele veranderingen werden waargenomen na infiltratie van AVR9 in planten die Cf-9 tot expressie brengen. Gelijktijdig met een sterke inductie van genen die verband houden met afweer en stress, zagen we dat genen die betrokken zijn bij algemeen metabolisme en fotosynthese omlaag gaan in expressie. Een beperkt aantal genen veranderde van expressieniveau na toediening van AVR9 aan normale aardappelplanten, maar de resultaten suggereren dat AVR9 betrokken kan zijn bij het beïnvloeden van de afweerreactie van de plant.

Expressie van antimicrobiële eiwitten in planten is één van de alternatieve methoden om gewassen te ontwikkelen met verhoogde resistentie tegen microbiële pathogenen. In hoofdstuk 6 wordt de identificatie van een nieuwe klasse antimicrobiele eiwitten beschreven die zijn gevonden in extracten van salicylzuur behandelde zonnebloem- en sla-bladeren. Eiwitten van ongeveer 60 kilodalton groot waren verantwoordelijk voor de antimicrobiele activiteit in de extracten. Typering van deze eiwitten en klonering van de coderende genen hebben uitgewezen dat deze eiwitten erg overeenkomen met plant oxidasen. Uitgebreide analyse van de enzymatische eigenschappen van deze eiwitten heeft geresulteerd in de classificatie als koolhydraat oxidasen (Ha-CHOX en Ls$\mathrm{CHOX)}$ met brede substraat specificiteit en waterstofperoxide als één van de eindproducten. Verder werd gevonden dat waterstofperoxide verantwoordelijk is voor de gevonden antimicrobiële activiteit. Tabaksplanten die één van deze eiwitten tot expressie brengen, waren beter bestand tegen infectie met de bacteriële pathogeen Pectobacterium carotovorum subsp. carotovorum. Het resistentieniveau kon worden gekoppeld aan het niveau van de enzymatische oxidase activiteit. Deze nieuwe groep van planteneiwitten kan dus worden gebruikt om planten te beschermen tegen specifieke microbiële pathogenen. 
Het praktijk gerichte onderzoek zoals beschreven in deze dissertatie heeft nieuwe componenten, methoden en inzichten opgeleverd die bijdragen aan de kwaliteit en werkzaamheid van genetisch gemodificeerde gewassen met verhoogde resistentie tegen ziekteverwekkers. Tevens draagt het onderzoek bij aan ons begrip van de mechanismen die planten gebruiken om microbiële pathogenen te herkennen en af te weren. 



\section{PUBLICATIONS}

Papers

Stuiver M.H. and Custers J.H.H.V., 2001. Engineering disease resistance in plants. Nature 411 : 865-868.

Custers J.H.H.V., Melchers L.S., Tigelaar H., Bade J.B., Spiegeler J.J.M., Van der Meijs P.J., Simons L.H. and Stuiver M.H., 2002. T-DNA tagging of a pathogen-inducible promoter in Arabidopsis thaliana. Mol. Plant Pathol. 3(4): 239-249.

Bade J., Van Grinsven E., Custers J., Hoekstra S. and Ponstein A. (2003) T-DNA tagging in Brassica napus as an efficient tool for the isolation of new promoters for selectable marker genes. Plant Mol. Biol. 52: 53-68.

Custers J.H.H.V., Harrison S.J., Sela-Buurlage M.B., Van Deventer E., Lageweg W., Howe P.W., Van der Meijs P.J., Ponstein A.S., Simons L.H., Melchers L.S. and Stuiver M.H., 2004. Isolation and characterisation of a class of carbohydrate oxidases from higher plants, with a role in active defence. Plant J. 39(2): 147-160.

Barouch D.H., Pau M.G., Custers J.H.H.V., Koudstaal W., Kostense S., Havenga M.J., Truitt D.M., Sumida S.M., Kishko M.G., Arthur J.C., Korioth-Schmitz B., Newberg M.H., Gorgone D.A., Lifton M.A., Panicali D.L., Nabel G.J., Letvin N.L., Goudsmit J., 2004. Immunogenicity of recombinant adenovirus serotype 35 vaccine in the presence of pre-existing anti-Ad5 immunity. J Immunol. 172(10): 6290-6297.

Holterman L., Vogels R., van der Vlugt R., Sieuwerts M., Grimbergen J., Kaspers J., Geelen E., van der Helm E., Lemckert A., Gillissen G., Verhaagh S., Custers J., Zuijdgeest D., Berkhout B., Bakker M., Quax P., Goudsmit J. and Havenga M., 2004. Novel replication-incompetent vector derived from adenovirus type 11 (Ad11) for vaccination and gene therapy: low seroprevalence and non-crossreactivity with Ad5. J Virol. 78(23): 13207-13215.

Sumida S.M., Truitt D.M., Lemckert A.A., Vogels R., Custers J.H., Addo M.M., Lockman S., Peter T., Peyerl F.W., Kishko M.G., Jackson S.S., Gorgone D.A., Lifton M.A., Essex M., Walker B.D., Goudsmit J., Havenga M.J., Barouch D.H., 2005. Neutralizing antibodies to adenovirus serotype 5 vaccine vectors are directed primarily against the adenovirus hexon protein. J Immunol. 174(11): 7179-7185.

Sullivan N.J., Geisbert T.W., Geisbert J.B., Shedlock D.J., Xu L., Lamoreaux L., Custers J.H.H.V., Popernack P.M., Yang Z-Y., Pau M.G., Roederer M., Koup R.A., Goudsmit J., Jahrling P.B. and Nabel G.J., 2006. Immune protection of nonhuman primates against Ebola virus with single lowdose Adenovirus vectors encoding modified GPs. PLoS Med 3(6): e177.

Stewart V.A., McGrath S.M., Pau M.G., Mettens P., Dubois P.M., Shott J., Cobb M., Burge J.R., Larson D., Ware L.A., Demoitie M-A., Weverling G.J., Bayat B., Custers J.H.H.V., Dubois M-C., Cohen J., Goudsmit J. and, Gray Heppner JR. D., 2006. Priming with an Adenovirus 35-CS vaccine followed by RTS,S/AS01B boosting significantly improves immunogenicity to $P$. falciparum CS over either vaccine alone. Submitted.

\section{Patents}

Sela-Buurlage M.B., Melchers L.S., Stuiver M.H., Lageweg W., Custers J.H.H.V., Ponstein A.S., Van Deventer J.P., 1998. Antifungal proteins, DNA coding therefore and host incorporating same. Publication WO98/13478.

Stuiver M.H., Lageweg W., Custers J.H.H.V., Van Deventer J.P., 1998. Antifungal composition containing ß-1,6-glucanase, and hosts incorporating same. Publication WO98/49331. 
Stuiver M.H., Simons L.H., Custers J.H.H.V., 1999. Method for the induction of pathogen resistance in plants. Publication WO99/45129.

Stuiver M.H., Simons L.H., Custers J.H.H.V., 1999. Pathogen inducible promoter. Publication WO99/50428.

Linhorst H.J.M., Verpoorte R., Verberne M.C., Moreno P.R.H., Van Tegelen L.J.P., Wullems G.J., Croes A.F., Stuiver M.H., Custers J.H.H.V., Simons L.H., Melchers L.S., Bol J.F., 1999. Salicylic acid pathway genes and their use for the induction of pathogen resistance in plants. Publication WO99/50423.

Custers J.H.H.V., Melchers L.S., 2000. Pathogen inducible promoter. Publication WO00/60086.

Bade J.B., Custers, J.H.H.V., 2001. New constitutive plant promoter. Publication WO02097103.

Bade J.B., Custers, J.H.H.V., 2001. New plant promoters. Publication WO02097085. 
NAWOORD

Het is zover. Na 5 jaar zwoegen is het boekje af. Nog "even" de verdediging en dan kan ik een van de hoofddoelen van de afgelopen jaren afsluiten. Het waren zeker niet de meest eenvoudige jaren. Werken bij Crucell, gezinsuitbreidingen, verbouwingen en tussendoor aan een proefschrift werken. Het spreekt voor zich dat ik het zonder de steun van een aantal mensen nooit had kunnen voltooien. Ten eerste Maarten, co-promotor op afstand. Dank voor je hulp bij het initiëren van dit proefschrift en je suggesties bij het schrijven van de verschillende hoofdstukken. Pierre, enorm bedankt voor je bereidheid om als promotor te fungeren. Je hulp was van onschatbare waarde, zeker tijdens de laatste fase van dit proefschrift. Alle ex-Mogenians, bedankt voor de goede tijd die ik daar heb gehad (misschien wordt deze promotie wel een soort reunie). Leo, jij hebt me enthousiast gemaakt voor dit vakgebied en me de eerste kneepjes van de moleculaire biologie bijgebracht, veel dank daarvoor. De studenten in de MOGEN tijd: Pieter, Nico, Steven en Lovely. Ik hoop dat ik op jullie een stukje passie voor de plantenbiotech heb kunnen overdragen. Ik heb in ieder geval veel van jullie geleerd. Jacob en Jan, dank voor jullie steun, adviezen en natuurlijk de gezelligheid tijdens onze etentjes in Leiden. Geweldig dat jullie bereid zijn om me bij te staan als paranimfen. Natuurlijk alle co-auteurs, bedankt voor jullie bijdragen aan het voltooien van vooral het experimentele deel van dit proefschrift. De mensen bij Syngenta: Stuart, thanks for your support. Your help was pivotal for the completion of this thesis. I also wish to thank lan Jepson for supporting the publication approval of the chapters.

En dan natuurlijk familie en vrienden. Jullie warme belangstelling is een enorme steun en motivatie geweest. In het bijzonder, m'n ouders, Ron, Germaine en Kees, bedankt voor jullie steun. Tot slot, Melanie; wat is jouw geduld op de proef gesteld.... In de weekenden ging je vaak alleen op pad met de kinderen om mij rustig te laten werken aan dit proefschrift, vanaf nu kunnen we vaker met $z$ 'n 5en op pad. En natuurlijk Sophie, Emma en Matthieu, het beste wat me is overkomen. Dit boekje is ook een beetje van jullie. 


\section{CURRICULUM VITAE}

Jerôme Custers werd op 7 januari 1969 geboren te Amstenrade. In juni 1987 behaalde hij aan scholengemeenschap Jeruzalem in Venray het Havo diploma. Een jaar later, in 1988, begon hij aan de Rijks Hogere Agrarische School Larenstein in Wageningen zijn studie Microbiologie/Biochemie. In het kader van deze studie doorliep hij een stage van 10 maanden bij Mogen International N.V. in Leiden (later Syngenta Mogen) onder begeleiding van Dr. Marcel de Groot, wijlen Dr. Stephan Ohl en onder supervisie van Dr. Leo Melchers. Na zijn militaire dienstplicht vervuld te hebben, kwam hij in 1994 in dienst van Mogen International N.V. om te werken aan de ontwikkeling van landbouwgewassen met een verhoogde resistentie tegen ziekteverwekkende schimmels. Delen van dat onderzoek zijn weergegeven in dit proefschrift. Na sluiting van Syngenta Mogen in 2002 maakte hij de overstap naar het farmaceutische biotechnologiebedrijf Crucell Holland B.V. in Leiden. Daar is hij betrokken bij de ontwikkeling van vaccins tegen infectieziekten. 
The research described in this thesis was performed at Syngenta Mogen B.V. Leiden, The Netherlands. The work was supported by Syngenta. 